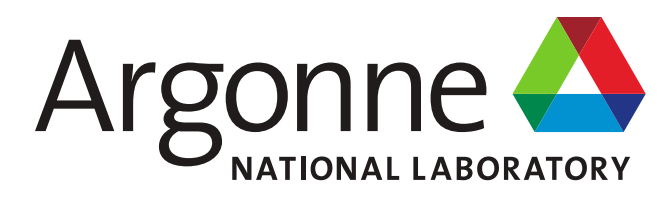

ANL/RTR/TM-19/12

\title{
REBUS-PC v1.5 Verification Test Summary
}

\author{
Nuclear Science \& Engineering Division
}


About Argonne National Laboratory

Argonne is a U.S. Department of Energy laboratory managed by UChicago Argonne, LLC under contract DE-AC02-06CH11357. The Laboratory's main facility is outside Chicago, at 9700 South Cass Avenue, Argonne, Illinois 60439. For information about Argonne and its pioneering science and technology programs, see www.anl.gov.

\section{DOCUMENT AVAILABILITY}

Online Access: U.S. Department of Energy (DOE) reports produced after 1991 and a growing number of pre-1991 documents are available free at OSTI.GOV (http://www.osti.gov/), a service of the U.S. Dept. of Energy's Office of Scientific and Technical Information)

Reports not in digital format may be purchased by the public from the National Technical Information Service (NTIS):

U.S. Department of Commerce

National Technical Information

Service 5301 Shawnee Rd

Alexandria, VA 22312

www.ntis.gov

Phone: (800) 553-NTIS (6847) or (703)

605-6000 Fax: (703) 605-6900

Email: orders@ntis.gov

Reports not in digital format are available to DOE and DOE contractors from the Office of Scientific and Technical Information (OSTI):

U.S. Department of Energy

Office of Scientific and Technical Information

P.O. Box 62

Oak Ridge, TN 37831-0062

www.osti.gov

Phone: (865) 576-8401

Fax: (865) 576-5728

Email: reports@osti.gov

Disclaimer

This report was prepared as an account of work sponsored by an agency of the United States Government. Neither the United States Government nor any agency thereof, nor UChicago Argonne, LLC, nor any of their employees or officers, makes any warranty, express or implied, or assumes any legal liability or responsibility for the accuracy, completeness, or usefulness of any information, apparatus, product, or process disclosed, or represents that its use would not infringe privately owned rights. Reference herein to any specific commercial product, process, or service by trade name, trademark, manufacturer, or otherwise, does not necessarily constitute or imply its endorsement, recommendation, or favoring by the United States Government or any agency thereof. The views and opinions of document authors expressed herein do not necessarily state or reflect those of the United States Government or any agency thereof, Argonne National Laboratory, or UChicago Argonne, LLC. 
ANL/RTR/TM-19/12

\section{REBUS-PC v1.5 Verification Test Summary}

prepared by

P. Deng, C. S. Lin, W. S. Yang, School of Nuclear Engineering at Purdue University M. A. Smith, Nuclear Science \& Engineering Division, Argonne National Laboratory

September 2019 
(This page left intentionally blank) 


\section{Executive Summary}

Motivated in part by its usage for analysis of the University of Missouri Research Reactor (MURR), the verification of the REBUS-PC software for $\theta-\mathrm{R}-\mathrm{Z}$ geometries is discussed and displayed in this manuscript. Of particular importance is to show that the eigenvalue, flux, power, and burnup outputs of the software given a user problem is correct. REBUS-PC contains many features and MURR only makes use of some of those aspects. As an example, the use of region specific cross section sets, interpolation of the cross section data with respect to burnup, and automatic movement of control rods during the fuel cycle is discussed and displayed.

To demonstrate the accuracy, 22 verification tests based upon 7 physical geometries are discussed. Geometry descriptions are provided in Section 2 and the REBUS-PC results for each verification test are discussed in Section 3. These verification tests consist of both analytic problems with known solutions and a more complicated input consistent with usage of REBUS-PC on the MURR reactor itself called STRZ. In this verification test summary report, the REBUS-PC software is repeatedly demonstrated to reproduce, or closely match, the eigenvalue, flux, and power distributions from analytic test problem solutions, demonstrating that the implemented finite difference approximation in $\theta-\mathrm{R}-\mathrm{Z}$ is working as intended. Several additional REBUS-PC features are tested, such as control rod movement by detailed comparisons of the results against reference solutions obtained using an auxiliary implemented MatLab program.

As expected, the REBUS-PC software produces results that are $100 \%$ consistent with the stated capabilities and thus the verification exercise is completed. These verification tests should be executed with each re-compilation of the REBUS-PC source and after any source code changes. All output results from any such new work should be rigorously compared against the stored output of the 22 verification tests cited in this report that forms the basis of the verification process. 


\section{Table of Contents}

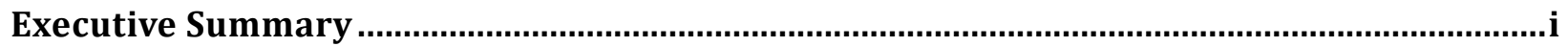

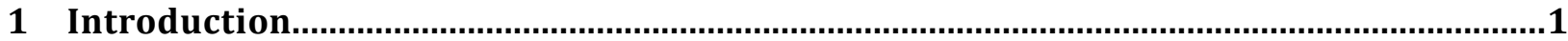

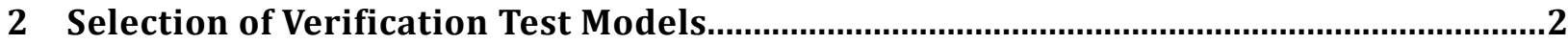

2.1 One-Group, 1-D Analytical Benchmark

2.2 One-Group, 1-D Analytical Benchmark with Internal Black Absorber ....................................... 3

2.3 One-Group, 3-D Analytical Benchmark............................................................................................... 4

2.4 One-Group, 3-D Analytical Benchmark with Internal Black Absorber ........................................ 4

2.5 Seven-Group 0-D Analytical Benchmark ................................................................................................ 4

2.6 Seven-Group 0-D Depletion Benchmark ........................................................................................... 4

2.7 Seven-Group 3-D Verification Benchmark......................................................................................... 5

2.8 Summary Discussion of Verification Test Suite ................................................................................. 5

3 Verification of Stated Capabilities ....................................................................................

3.1 REBUS-PC Example Input Detail and Relation to Capability Testing ........................................ 7

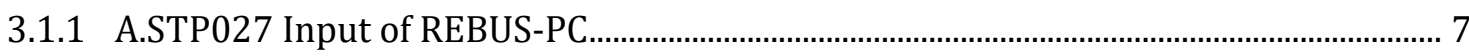

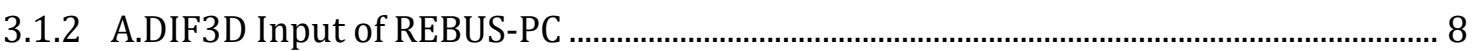

3.1.3 A.HMG4C Input of REBUS-PC ……............................................................................... 9

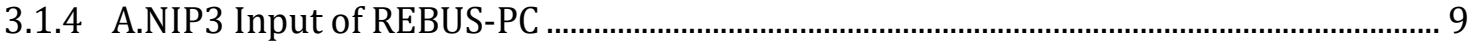

3.1.5 A.BURN Input of REBUS-PC ..........................................................................................

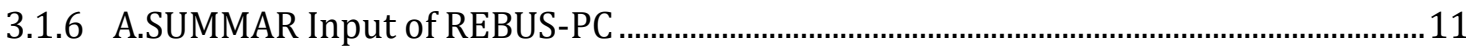

3.1.7 A.ISO and ISOTXS Input of REBUS-PC................................................................................11

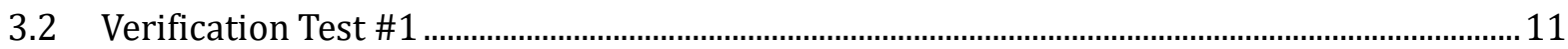

3.3 Verification Test \#2 .................................................................................................................... 18

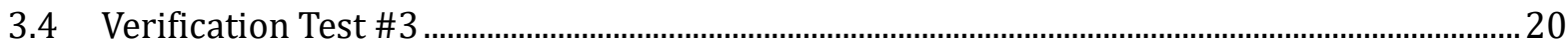

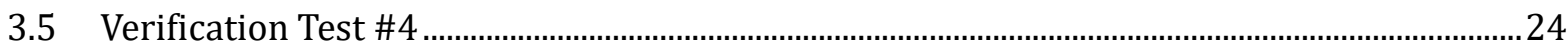

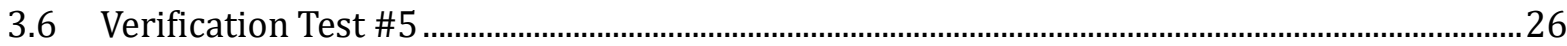

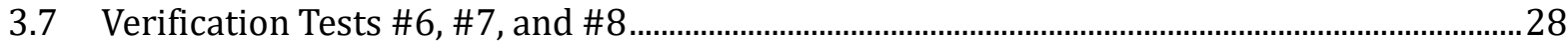

3.8 Verification Tests \#9, \#10, and \#11 …….............................................................................................29

3.9 Supplemental Verification of Capabilities 1, 4, and 5................................................................... 34

3.10 Verification Tests \#12, \#13, and \#14 ……....................................................................................... 36

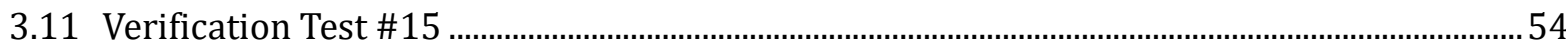

3.12 Verification Tests \#16 and \#17 …….....................................................................................61

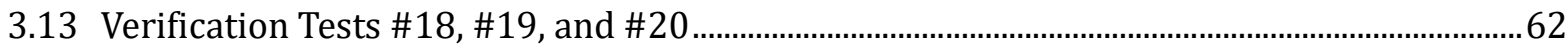

3.14 Verification Test \#21 and \#22 ……...............................................................................................

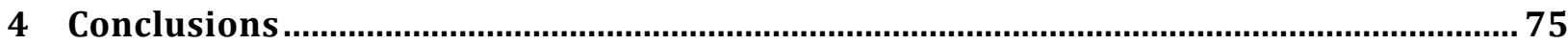




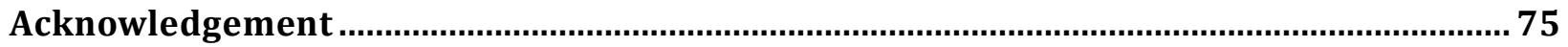

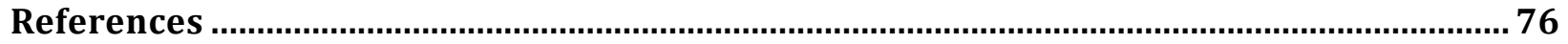




\section{List of Figures}

Figure 2-1. Illustration of Original IAEA Generic 10-MW Reactor Model ...................................................... 2

Figure 2-2. STRZ Benchmark Problem Geometry Details................................................................................... 2

Figure 2-3. 1GCYL_black Model Showing Black Absorber............................................................................ 4

Figure 2-4. Configuration of the 7GTRZ_het Model .................................................................................... 5

Figure 3-1. Truncated Input for Verification Test \#1 ……………....................................................................... 12

Figure 3-2. REBUS-PC Verification Test \#1 Output Excerpt \#1 ……......................................................... 13

Figure 3-3. REBUS-PC Verification Test \#1 Output Excerpt \#2 ….............................................................14

Figure 3-4. Truncated Input for Verification Test \#2 …..................................................................................... 18

Figure 3-5. REBUS-PC Verification Test \#2 Output Excerpt......................................................................... 19

Figure 3-6. Truncated Input for Verification Test \#3 ………..............................................................................20

Figure 3-7. REBUS-PC Verification Test \#3 Output Excerpt \#1 ……..................................................................22

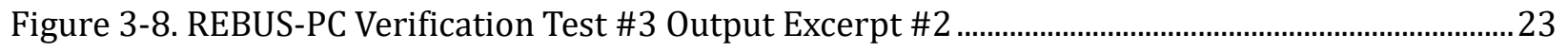

Figure 3-9. REBUS-PC Verification Test \#4 Output Excerpt..............................................................................25

Figure 3-11. REBUS-PC Verification Test \#5 Output Excerpt ..........................................................................27

Figure 3-12. Truncated Input for Verification Test \#6 …….......................................................................... 28

Figure 3-13. Truncated Input for Verification Test \#9 ……......................................................................... 30

Figure 3-14. Truncated Input for Verification Test \#10 ……..................................................................... 30

Figure 3-15. REBUS-PC Verification Tests \#9 and \#10 Output Differences ..............................................31

Figure 3-16. REBUS-PC Verification Tests \#9 and \#10 Output Similarities ...............................................32

Figure 3-17. Truncated Input for Verification Test \#11 ....................................................................................... 33

Figure 3-18. Reference Flux and Source Profiles for Supplemental Test Problem ...................................35

Figure 3-19. REBUS-PC Flux Profiles for Supplemental Test Problem ....................................................... 35

Figure 3-20. REBUS-PC Flux Error Profiles for Supplemental Test Problem...............................................36

Figure 3-21. Model Descriptions in REBUS-PC Standard Output .....................................................................37

Figure 3-22. Region Map Output Table Excerpt from REBUS-PC for Verification Test \#12 ....................37

Figure 3-23. Modified Geometry Inputs between Verification Tests \#12 and \#13 ..................................42

Figure 3-24. Modified Geometry Inputs between Verification Tests \#12 and \#14 ...................................42

Figure 3-25. Color Set Input Excerpt for Verification Test \#12 ......................................................................43

Figure 3-26. ISOTXS Cross Sections Differences for Verification Test \#12 ................................................44

Figure 3-27. Zone to Region Assignment Input Excerpt for Verification Test \#12 ..................................49

Figure 3-28. Excerpt of the Region to Area Assignment Edit for Verification Test \#12 2.........................49

Figure 3-29. Control Rod Input Details for Verification Test \#15 .................................................................55

Figure 3-30. Control Rod Tip Position for Verification Test \#15.................................................................55

Figure 3-31. Isotope Reactor Loading (kg) for Verification Test \#15 ……...............................................56

REBUSPC v1.5 Verification Test Summary iv 
Figure 3-32. Reactor Loading Output Excerpt for Verification Test \#15 56

Figure 3-33. REBUS-PC Output Excerpt Showing Control Rod Position Identification for Verification Test \#15

Figure 3-34. REBUS-PC Output Excerpt Showing Core Power and Flux Data Compared for Verification Test \#15 60

Figure 3-35. REBUS-PC A.ISO Input Excerpt for Verification Test \#16 .61

Figure 3-36. REBUS-PC A.BURN Input Excerpt for Verification Test \#19 62

Figure 3-37. POLYFI.BCD Excerpt for a Cubic Spline Fit in Verification Test \#19 .63

Figure 3-38. POLYFI.BCD Interpolated Cross Section for Verification Test \#19 63

Figure 3-39. Group Two $(n, \gamma)$ Capture Cross Sections of U-238 for Verification Test \#19. 64

Figure 3-40. Group One LFPA Isotope Cross Section Differences for Cubic Spline Fit in Verification Test \#19. 65

Figure 3-41. REBUS-PC Macroscopic Cross Section Output Excerpt of Verification Test \#19 .66

Figure 3-42. Macroscopic Fission Cross Section in Region FL11E for Cubic Spline Fit in Verification Test \#19 66

Figure 3-43. REBUS-PC A.BURN Input Excerpt for Verification Test \#18. 67

Figure 3-44. Group One LFPA Isotope Cross Section Differences for a Piecewise Linear Fit in Verification Test \#18 68

Figure 3-45. REBUS-PC Macroscopic Cross Section Output Excerpt of Verification Test \#18 69

Figure 3-46. Macroscopic Fission Cross Section in Region FL11E for Piecewise Linear Fit in Verification Test \#18 ... 69

Figure 3-47. A.BURN Depletion Chain Excerpt for Verification Test \#21 …………………………….........72

Figure 3-48. Input Geometry Definition for Verification Test \#22 ……....................................................... 74 


\section{List of Tables}

Table 1-1. REBUS-PC Identified Capabilities that Must be Verified................................................................ 1

Table 2-1. REBUS-PC Verification Test Suite..................................................................................................... 6

Table 3-1. Analytic and Computed Eigenvalue Results for Verification Test \#1 …....................................15

Table 3-2. Mesh Averaged Flux Comparisons For Verification Test \#1 ...................................................... 16

Table 3-3. Mesh Averaged Flux Comparisons For Altered Verification Test \#1 ........................................17

Table 3-4. Comparison of k-effective Values of 1GCYL_hom and 1GCYL_black Models ...........................19

Table 3-5. Mesh Averaged Flux Comparisons for Verification Test \#3 .......................................................24

Table 3-6. Verification Test \#6, \#7, and \#8 Setup Differences and Results .................................................28

Table 3-7. Verification Test \#12 Check of the $\theta$ Mesh Boundaries .....................................................................38

Table 3-8. Verification Test \#12 Check of the R Mesh Boundaries..................................................................39

Table 3-9. Verification Test \#12 Check of the Z Mesh Boundaries ................................................................39

Table 3-10. Verification Test \#12 Check of the Region and Area Volumes.................................................40

Table 3-11. Verification Tests \#12, \#13, and \#14 Eigenvalue Results .........................................................41

Table 3-12. Manual Check of the Input Density for Card Type 13 in Verification Test \#12 ....................45

Table 3-13. Check of the Computed Densities for Card Type 14 in Verification Test \#12 .......................46

Table 3-14. Macroscopic Principal Cross Sections of FUEL1 from Verification Test \#12 ......................47

Table 3-15. REBUS-PC Zone Assignment to Region............................................................................................ 48

Table 3-16. Region Power Comparison for Verification Test \#12

Table 3-17. Area Power Results for Verification Test \#12 ……........................................................................50

Table 3-18. Region FL11E Power and Burnup Edit Comparison for Verification Test \#12 ...................51

Table 3-19. Region FL11E Instantaneous Power Comparison for Verification Test \#12 ........................51

Table 3-20. k-effective Results for First Step Reconstruction of Verification Test \#12...........................52

Table 3-21. Power Results for First Step Reconstruction of Verification Test \#12 ...................................53

Table 3-22. k-effective Results for 7th Step Reconstruction of Verification Test \#12 …............................53

Table 3-23. Power Results for 7 th Step Reconstruction of Verification Test \#12 ……...............................54

Table 3-24. Control Rod Material Location Identification for Verification Test \#15................................58

Table 3-25. Core Multiplication Factors at Each Time Node for Verification Test \#15 ............................58

Table 3-26. Time Node 3 Flux and Power Comparison for Verification Test \#15.....................................59

Table 3-27. REBUS-PC K-effective Results for Different Cross Section Interpolation Schemes ............70

Table 3-28. Depletion Chain Setup for Verification Test \#21 ………............................................................ 71

Table 3-29. Comparison of Atom Density (atoms/barn-cm) for Verification Test \#21 ...........................73

Table 3-30. Comparison of Atom Densities at Each Iteration of Verification Test \#22............................74 


\section{Introduction}

The REBUS-PC software [1-3] has been used extensively to model fuel burnup in both thermal and fast spectrum systems. More recently, the REBUS-PC software has been used for reduced enrichment fuel design efforts for the University of Missouri Research Reactor (MURR). As part of the ongoing work on MURR [4-5], the reliability of the results obtained with REBUS-PC must be more rigorously verified and thus this maniscript serves as proof that the embedded algorithms and output obtained from REBUS-PC are correct.

To begin, the parts of REBUS-PC that must be tested with respect to the MURR work must first be identified. This was done previously [6] and the summary of those capabilities is given in Table 1-1.

Table 1-1. REBUS-PC Identified Capabilities that Must be Verified.

\begin{tabular}{|c|c|}
\hline Index & Description \\
\hline 1 & Properly implemented $\theta$-R-Z geometry modeling of the diffusion equation \\
\hline 2 & $\begin{array}{l}\text { Define cross section specific (color set) compositions for use in the multi-group diffusion } \\
\text { equation in specific regions }\end{array}$ \\
\hline 3 & $\begin{array}{l}\text { Depletion is based upon the provided cross section data in specific regions as defined by } \\
\text { Capability \#2. }\end{array}$ \\
\hline 4 & Properly implemented reflected boundary condition in the R direction \\
\hline 5 & Properly implemented extrapolated boundary condition in the $\mathrm{R}$ and $\mathrm{Z}$ directions \\
\hline 6 & $\begin{array}{l}\text { Properly implemented internal boundary conditions for control rods (i.e., "black" } \\
\text { boundary conditions) }\end{array}$ \\
\hline 7 & $\begin{array}{l}\text { Correct integral power output provided on input spatial regions and areas (collections of } \\
\text { regions). }\end{array}$ \\
\hline 8 & Properly implemented control rod movement during depletion over a given fuel cycle \\
\hline 9 & Properly implemented $\mathrm{Z}$ direction mesh refinement in control rod movement algorithm \\
\hline 10 & $\begin{array}{l}\text { K-effective solution of the forward multi-group diffusion equation using Tchebychev } \\
\text { acceleration and up-scattering iterations }\end{array}$ \\
\hline 11 & $\begin{array}{l}\text { Proper implementation of the cubic spline interpolation treatment of the cross section } \\
\text { data with respect to a reference isotope density. }\end{array}$ \\
\hline 12 & $\begin{array}{l}\text { Proper implementation of the linear interpolation treatment of the cross section data } \\
\text { with respect to a reference isotope density. }\end{array}$ \\
\hline 13 & Proper generation of TYPE13.BCD auxiliary output files \\
\hline 14 & $\begin{array}{l}\text { Proper implementation and convergence checking on the region density iteration scheme } \\
\text { for solving the Batement depletion equations (without extrapolation). }\end{array}$ \\
\hline
\end{tabular}

These various capabilities are connected, and thus each test case serves as a test of more than one capability. As an example, capability 1 cannot be verified independent of capabiliities 2, 4, 5, and 9 or vice-versa. Beyond this, capability 10 cannot be verified without first verifying capabilities $1-5$. In this sense, the verification test suite will have to use problems that combine the checking of each capability which, invariably, is some level of duplicate checking. 


\section{Selection of Verification Test Models}

For rigorous testing, a geometric setup in $\theta$-R-Z geometry was created based upon the IAEA Cartesian benchmark for a generic $10 \mathrm{MW}$ reactor [7]. The original $10 \mathrm{MW}$ Cartesian reactor layout is shown in Figure 2-1. The $\theta-\mathrm{R}-\mathrm{Z}$ representation of this benchmark problem is shown in Figure 2-2, which is referred to as STRZ (simple $\theta-\mathrm{R}-\mathrm{Z}$ ) in this manuscript.

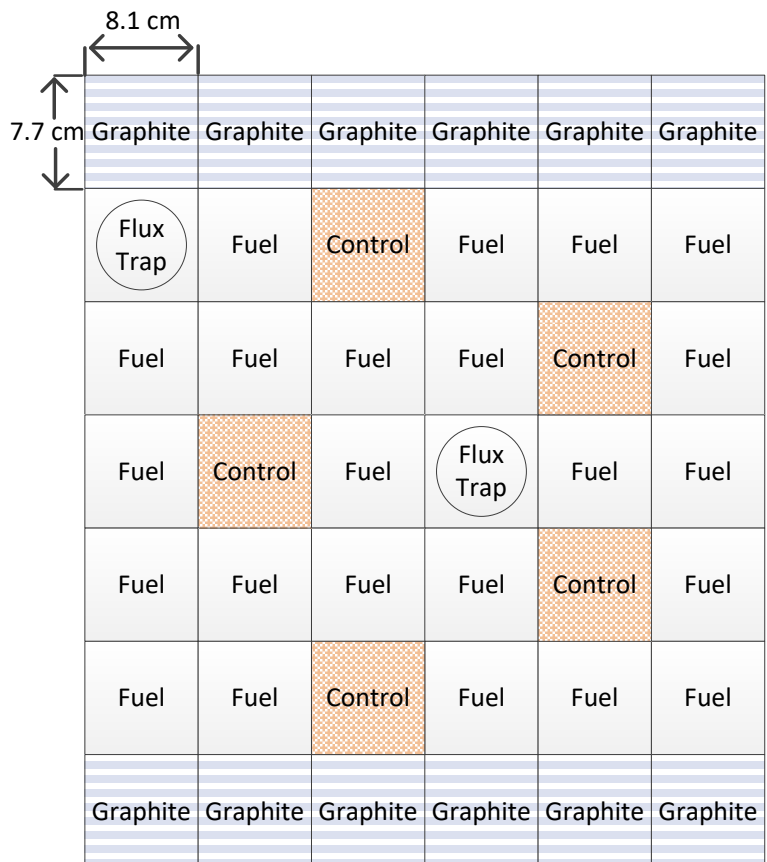

Figure 2-1. Illustration of Original IAEA Generic 10-MW Reactor Model
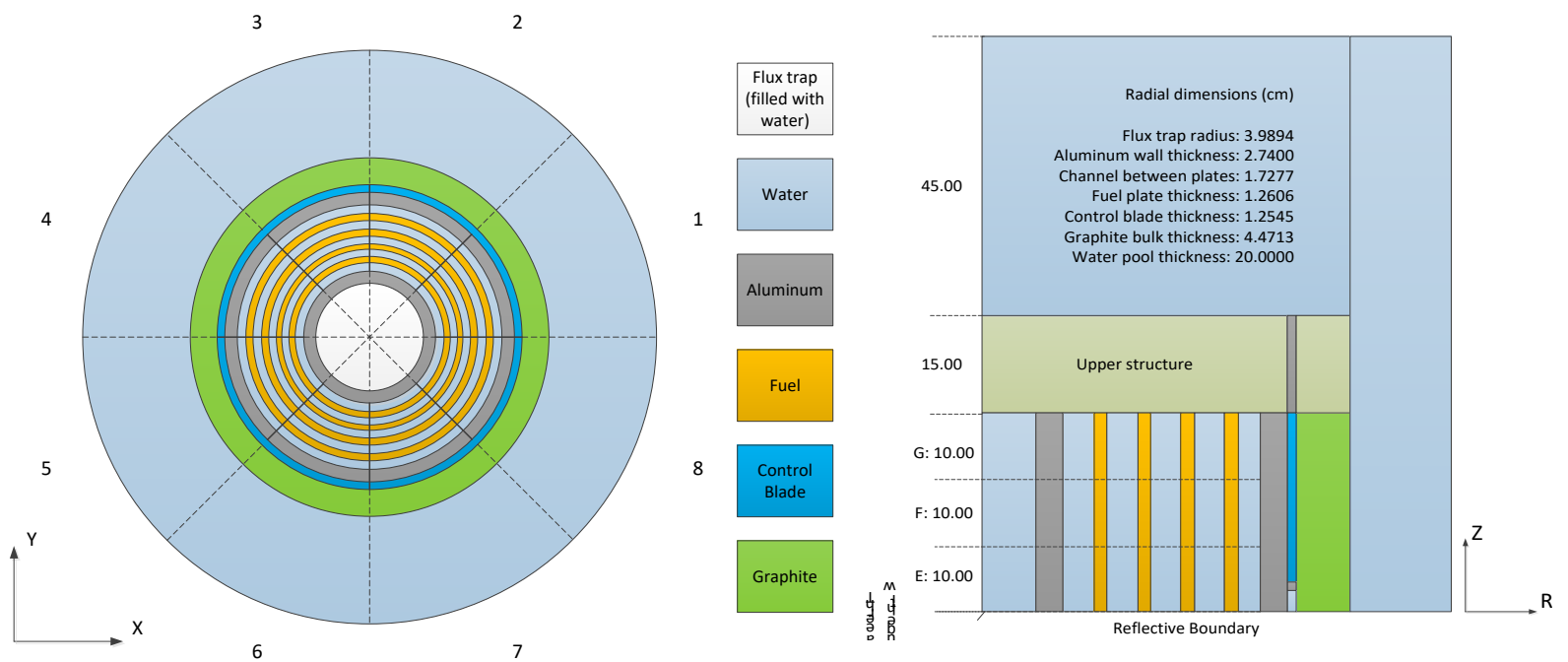

Figure 2-2. STRZ Benchmark Problem Geometry Details

From Figure 2-1 one can see that the original core is a $5 \times 6$ element core that contains 23 MTR-type standard fuel assemblies and 5 control assemblies. This core is reflected by graphite on two opposite sides and is surrounded by water. One water-filled flux trap is located near the center of the core and 
another near the upper left edge. Each fuel assembly consists of 23 fuel plates, and each control assembly consists of 17 fuel plates and $4 \mathrm{Al}$ control plates.

The STRZ problem in Figure 2-2 poses a realistic sized problem consistent with that used in the MURR work and the same input setup is thus used. The STRZ problem preserves the total fuel mass and the fuel to moderator ratio of the original IAEA benchmark problem. From Figure 2-2, the core has four annular rings of fuel each broken into 8 azimuthal regions each separated by water and surrounded overall by two aluminum annular rings. Each fuel region is the same thickness and is composed of a homogenized mixture of fuel meat and cladding. A control blade was placed outside of the core region and is broken into 4 pieces by quadrant, all of which are typically inserted to the same depth. The core is radially surrounded with an annular graphite reflector and water pool, and axially with an upper structure and axial pool region.

The material compositions and multi-group cross section libraries are taken from the IAEA reactor description. For verification purposes, the cycle length is set to one month (30 days) with 10 subintervals. REBUS-PC was used to compute the multiplication factors at the beginning and the end of cycle to be 1.07900 and 0.99859 , respectively. Block nuclide depletion is performed for each fuel plate and control blade. Each of the fuel plates is axially divided into three depletion zones with equal heights as shown in Figure 2-2. Four fission products (iodine-135, xenon-135, promethium-149 and samarium-149) and the major actinides (uranium, plutonium and neptunium) are modeled explicitly in the depletion chain. The REBUS-PC input file for this described test case of the STRZ benchmark problem is provided in the source code repository.

Given that the problem defined by Figure 2-2 and its described depletion chain is not analytically solvable, code-to-code comparisons are required or, alternatively, an independent solution of the underlying equations is required as a basis to support accuracy of REBUS-PC. These details are discussed later in this report when providing the calculated results for the STRZ benchmark problem.

In addition to the STRZ verification test, the multi-group diffusion equation can be solved analytically under certain circumstances which provides the best verification base of the steady state neutronics solver in REBUS-PC. In this work, a one-group and seven-group cross section data set is used to validate some of the capabilities in Table 1-1. To systematically verify several of the capabilities, the following benchmark problems were constructed to check the accuracy of the DIF3D finite difference diffusion theory flux solver and depletion capabilities of REBUS-PC.

\subsection{One-Group, 1-D Analytical Benchmark}

The first test case is a one-group, 1-D cylindrical homogeneous core problem which is named 1GCYL_hom. This benchmark uses a reflected boundary condition at the center and an extrapolated boundary condition at the outer edge of the cylinder. This benchmark problem checks the accuracy of the eigenvalue calculation routine of DIF3D (flux solver of REBUS-PC) and the radial boundary conditions.

\subsection{One-Group, 1-D Analytical Benchmark with Internal Black Absorber}

The second test case is a one-group, 1-D cylindrical homogeneous core problem named 1GCYL_black. This benchmark has a reflected boundary condition at the center and an extrapolated boundary condition at the outer edge of the cylinder. As can be seen in Figure 2-3, an additional layer of black absorber material is added around the homogeneous region. This benchmark problem checks both 
the eigenvalue calculation routine of DIF3D (flux solver of REBUS-PC) and the radial and black boundary conditions.

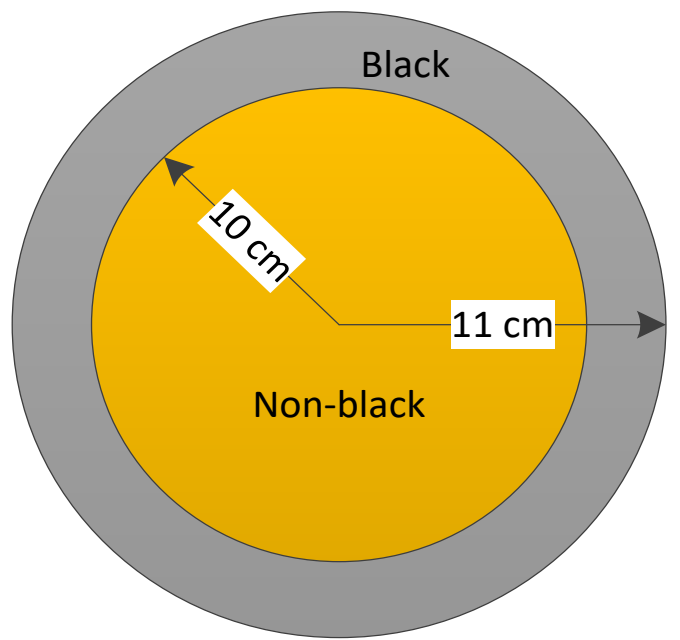

Figure 2-3. 1GCYL_black Model Showing Black Absorber

\subsection{One-Group, 3-D Analytical Benchmark}

Unlike the 1GCYL_hom benchmark problem, this problem consists of a single homogeneous region and makes use of radial extrapolated boundary conditions, axial reflected boundary conditions, and periodic boundary conditions in $\theta$ to produce an identical solution to 1GCYL_hom. It is named 1GTRZ_hom and uses the same composition as 1GCYL_hom for the core region. This problem can also be used to verify the accuracy of the eigenvalue calculation and the radial, axial, and $\theta$ boundary conditions.

\subsection{One-Group, 3-D Analytical Benchmark with Internal Black Absorber}

This is the 3-D representation of the 1GCYL_black problem. It uses radial extrapolated boundary conditions, axial reflected boundary conditions, and periodic boundary conditions in $\theta$ to produce an identical solution to $1 \mathrm{GCYL}$ black and is named 1GTRZ_black. It uses the same compositions as $1 G C Y L \_b l a c k$ and can be used to verify the accuracy of the eigenvalue calculation and the radial, axial, and $\theta$ boundary conditions.

\subsection{Seven-Group 0-D Analytical Benchmark}

In order to test the up-scattering capability listed in capability 10, a simple infinite homogeneous test case was created named 7GTRZ_hom. To test the accuracy of the up-scattering iteration, the cross section data was manipulated to have a significant fraction of up-scattering in the lower energy groups.

\subsection{Seven-Group 0-D Depletion Benchmark}

To verify the multi-region depletion capability 3 , a test problem was constructed of three separate, different sized regions but with equal flux levels named 7GXYZ_hom. A seven-group cross section library is used where identical fuel compositions are assigned to each region. A new utility program was created to serve as an independent calculation of the Bateman (depletion) equations to verify the accuracy of the REBUS-PC solution. 


\subsection{Seven-Group 3-D Verification Benchmark}

The last problem created is a seven-group heterogeneous core problem named 7GTRZ_het. This problem has two different fuel regions surrounded by two reflector regions. A reflected boundary condition is used at the radial center, extrapolated boundary conditions are used the outer radial edge and both axial surfaces, and periodic boundary conditions are used in the $\theta$ direction. The planar view of the configuration is illustrated in Figure 2-4.

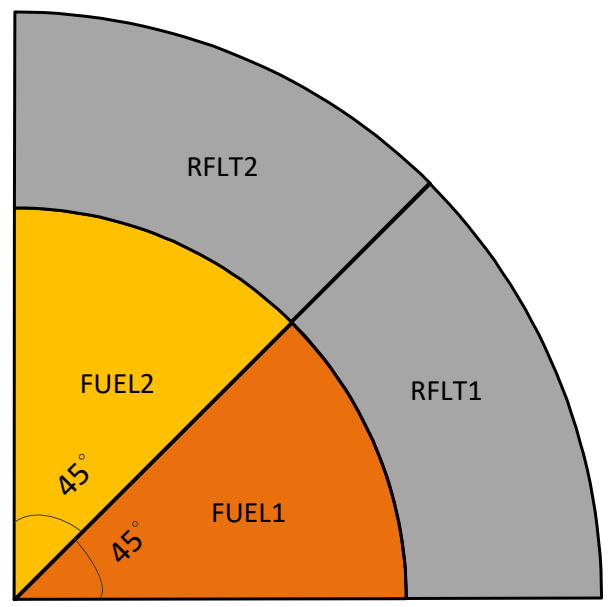

Figure 2-4. Configuration of the 7GTRZ_het Model

\subsection{Summary Discussion of Verification Test Suite}

Table 2-1 shows the set of verification tests constructed for REBUS-PC that are discussed in this report. For each row, the benchmark is named according to the preceding short description, and in some cases the specific purpose is listed. As an example, in verification test \#5, 1GTRZ_hom was modified to include reflected boundary conditions on all surfaces to verify capabilities 1, 4, and 5 .

In Section 3, input and output excerpts are presented for each verification test listed in Table 2-1. How each problem provides verification of the capabilities listed in Table 1-1 is also discussed. This will involve expanding the description of each capability in Table 1-1 and explaining how a given problem satisfies that aspect of the verification. With regard to the organization of the verification process, independently checking each capability with a single verification test is impractical as the various capabilities are interconnected. As shown in Table 2-1, the focus is placed on discussing each benchmark problem and how it satisfies a given capability rather than creating a list of verification tests that when combined verify a given capability. Thus, as discussed, the set of verification tests are duplicative as the same capability is tested in multiple test problems. 
Table 2-1. REBUS-PC Verification Test Suite

\begin{tabular}{|c|c|c|}
\hline Test & Description & Capabilities Verified \\
\hline 1 & 1GCYL_hom & \\
\hline 2 & 1GCYL_black & $1,4,5$ \\
\hline 3 & 1GTRZ_hom & 1,6 \\
\hline 4 & 1GTRZ_black & $1,4,5$ \\
\hline 5 & 1GTRZ_hom with reflected b.c.s & 10 \\
\hline 6 & 7GTRZ_hom & 10 \\
\hline 7 & 7GTRZ_hom & 10 \\
\hline 8 & 7GTRZ_het with fixed source & 1 \\
\hline 9 & 7GTRZ_het & 1 \\
\hline 10 & STRZ with fixed format input & $1,2,3,7,13$ \\
\hline 11 & STRZ with free format input & 1,2 \\
\hline 12 & STRZ with overlaid geometry & 1,2 \\
\hline 13 & STRZ with 1W and no CR movement & 8,9 \\
\hline 14 & Duplicate of Test \#19 using A.ISO input & 1 \\
\hline 15 & Duplicate of Test \#19 using ISOTXS input & 1 \\
\hline 16 & STRZ with linear spline XS interpolation & 3,12 \\
\hline 17 & STRZ with cubic spline XS interpolation & 3,11 \\
\hline 18 & STRZ with polynomial XS interpolation & 3,14 \\
\hline 19 & 1GCYL_hom with modified decay & 3,14 \\
\hline 20 & 7GXYZ_hom & \\
\hline 21 & & \\
\hline 22 & & \\
\hline
\end{tabular}




\section{Verification of Stated Capabilities}

The focus of this section is to provide concrete verification of the stated capabilities of REBUS-PC that are used in the MURR work. All of the verification tests are part of the REBUS-PC repository and verification checking system, and were first executed for version 1.5. Each time a source code change is made or a new executable is compiled, the set of verification checks that are described here, along with a selected MURR calculation, are executed to ensure the integrity of the work done here for verification and that done previously on the MURR work itself. In this regard, this work is instrumental in the creation of the first 22 verification tests in the REBUS-PC test suite, where the MURR benchmark can be identified as a verification test named "murr_ne_onestep." In addition to these tests, the IAEA $10 \mathrm{MW}$ benchmark problem mentioned previously is included in 5 verification tests along with other test cases taken from previous work using REBUS-PC. Combined, these verification tests ensure the integrity of the software as the software, compilers, and operating system progress.

\subsection{REBUS-PC Example Input Detail and Relation to Capability Testing}

From Table 1-1, several of the capabilities require that various aspects of the user input is checked. To do this, the REBUS-PC input itself, which is broken into several parts: A.STP027, A.SUMMAR, A.DIF3D, A.HMG4C, A.NIP3, A.BURN, and A.ISO or ISOTXS, must be discussed. Combined, these inputs define a problem to be solved using REBUS-PC and specify which outputs are desired by the user. To begin, an example MURR input deck is dissected when describing each segment of the input as it clearly demonstrates the user's typical input for a given problem. In total, the manual itself should be the ultimate guide for defining the input. The examples presented in this section are for illustration.

\subsubsection{A.STP027 Input of REBUS-PC}

The A.STP027 input is the control input for REBUS-PC. For the example MURR input it is:

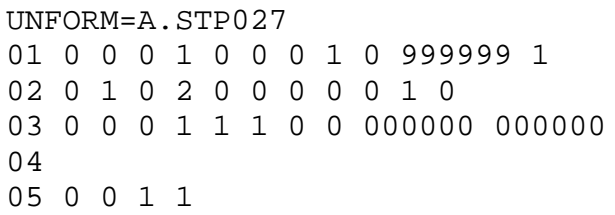

As can be seen, the input is wholly a set of integer values. In none of this input are the number of iterations controlled. This input is purely the decision process as to when and what outputs are to be printed during the iterative convergence. In some cases the array memory sizes can be controlled. The only real physics control is the integer flag ( 0 or 1$)$ that tells REBUS-PC whether an equilibrium or non-equilibrium problem is to be executed, of which, only the latter are relevant for REBUS-PC (the equilibrium solution option is actually physically disabled in REBUS-PC, such that only nonequilibrium problems can be executed).

Given this input constitutes basic control input, it can only be checked by comparing the function of the input and the expected output produced by REBUS-PC. As an example, one of the control flags allows the optional printing of the mass flow table and thus the only check that can be performed for this input is to ensure that the table of data is printed consistently with the provided input. 


\subsubsection{A.DIF3D Input of REBUS-PC}

The next section of input provided to REBUS-PC is the control input for the DIF3D steady state neutronics solver. Similar to the previous case, this input is primarily focused on the memory controls and what outputs are to be produced by the software. In addition, this section of input also controls the iteration limits to be applied in the neutronics solver along with what acceleration to apply and whether up-scattering iterations are to be used. The MURR example input is given as:

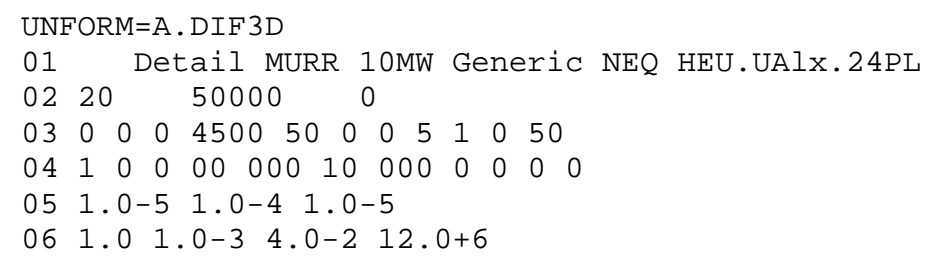

As can be seen, the input is broken into 6 different card types which is only a subset of the actual card input that is allowed by the software. Card type 01 is a simple title card which does not need to be verified. Card type 02 defines the array memory sizes to apply, which also does not need to be verified. Card type 03 controls the type of acceleration to use, the number of fission source iterations, upscattering iterations, and various other settings which control the behavior of the finite difference solver. Card type 04 controls the output tables that are produced by DIF3D, such as the region-wise and mesh-wise integrated power tables. Card type 05 specifies the desired convergence of the steady state neutronics solution at each time point in the depletion algorithm. Card type 06 specifies constraints on the convergence limits of card type 05 along with the total reactor power $(12.0 \mathrm{E}+6$ Watts).

With respect to software verification, the convergence criteria are the first to be discussed, which all have a lower limit of $\sim 10^{-12}$. Verification that the software properly implements these controls is done as part of the analytic solution set of test problems. As is the case for every problem, the analyst is required to verify that the settings are appropriate when they do their validation. Thus the setting for any particular control is problem dependent. For several of the test cases the convergence limit is set to the minimum value possible such that precise answers are obtained. This is sufficient proof that the convergence criteria are being observed by the software. To check the acceleration algorithms, they are disabled and the unaccelerated, fully converged result is compared with the accelerated converged result. This is part of the verification is required for capability 10 . Whether or not they pose any improvement in efficiency is not relevant to the software verification purpose of this report. Similarly, the software cannot be verified to explicity use a given number of upscattering iterations, as this information is not reported by REBUS-PC. Only the accuracy of the flux solution is can be checked given a fully converged system with and without upscattering iterations. Of course, the use of the upscattering iteration should have a notable impact on computational performance.

Much like the A.STP027 input, the output tables also do not need to be verified. As an example, card type 04 simply flags which output tables are to be produced and the fact that the desired output tables are produced by the software, as described later in this section, is sufficient proof that the controls are working. Of all of the A.DIF3D input, only the total power value used by REBUS-PC needs to be verified, which is covered in capabilities 1 and 7. To accomplish this, the analytical test cases are used to verify the reported power and flux magnitude are consistent with the expected values given the provided input data: capture \& fission rate power conversion factors. In conclusion, the only important aspect of this input data set to verify is that the selected power level is accurately computed by the software. 


\subsubsection{A.HMG4C Input of REBUS-PC}

This section of input controls the cross section homogenization scheme. It has its own title card which is selectively printed when the module is entered. The only physics control that is relevant in this section occurs in the seventh input on card type 02 . The user can choose to use a file-wide chi obtained from the base core composition or make a chi based upon the combination of isotopic chi. The limitation of using a file-wide chi is that it does not change with respect to depletion, and if the fuel burnup is high, the energy distribution of fission neutrons can change as U-235 fission is replaced with Pu-239 fission. The example input for MURR is given as

UNFORM=A . HMG4C

๑1 Detail 2008 MURR 12MW NEQ HEU.UAlx.24PL, 1.52gU/cC, 93.14 wt\% U235

$\odot 23000000011000$

In this example, the user has selected to use the file-chi option which is typical when the fuel burnup is low. As part of the testing, both options must be verified, which is covered by capabilities 2 and 3 .

\subsubsection{A.NIP3 Input of REBUS-PC}

The A.NIP3 input is typically the longest section of input provided to REBUS-PC as it defines both the geometry, compositions, and composition to geometry mapping information. The following excerpt from the MURR input shows at least one of each card type used.

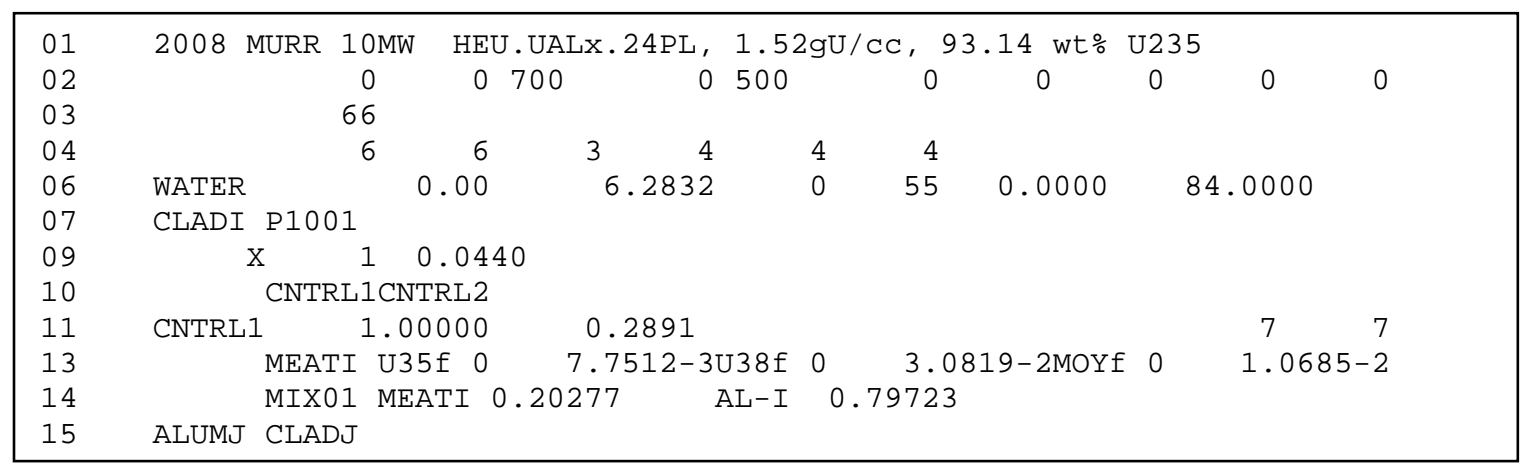

In the full input there are typically thousands of type 13 and type 14 cards and hundreds of card types 06 and 15. The first input card is again a title, which is only printed in the geometry processing section of input, and is taken care of at the beginning of the REBUS-PC execution. The card type 02 is used for debug printing, memory container sizes for the input processing, and some additional selection of output edits. Card type 03 selects the geometry type $(\theta-\mathrm{R}-\mathrm{Z}$ in this case) while type 04 selects the boundary conditions applied to that geometry. As discussed previously, capabilities 4 and 5 require that the inputs provided on the type 04 input translate to the correct application and solution in REBUS-PC.

Card type 06 specifies the geometry itself, which assigns regions (WATER in this example) to a given spatial position. Card type 07 allows the user to collect the region-wise information into "areas" for reactor core summary information. Card type 09 specifies the meshing to use on the geometry provided in card type 06 . All of these inputs are checked as part of capabilies 1 and 7.

Card types 10 and 11 are for the internal domain boundary conditions and will have to be checked as part of capability 6 . These boundary conditions are typically used to properly handle thermal energy 
black absorbers (B-10), which the finite difference methodology has difficulty modeling without considerable spatial meshing.

Card types 13 and 14 are used to define compositions and will have to be checked as part of capabilities 1 and 2. Card type 15 is the mapping between compositions and spatial regions and will be checked as part of capabilities 1 and 2 . As stated, these input cards form the bulk of the burden of user input. One aspect of the REBUS-PC software is to produce depleted compositions that the user can feed back into other neutroncis models, which is what capability 13 refers to. In this regard, the accuracy of that output with regard to using it as input must be verified.

From the combined discussion on A.NIP3 input, it should be clear that most of the capabilities are specifically focused on the accuracy of this input information. In this regard, most of the verification tests completed in this report are focused on problems that have no depletion. Rather, they are simple checks of the underlying solver of the neutron diffusion equation.

\subsubsection{A.BURN Input of REBUS-PC}

The A.BURN input is the main control section for the fuel cycle and depletion cases. It has specific inputs for equilibrium and non-equilibrium modes of fuel cycle operation and numerous inputs for external cycle operations such as fuel recycle, fabrication, and reprocessing. With respect to the MURR work and the verification requirements, only a subset of those inputs needs to be verified. The following is an exerpt from an example MURR input.

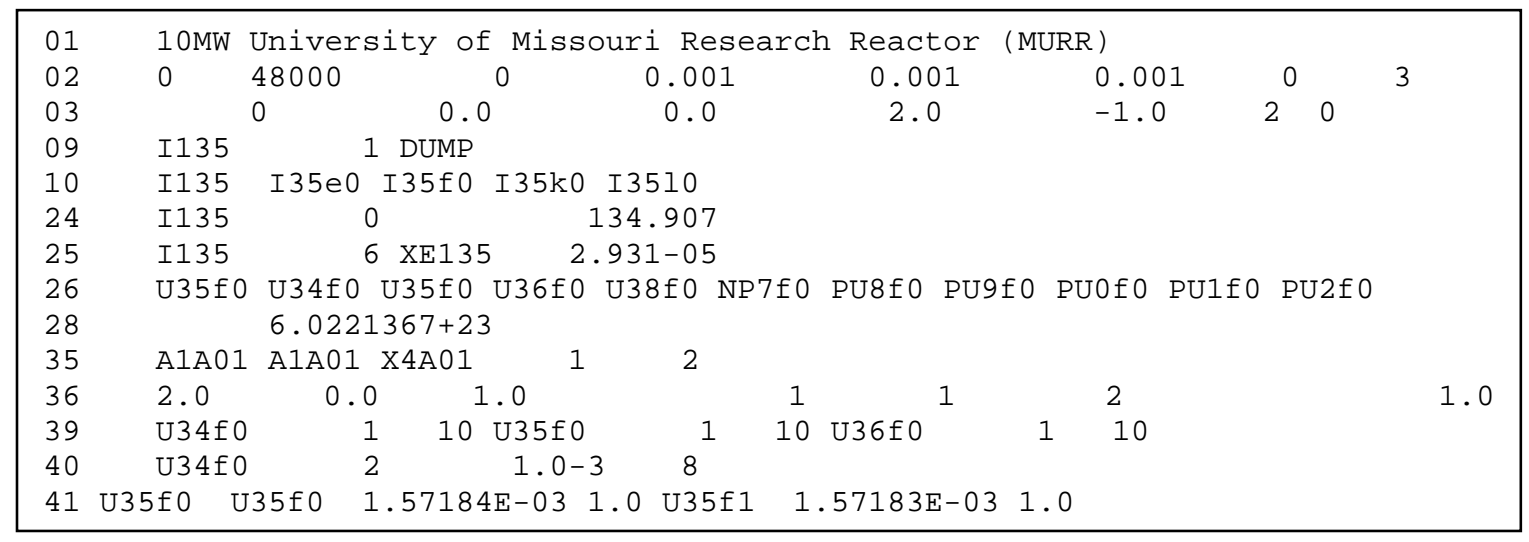

Card type 01 is a title card that is printed each time a fuel cycle module is entered and is not verified. Card type 02 defines the memory controls, the convergence and iteration limit settings on the regionwise depletion, and the convergence and iteration limits on the cyclic mode fuel cycle operations. Of these inputs, capability 14 requires that the region-wise depletion inputs are followed and that the depletion calculation itself is accurate. The seven-group depletion problem described in Section 2.6 is relied upon to demonstrate this.

Card type 03 defines the cyclic mode details such as fuel cycle length (days) and burnup convergence setting. Because this is a non-equilibrium problem, the verification is focused on card type 36 which specifies the time step information. In this example excerpt, the burnup convergence is set to -1.0. This basically disables the convergence check on burnup, which is not unusual for non-equilibrium problems. The information provided on card type 03 defines the first time step information in a nonequlibrium problem and thus its input and that of card type 36 will have to be verified. 
Card types $09,10,24,25$, and 28 are used to define a depletion chain and relate it to the set of isotopes provided in the cross section data. These inputs will have to be verified and is covered by capabilities 3 and 14.

Card types 26, 39, 40, and 41 are all used to define the cross section interpolation with respect to burnup. This input and usage of the physical data will be checked as part of capabilities 11, 12, and 14. In this MURR example, the polynomial approximation is used, although most cases use the cubic spline approach.

Card type 35 specifies the compositional assignments to regions as the reactor fuel cycle progresses along with the time step size and number of depletion steps to apply over each time step. This input is the foundation to the non-equilibrium cycle option and is verified by capabilities $3,11,12,13$, and 14.

\subsubsection{A.SUMMAR Input of REBUS-PC}

The A.SUMMAR is an optional input specification and its most valuable output is to provide whole core integral isotopic reaction rates. In the MURR work, this feature is not used and would only loosely fall under capability 7 . The following excerpt is taken from one of the verification tests.

\begin{tabular}{|c|c|c|c|c|c|c|c|c|}
\hline \multicolumn{9}{|c|}{ DATASET=A . SUMMAR } \\
\hline 01 & & & $\odot$ & ๑ 999999 & -1 & $\odot$ & 0 & 1 \\
\hline$\odot 4$ & \multicolumn{8}{|c|}{1 U35A_0U35C_0 } \\
\hline 06 & U235 & FISS & 235.044 & \multicolumn{5}{|c|}{ U35A_@U35C_@ } \\
\hline
\end{tabular}

The card type 01 input specifies memory and debugging controls and additional output tables. Card types 04 and 06 specify how the isotopes are to be mapped for the isotopic output tables produced by the SUMMAR module. From the list of capabilities, the accuracy of this output is not part of the verification. However, given that it produces supplemental input to capability 7 , it is included for completeness.

\subsubsection{A.ISO and ISOTXS Input of REBUS-PC}

The primary means of providing cross section data to REBUS-PC is to use a binary interface file called ISOTXS. The alternative is to include a section of ascii input called A.ISO. This ascii input will simply produce an ISOTXS in the early geometry and input processing from which the code operates as if the user provided that binary ISOTXS file. The verification aspect is only to ensure that both input options work consistently on a given problem, and that the correct answer is produced which falls under capabilities 2 and 3.

\subsection{Verification Test \#1}

The most logical way to discuss the verification process is to describe the input and output for each of the 22 verification tests and explain how it satisfies the verification of each capability. Verification test \#1 is a one-group, 1-D core geometry, and was identified previously in this report as 1GCYL_hom. An input excerpt is provided in Figure 3-1. As discussed, the external boundary conditions are specified on the type 04 cards and the internal boundary conditions are specified on the types 10 and 11 cards of the A.NIP3 dataset. The boundary conditions used by REBUS-PC are printed in the model descriptions of the REBUS-PC output as shown in Figure 3-2. As can be seen, REBUS-PC reports that a reflected condition is set for the first boundary condition on the first dimension and an extrapolated one is set for the second boundary condition on the first dimension. In addition, it provides the 
extrapolation parameter of 0.4692 as selected by the user input. (This extrapolation value is the default value used from diffusion theory, as indicated in the manual).

To check the spatial region configurations, the region map was printed in the standard output by turning on the third and fourth input flags of the type 04 card in dataset A.DIF3D. The region and zone map is shown in Figure 3-3. The numbers in the first and last row of each table denote the mesh index in the radial direction, while the numbers in between denote the region (or zone) number assigned to each position. In this example, there is a single composition, and thus there is only one region and one zone and one mesh index in the R-direction (i.e. the radial direction). Star symbols $(*)$ mark the region boundaries. Examination of the plotted region map confirms that the positions of individual regions conform to the user specification given in Figure 3-1. The mesh intervals and region volumes were also checked by comparing the values given in the output to those calculated by a hand calculation.

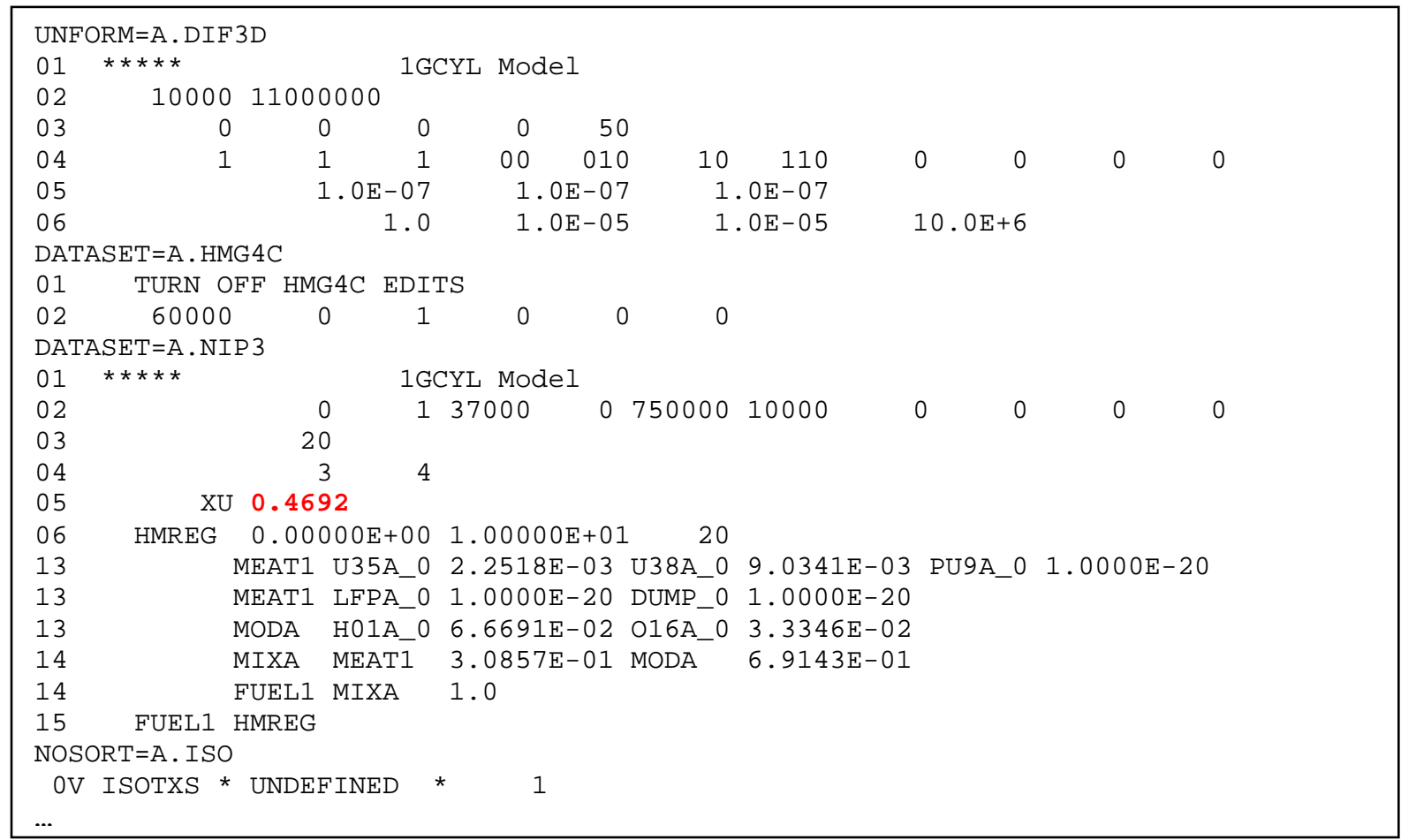

Figure 3-1. Truncated Input for Verification Test \#1 


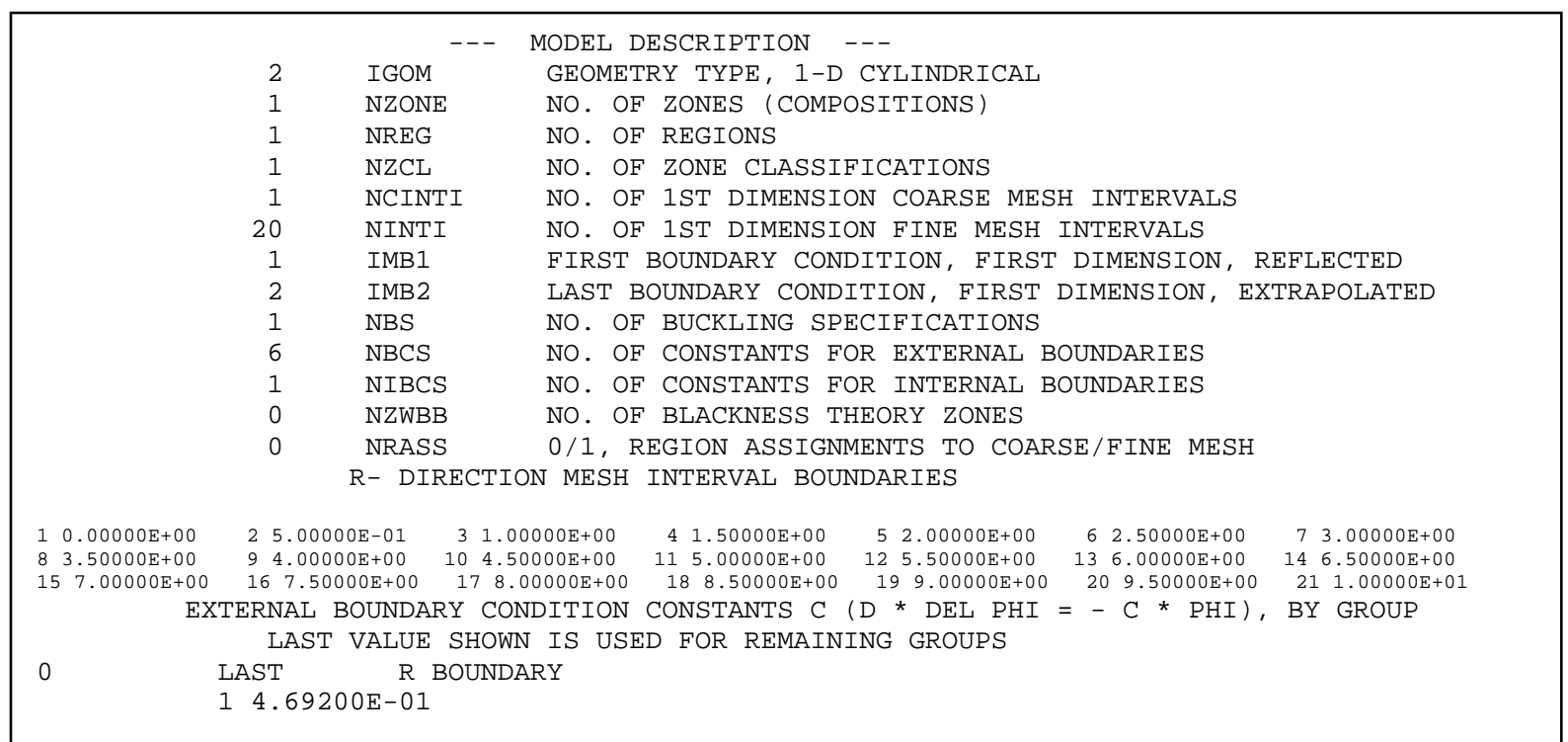

Figure 3-2. REBUS-PC Verification Test \#1 Output Excerpt \#1 


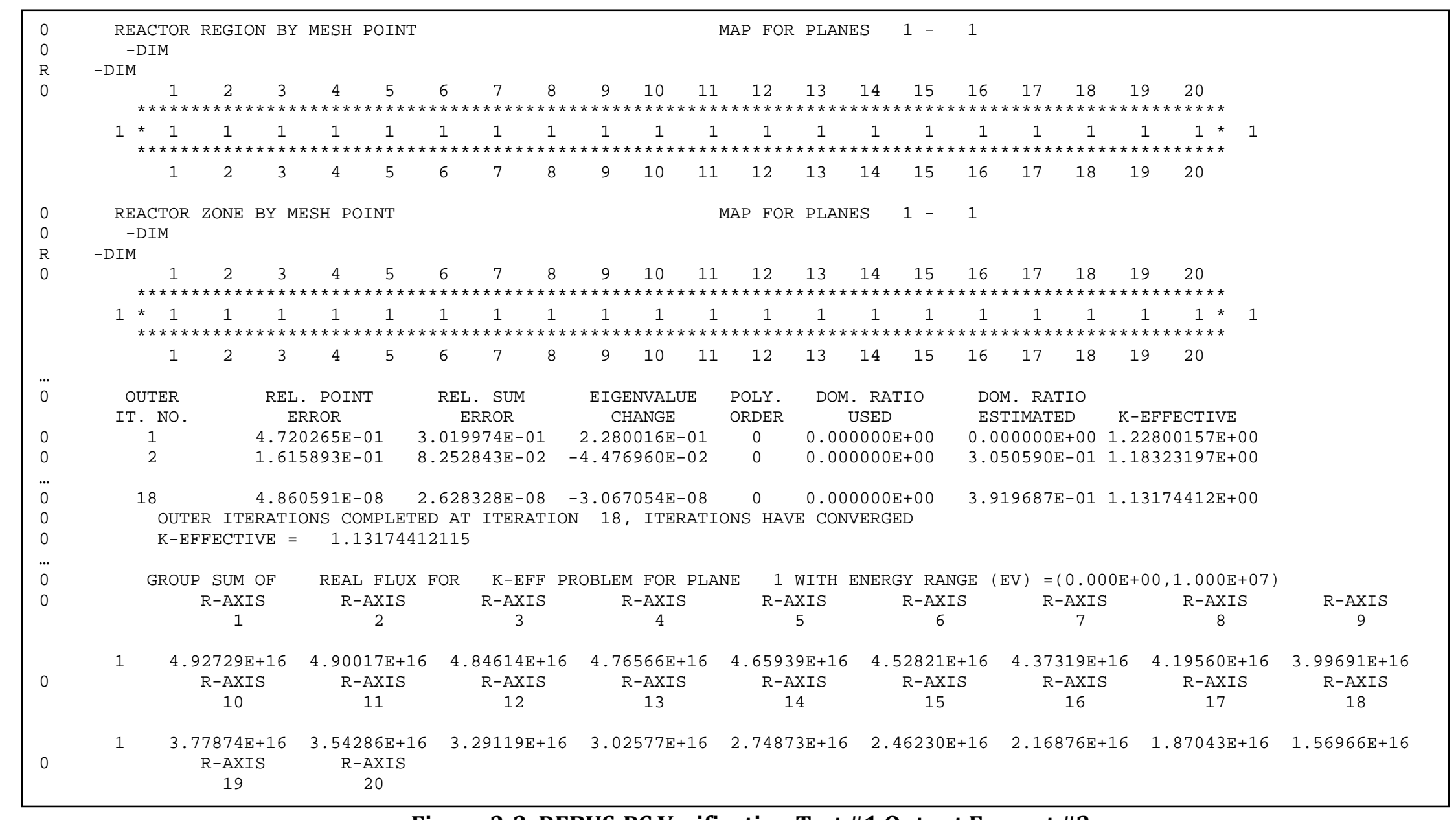

Figure 3-3. REBUS-PC Verification Test \#1 Output Excerpt \#2 
The analytical flux solution $\phi(r)$ of the neutron diffusion equation in a 1-D cylindrical geometry is a Bessel function of the first kind [8]:

$\phi(r)=C J_{0}(B \cdot r), \quad 0 \leq r \leq R$.

The normalization factor $C$ is defined by the total power input of $10 \mathrm{MW}$ in Figure 3-1. The constant $B$ is defined by the boundary condition at the maximum radius $R$. The general boundary condition can be expressed as

$$
\left.\alpha \vec{n} \cdot \vec{J}\right|_{\partial V}+\left.\beta \phi\right|_{\partial V}=\alpha D \phi^{\prime}(R)+\beta \phi(R)=0 \text {. }
$$

In this example, an extrapolated boundary condition was used, which REBUS-PC allows a userspecified constant $A=\beta / \alpha$. The zero flux boundary condition ( $\alpha=0$ and $\beta=1$ ) requires a specific boundary condition input, where as this input path allows any result between zero flux condition and the reflected condition ( $\alpha=1$ and $\beta=0$ ). As discussed previously, the default extrapolation factor $A=0.4692$ was used, as evident from the output file.

Inserting equation 1 into equation 2 produces

$-\alpha D B J_{1}(B R)+\beta J_{0}(B R)=0$,

where $J_{1}(B R)$ is the first-order Bessel function of the first kind. With a given constant $A$, equation 3 can be solved for the first positive root of $B$ using the Wolfram Mathematica program [9] or MathCAD [10]. With the obtained geometric buckling, $B^{2}$, the analytical k-effective can be defined as

$$
k_{e f f}=v \Sigma_{f} /\left(\Sigma_{r}+D B^{2}\right) \text {. }
$$

The finite difference methodology is not an analytic methodology and thus the solutions are dependent upon the mesh refinement. As such, equally spaced mesh refinement is used which should provide asymptotic convergence as opposed to gradient based meshing. In this regard, the input must be modified and executed several times to verify accuracy with respect to the analytic solution. Table 3-1 presents the results of this mesh refinement work for a zero flux boundary condition and two different extrapolation boundary conditions. As discussed in the preceding theory section, the analytic result was obtained using Mathematica and MathCAD.

\begin{tabular}{|c|c|c|c|c|c|}
\hline \multirow{2}{*}{\multicolumn{3}{|c|}{ Boundary Condition }} & \multirow{3}{*}{$\begin{array}{c}\text { Zero Flux at R } \\
\alpha=0, \beta=1 \\
1.0203692\end{array}$} & \multicolumn{2}{|c|}{ Extrapolated Condition at R } \\
\hline & & & & \multirow{2}{*}{$\begin{array}{l}A=\beta / \alpha=0.5 \\
1.1262925\end{array}$} & \multirow{2}{*}{$\begin{array}{c}A=\beta / \alpha=0.4692 \\
1.1326695\end{array}$} \\
\hline \multirow{4}{*}{ REBUS-PC } & \multirow{3}{*}{$\begin{array}{l}\text { Mesh Size } \\
\quad(\mathrm{cm})\end{array}$} & 1.00 & & & \\
\hline & & 0.50 & 1.0193621 & 1.1253599 & 1.1317441 \\
\hline & & 0.25 & 1.0191104 & 1.1251268 & 1.1315128 \\
\hline & \multicolumn{2}{|c|}{ Richardson Extrapolation } & 1.0190266 & 1.1250491 & 1.1314358 \\
\hline \multicolumn{3}{|c|}{ Analytic Solution } & 1.0190266 & 1.1250491 & 1.1314358 \\
\hline
\end{tabular}

Table 3-1. Analytic and Computed Eigenvalue Results for Verification Test \#1

Because this is a simple bare core geometry, it is more sensitive to mesh refinement than typical reactor problems, and thus this is an excellent choice for demonstrating the accuracy limitations of the finite difference methodology. As can be seen, the coarser the meshing in REBUS-PC, the larger the error with respect to the analytic solution. A Richardson Extrapolation [11] result based upon the 
three mesh results obtained with REBUS-PC is provided to demonstrate that with a zero mesh size, the REBUS-PC methodology will result in the correct solution.

The verification test corresponds to a mesh size of $0.5 \mathrm{~cm}$ and $A=0.4692$. From the output excerpt in Figure 3-3 one finds the eigenvalue matches that provided in Table 3-1. In addition to this basic check, the average flux results reported by REBUS-PC are also compared. Figure 3-3 shows the mesh averaged flux output edit from REBUS-PC which is compared against the analytic result taken from the MathCAD worksheet provided in the repository with the first verification test. Table 3-2 shows the comparison of the flux result and resulting error. As can be seen, the error is largest near the extrapolated boundary condition peaking at $0.034 \%$ error and, because of the normalization constraint, it becomes negative as it approaches the core center. This type of result is not surprising given the mesh size chosen and the gradient in the flux.

Table 3-2. Mesh Averaged Flux Comparisons For Verification Test \#1

\begin{tabular}{|c|c|c|c|}
\hline Mesh No. & $\begin{array}{c}\text { REBUS-PC } \\
\text { Results }\end{array}$ & $\begin{array}{c}\text { Analytical } \\
\text { Results }\end{array}$ & Error \\
\hline 1 & $4.92729 \mathrm{E}+16$ & $4.92679 \mathrm{E}+16$ & $-0.010 \%$ \\
\hline 2 & $4.90017 \mathrm{E}+16$ & $4.89967 \mathrm{E}+16$ & $-0.010 \%$ \\
\hline 3 & $4.84614 \mathrm{E}+16$ & $4.84566 \mathrm{E}+16$ & $-0.010 \%$ \\
\hline 4 & $4.76566 \mathrm{E}+16$ & $4.76520 \mathrm{E}+16$ & $-0.010 \%$ \\
\hline 5 & $4.65939 \mathrm{E}+16$ & $4.65896 \mathrm{E}+16$ & $-0.009 \%$ \\
\hline 6 & $4.52821 \mathrm{E}+16$ & $4.52781 \mathrm{E}+16$ & $-0.009 \%$ \\
\hline 7 & $4.37319 \mathrm{E}+16$ & $4.37282 \mathrm{E}+16$ & $-0.008 \%$ \\
\hline 8 & $4.19560 \mathrm{E}+16$ & $4.19528 \mathrm{E}+16$ & $-0.008 \%$ \\
\hline 9 & $3.99691 \mathrm{E}+16$ & $3.99664 \mathrm{E}+16$ & $-0.007 \%$ \\
\hline 10 & $3.77874 \mathrm{E}+16$ & $3.77851 \mathrm{E}+16$ & $-0.006 \%$ \\
\hline 11 & $3.54286 \mathrm{E}+16$ & $3.54269 \mathrm{E}+16$ & $-0.005 \%$ \\
\hline 12 & $3.29119 \mathrm{E}+16$ & $3.29107 \mathrm{E}+16$ & $-0.004 \%$ \\
\hline 13 & $3.02577 \mathrm{E}+16$ & $3.02571 \mathrm{E}+16$ & $-0.002 \%$ \\
\hline 14 & $2.74873 \mathrm{E}+16$ & $2.74873 \mathrm{E}+16$ & $0.000 \%$ \\
\hline 15 & $2.46230 \mathrm{E}+16$ & $2.46236 \mathrm{E}+16$ & $0.002 \%$ \\
\hline 16 & $2.16876 \mathrm{E}+16$ & $2.16887 \mathrm{E}+16$ & $0.005 \%$ \\
\hline 17 & $1.87043 \mathrm{E}+16$ & $1.87060 \mathrm{E}+16$ & $0.009 \%$ \\
\hline 18 & $1.56966 \mathrm{E}+16$ & $1.56989 \mathrm{E}+16$ & $0.015 \%$ \\
\hline 19 & $1.26881 \mathrm{E}+16$ & $1.26908 \mathrm{E}+16$ & $0.022 \%$ \\
\hline 20 & $9.70181 \mathrm{E}+15$ & $9.70508 \mathrm{E}+15$ & $0.034 \%$ \\
\hline
\end{tabular}

For completeness, the comparison results for a finer mesh solution for $A=0.5$ in provided in Table 3-3. This calculation is not part of the repository. Relative to the results for the coarser mesh in Table 3-2, the agreement between REBUS-PC and the analytic solution in Table 3-3 are almost an order of magnitude better, with a maximum error of $0.011 \%$ at the core edge. Combined, these results demonstrate that the flux solution methodology in REBUS-PC is accurate and correctly implemented with regard to the cross sections and power normalization constraint provided by the user. Because this verification test uses the 1-D cylindrical geometry in REBUS-PC, it does not satisfy any stated capability, although the exact same test can be used with the correct 3-D geometry in REBUS-PC with proper boundary conditions. 
Table 3-3. Mesh Averaged Flux Comparisons For Altered Verification Test \#1

\begin{tabular}{|c|c|c|c|}
\hline Mesh No. & $\begin{array}{l}\text { REBUS-PC } \\
\text { Results }\end{array}$ & $\begin{array}{l}\text { Analytical } \\
\text { Results }\end{array}$ & Error \\
\hline 1 & $4.98723 \mathrm{E}+16$ & $4.98709 \mathrm{E}+16$ & $-0.0028 \%$ \\
\hline 2 & $4.98025 \mathrm{E}+16$ & $4.98011 \mathrm{E}+16$ & $-0.0028 \%$ \\
\hline 3 & $4.96631 \mathrm{E}+16$ & $4.96617 \mathrm{E}+16$ & $-0.0028 \%$ \\
\hline 4 & $4.94543 \mathrm{E}+16$ & $4.94530 \mathrm{E}+16$ & $-0.0026 \%$ \\
\hline 5 & $4.91767 \mathrm{E}+16$ & $4.91753 \mathrm{E}+16$ & $-0.0028 \%$ \\
\hline 6 & $4.88307 \mathrm{E}+16$ & $4.88294 \mathrm{E}+16$ & $-0.0027 \%$ \\
\hline 7 & $4.84172 \mathrm{E}+16$ & $4.84158 \mathrm{E}+16$ & $-0.0029 \%$ \\
\hline 8 & $4.79369 \mathrm{E}+16$ & $4.79356 \mathrm{E}+16$ & $-0.0027 \%$ \\
\hline 9 & $4.73909 \mathrm{E}+16$ & $4.73896 \mathrm{E}+16$ & $-0.0027 \%$ \\
\hline 10 & $4.67803 \mathrm{E}+16$ & $4.67791 \mathrm{E}+16$ & $-0.0026 \%$ \\
\hline 11 & $4.61064 \mathrm{E}+16$ & $4.61052 \mathrm{E}+16$ & $-0.0026 \%$ \\
\hline 12 & $4.53706 \mathrm{E}+16$ & $4.53695 \mathrm{E}+16$ & $-0.0024 \%$ \\
\hline 13 & $4.45745 \mathrm{E}+16$ & $4.45734 \mathrm{E}+16$ & $-0.0025 \%$ \\
\hline 14 & $4.37196 \mathrm{E}+16$ & $4.37186 \mathrm{E}+16$ & $-0.0023 \%$ \\
\hline 15 & $4.28079 \mathrm{E}+16$ & $4.28070 \mathrm{E}+16$ & $-0.0021 \%$ \\
\hline 16 & $4.18411 \mathrm{E}+16$ & $4.18403 \mathrm{E}+16$ & $-0.0019 \%$ \\
\hline 17 & $4.08214 \mathrm{E}+16$ & $4.08206 \mathrm{E}+16$ & $-0.0020 \%$ \\
\hline 18 & $3.97507 \mathrm{E}+16$ & $3.97500 \mathrm{E}+16$ & $-0.0018 \%$ \\
\hline 19 & $3.86314 \mathrm{E}+16$ & $3.86308 \mathrm{E}+16$ & $-0.0016 \%$ \\
\hline 20 & $3.74658 \mathrm{E}+16$ & $3.74652 \mathrm{E}+16$ & $-0.0016 \%$ \\
\hline 21 & $3.62562 \mathrm{E}+16$ & $3.62557 \mathrm{E}+16$ & $-0.0014 \%$ \\
\hline 22 & $3.50052 \mathrm{E}+16$ & $3.50047 \mathrm{E}+16$ & $-0.0014 \%$ \\
\hline 23 & $3.37153 \mathrm{E}+16$ & 3.37149E+16 & $-0.0012 \%$ \\
\hline 24 & $3.23892 \mathrm{E}+16$ & $3.23889 \mathrm{E}+16$ & $-0.0009 \%$ \\
\hline 25 & $3.10296 \mathrm{E}+16$ & $3.10294 \mathrm{E}+16$ & $-0.0006 \%$ \\
\hline 26 & $2.96393 \mathrm{E}+16$ & $2.96392 \mathrm{E}+16$ & $-0.0003 \%$ \\
\hline 27 & $2.82211 \mathrm{E}+16$ & $2.82211 \mathrm{E}+16$ & $0.0000 \%$ \\
\hline 28 & $2.67779 \mathrm{E}+16$ & $2.67780 \mathrm{E}+16$ & $0.0004 \%$ \\
\hline 29 & $2.53127 \mathrm{E}+16$ & $2.53129 \mathrm{E}+16$ & $0.0008 \%$ \\
\hline 30 & $2.38284 \mathrm{E}+16$ & $2.38286 \mathrm{E}+16$ & $0.0008 \%$ \\
\hline 31 & $2.23281 \mathrm{E}+16$ & $2.23283 \mathrm{E}+16$ & $0.0009 \%$ \\
\hline 32 & $2.08146 \mathrm{E}+16$ & $2.08150 \mathrm{E}+16$ & $0.0019 \%$ \\
\hline 33 & $1.92911 \mathrm{E}+16$ & $1.92915 \mathrm{E}+16$ & $0.0021 \%$ \\
\hline 34 & $1.77606 \mathrm{E}+16$ & $1.77611 \mathrm{E}+16$ & $0.0028 \%$ \\
\hline 35 & $1.62261 \mathrm{E}+16$ & $1.62267 \mathrm{E}+16$ & $0.0037 \%$ \\
\hline 36 & $1.46908 \mathrm{E}+16$ & $1.46915 \mathrm{E}+16$ & $0.0048 \%$ \\
\hline 37 & $1.31575 \mathrm{E}+16$ & $1.31583 \mathrm{E}+16$ & $0.0061 \%$ \\
\hline 38 & $1.16294 \mathrm{E}+16$ & $1.16302 \mathrm{E}+16$ & $0.0069 \%$ \\
\hline 39 & $1.01094 \mathrm{E}+16$ & $1.01102 \mathrm{E}+16$ & $0.0079 \%$ \\
\hline 40 & $8.60037 \mathrm{E}+15$ & $8.60131 E+15$ & $0.0109 \%$ \\
\hline
\end{tabular}




\subsection{Verification Test \#2}

Verification test \#2 is also a one-group, 1-D geometry, but it uses the internal black absorber boundary condition. This problem was previously identified as 1GCYL_black. The external boundary conditions are specified on the type 04 cards and the internal boundary conditions are specified on the types 10 and 11 cards of A.NIP3, as seen in Figure 3-4. The boundary conditions used by REBUSPC are printed in the model descriptions of the REBUS-PC output, and are shown in Figure 3-5. As can be seen, REBUS-PC reports that a reflected condition is set for the first boundary condition on the first dimension and an extrapolated one is set for the second boundary condition on the first dimension with an extrapolation parameter of 0.4692 (the default). The black boundary condition setup is also reported in Figure 3-5, indicating the user input of Figure 3-4 is accepted and used by the software.

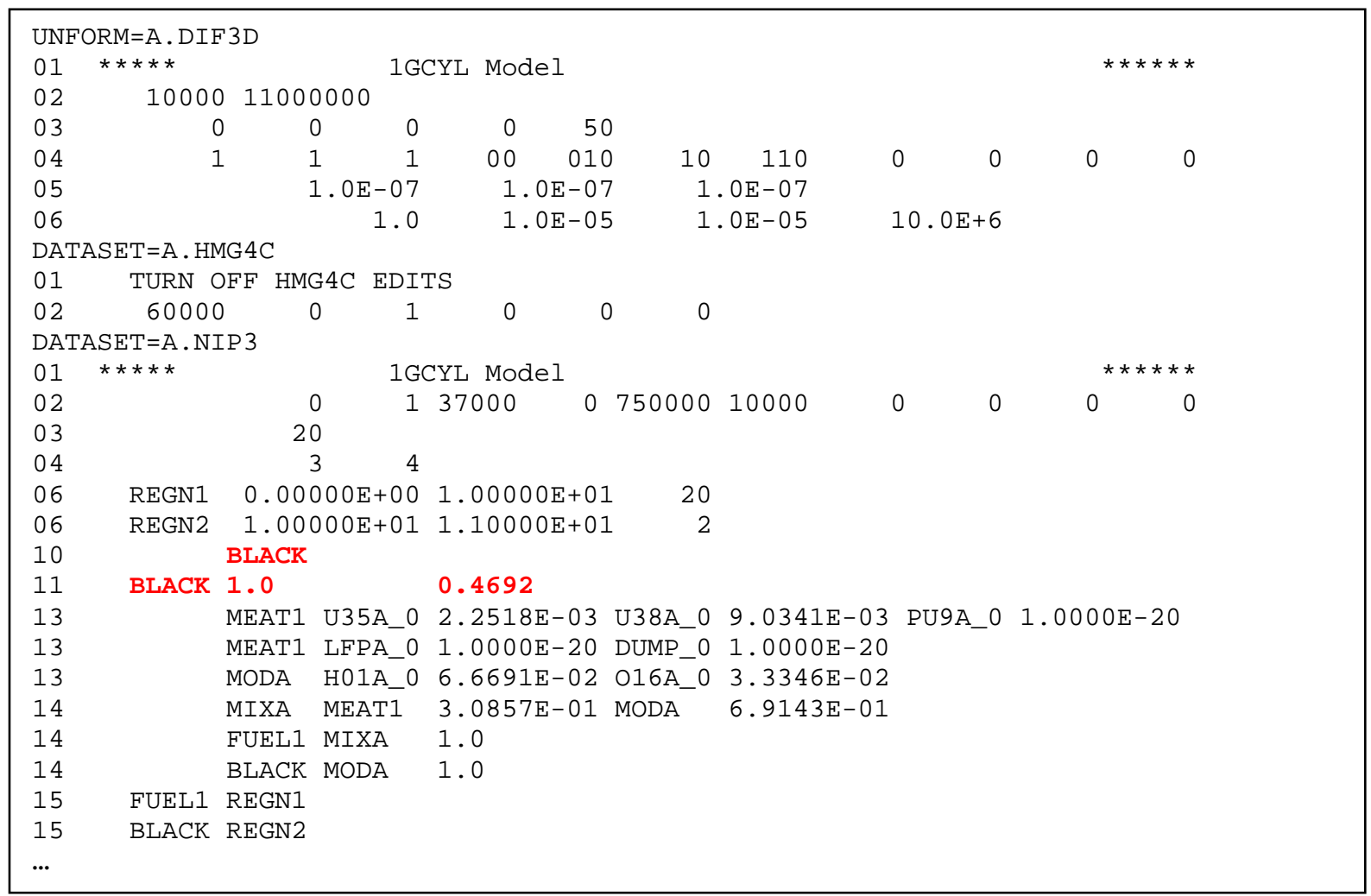

Figure 3-4. Truncated Input for Verification Test \#2

In DIF3D, the internal black absorber condition is specified similar to the external boundary condition:

$\left.\alpha \vec{n} \cdot \vec{J}\right|_{s}+\left.\beta \phi\right|_{s}=0$,

where $\left.\vec{J}\right|_{s}$ and $\left.\phi\right|_{s}$ are the current and flux on the internal boundary. By introducing an extrapolated boundary condition with the same constant $A=\beta / \alpha$ on the interface, the same analytic solution obtained in 1GCYL_hom will be obtained. 


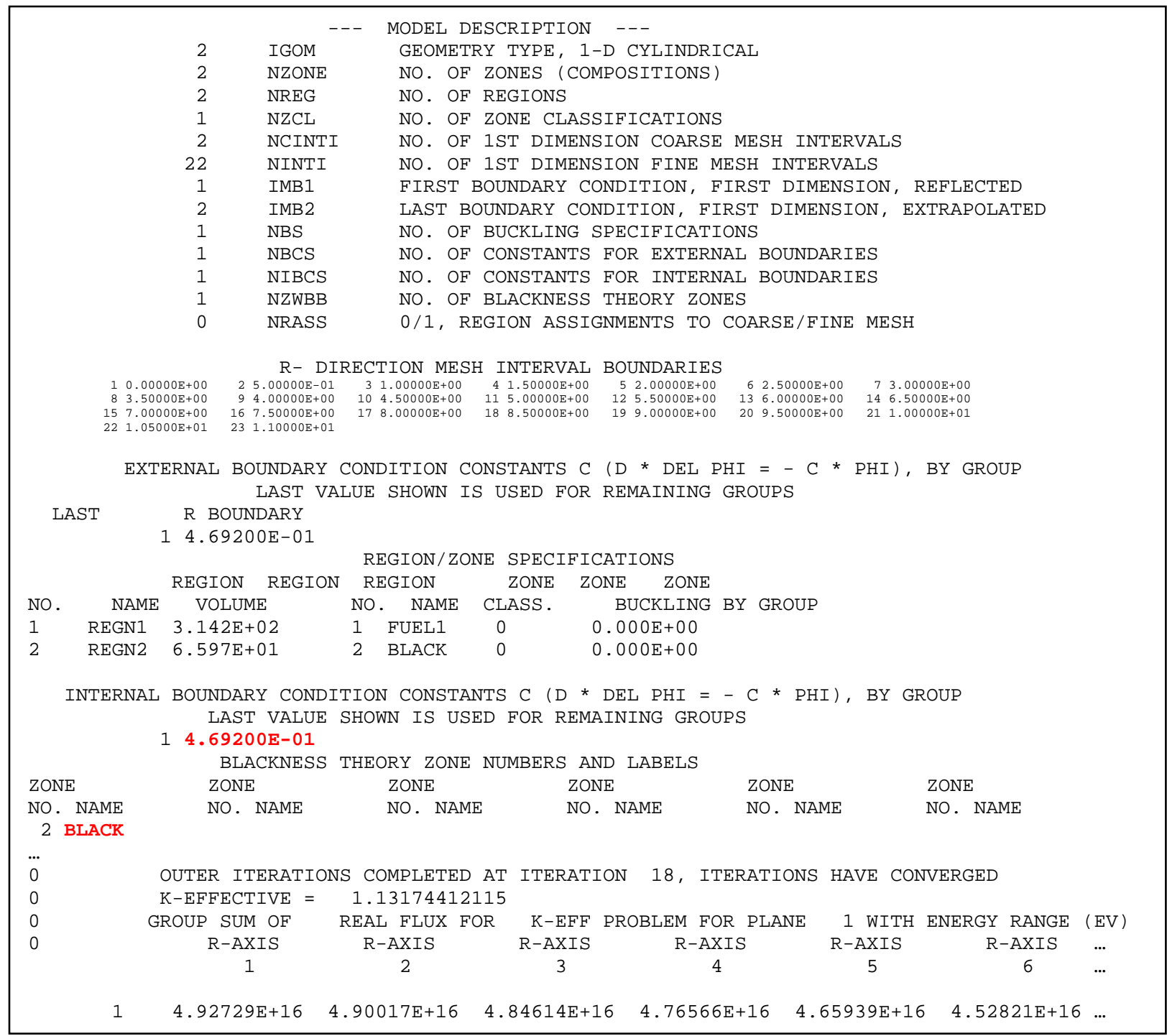

Figure 3-5. REBUS-PC Verification Test \#2 Output Excerpt

Table 3-4 shows the k-effective results of the 1GCYL_hom and 1GCYL_black problems for two different extrapolated boundary condition settings. The eigenvalue result shown is also provided in the output excerpt of Figure 3-5. The consistent k-effective results confirm that the internal black absorber condition is implemented correctly in REBUS-PC. Because this verification test again uses the 1-D cylinder geometry in REBUS-PC, it does not satisfy any stated capability, although it can be converted to the desired 3-D geometry in REBUS-PC with proper boundary conditions.

Table 3-4. Comparison of k-effective Values of 1GCYL_hom and 1GCYL_black Models

\begin{tabular}{|c|c|c|}
\hline Problem & $\mathrm{A}=0.5$ & $\mathrm{~A}=0.4692$ \\
\hline 1GCYL_hom & 1.1253599 & 1.1317441 \\
\hline 1GCYL_black & 1.1253599 & 1.1317441 \\
\hline
\end{tabular}




\subsection{Verification Test \#3}

Verification test \#3 is the 3-D $\theta-R-Z$ geometry representation of test \#1. To accomplish this, reflected boundary conditions are introduced in the $\mathrm{Z}$ direction and periodic boundary conditions are used in the $\theta$ direction. Figure 3-6 shows the truncated input for verification test \#3. Comparing Figure 3-1 to Figure 3-6 one finds the only real differences are in card types 03 through 06 and 09 of the A.NIP3 input.

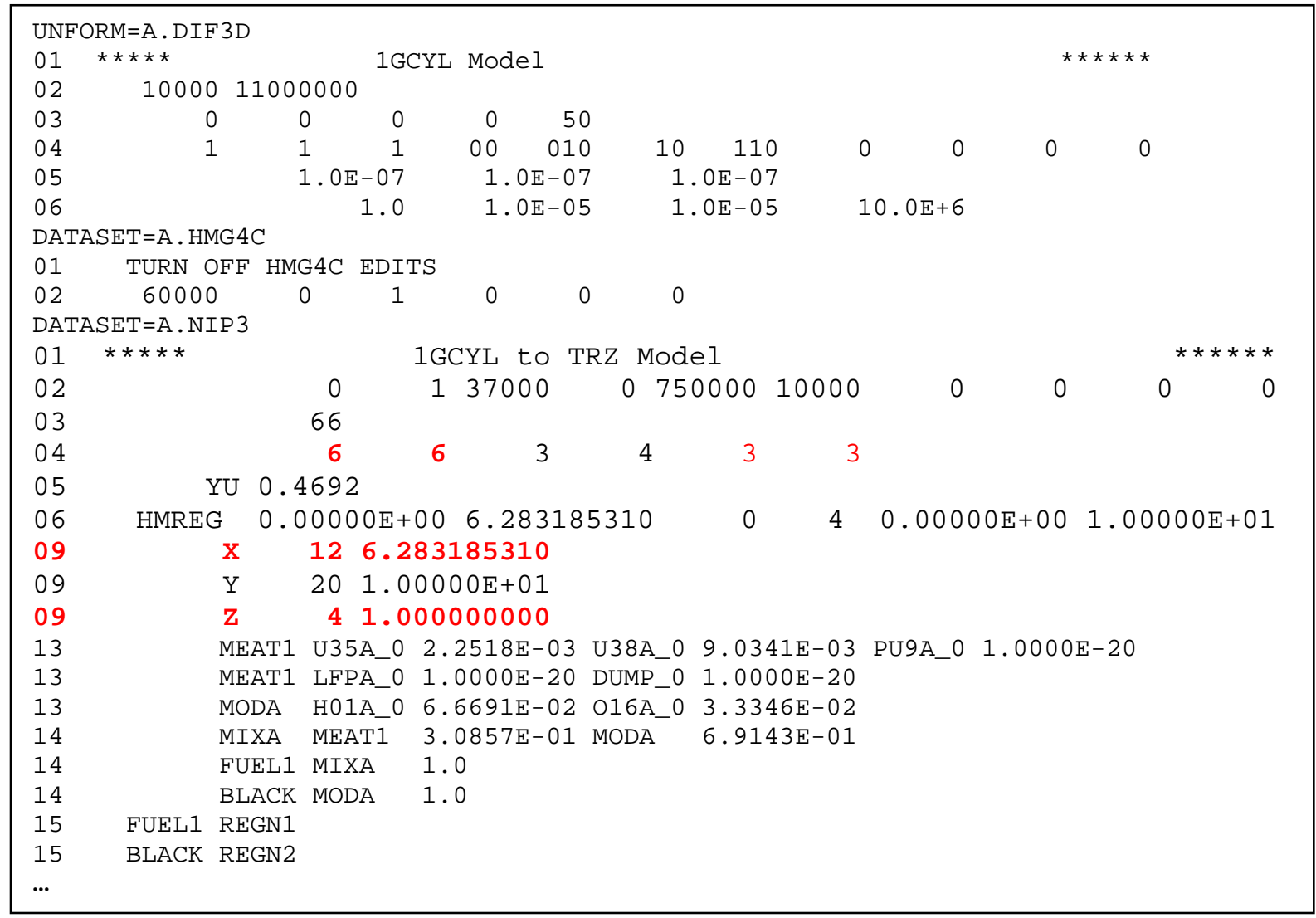

Figure 3-6. Truncated Input for Verification Test \#3

On card type 03, geometry type 66 is chosen (3-D) instead of 20 (1-D cylinder). On card type 04, because it is a 3-D geometry, there are more boundary conditions, where R is ordered second in $\theta-\mathrm{R}-\mathrm{Z}$. This means that the earlier boundary conditions now appear as the third and fourth inputs on the same line. For $\theta$, a type 6 boundary condition is used while for $\mathrm{Z}$ a type 3 is used. Type 3 is reflected while type 6 is periodic repeating with the opposite face. For type 6 , the opposite surface means the lower or upper surface of the given dimension ( $+X$ with $-X$ as an example) noting that type 7 is periodic adjacent and is intended to connect directions $\mathrm{X}$ and $\mathrm{Y}$. Because of the change in order of the $\mathrm{R}$ dimension, the card type 05 input is altered to point the extrapolated boundary condition to the upper Y dimension (actually R) instead of the upper X dimension.

The card type 06 and 09 changes are associated with the way DIF3D accepts 3-D input. Instead of providing the consecutive coordinates for a given region, card type 06 requires the $\mathrm{X}$ and $\mathrm{Y}$ coordinates in centimeters and the Z plane locations. In this regard, the " 04 " at the middle of the card type 06 specifies the region occupies planes $1-4$ between $\mathrm{Z}$ surfaces 0 and 4 . The actual coordinates of those surfaces are specified on card type 09. Because a reflected boundary condition was chosen 
for all surfaces in $Z$, the actual dimension is not important. A value of 1.0 was chosen for simplicity. For $\theta$, the entire domain $(2 \pi)$ is specified to keep the same power scaling as verification test \#1.

The output from verification test \#3 is much larger than that of \#1 because there are $12 \times 20 \times 4$ meshes instead of 20 meshes. The model description excerpt is provided in Figure 3-7 and sections of the flux and power tables in Figure 3-8. Starting with the model description, one can see that the input provided is correctly reported as $\theta-\mathrm{R}-\mathrm{Z}$; the geometry type number changes to 15 from 66 , as 15 is the standard ID of this geometry type in GEODST. The number of meshes, $12 \times 20 \times 4$ is reiterated, as is the boundary condition information, the numbers of which again change from the input values due to the GEODST standard ID. It is important to note that REBUS-PC reports the boundary conditions using the naming (REFLECTIVE, PERIODIC, etc...) rather than just the numerical ID. The mesh intervals REBUS-PC uses are also reported correctly and consistently with the input, as is the region volume: $\pi^{*}\left(10^{\circ} \mathrm{cm}\right)^{2 \cdot} 1^{\circ} \mathrm{cm}=314.15926536$. The last part of output provided in Figure $3-7$ is the eigenvalue convergence section which shows a final eigenvalue (1.13174412115) identical to the eigenvalue from verification test \#1 (1.13174412115), and consistent with the analytic solution (1.1314358). The previous zero mesh extrapolation applied here yields the same results as that observed in verification test \#1.

As can be inferred from the identical eigenvalue and problem setup, the flux solution is also identical as observed in Figure 3-8 and the tabulated data from verification tests \#1 and \#3 in Table 3-5. This result is not the expected outcome, as REBUS-PC uses an iterative solution technique and there can be some variance in the final converged result. Given the consistent results, along with the extended testing, this test demonstrates that REBUS-PC is correctly solving the $\theta$-R-Z geometry.

It is important to note in Figure 3-8 that the flux solution at all $\theta$ and $\mathrm{Z}$ values are identical. This is a result of the reflected and periodic boundary conditions being applied in both directions, leading to a flat flux approximation. In this regard, this analytic benchmark problem is not a full test of the implementation of a $\theta-\mathrm{R}-\mathrm{Z}$ finite difference solution algorithm. Because analytic solutions with a fission source are hard to create, fixed source cases are used to fulfill that need, and are shown later.

In addition to the average flux by mesh, the total flux and peak flux values reported by REBUS-PC are compared against the analytic benchmark. The peak occurs at the center of the domain and is calculated to be $4.989 \mathrm{E}+16$, where REBUS-PC returns $4.927 \mathrm{E}+16$, or a $1.2 \%$ error. Using a finer mesh, as done in verification test \#1, yields $4.932 \mathrm{E}+16$, which is somewhat closer to the analytic result. Using 120 meshes yields $4.933 \mathrm{E}+16$, indicating that REBUS-PC will never quite reach the analytic solution result. The total flux reported by REBUS-PC is $8.39223 \mathrm{E}+18$ for all three inputs while the analytic result is also $8.39223 \mathrm{E}+18$. This is consistent with the normalization constraint.

To understand the peak flux error issue, one must understand that DIF3D does not evaluate the flux at the center of the mesh, but uses the current at the mesh edges and mesh averaged flux (mesh center) to estimate the peak flux. In this regard the peak flux estimate is only somewhat reliable, although still rather accurate for this test. Of all the methodologies in DIF3D, DIF3D-VARIANT is the only one that can allow a rigorous evaluation of the peak flux. The implemented technique, chosen for speed, is an approximation and thus produces a result with similar errors seen above. Given that the peaking calculation is denoted in both the output and the manual as an approximation, the preceding check is considered sufficient verification that the outputs produced by the REBUS-PC software are correct. 


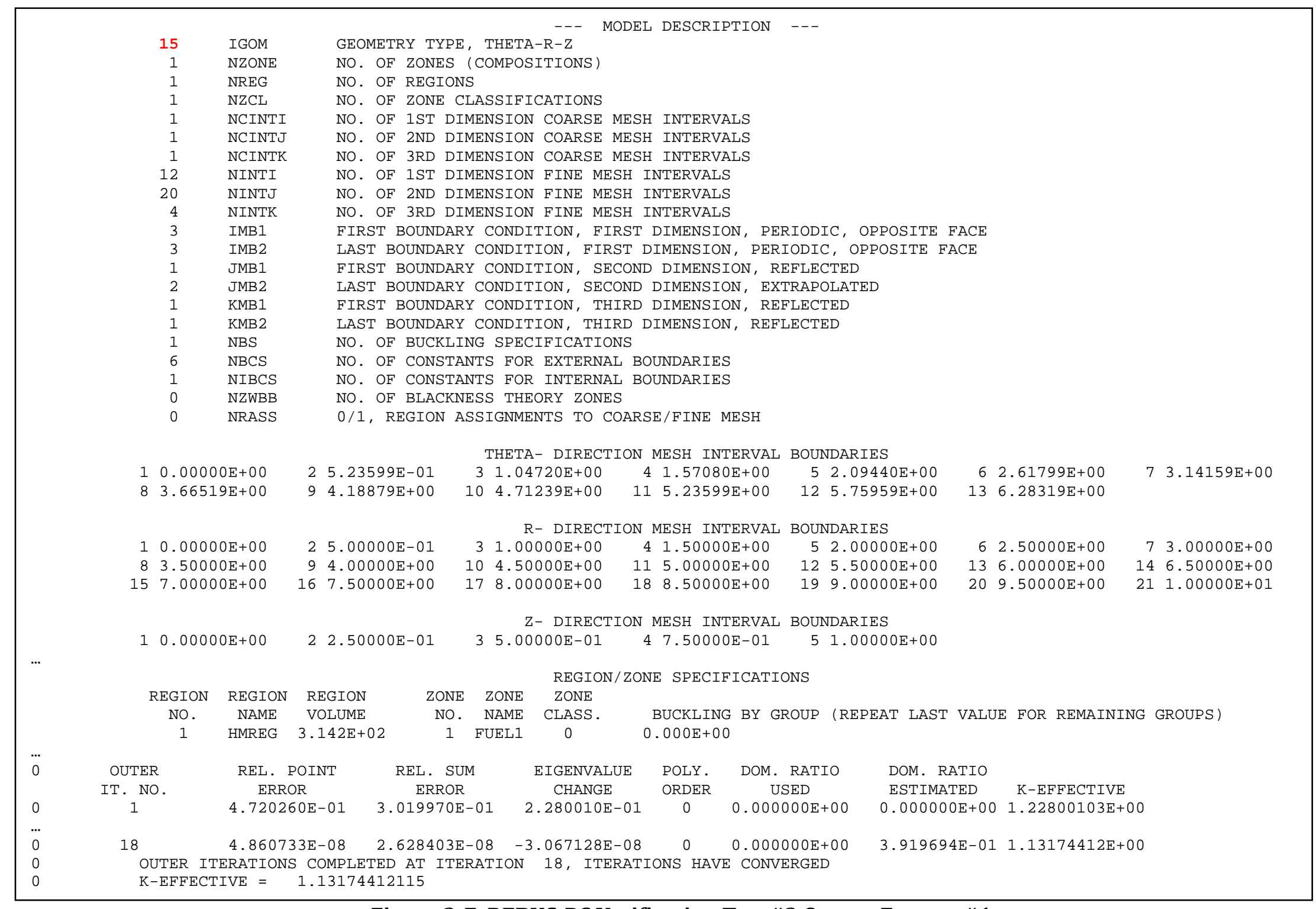

Figure 3-7. REBUS-PC Verification Test \#3 Output Excerpt \#1 


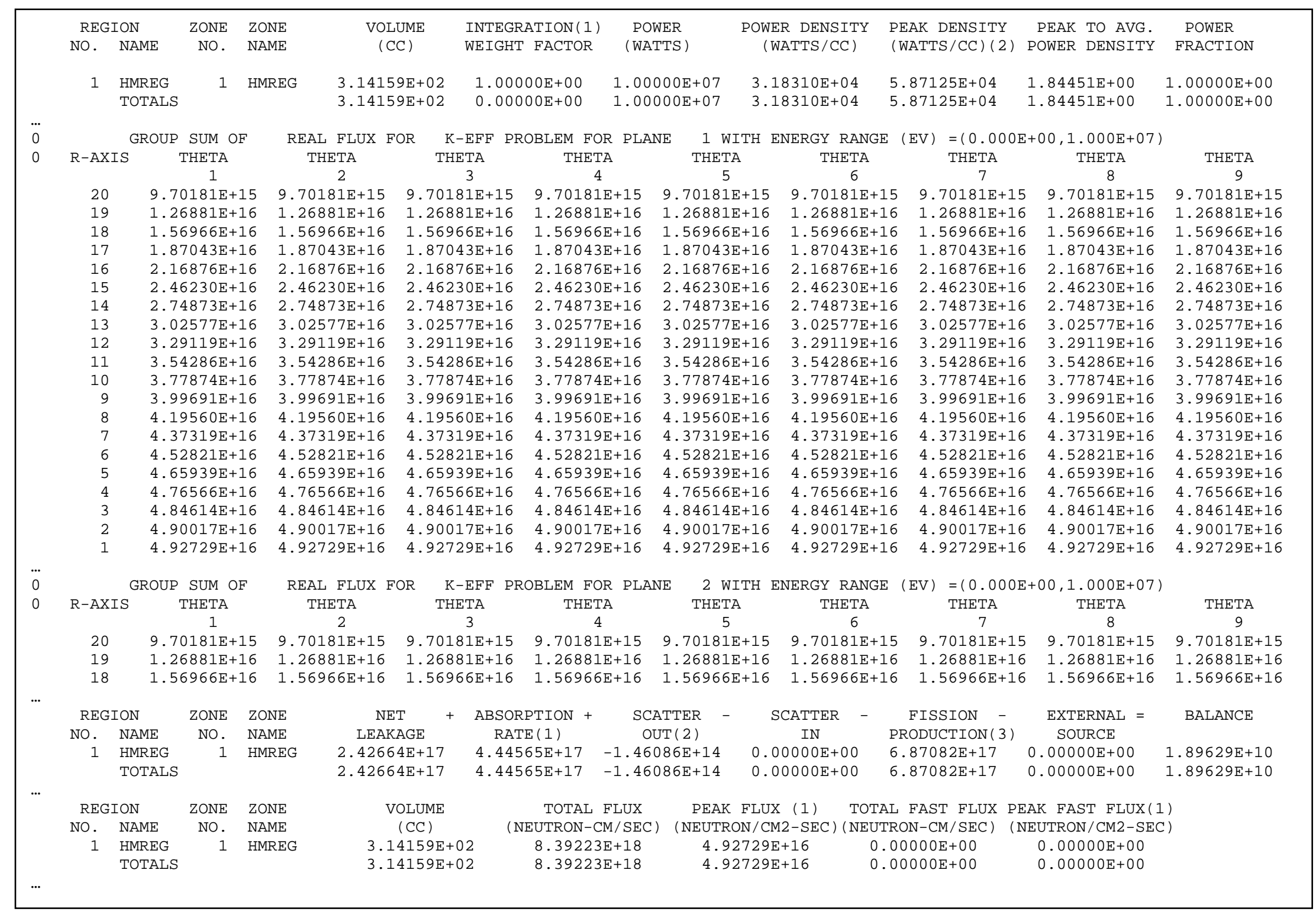

Figure 3-8. REBUS-PC Verification Test \#3 Output Excerpt \#2 
Table 3-5. Mesh Averaged Flux Comparisons for Verification Test \#3

\begin{tabular}{|c|c|c|c|c|}
\hline Mesh No. & $\begin{array}{c}\text { REBUS-PC } \\
\text { Verification Test \#1 }\end{array}$ & $\begin{array}{c}\text { REBUS-PC } \\
\text { Verification Test \#3 }\end{array}$ & $\begin{array}{c}\text { Analytical } \\
\text { Results }\end{array}$ & Error \\
\hline 1 & $4.92729 \mathrm{E}+16$ & $4.92729 \mathrm{E}+16$ & $4.92679 \mathrm{E}+16$ & $-0.010 \%$ \\
\hline 2 & $4.90017 \mathrm{E}+16$ & $4.90017 \mathrm{E}+16$ & $4.89967 \mathrm{E}+16$ & $-0.010 \%$ \\
\hline 3 & $4.84614 \mathrm{E}+16$ & $4.84614 \mathrm{E}+16$ & $4.84566 \mathrm{E}+16$ & $-0.010 \%$ \\
\hline 4 & $4.76566 \mathrm{E}+16$ & $4.76566 \mathrm{E}+16$ & $4.76520 \mathrm{E}+16$ & $-0.010 \%$ \\
\hline 5 & $4.65939 \mathrm{E}+16$ & $4.65939 \mathrm{E}+16$ & $4.65896 \mathrm{E}+16$ & $-0.009 \%$ \\
\hline 6 & $4.52821 \mathrm{E}+16$ & $4.52821 \mathrm{E}+16$ & $4.52781 \mathrm{E}+16$ & $-0.009 \%$ \\
\hline 7 & $4.37319 \mathrm{E}+16$ & $4.37319 \mathrm{E}+16$ & $4.37282 \mathrm{E}+16$ & $-0.008 \%$ \\
\hline 8 & $4.19560 \mathrm{E}+16$ & $4.19560 \mathrm{E}+16$ & $4.19528 \mathrm{E}+16$ & $-0.008 \%$ \\
\hline 9 & $3.99691 \mathrm{E}+16$ & $3.99691 \mathrm{E}+16$ & $3.99664 \mathrm{E}+16$ & $-0.007 \%$ \\
\hline 10 & $3.77874 \mathrm{E}+16$ & $3.77874 \mathrm{E}+16$ & $3.77851 \mathrm{E}+16$ & $-0.006 \%$ \\
\hline 11 & $3.54286 \mathrm{E}+16$ & $3.54286 \mathrm{E}+16$ & $3.54269 \mathrm{E}+16$ & $-0.005 \%$ \\
\hline 12 & $3.29119 \mathrm{E}+16$ & $3.29119 \mathrm{E}+16$ & $3.29107 \mathrm{E}+16$ & $-0.004 \%$ \\
\hline 13 & $3.02577 \mathrm{E}+16$ & $3.02577 \mathrm{E}+16$ & $3.02571 \mathrm{E}+16$ & $-0.002 \%$ \\
\hline 14 & $2.74873 \mathrm{E}+16$ & $2.74873 \mathrm{E}+16$ & $2.74873 \mathrm{E}+16$ & $0.000 \%$ \\
\hline 15 & $2.46230 \mathrm{E}+16$ & $2.46230 \mathrm{E}+16$ & $2.46236 \mathrm{E}+16$ & $0.002 \%$ \\
\hline 16 & $2.16876 \mathrm{E}+16$ & $2.16876 \mathrm{E}+16$ & $2.16887 \mathrm{E}+16$ & $0.005 \%$ \\
\hline 17 & $1.87043 \mathrm{E}+16$ & $1.87043 \mathrm{E}+16$ & $1.87060 \mathrm{E}+16$ & $0.009 \%$ \\
\hline 18 & $1.56966 \mathrm{E}+16$ & $1.56966 \mathrm{E}+16$ & $1.56989 \mathrm{E}+16$ & $0.015 \%$ \\
\hline 19 & $1.26881 \mathrm{E}+16$ & $1.26881 \mathrm{E}+16$ & $1.26908 \mathrm{E}+16$ & $0.022 \%$ \\
\hline 20 & $9.70181 \mathrm{E}+15$ & $9.70181 \mathrm{E}+15$ & $9.70508 \mathrm{E}+15$ & $0.034 \%$ \\
\hline
\end{tabular}

With the preceding results, this verification test demonstrates the following capabilities:

- Capability 1, as it compares an analytic eigenvalue based reference solution with the underlying finite difference approximation in REBUS-PC

- Capability 4, as the analytic benchmark requires the reflected boundary condition in R to work correctly in order to get the answer.

- Capability 5 is partially satisfied, as it demonstrates the extrapolated boundary condition in $\mathrm{R}$ works in order for it to match the analytic solution

- Capability 7 is partially satisfied, as it demonstrates the output edits for flux are consistent with the analytic solution.

The power calculation in this verification test only considers a simple scaling of the flux for one region and it is not considered a rigorous test of the stated capability 7 as intended.

\subsection{Verification Test \#4}

Verification test \#4 is the 3-D $\theta-\mathrm{R}-\mathrm{Z}$ geometry representation of test \#2. The same approached used to convert test \#1 into \#3 is used. Consequently, the excerpt of the input is omitted as it is a simple repeat of previous discussion of test \#2. Figure 3-9 provides part of the output from the verification test and one finds the eigenvalue exactly matches the value of 1.1317441 in Table 3-4. Additionally, one can see that the flux solution result exactly matches that provided in Table 3-5 except for the additional 0.0 flux values, which are associated with the black absorber region. The same meshing and appropriate boundary conditions are used to reproduce the results in Table 3-4. 


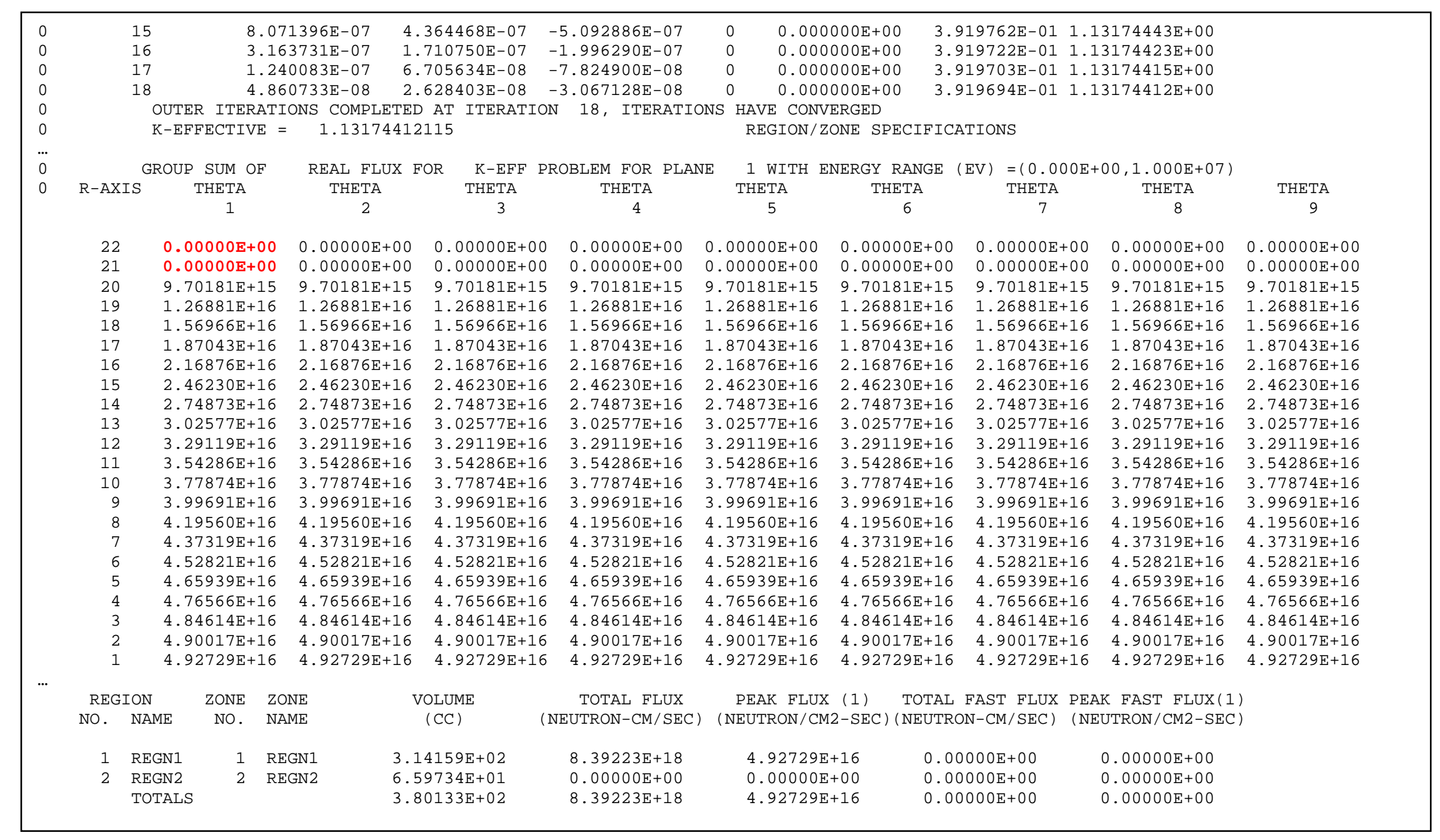

Figure 3-9. REBUS-PC Verification Test \#4 Output Excerpt 
With the preceding results, this verification test demonstrates the following capabilities:

- Capability 1, as it compares an analytic eigenvalue based reference solution with the underlying finite difference approximation in REBUS-PC.

- Capability 6, as it demonstrates the application of internal black boundary conditions compared against an analytic reference solution.

This verification test provides no additional accuracy information on capabilities 4, 5, or 7 from verification test \#3, as the identical analytical solution is applied.

\subsection{Verification Test \#5}

Verification test \#5 is effectively identical to verification test \#3 but with extrapolated boundary conditions in the axial direction. Figure 3-10 provides the truncated input, where the major changes from test \#3 are on the A.NIP3 card types 04 and 05, as indicated. This verification test is a true 2-D verification as there is no variance in the solution for the $\theta$ direction. The reference solution was obtained by independent implementation of the finite difference methodology with the Matlab program [12]. By executing the Matlab program, the same eigenvalue and flux solution are obtained as those found in the REBUS-PC, where no error exists due to the identical methodology and meshing being implemented. The output excerpt is provided in Figure 3-11 to record the eigenvalue and partial flux solution details obtained for the stated discrete math problem.

This verification test demonstrates the following capabilities:

- Capability 1, as it compares an analytic eigenvalue based reference solution with the underlying finite difference approximation in REBUS-PC.

- Capability 5, as it demonstrates the use of extrapolated boundary conditions in the R and $\mathrm{Z}$ directions.

This verification test provides no additional accuracy information on capabilities 4 or 7 from verification test \#3.

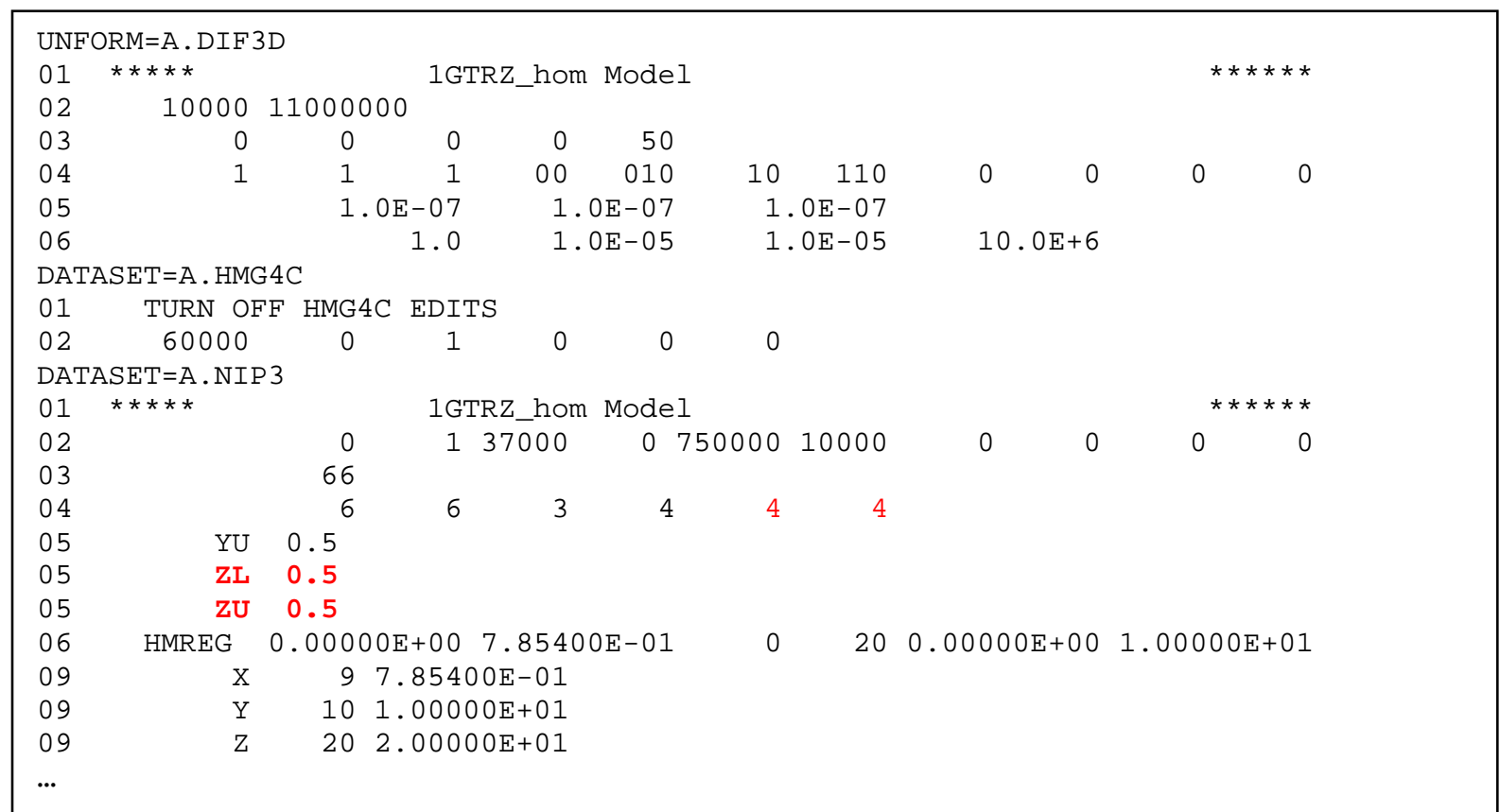

Figure 3-10. Truncated Input for Verification Test \#5 
OUTER ITERATIONS COMPLETED AT ITERATION 14, ITERATIONS HAVE CONVERGED

$\mathrm{K}-\mathrm{EFFECTIVE}=\quad 0.97603431185$

$\odot$

THETA

GROUP SUM OF THETA

1

2. $31249 \mathrm{E}+15$

2. $218808 \mathrm{E}+15$
3. $21829 \mathrm{E}+15$

4. $03603 \mathrm{E}+15$

$4.79486 \mathrm{E}+15$
$5.46999 \mathrm{E}+15$

$5.46999 \mathrm{E}+15$
$6.03919 \mathrm{E}+15$

$6.48358 \mathrm{E}+15$

$6.78836 \mathrm{E}+15$

$6.94335 \mathrm{E}+15$ GROUP SUM OF

REAL FLUX FOR THETA

$$
2
$$

THETA
1. $51249 \mathrm{E}+15$ $.36808 E+15$

4. $03603 E+15$

$.03603 E+15$
$4.79486 E+15$

5. $46999 \mathrm{E}+15$

$6.03919 \mathrm{E}+15$

$6.48358 \mathrm{E}+15$

$6.78836 \mathrm{E}+15$

$$
\begin{array}{cc}
\multicolumn{2}{c}{\text { K-EFF PROBLEM FOR PLANE }} \\
\text { THETA } & \text { THETA } \\
3 & 4 \\
51249 \mathrm{E}+15 & 1.51249 \mathrm{E}+15
\end{array}
$$

1 WI THETA

$\begin{array}{lll}1.51249 \mathrm{E}+15 & 1.51249 \mathrm{E}+15 & 1.51249 \mathrm{E}+15 \\ 2.36808 \mathrm{E}+15 & 2.36808 \mathrm{E}+15 & 2.36808 \mathrm{E}+15\end{array}$

$3.21829 E+15 \quad 3.21829 E+15 \quad 3.21829 E+15$

$4.03603 \mathrm{E}+15 \quad 4.03603 \mathrm{E}+15 \quad 4.03603 \mathrm{E}+15$

$\begin{array}{lll}4.79486 \mathrm{E}+15 & 4.79486 \mathrm{E}+15 & 4.79486 \mathrm{E}+15 \\ 5.46999 \mathrm{E}+15 & 5.46999 \mathrm{E}+15 & 5.46999 \mathrm{E}+15\end{array}$

$\begin{array}{lll}5.46999 E+15 & 5.46999 E+15 & 5.46999 E+15 \\ 6.03919 E+15 & 6.03919 E+15 & 6.03919 E+15\end{array}$

$\begin{array}{lll}6.48358 \mathrm{E}+15 & 6.48358 \mathrm{E}+15 & 6.48358 \mathrm{E}+15 \\ 6 & 0.78836\end{array}$

$\begin{array}{lll}6.78836 \mathrm{E}+15 & 6.78836 \mathrm{E}+15 & 6.78836 \mathrm{E}+15 \\ 6.15\end{array}$

REAL FLUX FOR K-EFF PROBLEM FOR PLANE

$94335 \mathrm{E}+15$
THETA
THETA
RGY RANGE $(E V)=(\odot .000 \mathrm{E}+00,1.000 \mathrm{E}+\odot 7)$

3

4

THETA

5

2. $31749 \mathrm{E}+15$

2

2. $31749 \mathrm{E}+15$

2. $31749 \mathrm{E}+15$

2. $31749 \mathrm{E}+15$

$3.62845 \mathrm{E}+15$

4. $93118 \mathrm{E}+15$

$4.93118 \mathrm{E}+15$

$3.62845 \mathrm{E}+15$

$4.93118 \mathrm{E}+15$

$4.93118 \mathrm{E}+15$

6. $18414 \mathrm{E}+15$

$\begin{array}{lll}6.18414 \mathrm{E}+15 & 6.18414 \mathrm{E}+15 & 6.18414 \mathrm{E}+15 \\ 7.34684 \mathrm{E}+15 & 7.34684 \mathrm{E}+15 & 7.34684 \mathrm{E}+15\end{array}$

$7.34684 \mathrm{E}+15$

7. $34684 \mathrm{E}+15$

$\begin{array}{lll}.34684 \mathrm{E}+15 & 7.34684 \mathrm{E}+15 & 7.34684 \mathrm{E}+15 \\ 8.38130 \mathrm{E}+15 & 8.38130 \mathrm{E}+15 & 8.38130 \mathrm{E}+15\end{array}$

$9.25345 \mathrm{E}+15$

(2)

$\begin{array}{lll}9.25345 \mathrm{E}+15 & 9.25345 \mathrm{E}+15 & 9.25345 \mathrm{E}+15\end{array}$

$9.93436 \mathrm{E}+15$

1. $04014 \mathrm{E}+16$
$1.06388 \mathrm{E}+16$

9.

1. $04014 \mathrm{E}+16$

$9.93436 \mathrm{E}+15 \quad 9.93436 \mathrm{E}+15 \quad 9.93436 \mathrm{E}+15$

$1.04014 \mathrm{E}+16 \quad 1.04014 \mathrm{E}+16 \quad 1.04014 \mathrm{E}+16$

1. $06388 \mathrm{E}+16$

$1.06388 \mathrm{E}+16$

$\begin{array}{lll}1.04014 \mathrm{E}+16 & 1.04014 \mathrm{E}+16 & 1.04014 \mathrm{E}+16 \\ 1.06388 \mathrm{E}+16 & 1.06388 \mathrm{E}+16 & 1.06388 \mathrm{E}+16\end{array}$

GROUP SUM OF

REAL FLUX FOR

THETA

$=(\odot . \odot \odot \odot)-10$
THETA

7

$\begin{array}{ccc}1.51249 \mathrm{E}+15 & 1.51249 \mathrm{E}+15 & 1.51249 \mathrm{E}+15\end{array}$

$\begin{array}{llll}.36808 \mathrm{E}+15 & 2.36808 \mathrm{E}+15 & 2.36808 \mathrm{E}+15 & 2.51249 \mathrm{E}+15\end{array}$

$3.21829 \mathrm{E}+15 \quad 3.21829 \mathrm{E}+15 \quad 3.21829 \mathrm{E}+15 \quad 3.21829 \mathrm{E}+15$

$4.03603 \mathrm{E}+15 \quad 4.03603 \mathrm{E}+15 \quad 4.03603 \mathrm{E}+15 \quad 4.03603 \mathrm{E}+15$

$\begin{array}{llll}4.79486 \mathrm{E}+15 & 4.79486 \mathrm{E}+15 & 4.79486 \mathrm{E}+15 & 4.79486 \mathrm{E}+15\end{array}$

$\begin{array}{llll}5.46999 \mathrm{E}+15 & 5.46999 \mathrm{E}+15 & 5.46999 \mathrm{E}+15 & 5.46999 \mathrm{E}+15\end{array}$

$\begin{array}{llll}6.03919 \mathrm{E}+15 & 6.03919 \mathrm{E}+15 & 6.03919 \mathrm{E}+15 & 6.03919 \mathrm{E}+15\end{array}$

$\begin{array}{llll}6.48358 \mathrm{E}+15 & 6.48358 \mathrm{E}+15 & 6.48358 \mathrm{E}+15 & 6.48358 \mathrm{E}+15\end{array}$

$\begin{array}{llll}6.78836 \mathrm{E}+15 & 6.78836 \mathrm{E}+15 & 6.78836 \mathrm{E}+15 & 6.78836 \mathrm{E}+15\end{array}$

THETA THETA THETA

6

$2.31749 \mathrm{E}+15 \quad 2.31749 \mathrm{E}+15$

8

$6.94335 \mathrm{E}+15$

$\begin{array}{llll}.62845 E+15 & 3.62845 E+15 & 3.62845 E+15 & 3.31749 E+15\end{array}$

$\begin{array}{llll}.93118 \mathrm{E}+15 & 4.93118 \mathrm{E}+15 & 4.93118 \mathrm{E}+15 & 4.93118 \mathrm{E}+15\end{array}$

$\begin{array}{llll}6.18414 \mathrm{E}+15 & 6.18414 \mathrm{E}+15 & 6.18414 \mathrm{E}+15 & 6.18414 \mathrm{E}+15\end{array}$

$\begin{array}{llll}7.34684 \mathrm{E}+15 & 7.34684 \mathrm{E}+15 & 7.34684 \mathrm{E}+15 & 7.34684 \mathrm{E}+15\end{array}$

$8.38130 E+15 \quad 8.38130 E+15 \quad 8.38130 E+15 \quad 8.38130 E+15$

$\begin{array}{llll}9.25345 \mathrm{E}+15 & 9.25345 \mathrm{E}+15 & 9.25345 \mathrm{E}+15 & 9.25345 \mathrm{E}+15\end{array}$

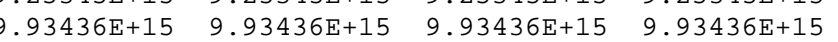

$\begin{array}{llll}.04014 \mathrm{E}+16 & 1.04014 \mathrm{E}+16 & 1.04014 \mathrm{E}+16 & 1.04014 \mathrm{E}+16\end{array}$ 2

THETA

THETA THETA

$$
5
$$

THETA

THETA

THETA

$\begin{array}{llll}1.51249 \mathrm{E}+15 & 1.51249 \mathrm{E}+15 & 1.51249 \mathrm{E}+15 & 1.51249 \mathrm{E}+15\end{array}$

$\begin{array}{lllllll}1.51249 \mathrm{E}+15 & 1.51249 \mathrm{E}+15 & 1.51249 \mathrm{E}+15 & 1.51249 \mathrm{E}+15 & 1.51249 \mathrm{E}+15 & 1.51249 \mathrm{E}+15 & 1.51249 \mathrm{E}+15 \\ 2.36808 \mathrm{E}+15 & 2.36808 \mathrm{E}+15 & 2.36808 \mathrm{E}+15 & 2.36808 \mathrm{E}+15 & 2.36808 \mathrm{E}+15 & 2.36808 \mathrm{E}+15 & 2.36808 \mathrm{E}+15\end{array}$

$\begin{array}{llllll}3.21829 \mathrm{E}+15 & 3.21829 \mathrm{E}+15 & 3.21829 \mathrm{E}+15 & 3.21829 \mathrm{E}+15 & 3.21829 \mathrm{E}+15 & 3.21829 \mathrm{E}+15\end{array}$

$2.36808 \mathrm{E}+15$
$3.21829 \mathrm{E}+15$

$2.36808 \mathrm{E}+15$

$3.21829 E+15$

$4.03603 \mathrm{E}+15$

$4.03603 \mathrm{E}+15 \quad 4.03603 \mathrm{E}+15 \quad 4.03603 \mathrm{E}+15$

4. $03603 \mathrm{E}+15$

$4.79486 \mathrm{E}+15$

$4.79486 \mathrm{E}+15 \quad 4.79486 \mathrm{E}+15 \quad 4.79486 \mathrm{E}+15$

4. $03603 \mathrm{E}+1$

4. $03603 \mathrm{E}+15$

4. $03603 \mathrm{E}+15$

$4.79486 \mathrm{E}+15$

$4.79486 \mathrm{E}+15$

$4.79486 \mathrm{E}+15$

3. $21829 \mathrm{E}+15$

$5.46999 \mathrm{E}+15 \quad 5.46999 \mathrm{E}+15$

$\begin{array}{lll}5.46999 E+15 & 5.46999 E+15 & 5.46999 E+15 \\ 6.03919 E+15 & 6.03919 E+15 & 6.03919 E+15\end{array}$

$6.48358 \mathrm{E}+15$

$.03919 \mathrm{E}+15$

$6.78836 \mathrm{E}+15$

$6.48358 \mathrm{E}+15$

$\begin{array}{lll}6.48358 \mathrm{E}+15 & 6.48358 \mathrm{E}+15 & 6.48358 \mathrm{E}+15\end{array}$

$5.46999 \mathrm{E}+15$

6. $03919 \mathrm{E}+15$

$6.48358 \mathrm{E}+15$

$6.48358 \mathrm{E}+15$

. $46999 \mathrm{E}+15$

$.79486 \mathrm{E}+15$

6. $94335 \mathrm{E}+15$

$\begin{array}{lll}6.78836 \mathrm{E}+15 & 6.78836 \mathrm{E}+15 & 6.78836 \mathrm{E}+15\end{array}$

$\begin{array}{lllll}6.94335 \mathrm{E}+15 & 6.94335 \mathrm{E}+15 & 6.94335 \mathrm{E}+15 & 6.94335 \mathrm{E}+15 & 6.94335 \mathrm{E}+15\end{array}$

$6.78836 \mathrm{E}+15 \quad 6.78836 \mathrm{E}+15$

$156.48358 \mathrm{E}+15$

Figure 3-11. REBUS-PC Verification Test \# 5 Output Excerpt 


\subsection{Verification Tests \#6, \#7, and \#8}

Verification tests \#6 through \#8 are modifications of the input to demonstrate the impact of upscattering iterations and Tchebychev acceleration. The base problem is the seven-group, 0-D benchmark which has a known analytical solution, described earlier as 7GTRZ_hom. Table 3-6 shows the setup differences between the three verification tests along with the resulting eigenvalue and number of fission source iterations used. Because the inputs all have the same setup on A.DIF3D card type 06, as shown in the verification test \#6 input excerpt in Figure 3-12, the number of inner iterations used in each up-scatter iteration of each fission source (outer) iteration is identical between the three verification tests.

Table 3-6. Verification Test \#6, \#7, and \#8 Setup Differences and Results

\begin{tabular}{|c|c|c|c|}
\hline Mesh No. & $\begin{array}{c}\text { Verification } \\
\text { Test \#6 }\end{array}$ & $\begin{array}{c}\text { Verification } \\
\text { Test \#7 }\end{array}$ & $\begin{array}{c}\text { Verification } \\
\text { Test \#8 }\end{array}$ \\
\hline $\begin{array}{c}\text { Tchebychev } \\
\text { Acceleration }\end{array}$ & No & No & Yes \\
\hline Up-scatter Iterations & 1 & 3 & 3 \\
\hline k-effective & 1.58383737224 & 1.58383737252 & 1.58383736899 \\
\hline $\begin{array}{c}\text { Fission Source } \\
\text { Iterations }\end{array}$ & 23 & 15 & 12 \\
\hline
\end{tabular}

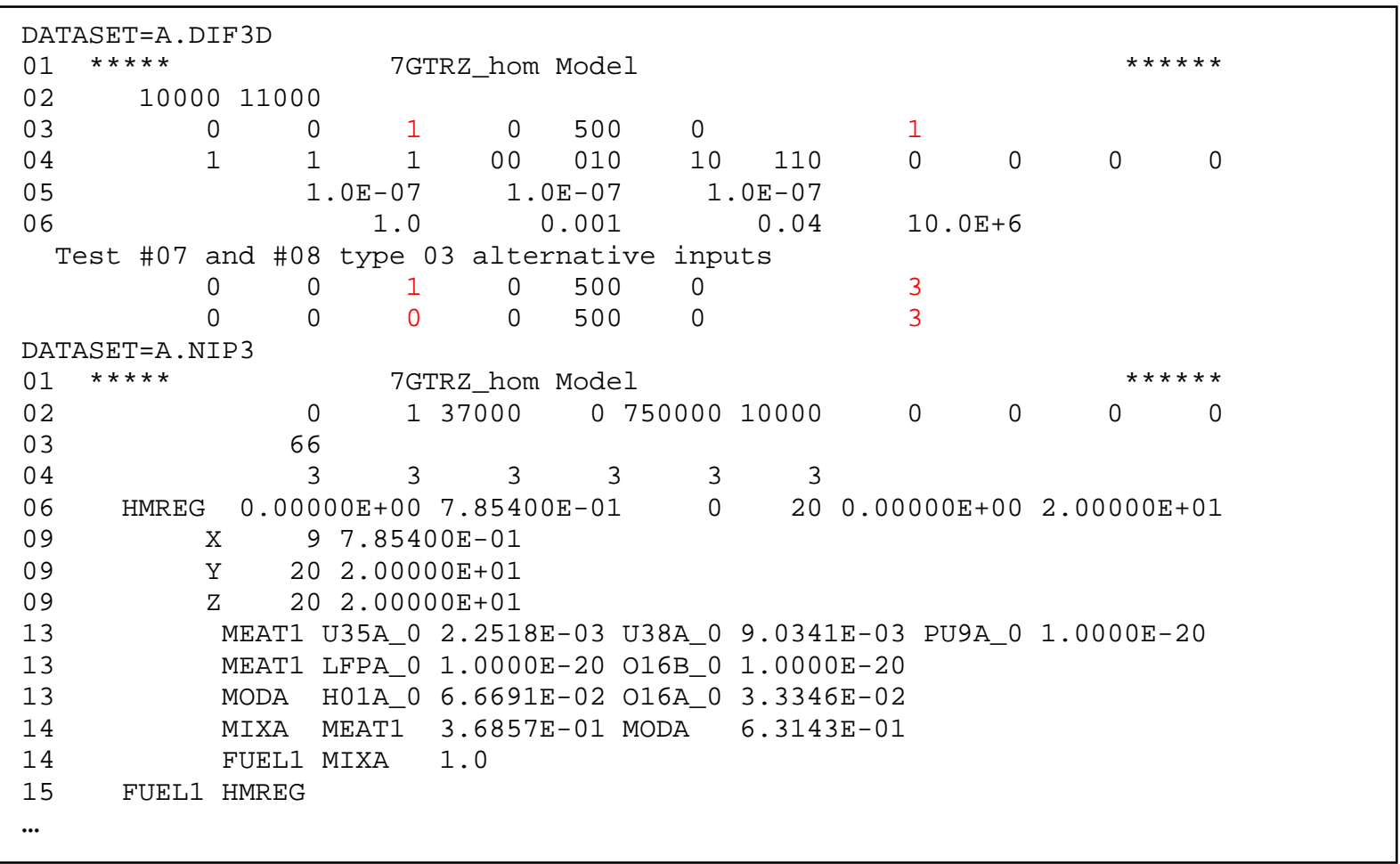

Figure 3-12. Truncated Input for Verification Test \#6

Because this is a homogeneous problem, the code will not stop until it reaches the same solution as the fission source error is directly related to the flux error everywhere in the domain. However, this verification test is sufficient proof that using up-scattering iterations impacts the solution scheme as anticipated. In Table 3-6, one can see that the software requires more fission source iterations to 
converge the problem when 1 up-scattering iterations is used relative to using three (tests \#7 and \#8). Similarly, Tchebychev acceleration (test \#8) reduces the total number of iterations required to complete the calculation. With regard to the differences in k-effective, one can see that they are within the 1.0E-7 convergence setting applied to the eigenvalue in Figure 3-12 on card type 06 of the A.DIF3D input.

These verification tests demonstrates the following capability:

- Capability 10, as it compares an analytic eigenvalue solution with results obtained with REBUS-PC. An additional test on a large scale problem is suggested for further confidence.

These tests provide no additional verification of the remaining capabilities.

\subsection{Verification Tests \#9, \#10, and \#11}

Verification tests \#9 through \#11 are focused on the seven-group 3-D problem shown earlier in Figure 2-4 to further support capabilities \#1, \#4, \#5, \#7, and \#10. Because of the complex solution capability, a modified input approach is used to verify the accuracy of the solution scheme. For any given mesh refinement, a new mathematically solvable system can be defined by taking the solution and converting it to a fixed source scheme. In this regard, the flux solution obtained from DIF3D in the standard eigenvalue mode of verification test \#10 was used to turn the fission source into a fixed source input and solve the problem again using a steady state fixed source driven algorithm in verification test \#9. Verification test \#11 uses a modified input setup specifically needed for verifying capability 1.

The fixed-source problem solved in DIF3D can be formulated as:

$$
M \vec{\phi}=F \vec{\phi}+\vec{S}_{e x},
$$

where $\vec{\phi}$ is the multi-group flux vector, $\vec{S}_{e x}$ is the independent external source distribution, $M$ is the migration and loss operator, and $F$ is the fission production operator. With an arbitrarily manufactured flux distribution $\vec{\phi}^{m}$, the corresponding independent source distribution can be deduced as:

$$
\vec{S}_{e x}=M \vec{\phi}^{m}-F \vec{\phi}^{m} .
$$

The source distribution can then be used in the DIF3D fixed-source calculation to test whether the resulting DIF3D flux solution $\vec{\phi}$ is identical to the original manufactured flux distribution $\vec{\phi}^{m}$. To simplify the preparation of the manufactured solution, the solution from verification test \#10 was used to construct the source in equation 7 . The resulting flux distribution $\vec{\phi}^{e}$ was chosen as the manufactured solution (i.e. $\vec{\phi}^{m}=\vec{\phi}^{e}$ ). The external source distribution in equation 7 was computed using a MATLAB script and the macroscopic cross sections printed out by the REBUS-PC software. The deduced independent source distribution was written in a FIXSRC file for input which is stored in the repository.

To understand the input differences, the input excerpts of verification test \# 9 are presented in Figure 3-13 showing the only sections of input that change relative to verification test \#10 in Figure 3-14. As can be seen, only the DATASET card input and fixed source switch in A.DIF3D change. To show the output similarities and differences, output excerpts are provided for tests \#9 and \#10 in Figure 3-15 (similarities in the REBUS-PC output) and Figure 3-16 (differences in the output). 


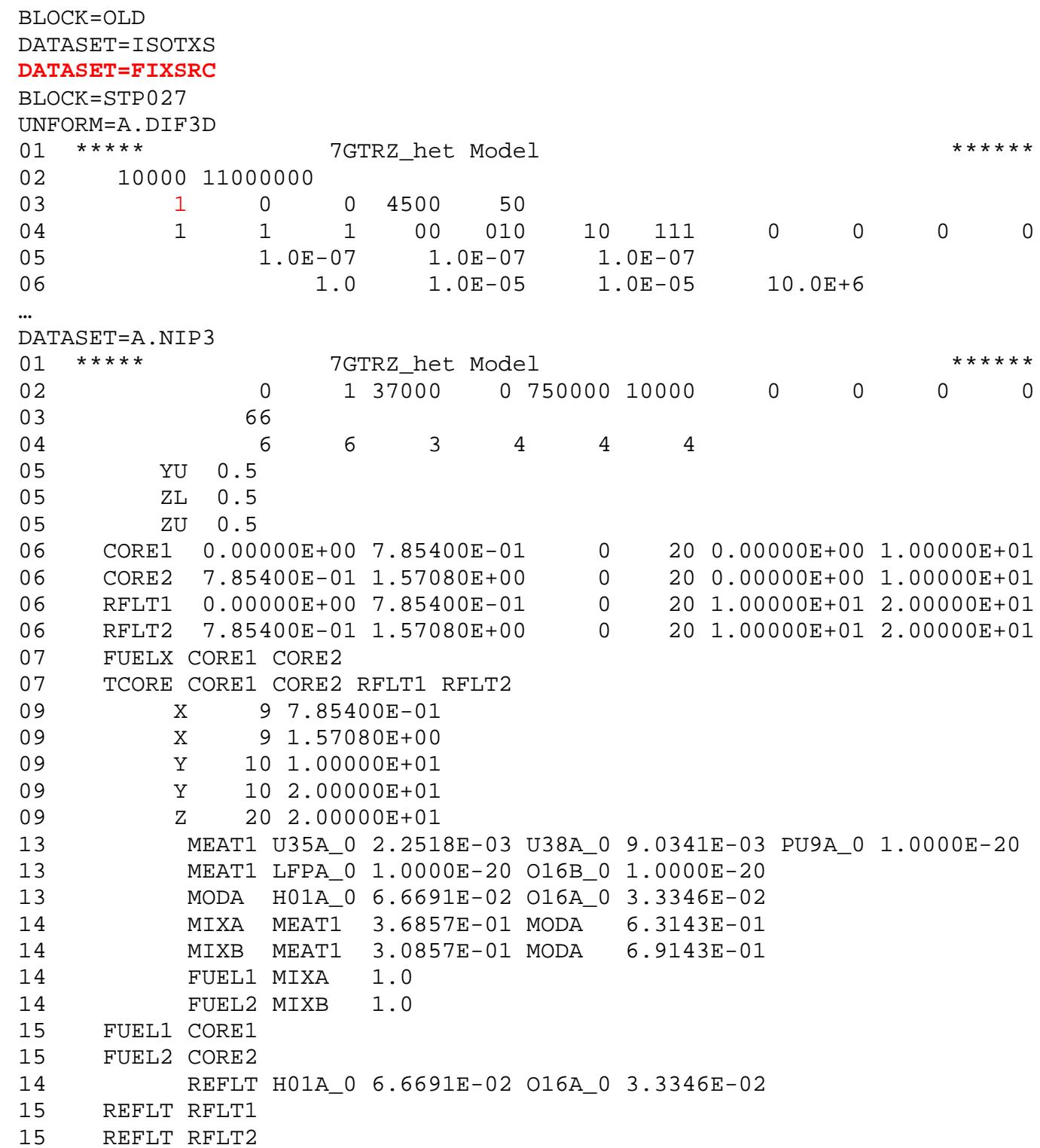

Figure 3-13. Truncated Input for Verification Test \#9

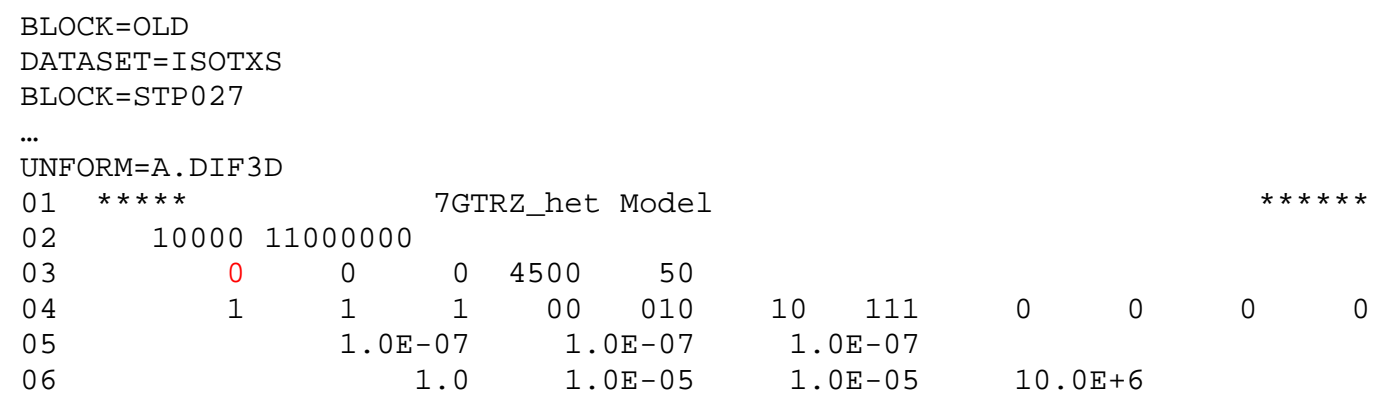

Figure 3-14. Truncated Input for Verification Test \#10 


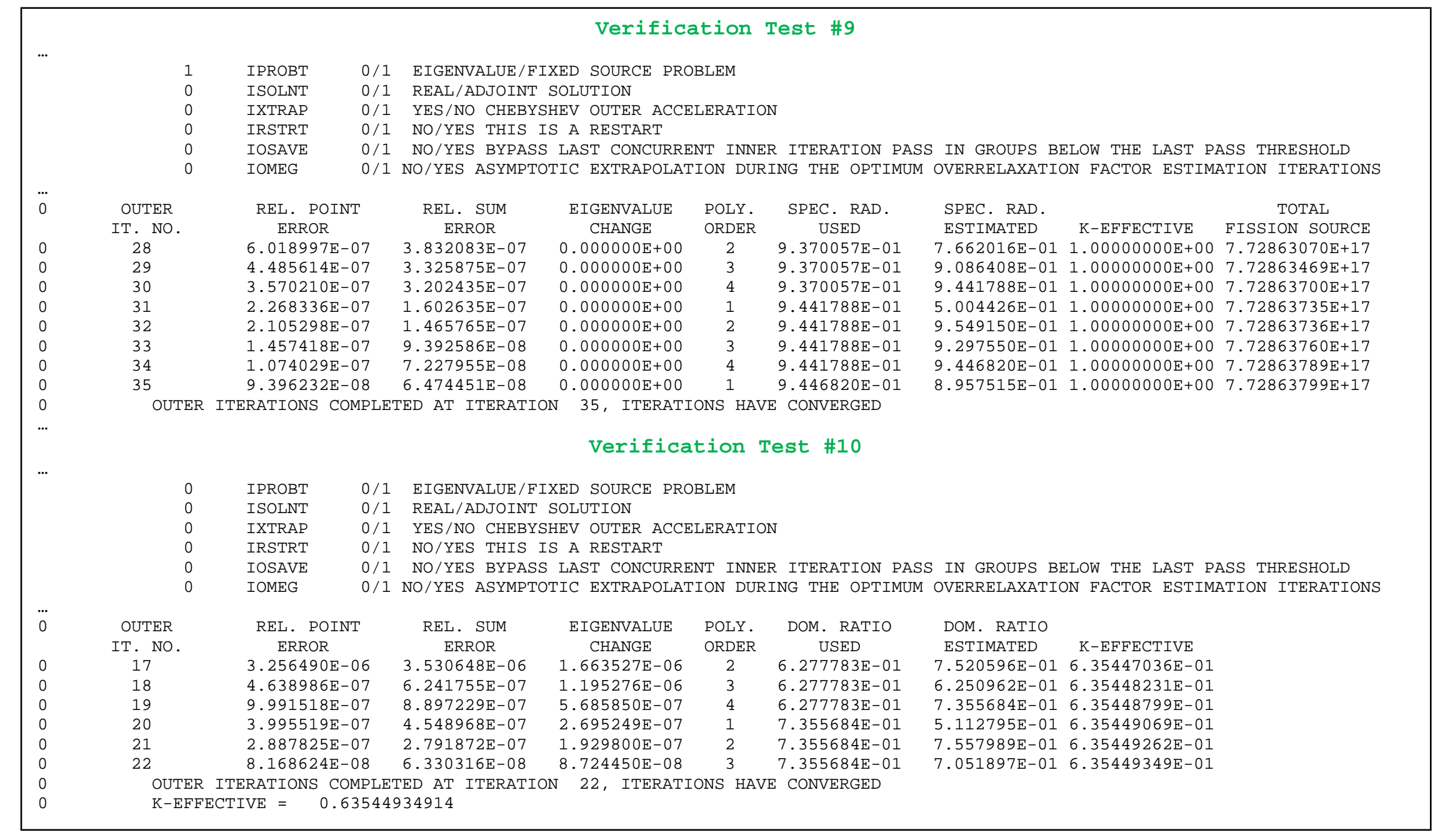

Figure 3-15. REBUS-PC Verification Tests \#9 and \#10 Output Differences 


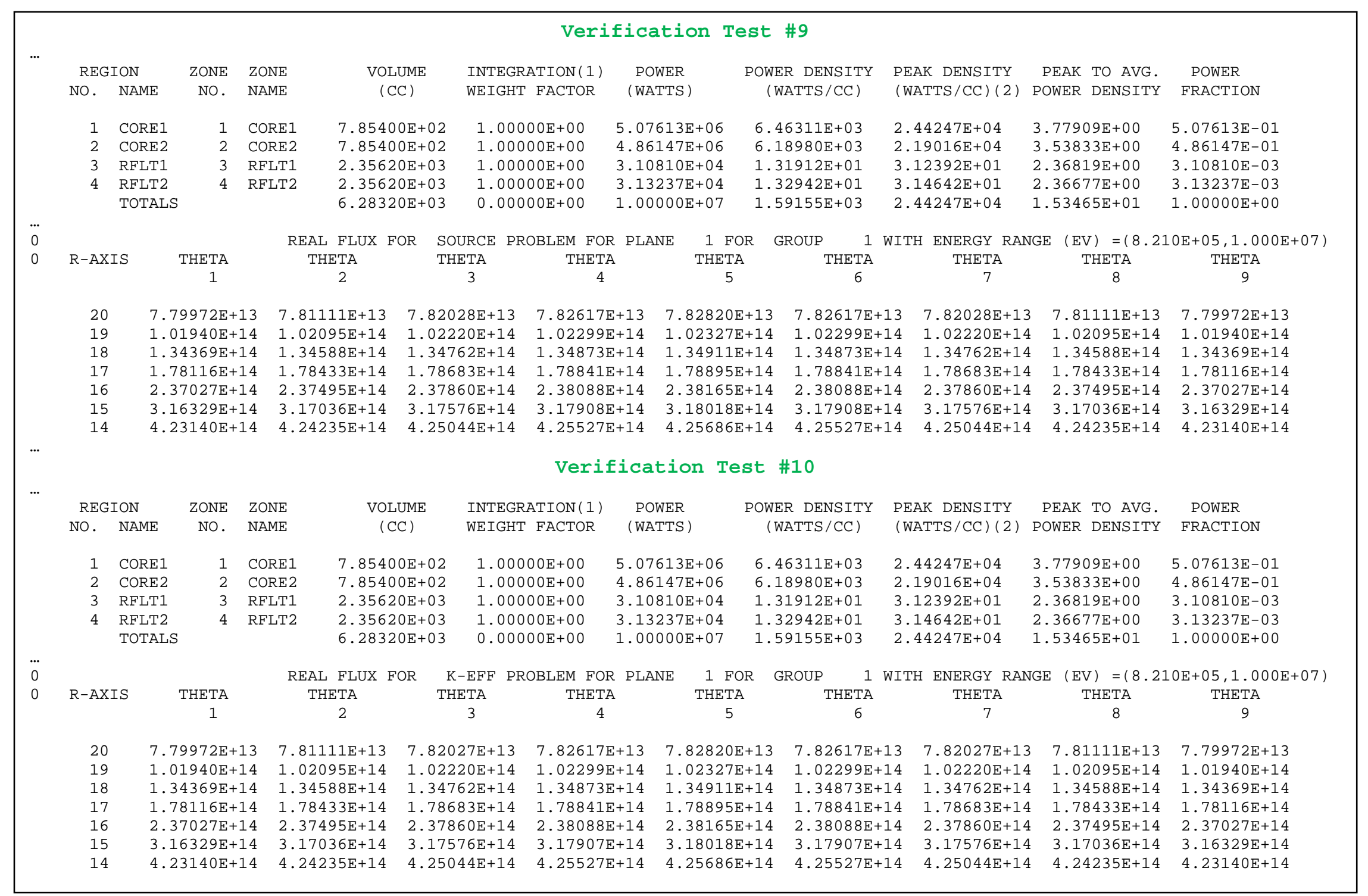

Figure 3-16. REBUS-PC Verification Tests \#9 and \#10 Output Similarities 
Looking at Figure 3-15, one can clearly see that the solution algorithm has switched from a fixed source case in test \#9 to a flux solution in test \#10. The iterative eigenvalue convergence routine in test \#10 is replaced by the fixed source driven sub-critical system algorithm in \#9, which is also visible in Figure 3-15. REBUS-PC Verification Tests \#9 and \#10 Output Differences. Looking at the flux solution excerpts from these tests in Figure 3-16 one finds that the solution is identical to six significant digits. Further inspection of the remaining flux and power output demonstrates that the REBUS-PC solutions between \#09 and \#10 are indistinguishable.

As an additional test of specific input handling, the input of verification tests \#9 and \#10 were modified to that seen in verification test \#11, as shown in Figure 3-17. A comparison of the input excerpt for verification test \#9 shows that two card type 15 inputs in A.NIP3 were replaced with a single card type 15 input in verification test \#11. The primary difference, of course, is that the new card type 15 uses the area specification to assign a composition rather than the region specification. Inspection of the output of verification test \#11 shows it is an identical result to that of \#10.

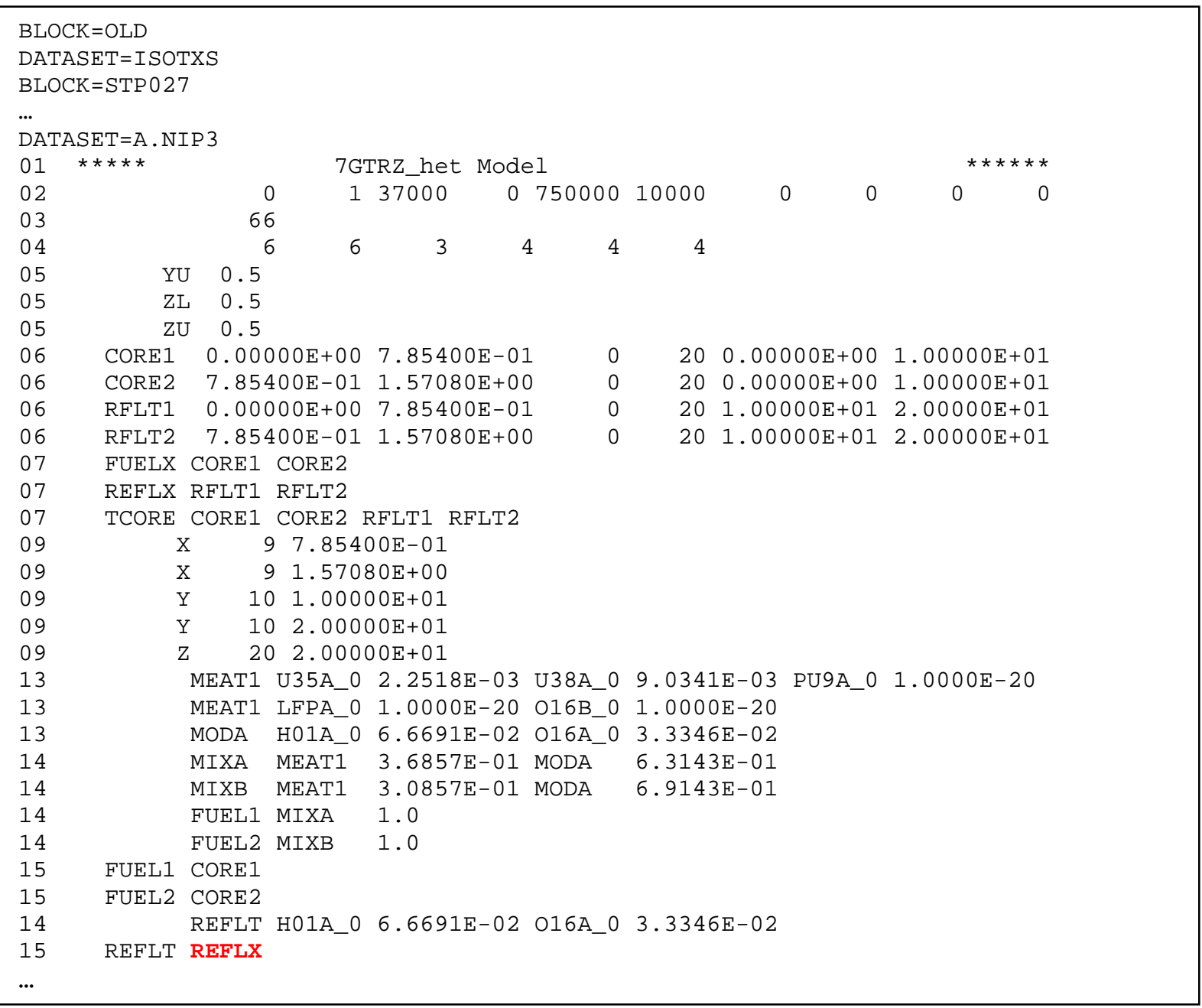

Figure 3-17. Truncated Input for Verification Test \#11

These three verification tests demonstrate the following capability:

- Capability 1, as it compares the solution for identical, but alternative 3-D $\theta-\mathrm{R}-\mathrm{Z}$ models 
These verification tests provide no additional verification of capabilities $4,5,7$, or 10 , as the details of the solution were not checked against an analytic solution or modified to test the impact of input changes. They also provide no additional verification for the remaining capabilities.

\subsection{Supplemental Verification of Capabilities 1, 4, and 5}

The preceding analytic solution only considers the radial aspect of the domain and effectively uses reflected boundary conditions in the axial and $\theta$ direction, eliminating the potential for gradients. To complete the test, a discrete math problem validation case is chosen that is testable using REBUS-PC. The primary problem with obtaining an analytic solution to the neutron transport or diffusion equation is the scattering and fission operators which depend upon the flux solution itself and spatial variations in the cross sections. If those cross sections become piece-wise constants, then the analytic solution quickly devolves into a very complex infinite series expansion. To overcome this the fixed source solution capability is used to demonstrate the remaining spatial fidelity by zeroing out the fission and scattering cross sections. A fixed source is introduced with constant cross sections over the whole domain to arrive at the differential equation

$\bar{\nabla} D \bar{\nabla} \phi(\theta, r, z)+\Sigma_{a} \cdot \phi(\theta, r, z)=S(\theta, r, z)$

Under certain circumstances and boundary conditions, this equation can have a manageable analytic solution which can be used to test REBUS-PC. In this case, an analytic solution is not required, as merely defining a flux solution that is consistent with the differential equation is sufficient to demonstrate the finite difference solver imbedded in REBUS-PC. Of particular interest for this work is that the differential equation, for certain sources, produces a relatively smooth solution that can be used to verify the $\theta$ and $\mathrm{Z}$ approximations, as the previous tests have already verified the $\mathrm{R}$ direction approximation. For simplicity, the boundary conditions impose a zero flux condition at the domain interfaces at $r=R, z=0, z=Z$, and periodic boundary condition in $\theta$, such that the following holds:

$$
\begin{aligned}
& \phi(\theta, r, 0)=0, \quad \phi(\theta, R, z)=0, \quad \phi(\theta, r, Z)=0, \\
& \left.\frac{\partial}{\partial r} \phi(\theta, r, 0)\right|_{r=0}=0, \quad \phi(0, r, z)=\phi(2 \cdot \pi, r, z)
\end{aligned}
$$

Because REBUS-PC cannot model an explicit spatially continuous source, the input must be progressively refined to show convergence towards a reference solution. To satisfy the above boundary conditions the flux solution can have the form:

$$
\phi(\theta, r, z)=\left(r^{3}-r^{4}\right) \cdot \cos (r \cdot 0.5 \cdot \pi) \cdot(1+0.5 \cdot \cos \theta) \sin (\pi z) \quad r \in 0,1 \quad z \in 0,1 \quad \theta \in 0,2 \pi
$$

The source for this system is obtained by substituting the flux solution into the differential equation:

$$
S(\theta, r, z)=D \cdot\left[\frac{1}{r} \frac{\partial}{\partial r} r \frac{\partial}{\partial r}+\frac{1}{r^{2}} \frac{\partial^{2}}{\partial^{2} \theta}+\frac{\partial^{2}}{\partial^{2} z}\right] \phi(\theta, r, z)+\Sigma_{a} \cdot \phi(\theta, r, z),
$$

where $\mathrm{D}=0.05 \mathrm{~cm}$ and $\Sigma=2 \mathrm{~cm}^{-1}$ are chosen, noting that negative source moments are not an issue for this mathematical problem. Because the functional representation of the source is very large, a spatial flux profile of the source is provided along with the flux solution in Figure 3-18. A quick inspection of equation 10 and the plots of Figure 3-18 shows that the solution satisfies the boundary conditions defined in equation 9 , and thus should be solvable by DIF3D.

The source is prepared for REBUS-PC by computing the average source over the volume of each REBUS-PC mesh and creating the appropriate card inputs for A.NIP3. The reference solution is obtained similarly by averaging the reference flux solution over each mesh. A MathCAD [10] program was used to prepare the source and reference flux solution appropriate for REBUS-PC. Because the 
solution data is extensive, the accuracy of the solution with respect to mesh refinement is considered. Figure 3-19 shows the radial flux profile ( $\theta x R x Z)$ at $Z=0.5$ for three different meshes in REBUS-PC along with the reference solution. As can be seen, the REBUS-PC profile converges to the reference solution as the number of mesh are increased. The appearance of the reference flux profiles differ between Figure 3-19 and Figure 3-18 only because of the use of different plotting software and choice of color tables.

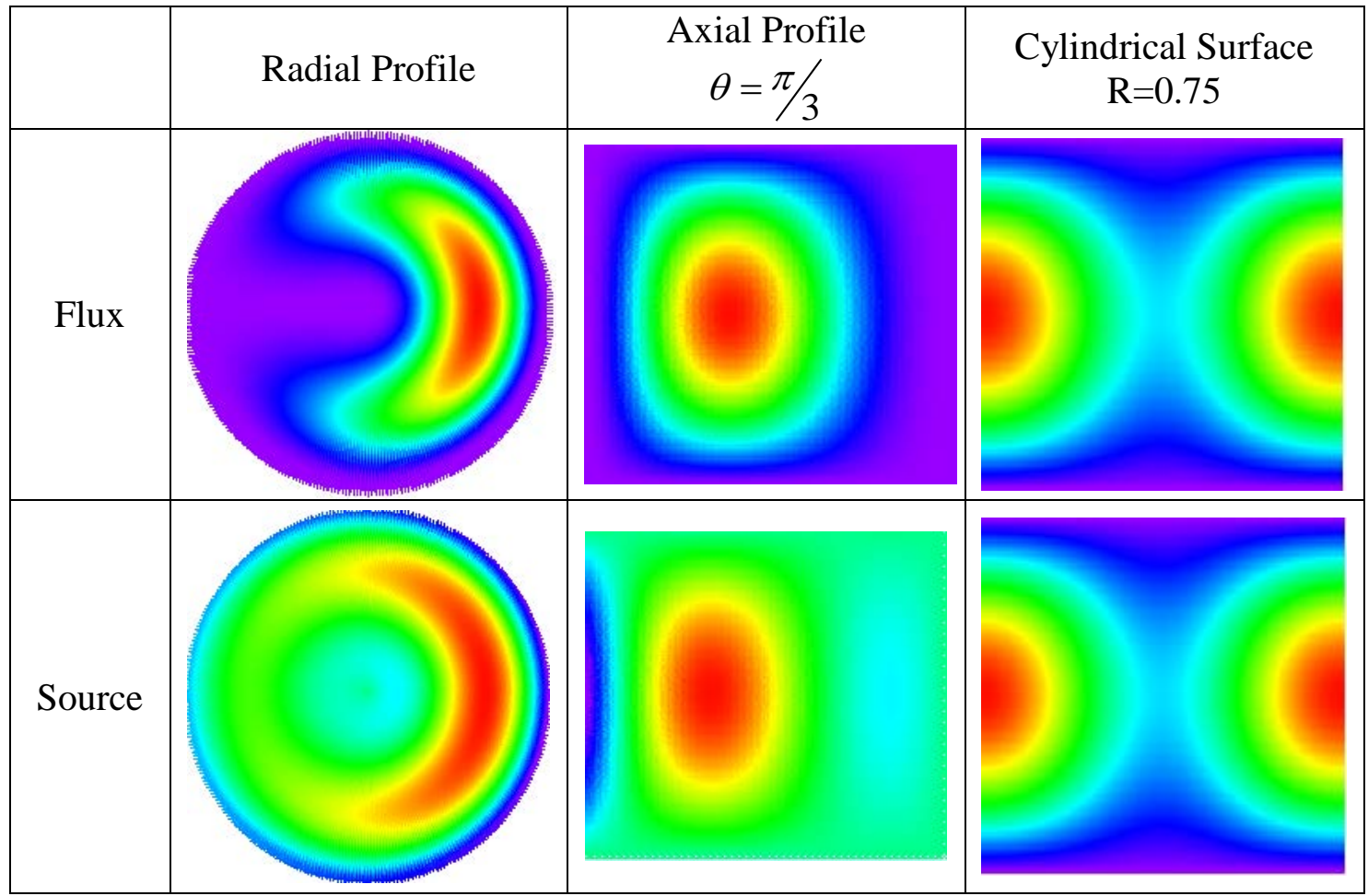

Figure 3-18. Reference Flux and Source Profiles for Supplemental Test Problem

\begin{tabular}{|c|c|c|c|}
\hline Reference & $\begin{array}{c}\text { REBUS-PC } \\
\text { 20x20x20 Mesh }\end{array}$ & $\begin{array}{c}\text { REBUS-PC } \\
\text { 40x40x40 Mesh }\end{array}$ & $\begin{array}{c}\text { REBUS-PC } \\
100 \times 90 x 90 \text { Mesh }\end{array}$ \\
\hline & & & \\
\hline & & & \\
\hline
\end{tabular}

Figure 3-19. REBUS-PC Flux Profiles for Supplemental Test Problem

To better illustrate the agreement between REBUS-PC and the reference solution, Figure 3-20 shows the $\theta$ flux trace at $\mathrm{Z}=0.5$ and $\mathrm{R}=0.75$ and the relative error results obtained using REBUS-PC. This particular trace was shown as it is part of both Figure 3-19 and Figure 3-18 and shows that the REBUS-PC calculated result has very little error. Even for the coarse mesh result, the relative error is still under $0.5 \%$. As the mesh is refined, the error drops to less than $0.005 \%$. It is important to note that the REBUS-PC flux solution is not accurate at all points, as REBUS-PC still produces negative flux solutions near the boundary and center of the domain due to insufficient mesh refinement to handle 
the gradients. Overall, however, this problem fully demonstrates that the $\theta-\mathrm{R}-\mathrm{Z}$ capability of REBUS-PC is functioning properly given the stated boundary conditions. This supplemental benchmark problem was not added to the verification test suite, as the remaining verification tests that demonstrate the STRZ geometry are sufficient to show that the flux solution capability is working properly, given that this demonstration was done, and track any issues that occur with the solution accuracy as the software progresses.

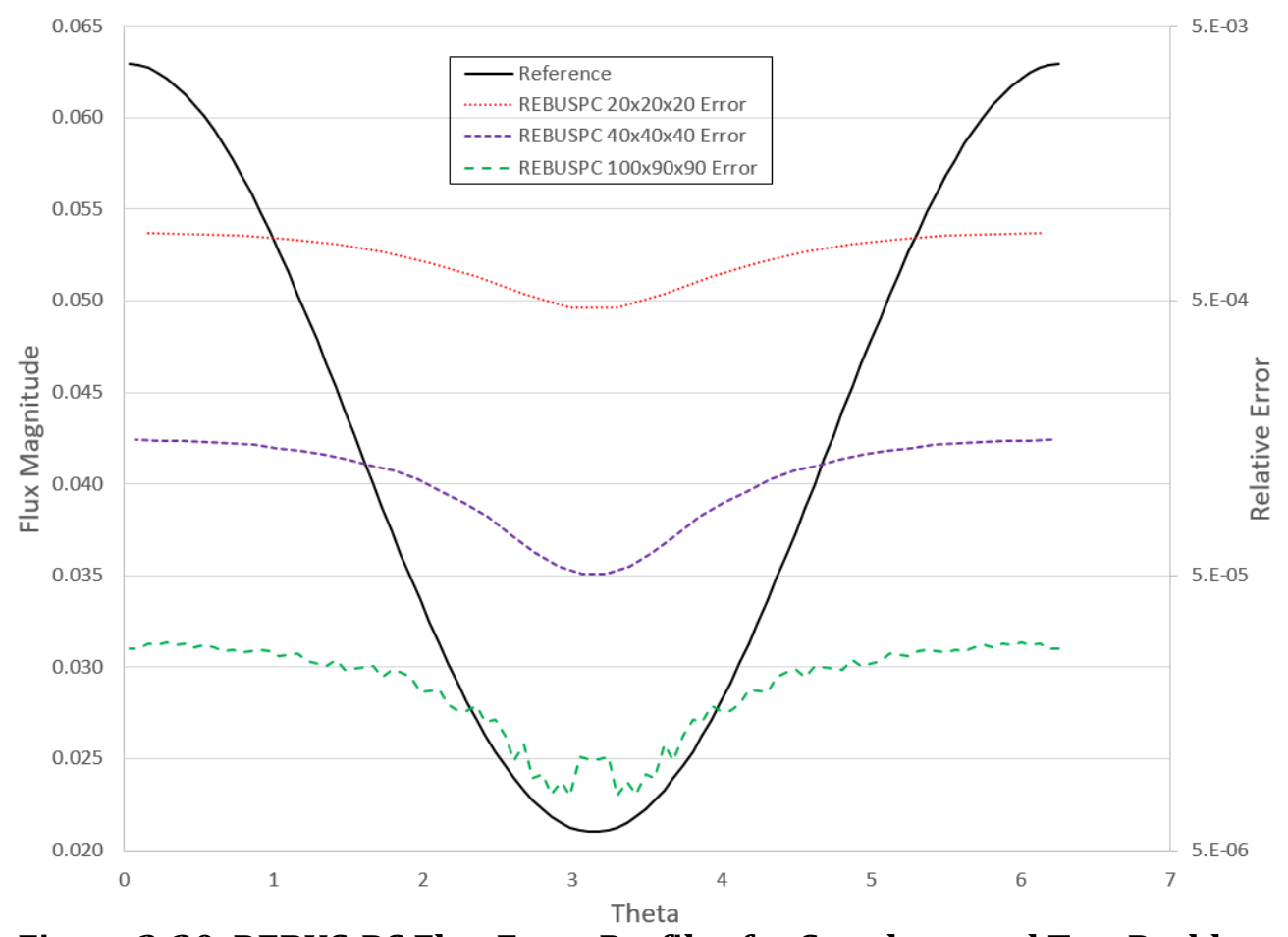

Figure 3-20. REBUS-PC Flux Error Profiles for Supplemental Test Problem

\subsection{Verification Tests \#12, \#13, and \#14}

Verification tests \#12 through \#14 are focused on checking that the input is properly processed by the REBUS-PC software. The STRZ benchmark geometry defined earlier in Figure 2-2 is the base geometry input for all three of these verification tests. The STRZ geometry is complex and contains seven depletion steps with control rod movements. The main purpose of verification test \#12 is to define the base solution for the STRZ benchmark and verify that the complicated geometry details of the STRZ benchmark are properly processed by DIF3D. Most of the verification can be done by looking at the processed geometry output of DIF3D. Starting with Figure 3-21, the number of regions, zones, and meshing required to define the STRZ benchmark can be verified to be consistent with the input. The region and zone map output of REBUS-PC, an excerpt of which is shown in Figure 3-22, can be compared to verify that DIF3D assigned the correct regions and zones to the spatial locations in STRZ. Finally, verification test \#12 is used to verify the power distribution and the TYPE13.BCD file output.

The region map in Figure 3-22 was produced by REBUS-PC by enabling the third and fourth input flags on card type 04 in A.DIF3D. In the region map, the numbers on the first row denote the mesh index in the theta-direction (i.e., the azimuthal direction) and the numbers in the first column denote the mesh index in R-direction (i.e. the radial direction). Star symbols (*) mark the region boundaries. The numbers other than the mesh indices refer to a region that contains the specific mesh. In another section of output, these region numbers are linked to the region names provided, and, via cross 
checking, the map shown can be shown to match the input specification. The region and area volumes were also checked by comparing the values given in the output and those calculated using Microsoft Excel [13]. The manual check is provided for the $\theta$ mesh boundaries in Table 3-7, the $\mathrm{R}$ mesh boundaries in Table 3-8 and the $\mathrm{Z}$ mesh boundaries in Table 3-9. This result is as expected as the mesh boundaries computed and reported by DIF3D are identical to those calculated in the Excel document.

\begin{tabular}{|rll|}
\hline & & \\
15 & IGOM & GEOMETRY TYPE, THETA-R-Z \\
10 & NZONE & NO. OF ZONES (COMPOSITIONS) \\
230 & NREG & NO. OF REGIONS \\
1 & NZCL & NO. OF ZONE CLASSIFICATIONS \\
8 & NCINTI & NO. OF 1ST DIMENSION COARSE MESH INTERVALS \\
15 & NCINTJ & NO. OF 2ND DIMENSION COARSE MESH INTERVALS \\
6 & NCINTK & NO. OF 3RD DIMENSION COARSE MESH INTERVALS \\
72 & NINTI & NO. OF 1ST DIMENSION FINE MESH INTERVALS \\
39 & NINTJ & NO. OF 2ND DIMENSION FINE MESH INTERVALS \\
28 & NINTK & NO. OF 3RD DIMENSION FINE MESH INTERVALS \\
3 & IMB1 & FIRST BOUNDARY CONDITION, FIRST DIMENSION, PERIODIC, OPPOSITE FACE \\
3 & IMB2 & LAST BOUNDARY CONDITION, FIRST DIMENSION, PERIODIC, OPPOSITE FACE \\
1 & JMB1 & FIRST BOUNDARY CONDITION, SECOND DIMENSION, REFLECTED \\
2 & JMB2 & LAST BOUNDARY CONDITION, SECOND DIMENSION, EXTRAPOLATED \\
1 & KMB1 & FIRST BOUNDARY CONDITION, THIRD DIMENSION, REFLECTED \\
2 & KMB2 & LAST BOUNDARY CONDITION, THIRD DIMENSION, EXTRAPOLATED \\
1 & NBS & NO. OF BUCKLING SPECIFICATIONS \\
1 & NBCS & NO. OF CONSTANTS FOR EXTERNAL BOUNDARIES \\
1 & NIBCS & NO. OF CONSTANTS FOR INTERNAL BOUNDARIES \\
0 & NZWBB & NO. OF BLACKNESS THEORY ZONES \\
0 & NRASS & O/1, REGION ASSIGNMENTS TO COARSE/FINE MESH \\
\hline
\end{tabular}

Figure 3-21. Model Descriptions in REBUS-PC Standard Output

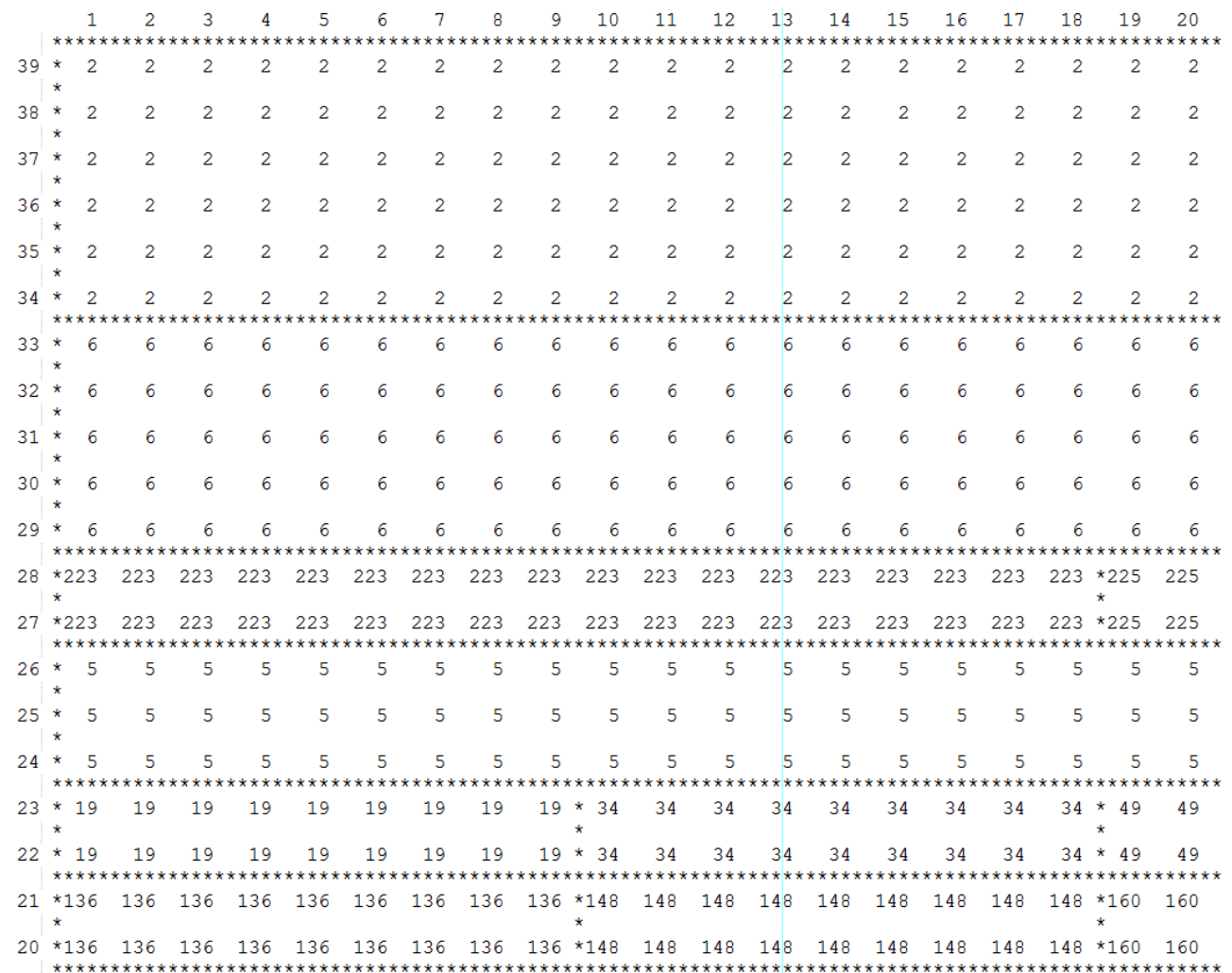

Figure 3-22. Region Map Output Table Excerpt from REBUS-PC for Verification Test \#12 
Table 3-7. Verification Test \#12 Check of the $\theta$ Mesh Boundaries

\begin{tabular}{|c|c|c|c|c|c|c|c|}
\hline No. & REBUS-PC & Excel & Diff. & No. & REBUS-PC & Excel & Diff. \\
\hline 1 & $0.00000 \mathrm{E}+00$ & $0.00000 \mathrm{E}+00$ & $0.00000 \mathrm{E}+00$ & 38 & $3.22886 \mathrm{E}+00$ & $3.22886 \mathrm{E}+00$ & $0.00000 \mathrm{E}+00$ \\
\hline 2 & 8.72664E-02 & 8.72664E-02 & $0.00000 \mathrm{E}+00$ & 39 & $3.31612 \mathrm{E}+00$ & $3.31612 \mathrm{E}+00$ & $0.00000 \mathrm{E}+00$ \\
\hline 3 & $1.74533 \mathrm{E}-01$ & $1.74533 \mathrm{E}-01$ & $0.00000 \mathrm{E}+00$ & 40 & $3.40339 \mathrm{E}+00$ & $3.40339 \mathrm{E}+00$ & $0.00000 \mathrm{E}+00$ \\
\hline 4 & 2.61799E-01 & 2.61799E-01 & $0.00000 \mathrm{E}+00$ & 41 & $3.49066 \mathrm{E}+00$ & $3.49066 \mathrm{E}+00$ & $0.00000 \mathrm{E}+00$ \\
\hline 5 & 3.49066E-01 & $3.49066 \mathrm{E}-01$ & $0.00000 \mathrm{E}+00$ & 42 & $3.57792 \mathrm{E}+00$ & $3.57792 \mathrm{E}+00$ & $0.00000 \mathrm{E}+00$ \\
\hline 6 & 4.36332E-01 & $4.36332 \mathrm{E}-01$ & $0.00000 \mathrm{E}+00$ & 43 & $3.66519 \mathrm{E}+00$ & $3.66519 \mathrm{E}+00$ & $0.00000 \mathrm{E}+00$ \\
\hline 7 & 5.23599E-01 & 5.23599E-01 & $0.00000 \mathrm{E}+00$ & 44 & $3.75246 \mathrm{E}+00$ & $3.75246 \mathrm{E}+00$ & $0.00000 \mathrm{E}+00$ \\
\hline 8 & 6.10865E-01 & 6.10865E-01 & $0.00000 \mathrm{E}+00$ & 45 & $3.83972 \mathrm{E}+00$ & $3.83972 \mathrm{E}+00$ & $0.00000 \mathrm{E}+00$ \\
\hline 9 & 6.98132E-01 & 6.98132E-01 & $0.00000 \mathrm{E}+00$ & 46 & $3.92699 \mathrm{E}+00$ & $3.92699 \mathrm{E}+00$ & $0.00000 \mathrm{E}+00$ \\
\hline 10 & 7.85398E-01 & 7.85398E-01 & $0.00000 \mathrm{E}+00$ & 47 & $4.01426 \mathrm{E}+00$ & $4.01426 \mathrm{E}+00$ & $0.00000 \mathrm{E}+00$ \\
\hline 11 & 8.72665E-01 & 8.72665E-01 & $0.00000 \mathrm{E}+00$ & 48 & $4.10152 \mathrm{E}+00$ & $4.10152 \mathrm{E}+00$ & $0.00000 \mathrm{E}+00$ \\
\hline 12 & 9.59932E-01 & 9.59932E-01 & $0.00000 \mathrm{E}+00$ & 49 & $4.18879 \mathrm{E}+00$ & $4.18879 \mathrm{E}+00$ & $0.00000 \mathrm{E}+00$ \\
\hline 13 & $1.04720 \mathrm{E}+00$ & $1.04720 \mathrm{E}+00$ & $0.00000 \mathrm{E}+00$ & 50 & $4.27606 \mathrm{E}+00$ & $4.27606 \mathrm{E}+00$ & $0.00000 \mathrm{E}+00$ \\
\hline 14 & $1.13447 \mathrm{E}+00$ & $1.13447 \mathrm{E}+00$ & $0.00000 \mathrm{E}+00$ & 51 & $4.36332 \mathrm{E}+00$ & $4.36332 \mathrm{E}+00$ & $0.00000 \mathrm{E}+00$ \\
\hline 15 & $1.22173 \mathrm{E}+00$ & $1.22173 \mathrm{E}+00$ & $0.00000 \mathrm{E}+00$ & 52 & $4.45059 \mathrm{E}+00$ & $4.45059 \mathrm{E}+00$ & $0.00000 \mathrm{E}+00$ \\
\hline 16 & $1.30900 \mathrm{E}+00$ & $1.30900 \mathrm{E}+00$ & $0.00000 \mathrm{E}+00$ & 53 & $4.53786 \mathrm{E}+00$ & $4.53786 \mathrm{E}+00$ & $0.00000 \mathrm{E}+00$ \\
\hline 17 & $1.39627 \mathrm{E}+00$ & $1.39627 \mathrm{E}+00$ & $0.00000 \mathrm{E}+00$ & 54 & $4.62512 \mathrm{E}+00$ & $4.62512 \mathrm{E}+00$ & $0.00000 \mathrm{E}+00$ \\
\hline 18 & $1.48353 \mathrm{E}+00$ & $1.48353 \mathrm{E}+00$ & $0.00000 \mathrm{E}+00$ & 55 & $4.71239 \mathrm{E}+00$ & $4.71239 \mathrm{E}+00$ & $0.00000 \mathrm{E}+00$ \\
\hline 19 & $1.57080 \mathrm{E}+00$ & $1.57080 \mathrm{E}+00$ & $0.00000 \mathrm{E}+00$ & 56 & $4.79966 \mathrm{E}+00$ & $4.79966 \mathrm{E}+00$ & $0.00000 \mathrm{E}+00$ \\
\hline 20 & $1.65807 \mathrm{E}+00$ & $1.65807 \mathrm{E}+00$ & $0.00000 \mathrm{E}+00$ & 57 & $4.88692 \mathrm{E}+00$ & $4.88692 \mathrm{E}+00$ & $0.00000 \mathrm{E}+00$ \\
\hline 21 & $1.74533 \mathrm{E}+00$ & $1.74533 \mathrm{E}+00$ & $0.00000 \mathrm{E}+00$ & 58 & $4.97419 \mathrm{E}+00$ & $4.97419 \mathrm{E}+00$ & $0.00000 \mathrm{E}+00$ \\
\hline 22 & $1.83260 \mathrm{E}+00$ & $1.83260 \mathrm{E}+00$ & $0.00000 \mathrm{E}+00$ & 59 & $5.06146 \mathrm{E}+00$ & $5.06146 \mathrm{E}+00$ & $0.00000 \mathrm{E}+00$ \\
\hline 23 & $1.91986 \mathrm{E}+00$ & $1.91986 \mathrm{E}+00$ & $0.00000 \mathrm{E}+00$ & 60 & $5.14872 \mathrm{E}+00$ & $5.14872 \mathrm{E}+00$ & $0.00000 \mathrm{E}+00$ \\
\hline 24 & $2.00713 \mathrm{E}+00$ & $2.00713 \mathrm{E}+00$ & $0.00000 \mathrm{E}+00$ & 61 & $5.23599 \mathrm{E}+00$ & $5.23599 \mathrm{E}+00$ & $0.00000 \mathrm{E}+00$ \\
\hline 25 & $2.09439 \mathrm{E}+00$ & $2.09439 \mathrm{E}+00$ & $0.00000 \mathrm{E}+00$ & 62 & $5.32326 \mathrm{E}+00$ & $5.32326 \mathrm{E}+00$ & $0.00000 \mathrm{E}+00$ \\
\hline 26 & $2.18166 \mathrm{E}+00$ & $2.18166 \mathrm{E}+00$ & $0.00000 \mathrm{E}+00$ & 63 & $5.41052 \mathrm{E}+00$ & $5.41052 \mathrm{E}+00$ & $0.00000 \mathrm{E}+00$ \\
\hline 27 & $2.26892 \mathrm{E}+00$ & $2.26892 \mathrm{E}+00$ & $0.00000 \mathrm{E}+00$ & 64 & $5.49779 \mathrm{E}+00$ & $5.49779 \mathrm{E}+00$ & $0.00000 \mathrm{E}+00$ \\
\hline 28 & $2.35619 \mathrm{E}+00$ & $2.35619 \mathrm{E}+00$ & $0.00000 \mathrm{E}+00$ & 65 & $5.58506 \mathrm{E}+00$ & $5.58506 \mathrm{E}+00$ & $0.00000 \mathrm{E}+00$ \\
\hline 29 & $2.44346 \mathrm{E}+00$ & $2.44346 \mathrm{E}+00$ & $0.00000 \mathrm{E}+00$ & 66 & $5.67232 \mathrm{E}+00$ & $5.67232 \mathrm{E}+00$ & $0.00000 \mathrm{E}+00$ \\
\hline 30 & $2.53072 \mathrm{E}+00$ & $2.53072 \mathrm{E}+00$ & $0.00000 \mathrm{E}+00$ & 67 & $5.75959 \mathrm{E}+00$ & $5.75959 \mathrm{E}+00$ & $0.00000 \mathrm{E}+00$ \\
\hline 31 & $2.61799 \mathrm{E}+00$ & $2.61799 \mathrm{E}+00$ & $0.00000 \mathrm{E}+00$ & 68 & $5.84685 \mathrm{E}+00$ & $5.84685 \mathrm{E}+00$ & $0.00000 \mathrm{E}+00$ \\
\hline 32 & $2.70526 \mathrm{E}+00$ & $2.70526 \mathrm{E}+00$ & $0.00000 \mathrm{E}+00$ & 69 & $5.93412 \mathrm{E}+00$ & $5.93412 \mathrm{E}+00$ & $0.00000 \mathrm{E}+00$ \\
\hline 33 & $2.79252 \mathrm{E}+00$ & $2.79252 \mathrm{E}+00$ & $0.00000 \mathrm{E}+00$ & 70 & $6.02138 \mathrm{E}+00$ & $6.02138 \mathrm{E}+00$ & $0.00000 \mathrm{E}+00$ \\
\hline 34 & $2.87979 \mathrm{E}+00$ & $2.87979 \mathrm{E}+00$ & $0.00000 \mathrm{E}+00$ & 71 & $6.10865 \mathrm{E}+00$ & $6.10865 \mathrm{E}+00$ & $0.00000 \mathrm{E}+00$ \\
\hline 35 & $2.96706 \mathrm{E}+00$ & $2.96706 \mathrm{E}+00$ & $0.00000 \mathrm{E}+00$ & 72 & $6.19591 \mathrm{E}+00$ & $6.19591 \mathrm{E}+00$ & $0.00000 \mathrm{E}+00$ \\
\hline 36 & $3.05432 \mathrm{E}+00$ & $3.05432 \mathrm{E}+00$ & $0.00000 \mathrm{E}+00$ & 73 & $6.28318 \mathrm{E}+00$ & $6.28318 \mathrm{E}+00$ & $0.00000 \mathrm{E}+00$ \\
\hline 37 & $3.14159 \mathrm{E}+00$ & $3.14159 \mathrm{E}+00$ & $0.00000 \mathrm{E}+00$ & & & & \\
\hline
\end{tabular}


Table 3-8. Verification Test \#12 Check of the R Mesh Boundaries

\begin{tabular}{|c|c|c|c|c|c|c|c|}
\hline No. & REBUS-PC & Excel & Diff. & No. & REBUS-PC & Excel & Diff. \\
\hline 1 & $0.00000 \mathrm{E}+00$ & $0.00000 \mathrm{E}+00$ & $0.00000 \mathrm{E}+00$ & 21 & $1.80522 \mathrm{E}+01$ & $1.80522 \mathrm{E}+01$ & $0.00000 \mathrm{E}+00$ \\
\hline 2 & $1.99471 \mathrm{E}+00$ & $1.99471 \mathrm{E}+00$ & $0.00000 \mathrm{E}+00$ & 22 & $1.86825 \mathrm{E}+01$ & $1.86825 \mathrm{E}+01$ & $0.00000 \mathrm{E}+00$ \\
\hline 3 & $3.98942 \mathrm{E}+00$ & $3.98942 \mathrm{E}+00$ & $0.00000 \mathrm{E}+00$ & 23 & $1.95464 \mathrm{E}+01$ & $1.95464 \mathrm{E}+01$ & $0.00000 \mathrm{E}+00$ \\
\hline 4 & $4.90275 \mathrm{E}+00$ & $4.90275 \mathrm{E}+00$ & $0.00000 \mathrm{E}+00$ & 24 & $2.04102 \mathrm{E}+01$ & $2.04102 \mathrm{E}+01$ & $0.00000 \mathrm{E}+00$ \\
\hline 5 & $5.81607 \mathrm{E}+00$ & $5.81607 \mathrm{E}+00$ & $0.00000 \mathrm{E}+00$ & 25 & $2.13235 \mathrm{E}+01$ & $2.13235 \mathrm{E}+01$ & $0.00000 \mathrm{E}+00$ \\
\hline 6 & $6.72940 \mathrm{E}+00$ & $6.72940 \mathrm{E}+00$ & $0.00000 \mathrm{E}+00$ & 26 & $2.22369 \mathrm{E}+01$ & $2.22369 \mathrm{E}+01$ & $0.00000 \mathrm{E}+00$ \\
\hline 7 & $7.59325 \mathrm{E}+00$ & $7.59325 \mathrm{E}+00$ & $0.00000 \mathrm{E}+00$ & 27 & $2.31502 \mathrm{E}+01$ & $2.31502 \mathrm{E}+01$ & $0.00000 \mathrm{E}+00$ \\
\hline 8 & $8.45710 \mathrm{E}+00$ & $8.45710 \mathrm{E}+00$ & $0.00000 \mathrm{E}+00$ & 28 & $2.37775 \mathrm{E}+01$ & $2.37775 \mathrm{E}+01$ & $0.00000 \mathrm{E}+00$ \\
\hline 9 & $9.08739 \mathrm{E}+00$ & $9.08739 \mathrm{E}+00$ & $0.00000 \mathrm{E}+00$ & 29 & $2.44047 \mathrm{E}+01$ & $2.44047 \mathrm{E}+01$ & $0.00000 \mathrm{E}+00$ \\
\hline 10 & $9.71768 \mathrm{E}+00$ & $9.71768 \mathrm{E}+00$ & $0.00000 \mathrm{E}+00$ & 30 & $2.52990 \mathrm{E}+01$ & $2.52990 \mathrm{E}+01$ & $0.00000 \mathrm{E}+00$ \\
\hline 11 & $1.05815 \mathrm{E}+01$ & $1.05815 \mathrm{E}+01$ & $0.00000 \mathrm{E}+00$ & 31 & $2.61932 \mathrm{E}+01$ & $2.61932 \mathrm{E}+01$ & $0.00000 \mathrm{E}+00$ \\
\hline 12 & $1.14454 \mathrm{E}+01$ & $1.14454 \mathrm{E}+01$ & $0.00000 \mathrm{E}+00$ & 32 & $2.70875 \mathrm{E}+01$ & $2.70875 \mathrm{E}+01$ & $0.00000 \mathrm{E}+00$ \\
\hline 13 & $1.20757 \mathrm{E}+01$ & $1.20757 \mathrm{E}+01$ & $0.00000 \mathrm{E}+00$ & 33 & $2.79817 \mathrm{E}+01$ & $2.79817 \mathrm{E}+01$ & $0.00000 \mathrm{E}+00$ \\
\hline 14 & $1.27060 \mathrm{E}+01$ & $1.27060 \mathrm{E}+01$ & $0.00000 \mathrm{E}+00$ & 34 & $2.88760 \mathrm{E}+01$ & $2.88760 \mathrm{E}+01$ & $0.00000 \mathrm{E}+00$ \\
\hline 15 & $1.35699 \mathrm{E}+01$ & $1.35699 \mathrm{E}+01$ & $0.00000 \mathrm{E}+00$ & 35 & $3.22093 \mathrm{E}+01$ & $3.22093 \mathrm{E}+01$ & $0.00000 \mathrm{E}+00$ \\
\hline 16 & $1.44337 \mathrm{E}+01$ & $1.44337 \mathrm{E}+01$ & $0.00000 \mathrm{E}+00$ & 36 & $3.55427 \mathrm{E}+01$ & $3.55427 \mathrm{E}+01$ & $0.00000 \mathrm{E}+00$ \\
\hline 17 & $1.50640 \mathrm{E}+01$ & $1.50640 \mathrm{E}+01$ & $0.00000 \mathrm{E}+00$ & 37 & $3.88760 \mathrm{E}+01$ & $3.88760 \mathrm{E}+01$ & $0.00000 \mathrm{E}+00$ \\
\hline 18 & $1.56942 \mathrm{E}+01$ & $1.56942 \mathrm{E}+01$ & $0.00000 \mathrm{E}+00$ & 38 & $4.22093 \mathrm{E}+01$ & $4.22093 \mathrm{E}+01$ & $0.00000 \mathrm{E}+00$ \\
\hline 19 & $1.65581 \mathrm{E}+01$ & $1.65581 \mathrm{E}+01$ & $0.00000 \mathrm{E}+00$ & 39 & $4.55427 \mathrm{E}+01$ & $4.55427 \mathrm{E}+01$ & $0.00000 \mathrm{E}+00$ \\
\hline 20 & $1.74219 \mathrm{E}+01$ & $1.74219 \mathrm{E}+01$ & $0.00000 \mathrm{E}+00$ & 40 & $4.88760 \mathrm{E}+01$ & $4.88760 \mathrm{E}+01$ & $0.00000 \mathrm{E}+00$ \\
\hline
\end{tabular}

Table 3-9. Verification Test \#12 Check of the Z Mesh Boundaries

\begin{tabular}{|c|c|c|c|c|c|c|c|}
\hline No. & REBUS-PC & Excel & Diff. & No. & REBUS-PC & Excel & Diff. \\
\hline 1 & $0.00000 \mathrm{E}+00$ & $0.00000 \mathrm{E}+00$ & $0.00000 \mathrm{E}+00$ & 21 & $3.00000 \mathrm{E}+01$ & $3.00000 \mathrm{E}+01$ & $0.00000 \mathrm{E}+00$ \\
\hline 2 & $2.00000 \mathrm{E}+00$ & $2.00000 \mathrm{E}+00$ & $0.00000 \mathrm{E}+00$ & 22 & $3.50000 \mathrm{E}+01$ & $3.50000 \mathrm{E}+01$ & $0.00000 \mathrm{E}+00$ \\
\hline 3 & $4.00000 \mathrm{E}+00$ & $4.00000 \mathrm{E}+00$ & $0.00000 \mathrm{E}+00$ & 23 & $4.00000 \mathrm{E}+01$ & $4.00000 \mathrm{E}+01$ & $0.00000 \mathrm{E}+00$ \\
\hline 4 & $6.00000 \mathrm{E}+00$ & $6.00000 \mathrm{E}+00$ & $0.00000 \mathrm{E}+00$ & 24 & $4.50000 \mathrm{E}+01$ & $4.50000 \mathrm{E}+01$ & $0.00000 \mathrm{E}+00$ \\
\hline 5 & $8.00000 \mathrm{E}+00$ & $8.00000 \mathrm{E}+00$ & $0.00000 \mathrm{E}+00$ & 25 & $4.75000 \mathrm{E}+01$ & $4.75000 \mathrm{E}+01$ & $0.00000 \mathrm{E}+00$ \\
\hline 6 & $1.00000 \mathrm{E}+01$ & $1.00000 \mathrm{E}+01$ & $0.00000 \mathrm{E}+00$ & 26 & $5.00000 \mathrm{E}+01$ & $5.00000 \mathrm{E}+01$ & $0.00000 \mathrm{E}+00$ \\
\hline 7 & $1.20000 \mathrm{E}+01$ & $1.20000 \mathrm{E}+01$ & $0.00000 \mathrm{E}+00$ & 27 & $5.50000 \mathrm{E}+01$ & $5.50000 \mathrm{E}+01$ & $0.00000 \mathrm{E}+00$ \\
\hline 8 & $1.40000 \mathrm{E}+01$ & $1.40000 \mathrm{E}+01$ & $0.00000 \mathrm{E}+00$ & 28 & $6.00000 \mathrm{E}+01$ & $6.00000 \mathrm{E}+01$ & $0.00000 \mathrm{E}+00$ \\
\hline 9 & $1.60000 \mathrm{E}+01$ & $1.60000 \mathrm{E}+01$ & $0.00000 \mathrm{E}+00$ & 29 & $6.50000 \mathrm{E}+01$ & $6.50000 \mathrm{E}+01$ & $0.00000 \mathrm{E}+00$ \\
\hline 10 & $1.80000 \mathrm{E}+01$ & $1.80000 \mathrm{E}+01$ & $0.00000 \mathrm{E}+00$ & 30 & $7.00000 \mathrm{E}+01$ & $7.00000 \mathrm{E}+01$ & $0.00000 \mathrm{E}+00$ \\
\hline 11 & $2.00000 \mathrm{E}+01$ & $2.00000 \mathrm{E}+01$ & $0.00000 \mathrm{E}+00$ & 31 & $7.50000 \mathrm{E}+01$ & $7.50000 \mathrm{E}+01$ & $0.00000 \mathrm{E}+00$ \\
\hline 12 & $2.20000 \mathrm{E}+01$ & $2.20000 \mathrm{E}+01$ & $0.00000 \mathrm{E}+00$ & 32 & $8.00000 \mathrm{E}+01$ & $8.00000 \mathrm{E}+01$ & $0.00000 \mathrm{E}+00$ \\
\hline 13 & $2.40000 \mathrm{E}+01$ & $2.40000 \mathrm{E}+01$ & $0.00000 \mathrm{E}+00$ & 33 & $8.50000 \mathrm{E}+01$ & $8.50000 \mathrm{E}+01$ & $0.00000 \mathrm{E}+00$ \\
\hline 14 & $2.60000 \mathrm{E}+01$ & $2.60000 \mathrm{E}+01$ & $0.00000 \mathrm{E}+00$ & 34 & $9.00000 \mathrm{E}+01$ & $9.00000 \mathrm{E}+01$ & $0.00000 \mathrm{E}+00$ \\
\hline 15 & $2.80000 \mathrm{E}+01$ & $2.80000 \mathrm{E}+01$ & $0.00000 \mathrm{E}+00$ & 35 & & & \\
\hline
\end{tabular}

In addition to the mesh boundaries, the region and area volumes reported by REBUS-PC were computed using Excel which is reported in Table 3-10.. As was the case with the mesh boundary calculations, the region and area volumes are identical to those of REBUS-PC. 
Table 3-10. Verification Test \#12 Check of the Region and Area Volumes

\begin{tabular}{|c|c|c|c|c|}
\hline \multirow{2}{*}{$\begin{array}{l}\text { Region/ } \\
\text { Area No. }\end{array}$} & \multirow{2}{*}{$\begin{array}{c}\text { Region/ } \\
\text { Area Name }\end{array}$} & \multicolumn{2}{|c|}{ Region/Area Volume (cc) } & \multirow{2}{*}{ Diff. } \\
\hline & & REBUS-PC & Excel & \\
\hline 1 & UPSTR & $3.64817 \mathrm{E}+04$ & $3.64817 \mathrm{E}+04$ & $0.00000 \mathrm{E}+00$ \\
\hline 2 & WPOOL & $5.57556 \mathrm{E}+05$ & $5.57556 \mathrm{E}+05$ & $0.00000 \mathrm{E}+00$ \\
\hline 3 & FTRAP & $1.50000 \mathrm{E}+03$ & $1.50000 \mathrm{E}+03$ & $0.00000 \mathrm{E}+00$ \\
\hline 4 & STWLI & $2.76799 \mathrm{E}+03$ & $2.76799 \mathrm{E}+03$ & $0.00000 \mathrm{E}+00$ \\
\hline 5 & STWLO & $1.12490 \mathrm{E}+04$ & $1.12490 \mathrm{E}+04$ & $0.00000 \mathrm{E}+00$ \\
\hline 6 & REFLT & $2.24530 \mathrm{E}+04$ & $2.24530 \mathrm{E}+04$ & $0.00000 \mathrm{E}+00$ \\
\hline 7 & CL11E & $1.03035 \mathrm{E}+02$ & $1.03035 \mathrm{E}+02$ & $0.00000 \mathrm{E}+00$ \\
\hline 8 & CL11F & $1.03035 \mathrm{E}+02$ & $1.03035 \mathrm{E}+02$ & $0.00000 \mathrm{E}+00$ \\
\hline 9 & CL11G & $1.03035 \mathrm{E}+02$ & $1.03035 \mathrm{E}+02$ & $0.00000 \mathrm{E}+00$ \\
\hline 10 & CL12E & $1.43586 \mathrm{E}+02$ & $1.43586 \mathrm{E}+02$ & $0.00000 \mathrm{E}+00$ \\
\hline 11 & CL12F & $1.43586 \mathrm{E}+02$ & $1.43586 \mathrm{E}+02$ & $0.00000 \mathrm{E}+00$ \\
\hline 12 & CL12G & $1.43586 \mathrm{E}+02$ & $1.43586 \mathrm{E}+02$ & $0.00000 \mathrm{E}+00$ \\
\hline 13 & CL13E & $1.84134 \mathrm{E}+02$ & $1.84134 \mathrm{E}+02$ & $0.00000 \mathrm{E}+00$ \\
\hline 14 & CL13F & $1.84134 \mathrm{E}+02$ & $1.84134 \mathrm{E}+02$ & $0.00000 \mathrm{E}+00$ \\
\hline 15 & CL13G & $1.84134 \mathrm{E}+02$ & $1.84134 \mathrm{E}+02$ & $0.00000 \mathrm{E}+00$ \\
\hline 16 & CL14E & $2.24681 \mathrm{E}+02$ & $2.24681 \mathrm{E}+02$ & $0.00000 \mathrm{E}+00$ \\
\hline 17 & CL14F & $2.24681 \mathrm{E}+02$ & $2.24681 \mathrm{E}+02$ & $0.00000 \mathrm{E}+00$ \\
\hline 18 & CL14G & $2.24681 \mathrm{E}+02$ & $2.24681 \mathrm{E}+02$ & $0.00000 \mathrm{E}+00$ \\
\hline 19 & CL15E & $2.65231 \mathrm{E}+02$ & $2.65231 \mathrm{E}+02$ & $0.00000 \mathrm{E}+00$ \\
\hline 20 & CL15F & $2.65231 \mathrm{E}+02$ & $2.65231 \mathrm{E}+02$ & $0.00000 \mathrm{E}+00$ \\
\hline 21 & CL15G & $2.65231 \mathrm{E}+02$ & $2.65231 \mathrm{E}+02$ & $0.00000 \mathrm{E}+00$ \\
\hline 127 & FL11E & $8.99703 \mathrm{E}+01$ & $8.99703 \mathrm{E}+01$ & $0.00000 \mathrm{E}+00$ \\
\hline 128 & FL11F & $8.99703 \mathrm{E}+01$ & $8.99703 \mathrm{E}+01$ & $0.00000 \mathrm{E}+00$ \\
\hline 129 & FL11G & $8.99703 \mathrm{E}+01$ & $8.99703 \mathrm{E}+01$ & $0.00000 \mathrm{E}+00$ \\
\hline 130 & FL12E & $1.19558 \mathrm{E}+02$ & $1.19558 \mathrm{E}+02$ & $0.00000 \mathrm{E}+00$ \\
\hline 131 & FL12F & $1.19558 \mathrm{E}+02$ & $1.19558 \mathrm{E}+02$ & $0.00000 \mathrm{E}+00$ \\
\hline 132 & FL12G & $1.19558 \mathrm{E}+02$ & $1.19558 \mathrm{E}+02$ & $0.00000 \mathrm{E}+00$ \\
\hline 133 & FL13E & $1.49132 \mathrm{E}+02$ & $1.49132 \mathrm{E}+02$ & $0.00000 \mathrm{E}+00$ \\
\hline 134 & FL13F & $1.49132 \mathrm{E}+02$ & $1.49132 \mathrm{E}+02$ & $0.00000 \mathrm{E}+00$ \\
\hline 135 & FL13G & $1.49132 \mathrm{E}+02$ & $1.49132 \mathrm{E}+02$ & $0.00000 \mathrm{E}+00$ \\
\hline 136 & FL14E & $1.78730 \mathrm{E}+02$ & $1.78730 \mathrm{E}+02$ & $0.00000 \mathrm{E}+00$ \\
\hline 137 & FL14F & $1.78730 \mathrm{E}+02$ & $1.78730 \mathrm{E}+02$ & $0.00000 \mathrm{E}+00$ \\
\hline 138 & FL14G & $1.78730 \mathrm{E}+02$ & $1.78730 \mathrm{E}+02$ & $0.00000 \mathrm{E}+00$ \\
\hline 223 & BLDW1 & $9.37102 \mathrm{E}+01$ & $9.37102 \mathrm{E}+01$ & $0.00000 \mathrm{E}+00$ \\
\hline 224 & FOLL1 & $9.37102 \mathrm{E}+01$ & $9.37102 \mathrm{E}+01$ & $0.00000 \mathrm{E}+00$ \\
\hline 225 & BLAD1 & $1.21823 \mathrm{E}+03$ & $1.21823 \mathrm{E}+03$ & $0.00000 \mathrm{E}+00$ \\
\hline 226 & HADL1 & $7.02826 \mathrm{E}+02$ & $7.02826 \mathrm{E}+02$ & $0.00000 \mathrm{E}+00$ \\
\hline 227 & BLDW2 & $1.87419 \mathrm{E}+02$ & $1.87419 \mathrm{E}+02$ & $0.00000 \mathrm{E}+00$ \\
\hline 228 & FOLL2 & $9.37096 \mathrm{E}+01$ & $9.37096 \mathrm{E}+01$ & $0.00000 \mathrm{E}+00$ \\
\hline 229 & BLAD2 & $1.12452 \mathrm{E}+03$ & $1.12452 \mathrm{E}+03$ & $0.00000 \mathrm{E}+00$ \\
\hline 230 & HADL2 & $7.02822 \mathrm{E}+02$ & $7.02822 \mathrm{E}+02$ & $0.00000 \mathrm{E}+00$ \\
\hline 231 & BLDW3 & $9.37102 \mathrm{E}+01$ & $9.37102 \mathrm{E}+01$ & $0.00000 \mathrm{E}+00$ \\
\hline 232 & FOLL3 & $9.37102 \mathrm{E}+01$ & $9.37102 \mathrm{E}+01$ & $0.00000 \mathrm{E}+00$ \\
\hline 233 & BLAD3 & $1.21823 \mathrm{E}+03$ & $1.21823 \mathrm{E}+03$ & $0.00000 \mathrm{E}+00$ \\
\hline 234 & HADL3 & $7.02826 \mathrm{E}+02$ & $7.02826 \mathrm{E}+02$ & $0.00000 \mathrm{E}+00$ \\
\hline \multicolumn{5}{|c|}{ Areas } \\
\hline 1 & FUELX & $1.28974 \mathrm{E}+04$ & $1.28974 \mathrm{E}+04$ & $0.00000 \mathrm{E}+00$ \\
\hline 2 & BLADE & $4.68550 \mathrm{E}+03$ & $4.68550 \mathrm{E}+03$ & $0.00000 \mathrm{E}+00$ \\
\hline 3 & BL\&FL & $1.75829 \mathrm{E}+04$ & $1.75829 \mathrm{E}+04$ & $0.00000 \mathrm{E}+00$ \\
\hline
\end{tabular}


The solution produced by STRZ uses many flux calculations to reach the end of the depletion calculation, as evident from the tabulated eigenvalue results in Table 3-11, which notably are identical for all three test cases.

Table 3-11. Verification Tests \#12, \#13, and \#14 Eigenvalue Results

\begin{tabular}{|c|c|c|c|}
\hline Time Point & Verification Test \#12 & Verification Test \#13 & Verification Test \#14 \\
\hline 0.00 & 1.07900 & 1.07900 & 1.07900 \\
\hline 3.00 & 1.03321 & 1.03321 & 1.03321 \\
\hline 3.00 & 1.03308 & 1.03308 & 1.03308 \\
\hline 6.00 & 1.02766 & 1.02766 & 1.02766 \\
\hline 6.00 & 1.02778 & 1.02778 & 1.02778 \\
\hline 9.00 & 1.02282 & 1.02282 & 1.02282 \\
\hline 9.00 & 1.02282 & 1.02282 & 1.02282 \\
\hline 12.00 & 1.01797 & 1.01797 & 1.01797 \\
\hline 12.00 & 1.01797 & 1.01797 & 1.01797 \\
\hline 15.00 & 1.01323 & 1.01323 & 1.01323 \\
\hline 15.00 & 1.01323 & 1.01323 & 1.01323 \\
\hline 18.00 & 1.01030 & 1.01030 & 1.01030 \\
\hline 18.00 & 1.01030 & 1.01030 & 1.01030 \\
\hline 21.00 & 1.00752 & 1.00752 & 1.00752 \\
\hline 21.00 & 1.00752 & 1.00752 & 1.00752 \\
\hline 24.00 & 1.00531 & 1.00531 & 1.00531 \\
\hline 24.00 & 1.00531 & 1.00531 & 1.00531 \\
\hline 27.00 & 1.00244 & 1.00244 & 1.00244 \\
\hline 27.00 & 1.00244 & 1.00244 & 1.00244 \\
\hline 30.00 & 0.99859 & 0.99859 & 0.99859 \\
\hline 30.00 & 0.99859 & 0.99859 & 0.99859 \\
\hline
\end{tabular}

Because the output file for each case is quite extensive, only those pieces that are relevant to the actual verification being done are compared. In verification test \#13 the free format usage is checked where verification test \#12 was provided to REBUS-PC using the fixed format input. The main input difference is thus a simple formatting change of the input such that it no longer has the required column layout of a fixed format input as shown in Figure 3-23. As expected, the results are identical, as inferred by Table 3-11, as the REBUS-PC input is effectively identical, thereby demonstrating that the free format input and fixed format input are handled identically in REBUS-PC

In verification test \#14, the "overlay" option for geometry specification is tested, which is a key feature of the REBUS-PC code. In this test, the type 06 cards in the dataset A.NIP3 were modified such that each water channel covers the adjacent fuel plate in the outward R direction. In the verification test input, these cards are provided before the fuel plate cards, and thus REBUS-PC will overlay the fuel on the extra water regions when it encounters the fuel plate card inputs. An excerpt of the modified type 06 cards of A.NIP3 are shown in Figure 3-24, which should match the verification test \#12 input provided in Figure 3-23. The modified portions are highlighted in Figure 3-24. The lines that "overlay" these inputs are also provided in Figure 3-24. If the "overlay" feature works as intended, the resulting model will be identical to the base model as the changes in Figure 3-24 only alter part 
of the geometry that is redefined later. The results of verification test \#14 are identical to those of verification tests \#12 and \#13 in Table 3-11, demonstrating that the overlay input feature is working properly.

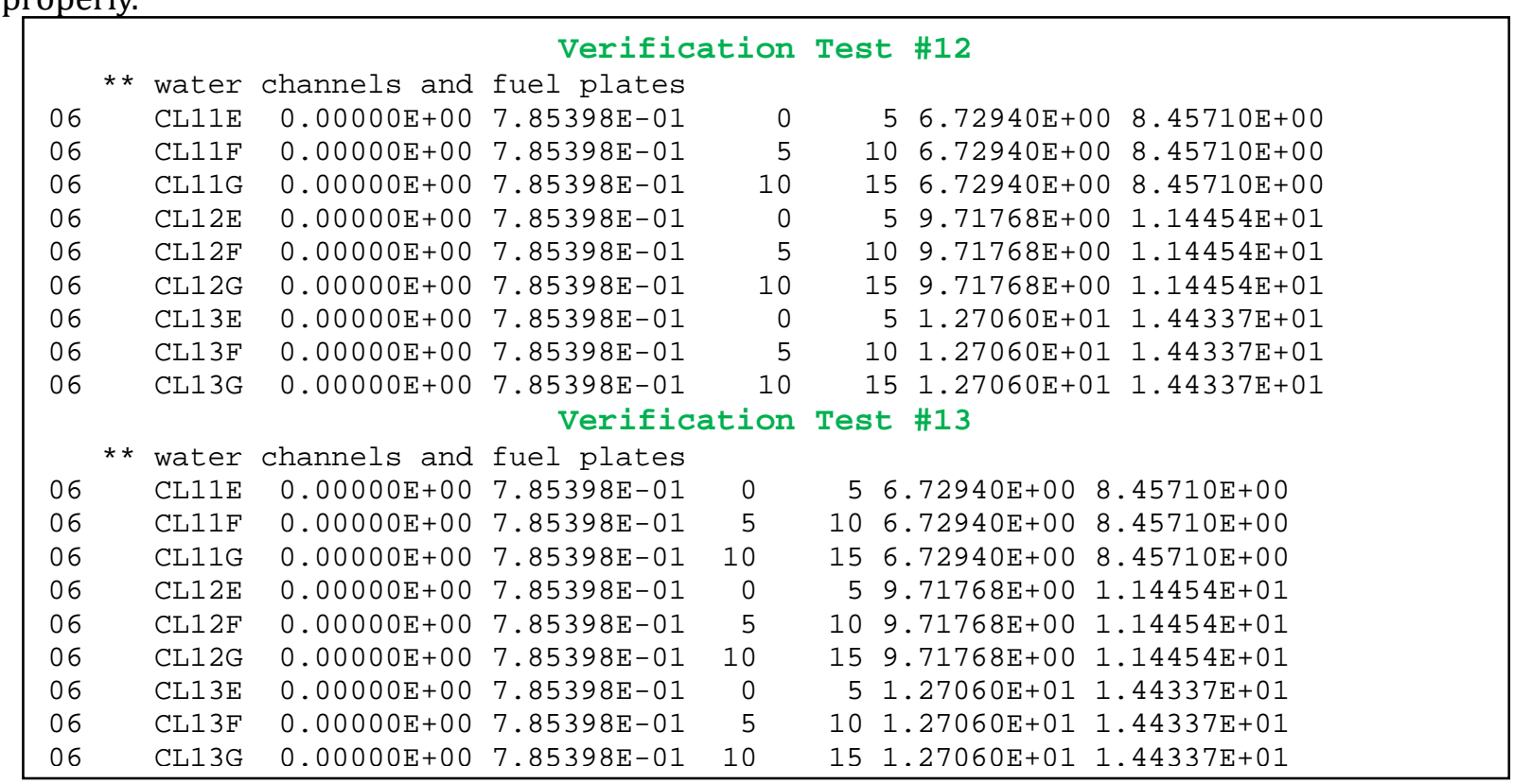

Figure 3-23. Modified Geometry Inputs between Verification Tests \#12 and \#13

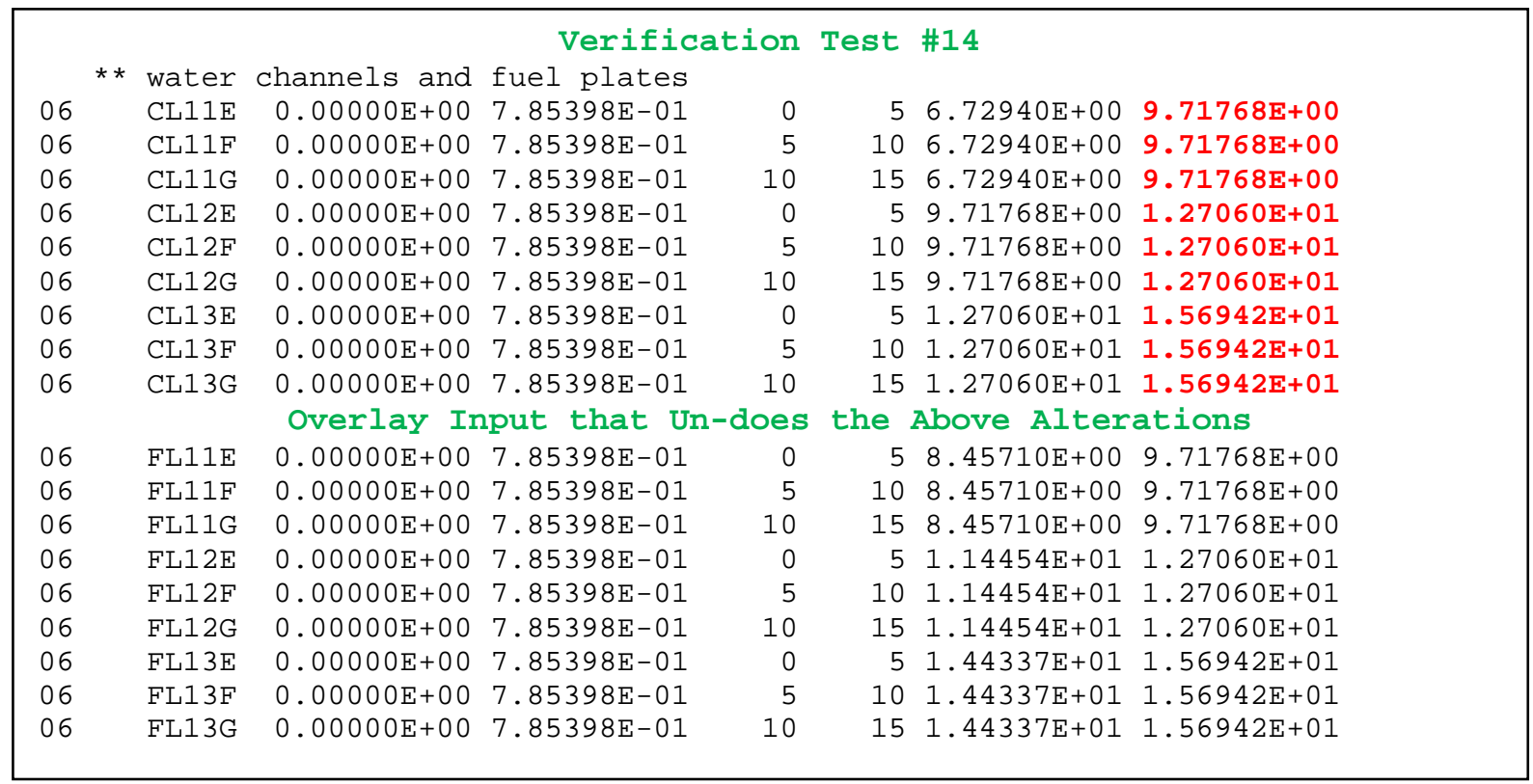

Figure 3-24. Modified Geometry Inputs between Verification Tests \#12 and \#14

In addition to the input checking, the STRZ benchmark is used to check "color set" based cross section capabilities. A "color set" means that a different specific pre-processed set of multi-group cross sections are applied to different regions in the domain. In this regard, the test consists of verifying that by using different isotope labels, the mechanism to allow color sets in REBUS-PC, the correct cross section data is used in the specified spatial region. Because the mechanism to map zones to regions has already been checked, this is only the verification of the correct isotope usage in a given zone. 
Figure 3-25 shows an excerpt of the color set input for REBUS-PC in the STRZ benchmark, where each fuel plate material defined in the geometry is assigned a specific set of isotopes. In order to complete the input setup, the depletion chain must be linked to each of these isotopes, as seen in the A.BURN section of input in the figure. To demonstrate that the regions have different cross sections, the ISOTXS binary file was setup to contain different cross sections for each of these isotopes as shown in Figure 3-26 for two example U-235 isotopes.

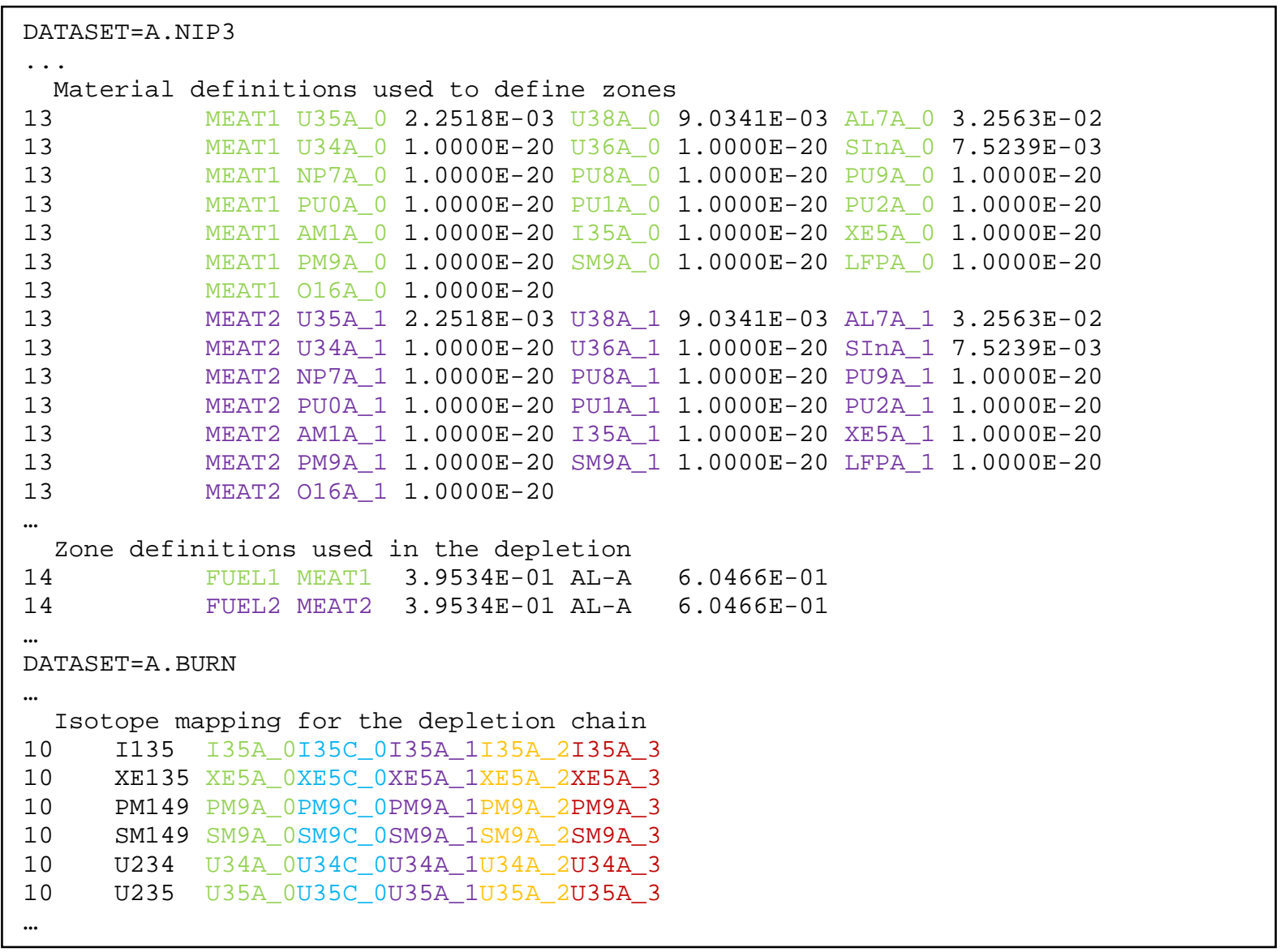

Figure 3-25. Color Set Input Excerpt for Verification Test \#12

The use of a particular isotope set in each zone will cause the homogenized cross sections in each zone to be unique and thus different cross sections will appear in those region. The first step in checking the input is to verify that the stated compositions consist of the correct isotopes and are assigned to the proper regions. The input for every zone was checked by manually comparing the atom density reported by REBUS-PC with the input provided in A.NIP3 via Excel. Table 3-12 shows a small selection of this comparison from the verification test \#12 input and output.

The zone definitions are defined by card type 14 and are typically composed of different materials or even zones. Excel is again used to compute the final densities of every zone in the domain, but only a selection of the comparison is shown between the REBUS-PC computed values and the Excel calculation in Table 3-13. In both Table 3-12 and Table 3-13 one can see that the Excel calculation identically matches the REBUS-PC reported values. These results demonstrate that REBUS-PC correctly processes the material specifications on the type 13 cards and the composition specifications on the type 14 cards of A.NIP3. 


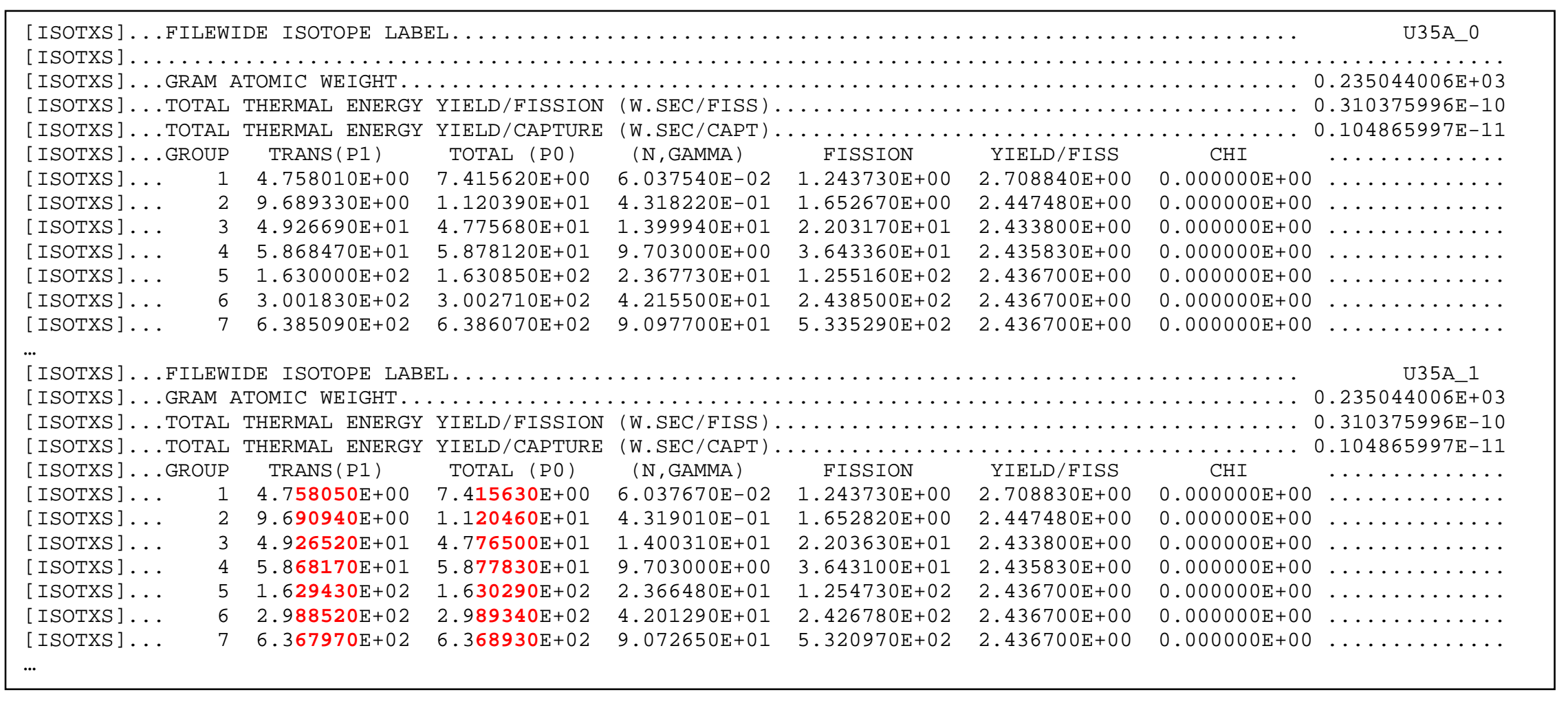

Figure 3-26. ISOTXS Cross Sections Differences for Verification Test \#12 
Table 3-12. Manual Check of the Input Density for Card Type 13 in Verification Test \#12

\begin{tabular}{|c|c|c|c|c|}
\hline Material & $\begin{array}{c}\text { Isotope } \\
\text { Label }\end{array}$ & $\begin{array}{c}\text { Density in } \\
\text { Output }\end{array}$ & Density in Input & Diff. \\
\hline \multirow{19}{*}{ MEAT1 } & AL7A_0 & 3.2563E-02 & 3.2563E-02 & $0.0000 \mathrm{E}+00$ \\
\hline & AM1A_0 & $1.0000 \mathrm{E}-20$ & $1.0000 \mathrm{E}-20$ & $0.0000 \mathrm{E}+00$ \\
\hline & I35A_0 & 1.0000E-20 & $1.0000 \mathrm{E}-20$ & $0.0000 \mathrm{E}+00$ \\
\hline & LFPA_0 & $1.0000 \mathrm{E}-20$ & 1.0000E-20 & $0.0000 \mathrm{E}+00$ \\
\hline & NP7A_0 & $1.0000 \mathrm{E}-20$ & 1.0000E-20 & $0.0000 \mathrm{E}+00$ \\
\hline & O16A_0 & $1.0000 \mathrm{E}-20$ & $1.0000 \mathrm{E}-20$ & $0.0000 \mathrm{E}+00$ \\
\hline & PM9A_0 & 1.0000E-20 & $1.0000 \mathrm{E}-20$ & $0.0000 \mathrm{E}+00$ \\
\hline & PU0A_0 & 1.0000E-20 & 1.0000E-20 & $0.0000 \mathrm{E}+00$ \\
\hline & PU1A_0 & 1.0000E-20 & 1.0000E-20 & $0.0000 \mathrm{E}+00$ \\
\hline & PU2A_0 & $1.0000 \mathrm{E}-20$ & $1.0000 \mathrm{E}-20$ & $0.0000 \mathrm{E}+00$ \\
\hline & PU8A_0 & $1.0000 \mathrm{E}-20$ & $1.0000 \mathrm{E}-20$ & $0.0000 \mathrm{E}+00$ \\
\hline & PU9A_0 & $1.0000 \mathrm{E}-20$ & $1.0000 \mathrm{E}-20$ & $0.0000 \mathrm{E}+00$ \\
\hline & SInA_0 & 7.5239E-03 & 7.5239E-03 & $0.0000 \mathrm{E}+00$ \\
\hline & SM9A_0 & 1.0000E-20 & $1.0000 \mathrm{E}-20$ & $0.0000 \mathrm{E}+00$ \\
\hline & U34A_0 & 1.0000E-20 & 1.0000E-20 & $0.0000 \mathrm{E}+00$ \\
\hline & U35A_0 & 2.2518E-03 & $2.2518 \mathrm{E}-03$ & $0.0000 \mathrm{E}+00$ \\
\hline & U36A_0 & $1.0000 \mathrm{E}-20$ & $1.0000 \mathrm{E}-20$ & $0.0000 \mathrm{E}+00$ \\
\hline & U38A_0 & 9.0341E-03 & $9.0341 \mathrm{E}-03$ & $0.0000 \mathrm{E}+00$ \\
\hline & XE5A_0 & $1.0000 \mathrm{E}-20$ & $1.0000 \mathrm{E}-20$ & $0.0000 \mathrm{E}+00$ \\
\hline \multirow{19}{*}{ MEAT2 } & AL7C_0 & 3.2563E-02 & 3.2563E-02 & $0.0000 \mathrm{E}+00$ \\
\hline & AM1C_0 & $1.0000 \mathrm{E}-20$ & $1.0000 \mathrm{E}-20$ & $0.0000 \mathrm{E}+00$ \\
\hline & I35C_0 & $1.0000 \mathrm{E}-20$ & $1.0000 \mathrm{E}-20$ & $0.0000 \mathrm{E}+00$ \\
\hline & LFPC_0 & $1.0000 \mathrm{E}-20$ & $1.0000 \mathrm{E}-20$ & $0.0000 \mathrm{E}+00$ \\
\hline & NP7C_0 & 1.0000E-20 & $1.0000 \mathrm{E}-20$ & $0.0000 \mathrm{E}+00$ \\
\hline & O16C_0 & 1.0000E-20 & $1.0000 \mathrm{E}-20$ & $0.0000 \mathrm{E}+00$ \\
\hline & PM9C_0 & $1.0000 \mathrm{E}-20$ & $1.0000 \mathrm{E}-20$ & $0.0000 \mathrm{E}+00$ \\
\hline & PU0C_0 & $1.0000 \mathrm{E}-20$ & $1.0000 \mathrm{E}-20$ & $0.0000 \mathrm{E}+00$ \\
\hline & PU1C_0 & 1.0000E-20 & $1.0000 \mathrm{E}-20$ & $0.0000 \mathrm{E}+00$ \\
\hline & PU2C_0 & $1.0000 \mathrm{E}-20$ & $1.0000 \mathrm{E}-20$ & $0.0000 \mathrm{E}+00$ \\
\hline & PU8C_0 & 1.0000E-20 & $1.0000 \mathrm{E}-20$ & $0.0000 \mathrm{E}+00$ \\
\hline & PU9C_0 & $1.0000 \mathrm{E}-20$ & $1.0000 \mathrm{E}-20$ & $0.0000 \mathrm{E}+00$ \\
\hline & SInC_0 & 7.5239E-03 & 7.5239E-03 & $0.0000 \mathrm{E}+00$ \\
\hline & SM9C_0 & $1.0000 \mathrm{E}-20$ & $1.0000 \mathrm{E}-20$ & $0.0000 \mathrm{E}+00$ \\
\hline & U34C_0 & $1.0000 \mathrm{E}-20$ & $1.0000 \mathrm{E}-20$ & $0.0000 \mathrm{E}+00$ \\
\hline & U35C_0 & 2.2518E-03 & 2.2518E-03 & $0.0000 \mathrm{E}+00$ \\
\hline & U36C_0 & $1.0000 \mathrm{E}-20$ & $1.0000 \mathrm{E}-20$ & $0.0000 \mathrm{E}+00$ \\
\hline & U38C_0 & 9.0341E-03 & $9.0341 \mathrm{E}-03$ & $0.0000 \mathrm{E}+00$ \\
\hline & XE5C_0 & 1.0000E-20 & $1.0000 \mathrm{E}-20$ & $0.0000 \mathrm{E}+00$ \\
\hline
\end{tabular}


Table 3-13. Check of the Computed Densities for Card Type 14 in Verification Test \#12

\begin{tabular}{|c|c|c|c|c|}
\hline Composition & $\begin{array}{c}\text { Isotope } \\
\text { Label }\end{array}$ & $\begin{array}{l}\text { REBUS-PC } \\
\text { Reported } \\
\text { Density }\end{array}$ & $\begin{array}{c}\text { Calculated } \\
\text { Density } \\
\text { (Excel) }\end{array}$ & Diff. \\
\hline \multirow{19}{*}{ FUEL1 } & AL7A_0 & 4.9312E-02 & 4.9312E-02 & $0.0000 \mathrm{E}+00$ \\
\hline & AM1A_0 & $3.9534 \mathrm{E}-17$ & $3.9534 \mathrm{E}-17$ & $0.0000 \mathrm{E}+00$ \\
\hline & I35A_0 & $3.9534 \mathrm{E}-17$ & $3.9534 \mathrm{E}-17$ & $0.0000 \mathrm{E}+00$ \\
\hline & LFPA_0 & $3.9534 \mathrm{E}-17$ & $3.9534 \mathrm{E}-17$ & $0.0000 \mathrm{E}+00$ \\
\hline & NP7A_0 & $3.9534 \mathrm{E}-17$ & $3.9534 \mathrm{E}-17$ & $0.0000 \mathrm{E}+00$ \\
\hline & 016A_0 & $3.9534 \mathrm{E}-17$ & $3.9534 \mathrm{E}-17$ & $0.0000 \mathrm{E}+00$ \\
\hline & PM9A_0 & $3.9534 \mathrm{E}-17$ & $3.9534 \mathrm{E}-17$ & $0.0000 \mathrm{E}+00$ \\
\hline & PU0A_0 & $3.9534 \mathrm{E}-17$ & $3.9534 \mathrm{E}-17$ & $0.0000 \mathrm{E}+00$ \\
\hline & PU1A_0 & $3.9534 \mathrm{E}-17$ & $3.9534 \mathrm{E}-17$ & $0.0000 \mathrm{E}+00$ \\
\hline & PU2A_0 & $3.9534 \mathrm{E}-17$ & $3.9534 \mathrm{E}-17$ & $0.0000 \mathrm{E}+00$ \\
\hline & PU8A_0 & $3.9534 \mathrm{E}-17$ & $3.9534 \mathrm{E}-17$ & $0.0000 \mathrm{E}+00$ \\
\hline & PU9A_0 & $3.9534 \mathrm{E}-17$ & $3.9534 \mathrm{E}-17$ & $0.0000 \mathrm{E}+00$ \\
\hline & SInA_0 & $2.9745 \mathrm{E}-03$ & $2.9745 \mathrm{E}-03$ & $0.0000 \mathrm{E}+00$ \\
\hline & SM9A_0 & $3.9534 \mathrm{E}-17$ & $3.9534 \mathrm{E}-17$ & $0.0000 \mathrm{E}+00$ \\
\hline & U34A_0 & $3.9534 \mathrm{E}-17$ & $3.9534 \mathrm{E}-17$ & $0.0000 \mathrm{E}+00$ \\
\hline & U35A_0 & 8.9023E-04 & 8.9023E-04 & $0.0000 \mathrm{E}+00$ \\
\hline & U36A_0 & $3.9534 \mathrm{E}-17$ & $3.9534 \mathrm{E}-17$ & $0.0000 \mathrm{E}+00$ \\
\hline & U38A_0 & $3.5715 \mathrm{E}-03$ & $3.5715 \mathrm{E}-03$ & $0.0000 \mathrm{E}+00$ \\
\hline & XE5A_0 & $3.9534 \mathrm{E}-17$ & $3.9534 \mathrm{E}-17$ & $0.0000 \mathrm{E}+00$ \\
\hline \multirow{2}{*}{ WCHNL } & H01B_0 & 6.6691E-02 & 6.6691E-02 & $0.0000 \mathrm{E}+00$ \\
\hline & 016B_0 & $3.3346 \mathrm{E}-02$ & $3.3346 \mathrm{E}-02$ & $0.0000 \mathrm{E}+00$ \\
\hline CR_AL & AL7D_0 & $6.0263 \mathrm{E}-02$ & $6.0263 \mathrm{E}-02$ & $0.0000 \mathrm{E}+00$ \\
\hline GRAPH & C12R_0 & 8.7240E-02 & 8.7240E-02 & $0.0000 \mathrm{E}+00$ \\
\hline \multirow{3}{*}{ MIXXB } & AL7B_0 & 4.4926E-02 & 4.4926E-02 & $0.0000 \mathrm{E}+00$ \\
\hline & H01B_0 & $1.6973 \mathrm{E}-02$ & $1.6973 \mathrm{E}-02$ & $0.0000 \mathrm{E}+00$ \\
\hline & 016B_0 & 8.4866E-03 & 8.4866E-03 & $0.0000 \mathrm{E}+00$ \\
\hline
\end{tabular}

In order to check whether the cross section data are referenced properly, the macroscopic cross sections of each composition must be compared. REBUS-PC can provide these details by turning on the fourth edit flag of the type 02 card of the dataset A.HMG4C. The homogenized cross sections were independently calculated using the MATLAB program [12] and the methodology for HMG4C described in the manual. For the STRZ benchmark, this produces a considerable amount of data. Consequently, only the comparison of the principal cross sections for one zone is shown in Table 3-14. As can be seen, there are minor differences observed between REBUS-PC and the Matlab calculation which are attributable to round off error in the computations of REBUS-PC.

To understand this, in REBUS-PC, the nuclide densities and macroscopic cross sections of each composition is stored in double precision (15 decimal place) containers, while the microscopic cross section data is stored in single precision (7 decimal place) containers. When carrying out floating point math, the resulting cross section data will at most have $\sim$ seven significant digit accuracy, and thus differences on the order of 10-7 are expected, as can be seen in Table 3-14. 
Table 3-14. Macroscopic Principal Cross Sections of FUEL1 from Verification Test \# 12

\begin{tabular}{|c|c|c|c|c|c|c|c|c|c|}
\hline & g & Total & Absorption & Removal & Transport & Fission & Nu*Fission & Chi & $(n, 2 n)$ \\
\hline \multirow{7}{*}{ 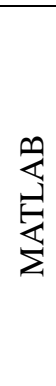 } & 1 & $3.098605 \mathrm{E}-03$ & 1.872179E-01 & $2.165476 \mathrm{E}-02$ & 1.172630E-01 & $2.509003 \mathrm{E}-03$ & $6.908351 \mathrm{E}-03$ & 7.654490E-01 & 7.404899E-05 \\
\hline & 2 & $2.938379 \mathrm{E}-03$ & 2.673692E-01 & $4.589980 \mathrm{E}-03$ & $1.903871 \mathrm{E}-01$ & $1.472945 \mathrm{E}-03$ & $3.605147 \mathrm{E}-03$ & $2.343930 \mathrm{E}-01$ & $0.000000 \mathrm{E}+00$ \\
\hline & 3 & $5.941304 \mathrm{E}-02$ & $2.229130 \mathrm{E}-01$ & $6.007291 \mathrm{E}-02$ & $2.118749 \mathrm{E}-01$ & $1.961405 \mathrm{E}-02$ & $4.773671 \mathrm{E}-02$ & $1.602830 \mathrm{E}-04$ & $0.000000 \mathrm{E}+00$ \\
\hline & 4 & 4.449686E-02 & 1.600869E-01 & 4.831203E-02 & 1.578015E-01 & 3.243417E-02 & 7.900412E-02 & $0.000000 \mathrm{E}+00$ & $0.000000 \mathrm{E}+00$ \\
\hline & 5 & $1.384206 \mathrm{E}-01$ & $2.552850 \mathrm{E}-01$ & 1.472695E-01 & $2.529815 \mathrm{E}-01$ & 1.117377E-01 & $2.722712 \mathrm{E}-01$ & $0.000000 \mathrm{E}+00$ & $0.000000 \mathrm{E}+00$ \\
\hline & 6 & 2.651013E-01 & 3.814249E-01 & 2.738767E-01 & 3.791968E-01 & $2.170818 \mathrm{E}-01$ & 5.289632E-01 & $0.000000 \mathrm{E}+00$ & $0.000000 \mathrm{E}+00$ \\
\hline & 7 & $5.760650 \mathrm{E}-01$ & 6.903819E-01 & 5.840869E-01 & 6.880675E-01 & 4.749618E-01 & $1.157339 \mathrm{E}+00$ & $0.000000 \mathrm{E}+00$ & $0.000000 \mathrm{E}+00$ \\
\hline
\end{tabular}

\begin{tabular}{|c|c|c|c|c|c|c|c|c|c|}
\hline \multirow{7}{*}{ 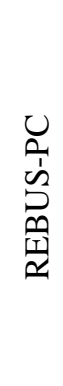 } & 1 & $3.098604 \mathrm{E}-03$ & 1.872179E-01 & $2.165476 \mathrm{E}-02$ & $1.172630 \mathrm{E}-01$ & 2.509003E-03 & $6.908351 \mathrm{E}-03$ & $7.654490 \mathrm{E}-01$ & 7.404899E-05 \\
\hline & 2 & $2.938378 \mathrm{E}-03$ & 2.673692E-01 & 4.589979E-03 & $1.903871 \mathrm{E}-01$ & $1.472944 \mathrm{E}-03$ & 3.605147E-03 & 2.343930E-01 & $0.000000 \mathrm{E}+00$ \\
\hline & 3 & $5.941304 \mathrm{E}-02$ & $2.229130 \mathrm{E}-01$ & $6.007290 \mathrm{E}-02$ & $2.118749 \mathrm{E}-01$ & $1.961405 \mathrm{E}-02$ & $4.773671 \mathrm{E}-02$ & $1.602830 \mathrm{E}-04$ & $0.000000 \mathrm{E}+00$ \\
\hline & 4 & 4.449686E-02 & $1.600869 \mathrm{E}-01$ & 4.831203E-02 & $1.578014 \mathrm{E}-01$ & $3.243417 \mathrm{E}-02$ & $7.900412 \mathrm{E}-02$ & $0.000000 \mathrm{E}+00$ & $0.000000 \mathrm{E}+00$ \\
\hline & 5 & $1.384205 \mathrm{E}-01$ & $2.552850 \mathrm{E}-01$ & $1.472694 \mathrm{E}-01$ & $2.529815 \mathrm{E}-01$ & $1.117377 \mathrm{E}-01$ & $2.722712 \mathrm{E}-01$ & $0.000000 \mathrm{E}+00$ & $0.000000 \mathrm{E}+00$ \\
\hline & 6 & 2.651013E-01 & 3.814249E-01 & $2.738767 \mathrm{E}-01$ & 3.791968E-01 & $2.170818 \mathrm{E}-01$ & 5.289632E-01 & $0.000000 \mathrm{E}+00$ & $0.000000 \mathrm{E}+00$ \\
\hline & 7 & $5.760650 \mathrm{E}-01$ & $6.903818 \mathrm{E}-01$ & $5.840868 \mathrm{E}-01$ & 6.880675E-01 & 4.749617E-01 & $1.157339 \mathrm{E}+00$ & $0.000000 \mathrm{E}+00$ & $0.000000 \mathrm{E}+00$ \\
\hline
\end{tabular}

\begin{tabular}{|c|c|c|c|c|c|c|c|c|c|}
\hline \multirow{7}{*}{ 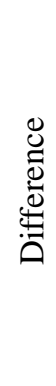 } & 1 & $3.23 \mathrm{E}-07$ & $0.00 \mathrm{E}+00$ & $0.00 \mathrm{E}+00$ & $0.00 \mathrm{E}+00$ & $0.00 \mathrm{E}+00$ & $0.00 \mathrm{E}+00$ & $0.00 \mathrm{E}+00$ & $0.00 \mathrm{E}+00$ \\
\hline & 2 & $3.40 \mathrm{E}-07$ & $0.00 \mathrm{E}+00$ & $2.18 \mathrm{E}-07$ & $0.00 \mathrm{E}+00$ & $6.79 \mathrm{E}-07$ & $0.00 \mathrm{E}+00$ & $0.00 \mathrm{E}+00$ & $0.00 \mathrm{E}+00$ \\
\hline & 3 & $0.00 \mathrm{E}+00$ & $0.00 \mathrm{E}+00$ & $1.66 \mathrm{E}-07$ & $0.00 \mathrm{E}+00$ & $0.00 \mathrm{E}+00$ & $0.00 \mathrm{E}+00$ & $0.00 \mathrm{E}+00$ & $0.00 \mathrm{E}+00$ \\
\hline & 4 & $0.00 \mathrm{E}+00$ & $0.00 \mathrm{E}+00$ & $0.00 \mathrm{E}+00$ & $6.34 \mathrm{E}-07$ & $0.00 \mathrm{E}+00$ & $0.00 \mathrm{E}+00$ & $0.00 \mathrm{E}+00$ & $0.00 \mathrm{E}+00$ \\
\hline & 5 & $7.22 \mathrm{E}-07$ & $0.00 \mathrm{E}+00$ & $6.79 \mathrm{E}-07$ & $0.00 \mathrm{E}+00$ & $0.00 \mathrm{E}+00$ & $0.00 \mathrm{E}+00$ & $0.00 \mathrm{E}+00$ & $0.00 \mathrm{E}+00$ \\
\hline & 6 & $0.00 \mathrm{E}+00$ & $0.00 \mathrm{E}+00$ & $0.00 \mathrm{E}+00$ & $0.00 \mathrm{E}+00$ & $0.00 \mathrm{E}+00$ & $0.00 \mathrm{E}+00$ & $0.00 \mathrm{E}+00$ & $0.00 \mathrm{E}+00$ \\
\hline & 7 & $0.00 \mathrm{E}+00$ & $1.45 \mathrm{E}-07$ & $1.71 \mathrm{E}-07$ & $0.00 \mathrm{E}+00$ & $2.11 \mathrm{E}-07$ & $0.00 \mathrm{E}+00$ & $0.00 \mathrm{E}+00$ & $0.00 \mathrm{E}+00$ \\
\hline
\end{tabular}


To check whether the compositions were assigned to the correct spatial regions, i.e. card type 15 of A.NIP3, the assignment map of regions to composition zones was examined. The zone assignment output from REBUS-PC is tabulated in Table 3-15.

Table 3-15. REBUS-PC Zone Assignment to Region

\begin{tabular}{|c|c|c|c|c|c|c|c|}
\hline $\begin{array}{c}\text { Region } \\
\text { No. }\end{array}$ & $\begin{array}{c}\text { Region } \\
\text { Name }\end{array}$ & $\begin{array}{c}\text { Zone } \\
\text { No. }\end{array}$ & Zone Name & $\begin{array}{l}\text { Region } \\
\text { No. }\end{array}$ & $\begin{array}{l}\text { Region } \\
\text { Name }\end{array}$ & $\begin{array}{c}\text { Zone } \\
\text { No. }\end{array}$ & Zone Name \\
\hline 1 & UPSTR & 10 & ALBOX & 131 & FL12F & 2 & FUEL2 \\
\hline 2 & WPOOL & 9 & $\mathrm{H} 2 \mathrm{O}$ & 132 & FL12G & 2 & FUEL2 \\
\hline 3 & FTRAP & 8 & FTH2O & 133 & FL13E & 3 & FUEL3 \\
\hline 4 & STWLI & 3 & MIXXB & 134 & FL13F & 3 & FUEL3 \\
\hline 5 & STWLO & 5 & MIXXD & 135 & FL13G & 3 & FUEL3 \\
\hline 6 & REFLT & 7 & GRAPH & 136 & FL14E & 4 & FUEL4 \\
\hline 7 & CL11E & 2 & WCHNL & 137 & FL14F & 4 & FUEL4 \\
\hline 8 & CL11F & 2 & WCHNL & 138 & FL14G & 4 & FUEL4 \\
\hline 9 & CL11G & 2 & WCHNL & 223 & BLDW1 & 10 & CRH2O \\
\hline 10 & CL12E & 2 & WCHNL & 224 & FOLL1 & 8 & MIXXD \\
\hline 11 & CL12F & 2 & WCHNL & 225 & BLAD1 & 7 & FUELC \\
\hline 12 & CL12G & 2 & WCHNL & 226 & HADL1 & 9 & CR_AL \\
\hline 13 & CL13E & 2 & WCHNL & 227 & BLDW2 & 10 & CRH2O \\
\hline 14 & CL13F & 2 & WCHNL & 228 & FOLL2 & 8 & MIXXD \\
\hline 15 & CL13G & 2 & WCHNL & 229 & BLAD2 & 7 & FUELC \\
\hline 16 & CL14E & 2 & WCHNL & 230 & HADL2 & 9 & CR_AL \\
\hline 17 & CL14F & 2 & WCHNL & 231 & BLDW3 & 10 & CRH2O \\
\hline 18 & CL14G & 2 & WCHNL & 232 & FOLL3 & 8 & MIXXD \\
\hline 19 & CL15E & 2 & WCHNL & 233 & BLAD3 & 7 & FUELC \\
\hline 20 & CL15F & 2 & WCHNL & 234 & HADL3 & 9 & CR_AL \\
\hline 21 & CL15G & 2 & WCHNL & 235 & BLDW4 & 10 & CRH2O \\
\hline 127 & FL11E & 1 & FUEL1 & 236 & FOLL4 & 8 & MIXXD \\
\hline 128 & FL11F & 1 & FUEL1 & 237 & BLAD4 & 7 & FUELC \\
\hline 129 & FL11G & 1 & FUEL1 & 238 & HADL4 & 9 & CR_AL \\
\hline 130 & FL12E & 2 & FUEL2 & & & & \\
\hline
\end{tabular}

Due to the rotational symmetry of the STRZ model, only the fuel plate and water channel regions located in the first quadrant are shown. The reader should consult the input for verification test \#12, an excerpt of which is provided in Figure 3-27, which shows that REBUS-PC zone to region information is fully consistent with the input.

Because verification test \#13 is the free format input of verification test \#12 (which used the fixed format of A.NIP3), and test \#14 is effectively the same, the same comparisons as performed above result in no observable differences in the output. However, a detailed comparison of the output shows that verification test \#13 and verification test \#12 do differ on a few lines of the output. Of particular issue is the dominance ratio number, which is printed to 13 significant digits in the output and shows a difference in the $10^{\text {th }}$ significant digit between the two tests. The different input processing performed by REBUS-PC for free format input versus fixed format leads to these slight differences in the floating point math. This magnitude of difference is not unusual for REBUS-PC. 


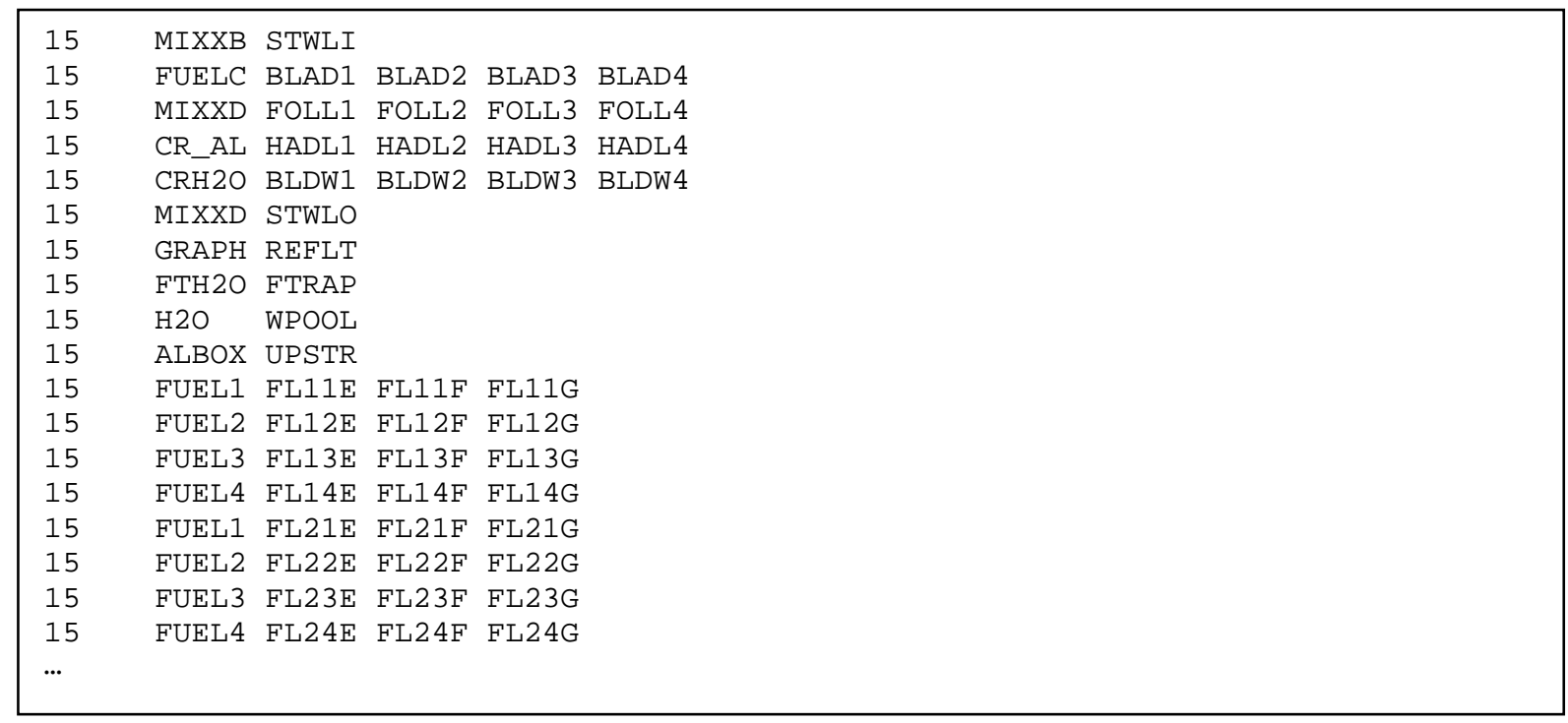

Figure 3-27. Zone to Region Assignment Input Excerpt for Verification Test \#12

Capability 7 is focused on verifying the accuracy of the power edits for regions and areas. The processing of the A.NIP3 type 07 cards is first checked for area specifications against the REBUS-PC output, as illustrated in Figure 3-28. Given the previous verification of the region and area volumes, this check serves as a duplicative verification that REBUS-PC is processing the type 07 input correctly.

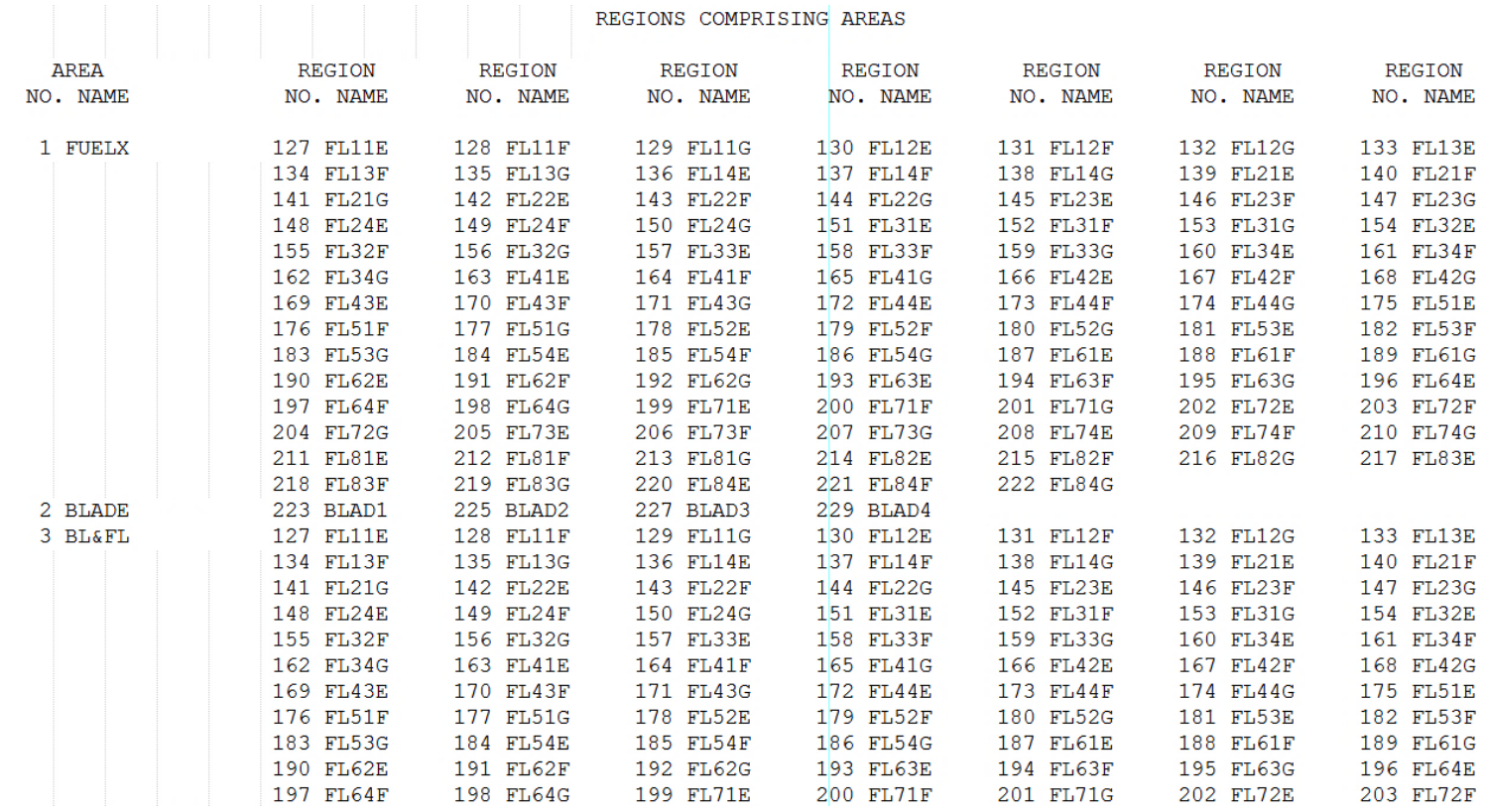

Figure 3-28. Excerpt of the Region to Area Assignment Edit for Verification Test \#12

To check the power edits in the REBUS-PC output the region flux results provided by REBUS-PC and the power conversion factors printed in the macroscopic cross section edits are combined in Excel. Table 3-16 compares the region power edits in the REBUS-PC output with the values calculated using Excel. For brevity, only a small sample of regions is included, noting that all of the regions had similar accuracy. As can be seen, errors only appear in the sixth significant digit, as highlighted. These differences are traceable to round-off errors in the printed tables of region flux and power conversion factors. 
Table 3-16. Region Power Comparison for Verification Test \#12

\begin{tabular}{|l|l|l|l|l|l|}
\hline \multirow{2}{*}{$\begin{array}{l}\text { Region } \\
\text { No. }\end{array}$} & \multirow{2}{*}{$\begin{array}{l}\text { Region } \\
\text { Name }\end{array}$} & Data from REBUS-PC Output & Excel \\
\cline { 3 - 6 } & & Volume (cc) & $\begin{array}{l}\text { Power Density } \\
(\mathrm{W} / \mathrm{cc})\end{array}$ & $\begin{array}{l}\text { Region Power } \\
(\mathrm{W})\end{array}$ & $\begin{array}{l}\text { Region Power } \\
(\mathrm{W})\end{array}$ \\
\hline 1 & UPSTR & $3.64817 \mathrm{E}+04$ & $5.64615 \mathrm{E}-01$ & $2.05981 \mathrm{E}+04$ & $2.05981 \mathrm{E}+04$ \\
\hline 2 & WPOOL & $5.57556 \mathrm{E}+05$ & $8.43067 \mathrm{E}-02$ & $4.70057 \mathrm{E}+04$ & $4.70057 \mathrm{E}+04$ \\
\hline 3 & FTRAP & $1.50000 \mathrm{E}+03$ & $2.86018 \mathrm{E}+00$ & $4.29025 \mathrm{E}+03$ & $4.29025 \mathrm{E}+03$ \\
\hline 4 & STWLI & $2.76799 \mathrm{E}+03$ & $3.37740 \mathrm{E}+00$ & $9.34862 \mathrm{E}+03$ & $9.34862 \mathrm{E}+03$ \\
\hline 5 & STWLO & $1.12490 \mathrm{E}+04$ & $1.37837 \mathrm{E}+00$ & $1.55053 \mathrm{E}+04$ & $1.55053 \mathrm{E}+04$ \\
\hline 6 & REFLT & $2.24530 \mathrm{E}+04$ & $2.05102 \mathrm{E}-02$ & $4.60515 \mathrm{E}+02$ & $4.60516 \mathrm{E}+02$ \\
\hline 7 & CL11E & $1.03035 \mathrm{E}+02$ & $1.54423 \mathrm{E}+00$ & $1.59110 \mathrm{E}+02$ & $1.59110 \mathrm{E}+02$ \\
\hline 8 & CL11F & $1.03035 \mathrm{E}+02$ & $1.29457 \mathrm{E}+00$ & $1.33386 \mathrm{E}+02$ & $1.33386 \mathrm{E}+02$ \\
\hline 9 & CL11G & $1.03035 \mathrm{E}+02$ & $8.86429 \mathrm{E}-01$ & $9.13335 \mathrm{E}+01$ & $9.13334 \mathrm{E}+01$ \\
\hline 127 & FL11E & $8.99703 \mathrm{E}+01$ & $9.58439 \mathrm{E}+02$ & $8.62311 \mathrm{E}+04$ & $8.62311 \mathrm{E}+04$ \\
\hline 128 & FL11F & $8.99703 \mathrm{E}+01$ & $8.02991 \mathrm{E}+02$ & $7.22454 \mathrm{E}+04$ & $7.22454 \mathrm{E}+04$ \\
\hline 129 & FL11G & $8.99703 \mathrm{E}+01$ & $5.58569 \mathrm{E}+02$ & $5.02546 \mathrm{E}+04$ & $5.02547 \mathrm{E}+04$ \\
\hline 223 & BLAD1 & $1.40565 \mathrm{E}+03$ & $3.67625 \mathrm{E}+02$ & $5.16754 \mathrm{E}+05$ & $5.16753 \mathrm{E}+05$ \\
\hline 224 & HADL1 & $7.02826 \mathrm{E}+02$ & $6.74158 \mathrm{E}-01$ & $4.73816 \mathrm{E}+02$ & $4.73815 \mathrm{E}+02$ \\
\hline
\end{tabular}

With the region power edits verified, it is a simple task to check the area edits. Table 3-17 shows the area powers extracted from the REBUS-PC output and the values calculated using Excel. Unlike the previous region power values, the area power values at three different time nodes were computed to further confirm the accuracy. As can be seen, the results are identical, thereby confirming the accuracy of the region and area power edits.

For completeness, the auxiliary table of burnup and power data produced by REBUS-PC in another output section is also checked. Table 3-18 provides the region power and burnup edits from REBUSPC against those calculated using Excel. The burnup value was checked by using the initial mass of fissionable isotopes and the average daily fission power produced in each region as edited by REBUSPC. From Table 3-18, one can see that the reported burnup edit and the Excel calculated values are consistent. The minor differences in the burnup values are again attributable to the limited precision of the edited values in the REBUS-PC output.

Table 3-17. Area Power Results for Verification Test \#12

\begin{tabular}{|c|c|c|c|c|}
\hline \multirow{2}{*}{$\begin{array}{c}\text { Time } \\
\text { Node }\end{array}$} & \multirow{2}{*}{ Data Source } & \multicolumn{3}{|c|}{ Area Powers (Watts) } \\
\cline { 3 - 5 } & & FUELX & BLADE & BL\&FL \\
\hline \multirow{2}{*}{0} & Output Edit & $7.81777 \mathrm{E}+06$ & $2.06701 \mathrm{E}+06$ & $9.88478 \mathrm{E}+06$ \\
\cline { 2 - 5 } & Excel & $7.81777 \mathrm{E}+06$ & $2.06701 \mathrm{E}+06$ & $9.88478 \mathrm{E}+06$ \\
\hline \multirow{2}{*}{1} & Output Edit & $7.80138 \mathrm{E}+06$ & $2.07915 \mathrm{E}+06$ & $9.88053 \mathrm{E}+06$ \\
\cline { 2 - 5 } & Excel & $7.80138 \mathrm{E}+06$ & $2.07915 \mathrm{E}+06$ & $9.88053 \mathrm{E}+06$ \\
\hline \multirow{2}{*}{10} & Output Edit & $7.84945 \mathrm{E}+06$ & $2.02598 \mathrm{E}+06$ & $9.87543 \mathrm{E}+06$ \\
\cline { 2 - 5 } & Excel & $7.84945 \mathrm{E}+06$ & $2.02598 \mathrm{E}+06$ & $9.87543 \mathrm{E}+06$ \\
\hline
\end{tabular}


Table 3-18. Region FL11E Power and Burnup Edit Comparison for Verification Test \#12

\begin{tabular}{|c|c|c|c|c|}
\hline \multirow[b]{2}{*}{$\begin{array}{l}\text { Time } \\
\text { (Days) }\end{array}$} & \multirow{2}{*}{$\begin{array}{c}\text { Initial Mass of } \\
\text { Fissionable } \\
\text { Isotopes } \\
M_{0}(\mathrm{Kg})\end{array}$} & \multirow[b]{2}{*}{$\begin{array}{c}\text { Average Daily } \\
\text { Fission Power } \\
\bar{P}_{f i s}(\mathrm{MW})\end{array}$} & REBUS-PC & Excel \\
\hline & & & $\begin{array}{l}\text { Ave. Burnup } \\
\text { from Output } \\
\text { (MWD/MT) }\end{array}$ & $\begin{array}{c}\bar{P}_{\text {fiss }} \cdot \Delta T / M_{0} \\
(\mathrm{MWD} / \mathrm{MT}) \\
(\Delta T \text { - time interval) }\end{array}$ \\
\hline 0.0 & 1.58281E-01 & $0.00000 \mathrm{E}+00$ & $0.00000 \mathrm{E}+00$ & $0.00000 \mathrm{E}+00$ \\
\hline 3.0 & 1.58281E-01 & 8.48812E-02 & $1.60880 \mathrm{E}+03$ & $1.60881 \mathrm{E}+03$ \\
\hline 6.0 & 1.58281E-01 & 8.43977E-02 & $1.59964 \mathrm{E}+03$ & $1.59964 \mathrm{E}+03$ \\
\hline 9.0 & 1.58281E-01 & 8.42382E-02 & $1.59662 \mathrm{E}+03$ & $1.59662 \mathrm{E}+03$ \\
\hline 12.0 & 1.58281E-01 & 8.41106E-02 & $1.59420 \mathrm{E}+03$ & $1.59420 \mathrm{E}+03$ \\
\hline 15.0 & 1.58281E-01 & 8.39909E-02 & $1.59193 \mathrm{E}+03$ & $1.59193 \mathrm{E}+03$ \\
\hline 18.0 & $1.58281 \mathrm{E}-01$ & 8.38676E-02 & $1.58959 \mathrm{E}+03$ & $1.58960 \mathrm{E}+03$ \\
\hline 21.0 & 1.58281E-01 & 8.37375E-02 & $1.58713 \mathrm{E}+03$ & $1.58713 \mathrm{E}+03$ \\
\hline 24.0 & 1.58281E-01 & 8.36007E-02 & $1.58453 \mathrm{E}+03$ & $1.58454 \mathrm{E}+03$ \\
\hline 27.0 & $1.58281 \mathrm{E}-01$ & 8.34584E-02 & $1.58184 \mathrm{E}+03$ & $1.58184 \mathrm{E}+03$ \\
\hline 30.0 & 1.58281E-01 & 8.33115E-02 & $1.57905 E+03$ & $1.57906 \mathrm{E}+03$ \\
\hline
\end{tabular}

Table 3-19 compares the instantaneous powers reported by REBUS-PC in the depletion section with the region powers edited in the flux solver module for region FL11E. It should be no surprise that the power results are consistent, indicating that the data is properly transferred from one section of the code to another.

Table 3-19. Region FL11E Instantaneous Power Comparison for Verification Test \#12

\begin{tabular}{|c|c|c|}
\hline $\begin{array}{c}\text { Time } \\
\text { (Days) }\end{array}$ & $\begin{array}{c}\text { Region Instantaneous } \\
\text { Power (MW) }\end{array}$ & $\begin{array}{c}\text { Region Power Edited } \\
\text { by DIF3D (MW) }\end{array}$ \\
\hline 0.0 & $8.62311 \mathrm{E}-02$ & $8.62311 \mathrm{E}-02$ \\
\hline 3.0 & $8.56637 \mathrm{E}-02$ & $8.56637 \mathrm{E}-02$ \\
\hline 6.0 & $8.54954 \mathrm{E}-02$ & $8.54954 \mathrm{E}-02$ \\
\hline 9.0 & $8.53690 \mathrm{E}-02$ & $8.53690 \mathrm{E}-02$ \\
\hline 12.0 & $8.52547 \mathrm{E}-02$ & $8.52547 \mathrm{E}-02$ \\
\hline 15.0 & $8.51379 \mathrm{E}-02$ & $8.51379 \mathrm{E}-02$ \\
\hline 18.0 & $8.50136 \mathrm{E}-02$ & $8.50136 \mathrm{E}-02$ \\
\hline 21.0 & $8.48819 \mathrm{E}-02$ & $8.48819 \mathrm{E}-02$ \\
\hline 24.0 & $8.47439 \mathrm{E}-02$ & $8.47439 \mathrm{E}-02$ \\
\hline 27.0 & $8.46008 \mathrm{E}-02$ & $8.46008 \mathrm{E}-02$ \\
\hline 30.0 & $8.44537 \mathrm{E}-02$ & $8.44537 \mathrm{E}-02$ \\
\hline
\end{tabular}

The final capability to demonstrate with verification test \#12 is the accuracy of the TYPE13.BCD files. The TYPE13.BCD file provide the zone atom density definitions and assignments to each region at each time node. Given that REBUS-PC only follows the fuel up to its discharge from the system, this capability is primarily used in complex shuffling schemes that are too difficult for REBUS-PC to handle directly. In these cases, the user intervenes and does intermediate decay and shuffling between different REBUS-PC loadings. Fundamentally, the output file provides users a means to construct a new, equivalent REBUS-PC input at each time point of a depletion cycle. The TYPE13.BCD file is 
intentionally formatted for use in the A.NIP3 section of the REBUS-PC input. To verify the data in TYPE13.BCD is consistent with the REBUS-PC results is relatively easy, as REBUS-PC prints the same atom density information at the beginning of each time point. The comparison of the output shows that the TYPE13.BCD output is fully consistent with the REBUS-PC reported atom densities at each time point.

To verify its intended use, the TYPE13.BCD data was used to create a new REBUS-PC input file. If setup correctly, the resulting REBUS-PC calculation should identically reproduce the solution for the remainder of the depletion calculation of the originating REBUS-PC input. This modified input requires the material composition data (type 13,14 and 15 cards of A.NIP3) to be replaced with those provided in TYPE13.BCD, in addition to modifications to the fuel management input card (type 35 card of A.BURN), such that it matches the original depletion steps from the chosen time node. Table 3-20 compares the k-effective results obtained from the original REBUS-PC calculation with that of the reconstructed input. Similarly, Table 3-21 compares the region-wise power of selected regions at the zeroth and fifth time nodes. One can see that the reconstructed input file using the TYPE13.BCD file produces nearly identical k-effective and region power results at each time node to the original input deck. The small errors are traceable to the input precision of the atom density information derived from TYPE13.BCD relative to data values stored internal to REBUS-PC.

Table 3-20. k-effective Results for First Step Reconstruction of Verification Test \#12

\begin{tabular}{|c|c|c|c|}
\hline Time Node & Time (day) & Original & Modified \\
\hline 0 & 0.0 & 1.0974214 & 1.0974215 \\
\hline 1 & 3.0 & 1.0492686 & 1.0492687 \\
\hline 2 & 6.0 & 1.0433497 & 1.0433498 \\
\hline 3 & 9.0 & 1.0383722 & 1.0383723 \\
\hline 4 & 12.0 & 1.0340850 & 1.0340851 \\
\hline 5 & 15.0 & 1.0302067 & 1.0302067 \\
\hline 6 & 18.0 & 1.0265364 & 1.0265365 \\
\hline 7 & 21.0 & 1.0229592 & 1.0229592 \\
\hline 8 & 24.0 & 1.0194142 & 1.0194143 \\
\hline 9 & 27.0 & 1.0158711 & 1.0158712 \\
\hline 10 & 30.0 & 1.0123150 & 1.0123151 \\
\hline
\end{tabular}

An additional REBUS-PC input file was prepared using the material composition data and fuel management specifications from TYPE13.BCD at the seventh time node (21.0 days) of verification test \#12. The k-effective results are compared in Table 3-22 and the region power data in Table 3-23 for each of the time nodes starting from 21.0 days. As was the case with the $0^{\text {th }}$ time point, the keffective and region powers show small errors with regards to the original input results at the same time points. These errors are again attributable to the input precision allowed by using the TYPE13.BCD data relative to the data stored internal to REBUS-PC. 
Table 3-21. Power Results for First Step Reconstruction of Verification Test \#12

\begin{tabular}{|c|c|c|c|c|}
\hline \multirow{2}{*}{$\begin{array}{c}\text { Region } \\
\text { Name }\end{array}$} & \multicolumn{2}{|c|}{ Region Power at BOC } & Region Power after 15-day Irradiation \\
\cline { 2 - 5 } & Original Input & Modified Input & Original Input & Modified Input \\
\hline UPSTR & $2.05981 \mathrm{E}+04$ & $2.05981 \mathrm{E}+04$ & $2.20371 \mathrm{E}+04$ & $2.20371 \mathrm{E}+04$ \\
\hline WPOOL & $4.70057 \mathrm{E}+04$ & $4.70057 \mathrm{E}+04$ & $4.98223 \mathrm{E}+04$ & $4.98223 \mathrm{E}+04$ \\
\hline FTRAP & $4.29025 \mathrm{E}+03$ & $4.29025 \mathrm{E}+03$ & $4.54431 \mathrm{E}+03$ & $4.54431 \mathrm{E}+03$ \\
\hline STWLI & $9.34862 \mathrm{E}+03$ & $9.34863 \mathrm{E}+03$ & $9.87988 \mathrm{E}+03$ & $9.87989 \mathrm{E}+03$ \\
\hline STWLO & $1.55053 \mathrm{E}+04$ & $1.55053 \mathrm{E}+04$ & $1.62998 \mathrm{E}+04$ & $1.62998 \mathrm{E}+04$ \\
\hline REFLT & $4.60515 \mathrm{E}+02$ & $4.60515 \mathrm{E}+02$ & $4.83178 \mathrm{E}+02$ & $4.83177 \mathrm{E}+02$ \\
\hline CL11E & $1.59110 \mathrm{E}+02$ & $1.59110 \mathrm{E}+02$ & $1.66818 \mathrm{E}+02$ & $1.66818 \mathrm{E}+02$ \\
\hline CL11F & $1.33386 \mathrm{E}+02$ & $1.33386 \mathrm{E}+02$ & $1.40456 \mathrm{E}+02$ & $1.40456 \mathrm{E}+02$ \\
\hline CL11G & $9.13335 \mathrm{E}+01$ & $9.13334 \mathrm{E}+01$ & $9.67413 \mathrm{E}+01$ & $9.67413 \mathrm{E}+01$ \\
\hline FL11E & $8.62311 \mathrm{E}+04$ & $8.62311 \mathrm{E}+04$ & $8.51379 \mathrm{E}+04$ & $8.51379 \mathrm{E}+04$ \\
\hline FL11F & $7.22454 \mathrm{E}+04$ & $7.22454 \mathrm{E}+04$ & $7.20151 \mathrm{E}+04$ & $7.20151 \mathrm{E}+04$ \\
\hline FL11G & $5.02546 \mathrm{E}+04$ & $5.02546 \mathrm{E}+04$ & $5.08226 \mathrm{E}+04$ & $5.08225 \mathrm{E}+04$ \\
\hline BLAD1 & $5.16754 \mathrm{E}+05$ & $5.16754 \mathrm{E}+05$ & $5.14444 \mathrm{E}+05$ & $5.14444 \mathrm{E}+05$ \\
\hline HADL1 & $4.73816 \mathrm{E}+02$ & $4.73816 \mathrm{E}+02$ & $5.05679 \mathrm{E}+02$ & $5.05679 \mathrm{E}+02$ \\
\hline
\end{tabular}

Table 3-22. k-effective Results for $7^{\text {th }}$ Step Reconstruction of Verification Test \#12

\begin{tabular}{|c|c|c|c|}
\hline Time Node & Time (day) & Original & Modified \\
\hline 7 & 21.0 & 1.0229592 & 1.0229591 \\
\hline 8 & 24.0 & 1.0194142 & 1.0194141 \\
\hline 9 & 27.0 & 1.0158711 & 1.0158708 \\
\hline 10 & 30.0 & 1.0123150 & 1.0123149 \\
\hline
\end{tabular}

With the preceding results, verification tests \#12 through \#14 demonstrate the following capabilities:

- Capability 1, as it checks that the detailed input is processed correctly by REBUS-PC using all of the input pathways. In particular A.NIP3 card types 06, 07, 09, 13, 14, and 15 were thoroughly checked.

- Capability 2, as color set cross sections were defined and the homogenized cross sections were verified to be accurate within the floating point math being applied.

- Capability 3 is demonstrated, as all three of these verification use spatially dependent cross section data which leads to region dependent depletion behavior. However, the STRZ benchmark does not have a reference solution, and thus additional verification is required which is included later in this report.

- Capability 4 is additionally verified, as the reflected boundary condition is used.

- Capability 7 is demonstrated, as the region and area power integrals were checked using Excel.

- Capability 13 is demonstrated, as the TYPE13.BCD data was matched to the atom density output produced by REBUS-PC at each time point and was used to construct a new input that generated consistent results with the original input deck. 
Table 3-23. Power Results for $7^{\text {th }}$ Step Reconstruction of Verification Test \#12

\begin{tabular}{|l|c|c|c|c|}
\hline \multirow{2}{*}{$\begin{array}{l}\text { Region } \\
\text { Name }\end{array}$} & \multicolumn{2}{|c|}{ Region Power after 21 -day Irradiation } & \multicolumn{2}{c|}{ Region Power after 30-day Irradiation } \\
\cline { 2 - 5 } & Original Input & Modified Input & Original Input & Modified Input \\
\hline UPSTR & $2.22638 \mathrm{E}+04$ & $2.22639 \mathrm{E}+04$ & $2.26169 \mathrm{E}+04$ & $2.26169 \mathrm{E}+04$ \\
\hline WP00L & $5.01660 \mathrm{E}+04$ & $5.01678 \mathrm{E}+04$ & $5.06781 \mathrm{E}+04$ & $5.06781 \mathrm{E}+04$ \\
\hline FTRAP & $4.58244 \mathrm{E}+03$ & $4.58244 \mathrm{E}+03$ & $4.63981 \mathrm{E}+03$ & $4.63981 \mathrm{E}+03$ \\
\hline STWLI & $9.96571 \mathrm{E}+03$ & $9.96573 \mathrm{E}+03$ & $1.00954 \mathrm{E}+04$ & $1.00954 \mathrm{E}+04$ \\
\hline STWLO & $1.64682 \mathrm{E}+04$ & $1.64682 \mathrm{E}+04$ & $1.67239 \mathrm{E}+04$ & $1.67239 \mathrm{E}+04$ \\
\hline REFLT & $4.88776 \mathrm{E}+02$ & $4.88774 \mathrm{E}+02$ & $4.97272 \mathrm{E}+02$ & $4.97272 \mathrm{E}+02$ \\
\hline CL11E & $1.68215 \mathrm{E}+02$ & $1.68215 \mathrm{E}+02$ & $1.70300 \mathrm{E}+02$ & $1.70300 \mathrm{E}+02$ \\
\hline CL11F & $1.41772 \mathrm{E}+02$ & $1.41772 \mathrm{E}+02$ & $1.43775 \mathrm{E}+02$ & $1.43775 \mathrm{E}+02$ \\
\hline CL11G & $9.77740 \mathrm{E}+01$ & $9.77741 \mathrm{E}+01$ & $9.93817 \mathrm{E}+01$ & $9.93817 \mathrm{E}+01$ \\
\hline FL11E & $8.48819 \mathrm{E}+04$ & $8.48820 \mathrm{E}+04$ & $8.44537 \mathrm{E}+04$ & $8.44537 \mathrm{E}+04$ \\
\hline FL11F & $7.20021 \mathrm{E}+04$ & $7.20021 \mathrm{E}+04$ & $7.19723 \mathrm{E}+04$ & $7.19723 \mathrm{E}+04$ \\
\hline FL11G & $5.10221 \mathrm{E}+04$ & $5.10222 \mathrm{E}+04$ & $5.13486 \mathrm{E}+04$ & $5.13486 \mathrm{E}+04$ \\
\hline BLAD1 & $5.11371 \mathrm{E}+05$ & $5.11369 \mathrm{E}+05$ & $5.06496 \mathrm{E}+05$ & $5.06496 \mathrm{E}+05$ \\
\hline HADL1 & $5.10752 \mathrm{E}+02$ & $5.10757 \mathrm{E}+02$ & $5.18612 \mathrm{E}+02$ & $5.18612 \mathrm{E}+02$ \\
\hline
\end{tabular}

\subsection{Verification Test \#15}

Verification test \#15 takes the STRZ geometry as its base input but is focused on satisfying capabilities \#8 and \#9. To do this, a zero (1 watt) power level is chosen along with a short depletion time and control rod movements. Because the previous verification test demonstrates that the flux solution capability of REBUS-PC is working, a new input geometry was constructed for each control rod position by manually inserting the meshes that are required and reassigning the materials, such that the expected (and observed) REBUS-PC input is reproduced at each time point. Using a low power prevents any change in the isotopic content and thereby demonstrates that REBUS-PC is correctly modifying the geometry and computing the correct solution at each time point.

The initial work focused on using two control rod banks, but a fatal error bug in the REBUS-PC software only allowed a single control rod bank to be used. Since the bug was not encountered before, it is obvious that all previous work using control rod movement was carried out using at most one control rod bank. Consequently, this verification test was tailored to have a single control rod bank with the specific inputs shown in Figure 3-29. To understand how this is done, the control rod tip position at each time point is provided, which can be identified by the region name FOLL1 from the input. A simple hump pattern of the control rod position is displayed in Figure 3-30. 


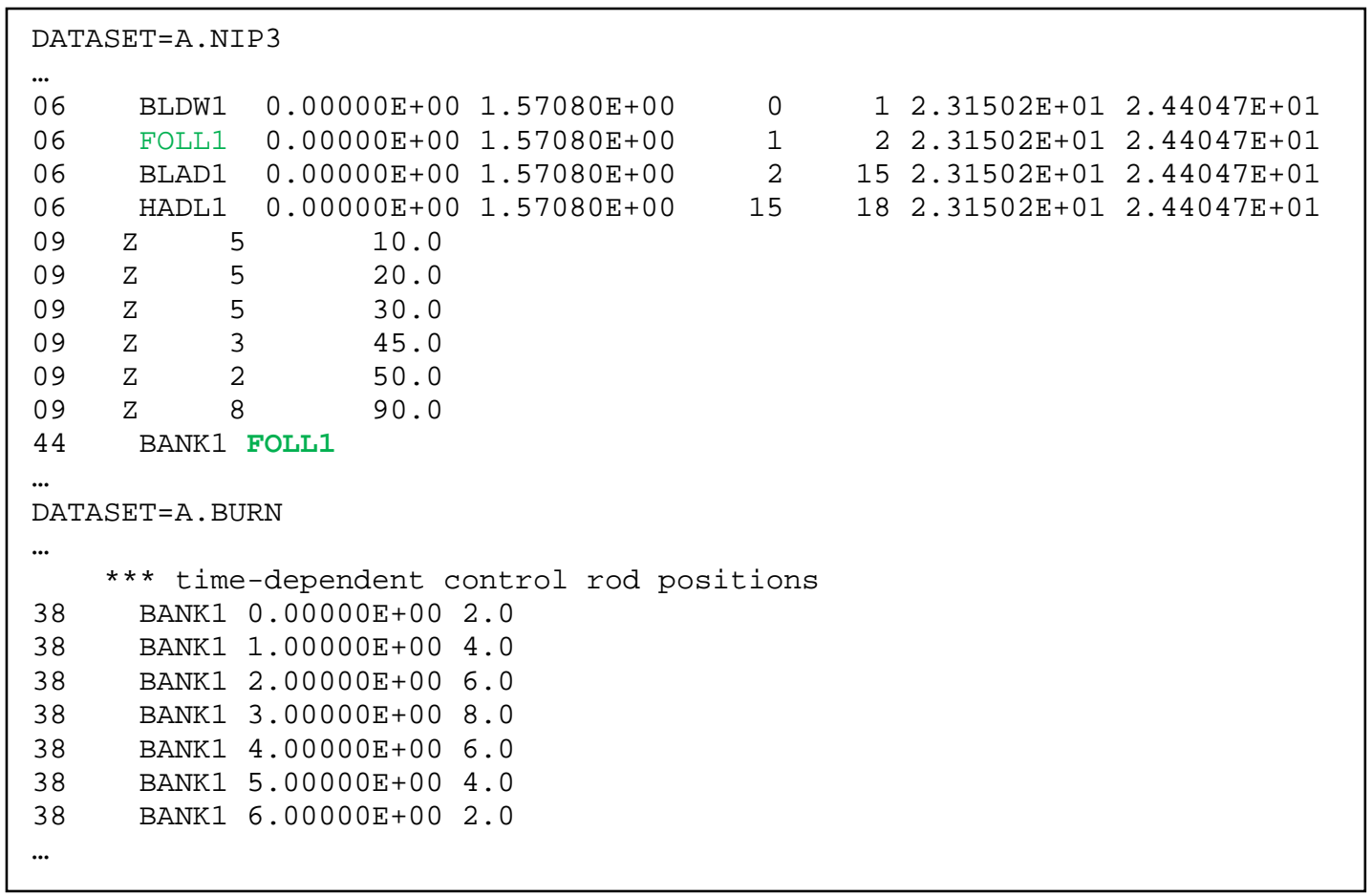

Figure 3-29. Control Rod Input Details for Verification Test \#15

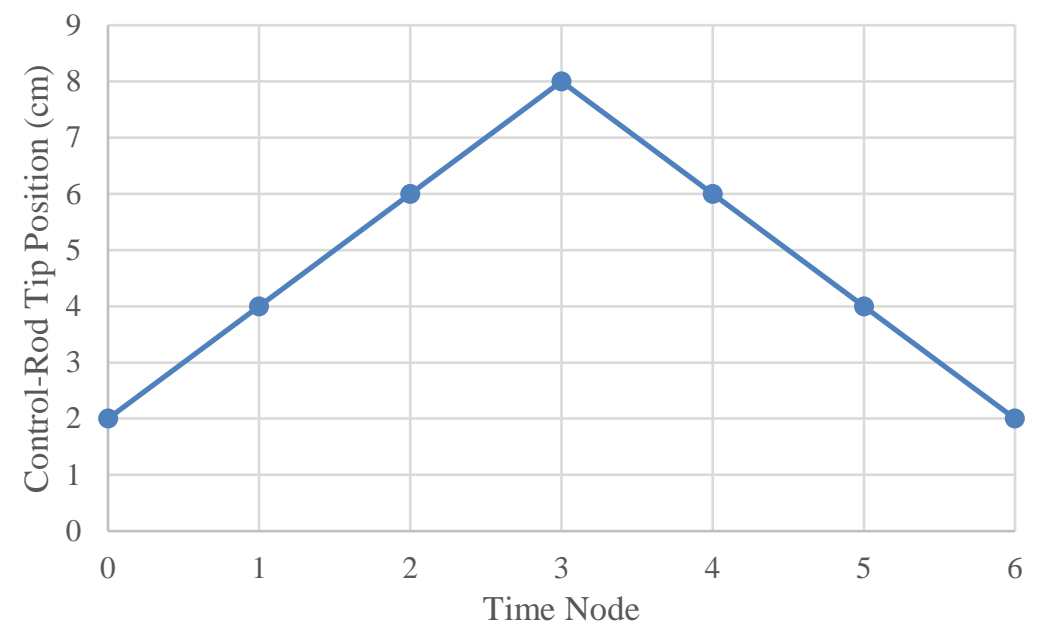

Figure 3-30. Control Rod Tip Position for Verification Test \#15

With regard to checking the output, the isotopic content is first verified to not change by extracting the total reactor loading at each time point. This data is plotted in Figure 3-31 and excerpts from time points 1 and 2 are shown in Figure 3-32. Note that only the U-235 and U-238 content are in the kg range and thus are plotted using the right hand scale, while the remaining isotopes are plotted using the left hand scale. From the output excerpt and compiled results, one can see that the total isotopic change over the 6 day depletion is minimal. 


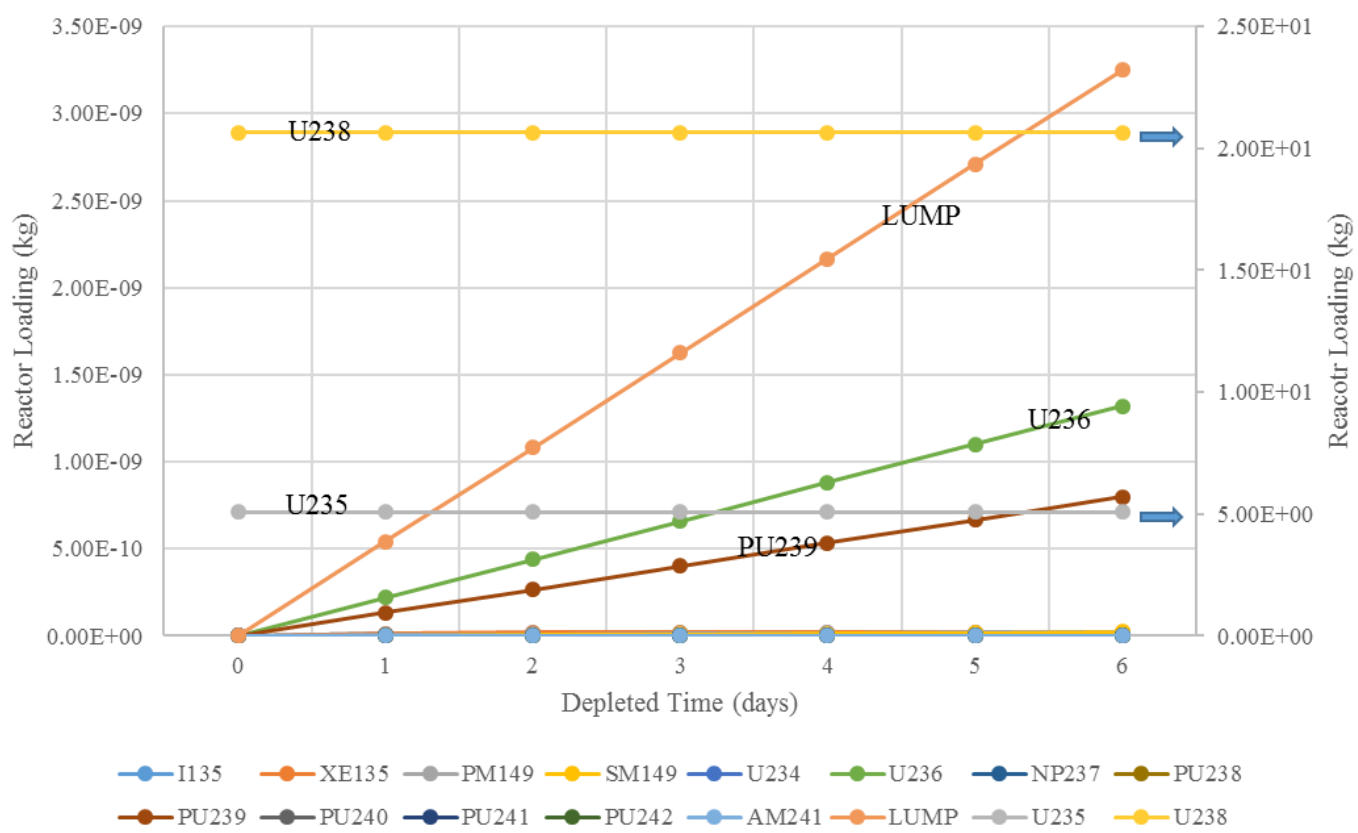

Figure 3-31. Isotope Reactor Loading (kg) for Verification Test \#15

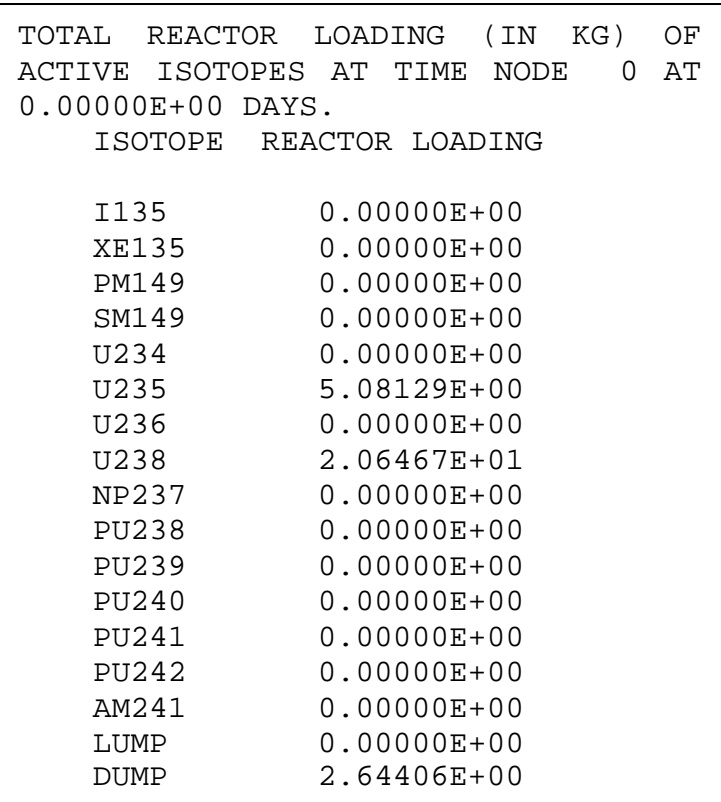

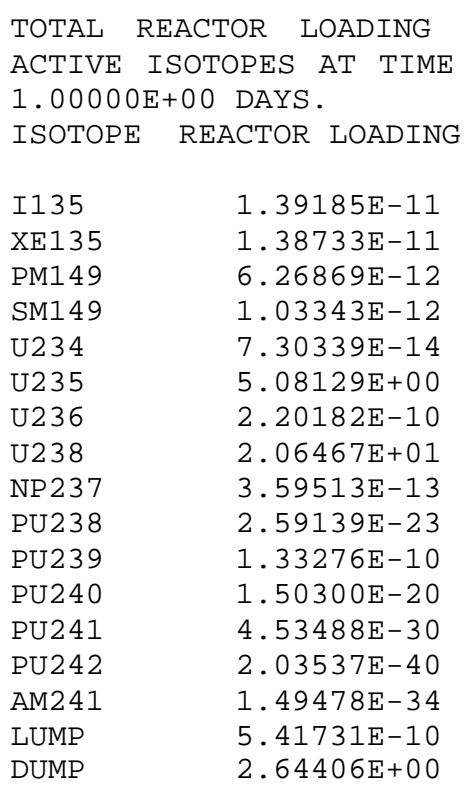

Figure 3-32. Reactor Loading Output Excerpt for Verification Test \#15

The next check is to verify that REBUS-PC correctly moves the control rod tip. From the input excerpt in Figure 3-29, and the tip position shown in Figure 3-30, the initial input specification defines the control rod tip at $2 \mathrm{~cm}$. To verify this in the REBUS-PC input, the same checking mechanism shown earlier is used for verification tests \#12 through \#14, where the region map is checked with the region id list. Figure 3-33 shows the type of output that was used at each time point to identify the axial positions of each region in the control rod. To begin, the assigned region number for the control rod tip was identified at each time point. From there, the same region index was found in the region map output which gives the planes that the region fills. Finally, the axial meshing specifies the physical location of each plane. 


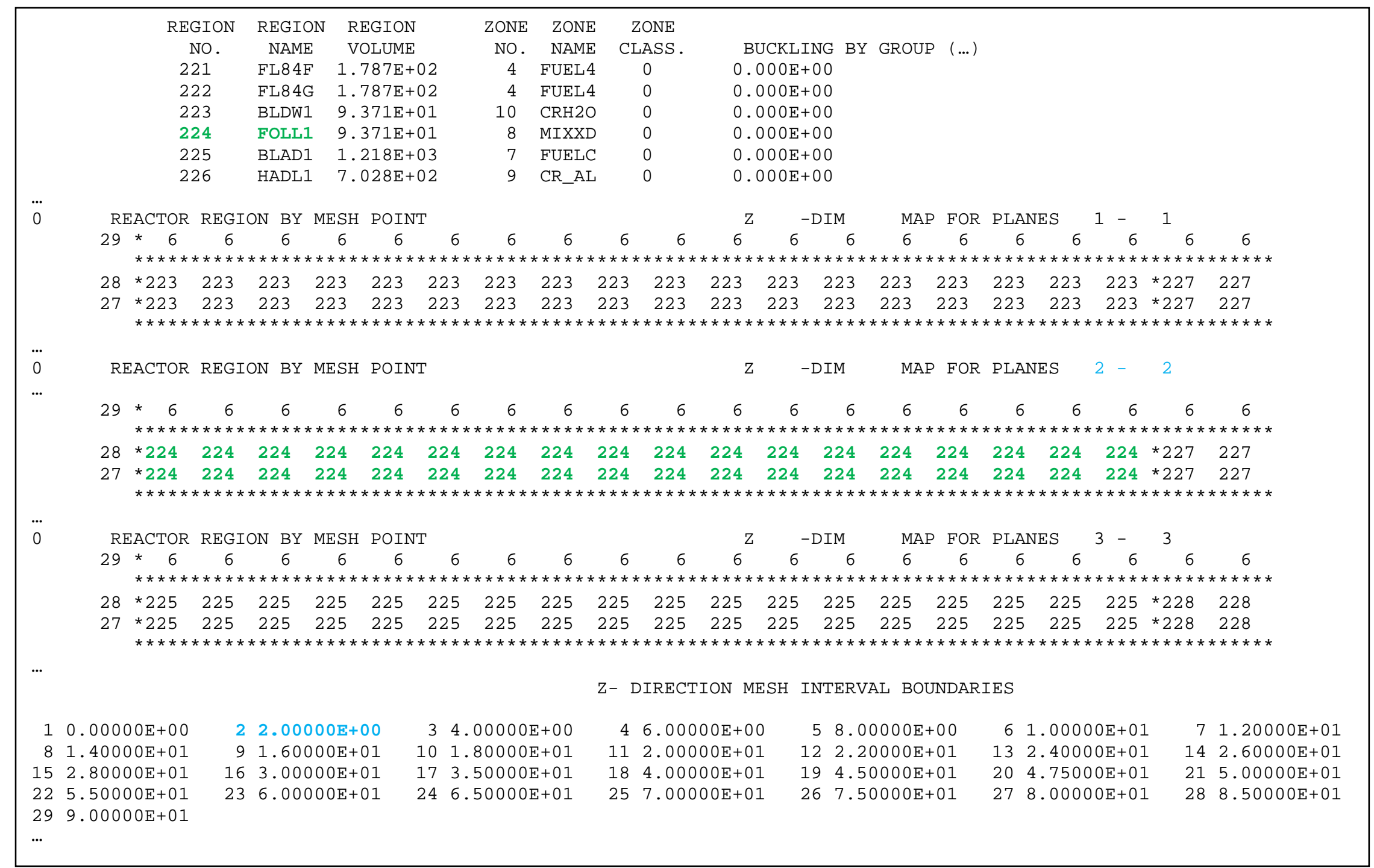

Figure 3-33. REBUS-PC Output Excerpt Showing Control Rod Position Identification for Verification Test \#15 
Table 3-24 summarizes this effort for all time points, which verifies that the input provided to REBUSPC is being correctly followed at each time point. It is important to note that the mesh boundaries of Table 3-24 are not present in Figure 3-29 such that REBUS-PC must introduce many of the meshes in order to construct the problem.

Table 3-24. Control Rod Material Location Identification for Verification Test \# 15.

\begin{tabular}{|c|c|c|c|c|c|c|c|c|}
\hline \multirow{2}{*}{$\begin{array}{c}\text { Time } \\
\text { Node } \\
\text { (day) }\end{array}$} & $\begin{array}{c}\text { Bank } \\
\text { Position } \\
(\mathrm{cm})\end{array}$ & $\begin{array}{c}\text { Rod-tip } \\
\text { Region }\end{array}$ & Label & Mesh & \multicolumn{5}{|c|}{$\begin{array}{c}\text { Cell in } \\
\text { Channel }\end{array}$} & \multicolumn{5}{|c|}{\begin{tabular}{c} 
Channel (cm) \\
\cline { 5 - 9 }
\end{tabular}} & BLDW1 & FOLL1 & BLAD1 & HADL1 & WPOOL \\
\hline 0.0 & 2.0 & FOLL1 & 36 & 0.0 & 2.0 & 4.0 & 30.0 & 45.0 \\
\hline 1.0 & 2.6 & FOLL1 & 36 & 0.0 & 4.0 & 6.0 & 32.0 & 47.0 \\
\hline 2.0 & 3.2 & FOLL1 & 36 & 0.0 & 6.0 & 8.0 & 34.0 & 49.0 \\
\hline 3.0 & 3.8 & FOLL1 & 36 & 0.0 & 8.0 & 10.0 & 36.0 & 51.0 \\
\hline 4.0 & 4.4 & FOLL1 & 36 & 0.0 & 6.0 & 8.0 & 34.0 & 49.0 \\
\hline 5.0 & 5.0 & FOLL1 & 36 & 0.0 & 4.0 & 6.0 & 32.0 & 47.0 \\
\hline 6.0 & 4.4 & FOLL1 & 36 & 0.0 & 2.0 & 4.0 & 30.0 & 45.0 \\
\hline
\end{tabular}

As discussed, the input was verified to construct new input geometries identical to the ones that result after the control rod movement and REBUS-PC produced the same results as that obtained at each time point. Table 3-25 provides the compiled REBUS-PC executable results for each time step. As can be seen, the results are identical to seven significant digits. Because the convergence criteria was set to $10^{-7}$, there are notable minor differences in the results beyond the precision shown due to different initializations of the two calculations.

Table 3-25. Core Multiplication Factors at Each Time Node for Verification Test \#15

\begin{tabular}{|c|c|c|}
\hline Days & $\begin{array}{c}\text { Control Rod } \\
\text { Movement }\end{array}$ & $\begin{array}{c}\text { Manually Created } \\
\text { Equivalent Input }\end{array}$ \\
\hline 0 & 1.07899592 & 1.07899596 \\
\hline 1 & 1.07879025 & 1.07879031 \\
\hline 2 & 1.07596887 & 1.07596894 \\
\hline 3 & 1.07383873 & 1.07383881 \\
\hline 4 & 1.07596887 & 1.07596896 \\
\hline 5 & 1.07879024 & 1.07879031 \\
\hline 6 & 1.07899588 & 1.07899594 \\
\hline
\end{tabular}

Because the composition does not change and the control rod positioning results in several time points with identical control rod positions (i.e., 0 and 6 days, 1 and 5 days, 2 and 4 days), one can see in Table 3-25 that these time points have the same multiplication factor.

The last part of this test to verify is that the flux and power output tables are identical between the control rod movement and the reproduced cases. As was the case from the previous STRZ verification tests, this is a vast amount of output detail and only an excerpt of that output is provided here as shown in Table 3-26. Time node 3 was selected and highlights the differences between the verification test and the manufactured comparison problems. As can be seen, the results shown are nearly identical and well within the input error tolerance of $10^{-5}$. This output was taken from the 
region and area power integral tables, an excerpt of which is shown in Figure 3-34, and which shows identical values to those that appear in Table 3-26.

Table 3-26. Time Node 3 Flux and Power Comparison for Verification Test \#15

\begin{tabular}{|c|c|c|c|c|c|c|}
\hline \multirow[b]{2}{*}{$\begin{array}{c}\text { Region } \\
\text { Name }\end{array}$} & \multicolumn{2}{|c|}{ Total Flux } & \multicolumn{2}{|c|}{ Total Power } & \multicolumn{2}{|c|}{ Group 4 Flux } \\
\hline & $\begin{array}{l}\text { Control Rod } \\
\text { Movement }\end{array}$ & $\begin{array}{c}\text { Manually } \\
\text { Created }\end{array}$ & $\begin{array}{c}\text { Control Rod } \\
\text { Movement }\end{array}$ & $\begin{array}{c}\text { Manually } \\
\text { Created }\end{array}$ & $\begin{array}{c}\text { Control Rod } \\
\text { Movement }\end{array}$ & $\begin{array}{l}\text { Manually } \\
\text { Created }\end{array}$ \\
\hline UPSTR & $3.88388 E+11$ & $3.88389 \mathrm{E}+11$ & $2.25499 \mathrm{E}-03$ & $2.25499 \mathrm{E}-03$ & $1.06079 \mathrm{E}+10$ & $1.06079 \mathrm{E}+10$ \\
\hline WPOOL & $9.14268 \mathrm{E}+11$ & $9.14269 \mathrm{E}+11$ & 4.72191E-03 & $4.72191 \mathrm{E}-03$ & $1.91490 \mathrm{E}+10$ & $1.91490 \mathrm{E}+10$ \\
\hline FTRAP & $1.07838 \mathrm{E}+11$ & $1.07838 \mathrm{E}+11$ & $4.54780 \mathrm{E}-04$ & $4.54780 \mathrm{E}-04$ & $3.32989 E+09$ & $3.32989 E+09$ \\
\hline STWLI & $1.73742 \mathrm{E}+11$ & $1.73742 \mathrm{E}+11$ & $9.90384 \mathrm{E}-04$ & $9.90384 \mathrm{E}-04$ & $6.34908 \mathrm{E}+09$ & $6.34908 E+09$ \\
\hline STWLO & $4.14279 \mathrm{E}+11$ & $4.14279 \mathrm{E}+11$ & $1.76088 \mathrm{E}-03$ & $1.76088 \mathrm{E}-03$ & $1.62570 \mathrm{E}+10$ & $1.62570 \mathrm{E}+10$ \\
\hline REFLT & $5.55333 \mathrm{E}+11$ & $5.55333 \mathrm{E}+11$ & -05 & 5.5 & $2.06251 \mathrm{E}+10$ & $2.06251 \mathrm{E}+10$ \\
\hline CL11E & $7.24628 \mathrm{E}+09$ & $7.24628 \mathrm{E}+09$ & $1.63942 \mathrm{E}-05$ & $1.63942 \mathrm{E}-05$ & $2.90022 \mathrm{E}+08$ & $2.90022 \mathrm{E}+08$ \\
\hline CL11F & $6.21672 E+09$ & $6.21672 \mathrm{E}+09$ & $1.40338 \mathrm{E}-05$ & $1.40338 \mathrm{E}-05$ & $2.48817 \mathrm{E}+08$ & $2.48817 \mathrm{E}+08$ \\
\hline CL11G & $4.18432 \mathrm{E}+09$ & $4.18432 \mathrm{E}+09$ & 9.84139E-06 & $9 \mathrm{E}-06$ & $13 \mathrm{E}+08$ & $1.65013 \mathrm{E}+08$ \\
\hline CL12E & $8.76684 \mathrm{E}+09$ & $8.76684 \mathrm{E}+09$ & $1.16207 \mathrm{E}-05$ & 07E-05 & $3.93203 E+08$ & $3.93203 \mathrm{E}+08$ \\
\hline CL12F & $7.57513 \mathrm{E}+09$ & $7.57513 \mathrm{E}+09$ & $1.00273 \mathrm{E}-05$ & $1.00273 \mathrm{E}-05$ & $3.39668 E+08$ & $3.39668 \mathrm{E}+08$ \\
\hline CL12G & $5.09519 \mathrm{E}+09$ & $5.09519 \mathrm{E}+09$ & 7.13191E-06 & 7.13191E-06 & $2.26915 \mathrm{E}+08$ & $2.26915 \mathrm{E}+08$ \\
\hline CL13E & $1.03926 \mathrm{E}+10$ & $1.03926 \mathrm{E}+10$ & $1.28822 \mathrm{E}-05$ & $1.28822 \mathrm{E}-05$ & $4.71056 \mathrm{E}+08$ & $4.71056 \mathrm{E}+08$ \\
\hline CL13F & $9.07721 \mathrm{E}+09$ & $9.07720 \mathrm{E}+09$ & 1.12319E-05 & $1.12319 \mathrm{E}-05$ & $4.11650 \mathrm{E}+08$ & $4.11650 \mathrm{E}+08$ \\
\hline CL13G & $6.14520 \mathrm{E}+09$ & $6.14520 \mathrm{E}+09$ & 8.05979E-06 & 8.05979E-06 & $2.77210 \mathrm{E}+08$ & $2.77210 \mathrm{E}+08$ \\
\hline CL14E & $1.12208 \mathrm{E}+10$ & $1.12208 \mathrm{E}+10$ & $1.50617 \mathrm{E}-05$ & $7 \mathrm{E}-05$ & $5.02808 \mathrm{E}+08$ & $5.02807 \mathrm{E}+08$ \\
\hline CL14F & $9.96205 \mathrm{E}+09$ & $9.96205 \mathrm{E}+09$ & $1.31524 \mathrm{E}-05$ & $4 \mathrm{E}-05$ & $95 E+08$ & $4.48995 \mathrm{E}+08$ \\
\hline CL14G & $6.81045 E+09$ & $6.81045 E+09$ & $9.46271 \mathrm{E}-06$ & $9.46271 \mathrm{E}-06$ & $3.05640 \mathrm{E}+08$ & $3.05640 \mathrm{E}+08$ \\
\hline CL15E & $1.25135 \mathrm{E}+10$ & $1.25135 \mathrm{E}+10$ & $2.96187 \mathrm{E}-05$ & $2.96187 \mathrm{E}-05$ & $4.97513 \mathrm{E}+08$ & $4.97513 E+08$ \\
\hline CL15F & $1.11116 \mathrm{E}+10$ & $1.11116 \mathrm{E}+10$ & $2.36456 \mathrm{E}-05$ & $2.36456 \mathrm{E}-05$ & $4.62237 \mathrm{E}+08$ & $4.62237 \mathrm{E}+08$ \\
\hline CL15G & $7.66313 \mathrm{E}+09$ & $7.66313 \mathrm{E}+09$ & $1.65601 \mathrm{E}-05$ & $1.65601 \mathrm{E}-05$ & $3.18132 \mathrm{E}+08$ & $3.18132 \mathrm{E}+08$ \\
\hline CL21E & $7.24632 \mathrm{E}+09$ & $7.24632 \mathrm{E}+09$ & $1.63943 \mathrm{E}-05$ & $1.63943 \mathrm{E}-05$ & $2.90023 \mathrm{E}+08$ & $2.90023 \mathrm{E}+08$ \\
\hline CL21F & $6.21675 E+09$ & $6.21675 \mathrm{E}+09$ & $1.40339 \mathrm{E}-05$ & $1.40339 \mathrm{E}-05$ & $2.48818 \mathrm{E}+08$ & $2.48818 \mathrm{E}+08$ \\
\hline CL21G & $4.18435 \mathrm{E}+09$ & $4.18435 \mathrm{E}+09$ & $9.84144 \mathrm{E}-06$ & $9.84144 \mathrm{E}-06$ & $1.65014 \mathrm{E}+08$ & $1.65014 \mathrm{E}+08$ \\
\hline CL22E & $8.76688 \mathrm{E}+09$ & $8.76688 \mathrm{E}+09$ & $1.16208 \mathrm{E}-05$ & $1.16208 \mathrm{E}-05$ & $3.93205 \mathrm{E}+08$ & $3.93205 \mathrm{E}+08$ \\
\hline CL22F & $7.57517 \mathrm{E}+09$ & $7.57517 \mathrm{E}+09$ & $1.00274 \mathrm{E}-05$ & $1.00274 \mathrm{E}-05$ & $3.39669 \mathrm{E}+08$ & $3.39669 E+08$ \\
\hline CL22G & $5.09522 \mathrm{E}+09$ & $5.09522 \mathrm{E}+09$ & 7.13195E-06 & 7.13195E-06 & $2.26916 \mathrm{E}+08$ & $2.26916 \mathrm{E}+08$ \\
\hline CL23E & $1.03927 \mathrm{E}+10$ & $1.03927 \mathrm{E}+10$ & $1.28823 \mathrm{E}-05$ & $1.28823 \mathrm{E}-05$ & $4.71058 \mathrm{E}+08$ & $4.71058 \mathrm{E}+08$ \\
\hline CL23F & $9.07725 \mathrm{E}+09$ & $9.07725 \mathrm{E}+09$ & $1.12319 \mathrm{E}-05$ & 1.12319E-05 & $4.11652 \mathrm{E}+08$ & $4.11652 \mathrm{E}+08$ \\
\hline CL23G & $6.14523 \mathrm{E}+09$ & $6.14523 \mathrm{E}+09$ & 8.05983E-06 & 8.05983E-06 & $2.77211 \mathrm{E}+08$ & $2.77211 \mathrm{E}+08$ \\
\hline
\end{tabular}

In addition to these tables, the mesh wise flux and power tables were also compared, showing similar small differences. Based upon this work, the modeling of a single control rod bank is demonstrated to be correctly handled with REBUS-PC during fuel cycle operations. 


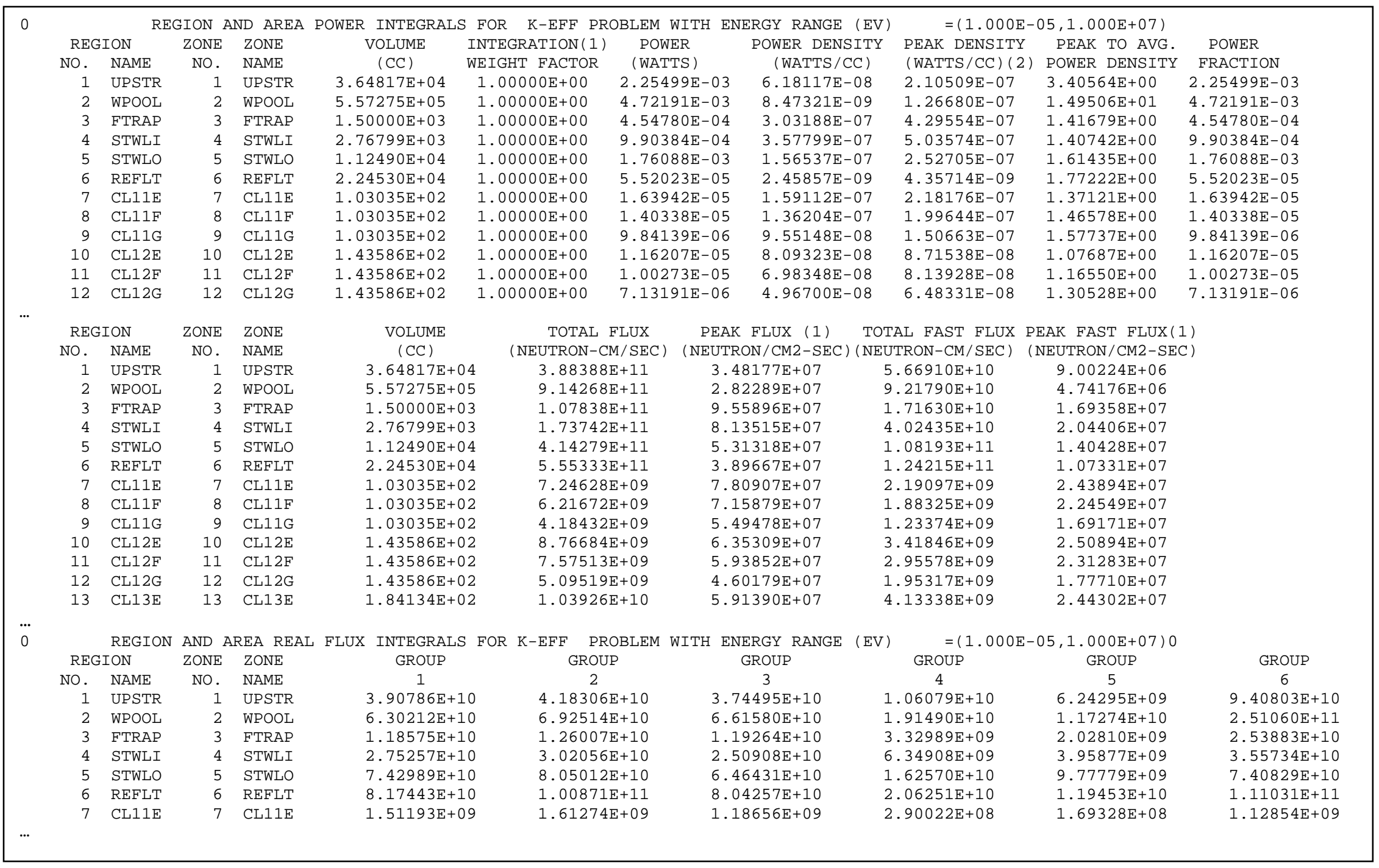

Figure 3-34. REBUS-PC Output Excerpt Showing Core Power and Flux Data Compared for Verification Test \#15 
With the preceding work, verification test \#15 demonstrates the following capabilities:

- Capability 8, as it verifies that the control rod movement is properly handled by REBUS-PC for a single control rod bank.

- Capability 9, as it verifies the remeshing required to handle new movement of fixed control rod boundaries is handled properly by REBUS-PC.

This verification test also provides addition demonstration of capabilities $1,2,3,4$, and 7 , but provides no additional information than that previously derived from the STRZ verification tests \#12 through \#14.

\subsection{Verification Tests \#16 and \#17}

These verification tests are focused on addressing another part of capability 1 . As part of capability 1 , REBUS-PC must be verified to execute identically when provided the A.ISO and the binary file ISOTXS microscopic cross section input. Verification test \#16 uses the A.ISO, an excerpt of which is provided in Figure 3-35. The input for this verification test is considerably longer than that of verification test \#17, which uses the binary ISOTXS file. Both of these tests are exact duplicates of verification test \#19 discussed later. In the case of verification test \#17, modified comment cards are the only reason it produces a different output from verification test \#19.

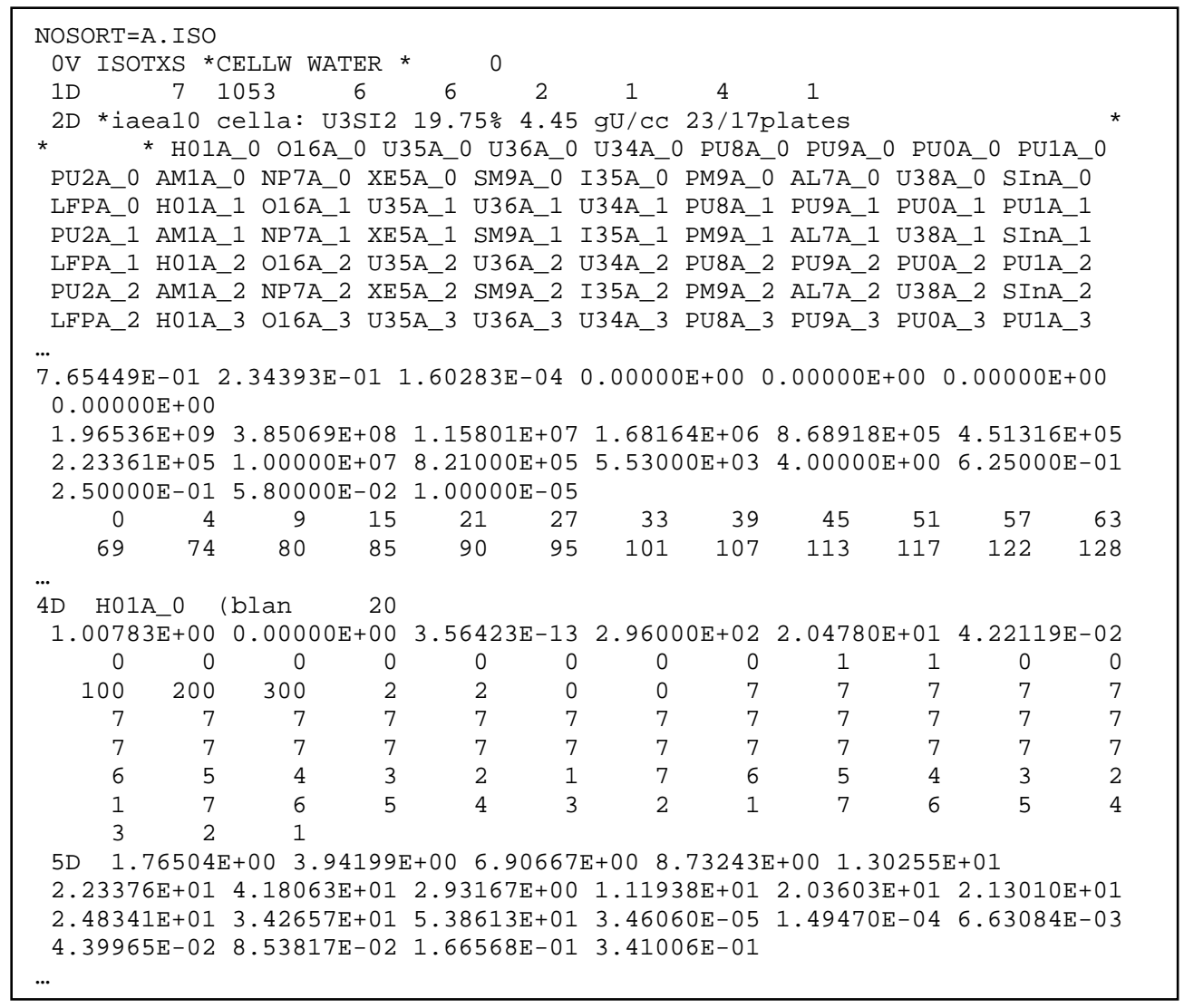

Figure 3-35. REBUS-PC A.ISO Input Excerpt for Verification Test \#16

The A.ISO file format is the ascii version of the data stored in the binary ISOTXS file. As expected, verification tests \#16 and \#17 produce identical answers within the small round off errors caused by the precision of the numbers in the ascii versus the binary versions of the cross section data, which 
has a negligible impact on the answers. Because the output files are identical to verification test \#19, all output excerpts are deferred to the discussion of verification test \#19. Duplication of verification test \#19 was chosen as its usage of the ISOTXS data (cross section interpolation) is the most complex of all of the test problems.

With the preceding analysis, these verification test demonstrate the following capability:

- Capability 2, as it verifies that the ASCII and binary ISOTXS input yield equivalent results

\subsection{Verification Tests \#18, \#19, and \#20}

These verification tests are designed to verify capabilities 11 and 12 . The way that this is accomplished is by reproducing the cross section interpolation for several regions and verifying it against the output of REBUS-PC. It is important to note that this action also supports capability \#3 as it proves REBUS-PC is using specific ISOTXS cross sections in specific regions for the STRZ benchmark.

Figure 3-36 shows an excerpt of the A.BURN input for verification test \#19 specifying burnup dependent cross sections of U-238. The type 26 cards specify the labels of the reference base isotope and the isotopes with burnup dependent cross sections. The type 39 cards specify the burnup dependent energy groups, and the type 40 cards specify the allowable error in the absolute value of the relative residue in the polynomial or spline fit. The type 41 cards specify the labels of isotopes in the ISOTXS library whose cross sections are included in the polynomial or spline fit and the corresponding number densities of the reference isotope.

\begin{tabular}{|c|c|c|c|c|c|c|}
\hline \multicolumn{7}{|c|}{ BURNUP DEPENDENT XS DATA FOR U38A_ $\odot$, DEPENDING ON U35A_ $\odot$ NUMBER DENSITY } \\
\hline 26 & U35A_0U38A_0 & & & & & \\
\hline 39 & U35A_0 & 7U38A_@ & 1 & 7PU9A_O & 7 & \\
\hline 39 & U35C_@ & 7U38C_0 & 1 & 7PU9C_@ & 7 & \\
\hline 39 & LFPA_@ $\odot$ & 7LFPC_@ 9 & 1 & 7 & & \\
\hline 40 & U38A_0 & $1.0-3$ & 8U38A_C & 32 & $1.0-3$ & 8 \\
\hline 41 & U38A_0U38A_0 & $8.90249 \mathrm{E}-\odot 4$ & $1.0+\overline{3}$ & U38A_1 & $8.87191 \mathrm{E}-04$ & 1.0 \\
\hline 41 & U38A_0U38A_2 & $8.84131 \mathrm{E}-\odot 4$ & 1.0 & U38A_3 & $8.81076 \mathrm{E}-\odot 4$ & 1.0 \\
\hline 41 & U38A_-OU38A_4 & $8.74968 \mathrm{E}-\odot 4$ & 1.0 & U38A_5 & $8.68874 \mathrm{E}-\odot 4$ & 1.0 \\
\hline 41 & U38A_OU38A_6 & $8.65830 \mathrm{E}-\odot 4$ & 1.0 & U38A_7 & $8.53699 \mathrm{E}-\odot 4$ & 1.0 \\
\hline 41 & U38A_0U38A_8 & $8.41609 E-\odot 4$ & 1.0 & U38A_9 & $8.29566 \mathrm{E}-\odot 4$ & 1.0 \\
\hline 41 & U38A_@U38Ā10 & $8.23559 E-\odot 4$ & 1.0 & U38A11 & 7. $99701 \mathrm{E}-\odot 4$ & 1.0 \\
\hline 41 & U38A_0U38A12 & $7.76015 \mathrm{E}-\odot 4$ & 1.0 & U38A13 & $7.52494 \mathrm{E}-\odot 4$ & 1.0 \\
\hline 41 & U38A_-0U38A14 & $7.4 \odot 798 \mathrm{E}-\odot 4$ & 1.0 & U38A15 & $6.94709 \mathrm{E}-\odot 4$ & 1.0 \\
\hline 41 & U38A_-OU38A16 & $6.49282 \mathrm{E}-\odot 4$ & 1.0 & U38A17 & $6.04544 \mathrm{E}-\odot 4$ & 1.0 \\
\hline 41 & U38A_0U38A18 & $5.82434 \mathrm{E}-\odot 4$ & 1.0 & U38A19 & $4.97058 \mathrm{E}-\odot 4$ & 1.0 \\
\hline 41 & U38A_0U38A20 & $4.14788 \mathrm{E}-\odot 4$ & 1.0 & U38A21 & $3.35994 \mathrm{E}-\odot 4$ & 1.0 \\
\hline 41 & U38A_@U38A22 & $2.98069 \mathrm{E}-\odot 4$ & 1.0 & U38A23 & $2.28978 \mathrm{E}-\odot 4$ & 1.0 \\
\hline 41 & U38A_OU38A24 & $1.65557 \mathrm{E}-\odot 4$ & 1.0 & U38A25 & 1. $\odot 9277 \mathrm{E}-\odot 4$ & 1.0 \\
\hline
\end{tabular}

Figure 3-36. REBUS-PC A.BURN Input Excerpt for Verification Test \#19

During the execution of REBUS-PC, an auxiliary output file POLYFI.BCD is generated when the burnup dependent cross section option is invoked. Figure 3-37 and Figure 3-38 show the details of the POLYFI.BCD file which provides the input specification for burnup dependent cross section data and example interpolated relative cross section data at the mid-point of each atom density interval with respect to the reference isotope density (denoted by the column "X").

By comparing the input data specified on the type 41 cards of the A.BURN dataset with the input cross sections saved in the output file POLYFI.BCD, the burnup dependent cross section data can be verified. The interpolated cross sections of REBUS-PC were verified by comparing them with the reference values obtained with a MATLAB program. The MATLAB script to perform the cubic spline 
interpolation of burnup dependent cross sections is provided in the repository. Figure 3-39 compares isotopic cross section data with the interpolated equivalent for the $(n, \gamma)$ cross section of $U-238$ in the STRZ fuel composition. As can be seen, the two sets of cross sections appear identical and upon detailed inspection are accurate to the precision of the stored data.

\begin{tabular}{|c|c|c|c|c|c|c|c|}
\hline & CROSS & ONS FOR IS & 38A_0 & SROUP & & & \\
\hline & $x$ & CAPTURE & FISSION & $\mathrm{N}, \mathrm{P}$ & $\mathrm{N}, \mathrm{ALPHA}$ & $N, D$ & $\mathrm{~N}, \mathrm{~T}$ \\
\hline 1 & $1.09277 \mathrm{E}-\odot 4$ & $2.56253 E-01$ & $4.74 \odot 41 \mathrm{E}-\odot 4$ & $\odot . \odot \odot \odot \odot \odot E+\odot \odot$ & $\odot . \odot \odot \odot \odot \odot E+\odot \odot$ & $\odot . \odot \odot \odot \odot \odot E+\odot \odot$ & $\ominus \odot \odot \odot \odot E+C$ \\
\hline 2 & & & & & & & \\
\hline 3 & $78 E-\odot 4$ & 6169E-01 & $118 E-04$ & $E+\odot \odot$ & $\bullet \odot$ & $+\odot \odot$ & $E+\odot \odot$ \\
\hline 4 & $2.98069 \mathrm{E}-\odot 4$ & $2.56138 \mathrm{E}-01$ & $4.74134 \mathrm{E}-\odot 4$ & $\odot . \odot \odot \odot \odot \odot E+\odot \odot$ & $\odot \odot E+\odot \odot$ & $\odot \odot E+\odot \odot$ & $E+\odot \odot$ \\
\hline 5 & $3.35994 \mathrm{E}-04$ & $2.56120 \mathrm{E}-\odot 1$ & $4.74147 \mathrm{E}-\odot 4$ & $\odot . \odot \odot \odot \odot \odot E+\odot \odot$ & $\odot . \odot \odot \odot \odot \odot E+\odot \odot$ & $\odot . \odot \odot \odot \odot \odot E+\odot \odot$ & $\ominus \odot E+\odot \odot$ \\
\hline 6 & $4.14788 E-\odot 4$ & $2.56133 \mathrm{E}-\odot 1$ & $4.74083 E-\odot 4$ & $\odot . \odot \odot \odot \odot \odot E+\odot \odot$ & $\odot E+\odot \odot$ & $+\odot \odot$ & $E+\odot \odot$ \\
\hline 7 & $058 E-04$ & $2.56109 \mathrm{E}-01$ & $4.74085 \mathrm{E}-\odot 4$ & 0.000 & & & \\
\hline 8 & $434 E-\odot 4$ & $2.56088 \mathrm{E}-01$ & $4.74084 \mathrm{E}-\odot 4$ & $\odot . \odot \odot \odot \odot \odot E+\odot \odot$ & $+\odot \odot$ & $\odot$. & $\odot \odot$ \\
\hline 9 & $544 \mathrm{E}-04$ & $2.56036 \mathrm{E}-01$ & $4163 E-04$ & $\odot . \odot \odot \odot \odot \odot E+\odot \odot$ & & & \\
\hline 10 & $6.49282 \mathrm{E}-\odot 4$ & $2.56019 \mathrm{E}-01$ & $4.74171 \mathrm{E}-\odot 4$ & $\odot . \odot \odot \odot \odot \odot E+\odot \odot$ & & 0.0 & $\odot \odot$ \\
\hline 11 & $709 E-\odot 4$ & $2.56003 \mathrm{E}-\odot 1$ & $4.74178 \mathrm{E}-\odot 4$ & $\odot . \odot \odot \odot \odot \odot E+\odot \odot$ & & & $\odot \odot$ \\
\hline 12 & $E-\odot 4$ & $2.55983 \mathrm{E}-01$ & $4.74194 \mathrm{E}-\odot 4$ & $\ominus \mathrm{E}+\odot \odot$ & & & \\
\hline 13 & 494E-๑4 & $2.55978 \mathrm{E}-01$ & $4.74195 \mathrm{E}-\odot 4$ & $\odot .0 \odot$ & & $\odot$. & $\odot \odot$ \\
\hline 14 & $7.76015 \mathrm{E}-\odot 4$ & 7०E-๑1 & $4.74199 \mathrm{E}-\odot 4$ & $\ominus \mathrm{E}+\odot \odot$ & & & $\odot \odot$ \\
\hline 15 & $7.99701 \mathrm{E}-\odot 4$ & $2.55962 \mathrm{E}-01$ & $4.74202 \mathrm{E}-\odot 4$ & $\odot . \odot \odot \odot \odot \odot E+\odot \odot$ & $+\odot \odot$ & $+\odot \odot$ & $+\odot \odot$ \\
\hline 16 & $559 E-\odot 4$ & $553 E-01$ & 4.742 & $\odot . \odot \odot$ & $\odot$. & $\bullet \odot$ & $\odot \odot$ \\
\hline $1 /$ & 8.2 & $51 E-01$ & $E-\odot 4$ & 0.0 & & & \\
\hline 18 & 8.4 & $3 E-01$ & $1 E-04$ & $E+0 \odot$ & & & \\
\hline 19 & $699 E-\odot 4$ & $2.55989 \mathrm{E}-01$ & $4.74132 \mathrm{E}-\odot 4$ & $\odot E+\odot \odot$ & & & $\odot \odot$ \\
\hline 20 & $8.65830 E-\odot 4$ & $2.55986 \mathrm{E}-\odot 1$ & $4.74133 E-\odot 4$ & $\odot . \odot \odot \odot \odot \odot E+\odot \odot$ & $\odot E+\odot \odot$ & $+\odot \odot$ & $E+\odot \odot$ \\
\hline 21 & $8.68874 E-\odot 4$ & $2.55985 \mathrm{E}-01$ & $4.74133 \mathrm{E}-\odot 4$ & $\odot . \odot \odot \odot \odot \odot E+\odot \odot$ & $\odot E+\odot \odot$ & $+\odot \odot$ & $\odot \mathrm{E}+\odot \odot$ \\
\hline 22 & & $2.55983 \mathrm{E}-01$ & $4.74133 \mathrm{E}-\odot 4$ & & & & $+\odot \odot$ \\
\hline 23 & $8.81076 \mathrm{E}-\odot 4$ & $2.55982 \mathrm{E}-01$ & $4.74134 \mathrm{E}-04$ & $0 \odot \mathrm{E}+\odot \odot$ & & & \\
\hline 24 & $8.84131 \mathrm{E}-04$ & 2.55 & $4.74134 \mathrm{E}$ & $\odot \odot$ & & & $E+0 \odot$ \\
\hline 25 & $91 \mathrm{E}$ & 2.55 & $135 \mathrm{E}$ & $\odot \mathrm{E}+\mathrm{C}$ & & $\odot . \odot$ & ل \\
\hline & $8.9024 \mathrm{~s}$ & UE & $4.74218 \mathrm{E}-\bullet$ & S & SE+OUE & $0.000000+00$ & ०.00000E+० \\
\hline
\end{tabular}

Figure 3-37. POLYFI.BCD Excerpt for a Cubic Spline Fit in Verification Test \#19

\begin{tabular}{|c|c|c|c|c|c|c|c|}
\hline \multicolumn{8}{|c|}{ 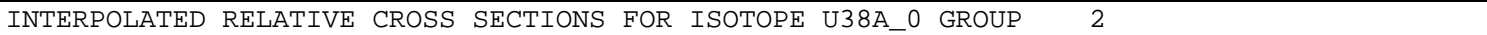 } \\
\hline & $\mathrm{x}$ & CAPTURE & FISSION & $\mathrm{N}, \mathrm{P}$ & $\mathrm{N}, \mathrm{ALPHA}$ & $\mathrm{N}, \mathrm{D}$ & $\mathrm{N}, \mathrm{T}$ \\
\hline 1 & $1.37417 \mathrm{E}-04$ & 1. $00114 \mathrm{E}+00$ & $9.99707 \mathrm{E}-01$ & $0.00000 \mathrm{E}+0 \odot$ & $0.00000 \mathrm{E}+00$ & $\odot .00000 \mathrm{E}+0 \odot$ & $0.00000 \mathrm{E}+00$ \\
\hline 2 & $7267 \mathrm{E}-\odot 4$ & $1.00098 \mathrm{E}+0 \odot$ & $99789 E-01$ & $\odot \odot E+\odot \odot$ & $0.00000 \mathrm{E}+00$ & $\odot .00000 \mathrm{E}+0 \odot$ & $0 \mathrm{E}+0 \odot$ \\
\hline 3 & $3523 E-04$ & $1 . \odot \odot \odot 88 \mathrm{E}+\odot \odot$ & 9. 99797E-01 & $\odot \odot E+\odot \odot$ & $\odot . \odot \odot \odot \odot \odot E+\odot \odot$ & $\odot . \odot \odot \odot \odot \odot E+\odot \odot$ & $\odot . \odot \odot \odot \odot \odot E+\odot \odot$ \\
\hline 4 & $3.17032 \mathrm{E}-\odot 4$ & 1. $\odot \odot \odot 77 \mathrm{E}+\odot \odot$ & $9.99843 \mathrm{E}-01$ & $\odot . \odot \odot \odot \odot \odot E+\odot \odot$ & $\odot . \odot \odot \odot \odot \odot E+\odot \odot$ & $\odot . \odot \odot \odot \odot \odot E+\odot \odot$ & $\odot . \odot \odot \odot \odot \odot E+\odot \odot$ \\
\hline 5 & $3.75391 E-04$ & 1. $0 \odot \odot 76 \mathrm{E}+\odot \odot$ & $9.99788 \mathrm{E}-01$ & $\odot . \odot \odot \odot \odot \odot E+\odot \odot$ & $\odot . \odot \odot \odot \odot \odot E+\odot \odot$ & $\odot .0 \odot \odot \odot \odot E+\odot \odot$ & $\odot . \odot \odot \odot \odot \odot E+\odot \odot$ \\
\hline 6 & $4.55923 E-04$ & 1. $0 \odot \odot 74 \mathrm{E}+\odot \odot$ & $9.99724 \mathrm{E}-01$ & $\odot . \odot \odot \odot \odot \odot E+\odot \odot$ & $\odot . \odot \odot \odot \odot \odot E+\odot \odot$ & $\odot . \odot \odot \odot \odot \odot E+\odot \odot$ & $\odot . \odot \odot \odot \odot \odot E+\odot \odot$ \\
\hline 7 & $5.39746 \mathrm{E}-\odot 4$ & 1. $\odot \odot \odot 75 \mathrm{E}+\odot \odot$ & $9.99630 \mathrm{E}-01$ & $\odot . \odot \odot \odot \odot \odot E+\odot \odot$ & $\odot . \odot \odot \odot \odot \odot E+\odot \odot$ & $\odot . \odot \odot \odot \odot \odot E+\odot \odot ~$ & $\odot \mathrm{E}+\odot \odot$ \\
\hline 8 & $5.93489 E-\odot 4$ & 1. $\odot \odot \odot 51 \mathrm{E}+\odot \odot$ & $9.99804 \mathrm{E}-01$ & $\odot . \odot \odot \odot \odot \odot E+\odot \odot$ & $\odot . \odot \odot \odot \odot \odot E+\odot \odot$ & $\odot E+\odot \odot$ & $\odot$. \\
\hline 9 & $6.26913 E-04$ & 1. $0 \odot \odot 34 \mathrm{E}+0 \odot$ & $9.99930 \mathrm{E}-01$ & $\odot \odot E+\odot \odot$ & 0.00 & $+\odot \odot$ & $+0 \odot$ \\
\hline 10 & $6.71996 \mathrm{E}-04$ & 1. $0 \odot \odot 33 E+\odot \odot$ & $9.99896 \mathrm{E}-01$ & $\odot . \odot \odot \odot \odot \odot E+\odot \odot$ & $\odot . \odot \odot \odot \odot \odot E+\odot \odot$ & $\odot . \odot \odot \odot \odot \odot E+\odot \odot$ & $\odot . \odot \odot \odot \odot \odot E+\odot \odot$ \\
\hline 11 & $7.17754 \mathrm{E}-04$ & 1. $\odot \odot \odot 24 \mathrm{E}+\odot \odot$ & $9.99937 \mathrm{E}-01$ & $\odot . \odot \odot \odot \odot \odot E+\odot \odot$ & $\odot . \odot \odot \odot \odot \odot E+\odot \odot$ & $\odot . \odot \odot \odot \odot \odot E+\odot \odot$ & $\odot . \odot \odot \odot \odot \odot E+\odot \odot$ \\
\hline 12 & \$46E- -44 & 1. $\odot \odot \odot 20 \mathrm{E}+\odot \odot$ & $51 E-01$ & $\odot . \odot \odot \odot \odot \odot E+\odot \odot$ & $\odot . \odot \odot \odot \odot \odot E+\odot \odot$ & $\odot .0 \odot$ & $E+\odot \odot$ \\
\hline 13 & $7.64254 \mathrm{E}-04$ & 1. $0 \odot \odot 17 \mathrm{E}+\odot \odot$ & 9. $99955 \mathrm{E}-01$ & $\odot . \odot \odot \odot \odot \odot E+\odot \odot$ & $\odot . \odot \odot \odot \odot \odot E+\odot \odot$ & $\odot .0 \odot$ & 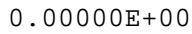 \\
\hline 14 & $7.87858 E-04$ & 1. $0 \odot \odot 14 \mathrm{E}+\odot \odot$ & $9.99966 \mathrm{E}-01$ & $\odot . \odot \odot \odot \odot \odot E+\odot \odot$ & $\odot . \odot \odot \odot \odot \odot E+\odot \odot$ & $\odot E+\odot \odot$ & $\odot .00 \odot$ \\
\hline 15 & $8.11630 E-04$ & 1. $\odot \odot \odot 12 \mathrm{E}+\odot \odot$ & $9.99960 \mathrm{E}-01$ & $\odot . \odot \odot \odot \odot \odot E+\odot \odot$ & $\odot . \odot \odot \odot \odot \odot E+\odot \odot$ & 0.00 & $\odot .0 \odot$ \\
\hline 16 & $8.26563 E-04$ & 1. $\odot \odot \odot \odot ८ E+\odot \odot$ & $9.99977 \mathrm{E}-01$ & $\odot . \odot \odot \odot \odot \odot E+\odot \odot$ & $\odot . \odot \odot \odot \odot \odot E+\odot \odot$ & $\odot . \odot \odot \odot \odot \odot E+\odot \odot$ & $\odot . \odot \odot \odot \odot \odot E+\odot \odot$ \\
\hline 17 & 8.3 & 1. $0 \odot \odot 16 \mathrm{E}+\odot \odot$ & $9.99898 \mathrm{E}-01$ & $\odot . \odot \odot \odot \odot \odot E+\odot \odot$ & $\odot . \odot \odot \odot \odot \odot E+\odot \odot$ & $\odot E+\odot \odot$ & $\ominus \mathrm{E}+\Theta \odot$ \\
\hline 18 & $554 E-04$ & 1. $00026 \mathrm{E}+0 \odot$ & 9. 99801E-01 & $\odot \odot E+\odot \odot$ & $\odot \odot \mathrm{E}+\odot \odot$ & $+\infty \odot$ & $\odot \odot$ \\
\hline 19 & $8.59765 \mathrm{E}-04$ & $1.00022 \mathrm{E}+0 \odot$ & $9.99824 \mathrm{E}-01$ & $\odot .00000 \mathrm{E}+\odot \odot$ & $\odot . \odot \odot \odot \odot \odot E+\odot \odot$ & 0.00 & $+\odot \odot$ \\
\hline 20 & $8.67352 \mathrm{E}-\odot 4$ & $1.00022 \mathrm{E}+\odot \odot$ & $9.99821 \mathrm{E}-01$ & $\odot . \odot \odot \odot \odot \odot E+\odot \odot$ & $\odot . \odot \odot \odot \odot \odot E+\odot \odot$ & $\odot . \odot \odot \odot \odot \odot E+\odot \odot$ & $\odot . \odot \odot \odot$ \\
\hline 21 & $8.71921 \mathrm{E}-04$ & 1. $\odot \odot \odot 21 \mathrm{E}+\odot \odot$ & $9.99821 \mathrm{E}-01$ & $\odot . \odot \odot \odot \odot \odot E+\odot \odot$ & $\odot . \odot \odot \odot \odot \odot E+\odot \odot$ & $\odot . \odot \odot \odot \odot \odot E+\odot \odot$ & $\odot . \odot \odot \odot \odot \odot E+\odot \odot$ \\
\hline 22 & $8.78022 \mathrm{E}-\odot 4$ & 1. $0 \odot \odot 21 \mathrm{E}+0 \odot$ & $9.99820 \mathrm{E}-01$ & $\odot . \odot \odot \odot \odot \odot E+\odot \odot$ & $\odot . \odot \odot \odot \odot \odot E+\odot \odot$ & $\odot . \odot \odot \odot \odot \odot E+\odot \odot$ & $\odot . \odot \odot \odot \odot \odot E+\odot \odot$ \\
\hline 23 & $8.82603 E-\odot 4$ & 1. $0 \odot \odot 20 \mathrm{E}+\odot \odot$ & $9.99826 \mathrm{E}-01$ & $\odot . \odot \odot \odot \odot \odot E+\odot \odot$ & $\odot . \odot \odot \odot \odot \odot E+\odot \odot$ & $\odot . \odot \odot \odot \odot \odot E+\odot \odot$ & 0.000 \\
\hline 24 & 661E-๑4 & 1. $0 \odot \odot 21 \mathrm{E}+\odot \odot$ & $9.99811 \mathrm{E}-01$ & $\odot . \odot \odot \odot \odot \odot E+\odot \odot$ & $\odot . \odot \odot \odot \odot \odot E+\odot \odot$ & $\odot . \odot \odot \odot \odot \odot E+\odot \odot$ & $\mathrm{E}+\Theta \odot$ \\
\hline 25 & $8.88720 E-04$ & $1.00012 \mathrm{E}+0 \odot$ & $9.99895 \mathrm{E}-01$ & $\odot .0000 \odot \mathrm{E}+\odot \odot$ & $\odot . \odot \odot \odot \odot \odot E+\odot \odot$ & $\odot . \odot \odot \odot \odot \odot E+\odot \odot$ & $\odot .0 \odot \odot \odot \odot E+\odot \odot$ \\
\hline
\end{tabular}

Figure 3-38. POLYFI.BCD Interpolated Cross Section for Verification Test \#19 


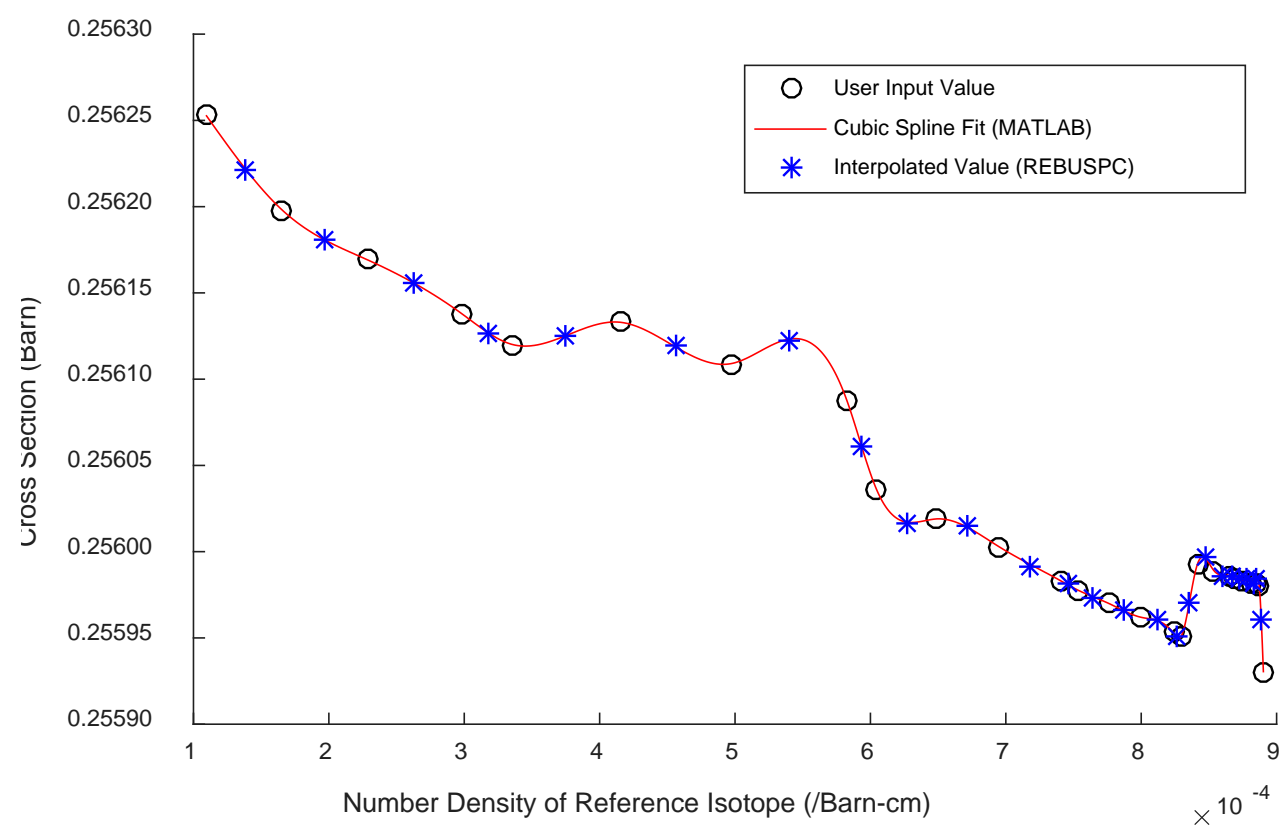

Figure 3-39. Group Two $(n, \gamma)$ Capture Cross Sections of U-238 for Verification Test \#19

All of the isotopes specified as burnup dependent in REBUS-PC can be compared with the MATLAB program results for the same data. The interpolated cross sections of REBUS-PC and MATLAB were written to ASCII files with the same format as POLYFI.BCD. As an example, Figure 3-40 compares the burnup dependent cross sections for group 1 of the lumped fission product isotope LFPA_0. The upper section shows REBUS-PC result while the lower section shows the MATLAB program and the highlighting shows which lines differ and which parts of each line are different. A quick inspection of the output shows that the results only differ in the last significant digit, which is consistent with the accuracy of the math in REBUS-PC (single precision).

Given that the cubic spline fit of the cross section data is verified, its usage by REBUS-PC must be verified. This is easy to verify as REBUS-PC can print out the macroscopic cross sections used at each time node in each region or the microscopic cross sections and the atom densities of each region. Because the interpolation is based upon the calculated atom density, the atom density printout is combined with the macroscopic cross section print out for the verification. Figure 3-41 shows the output excerpt taken for the macroscopic cross section data, where previous excerpts have shown the typical atom density printout. MATLAB is again used to compute the macroscopic cross sections given the evaluation of the microscopic cross section using the spline fit. This involved the interpolation of numerous isotopic cross sections (U-235, U-238, Pu-239, LFP, Xe-135, etc...) given the density of the reference isotope (U-235). Because of the extensive amount of output that this generates, only a sample of the fission cross section comparison is provided in Figure 3-42 for region FL11E. The verification test has 11 distinct time node outputs and the information from Figure 3-41 is condensed from all 11 time nodes to create Figure 3-42.

As was the case with the microscopic cross section comparison, the differences between the REBUSPC and MATLAB calculations only appear in the sixth significant digit, which is within the limits of the math precision. Similar errors were observed from additional comparisons for other regions and reactions. The results demonstrate that the cubic spline routine of REBUS-PC correctly performs the cross section interpolation consistent with that described in the manual and thus satisfies 
capability 11. In addition, the isotopes specified in the ISOTXS file are properly linked to the region of interest, thereby demonstrating capability 3.

\begin{tabular}{|c|c|c|c|c|c|c|c|}
\hline \multicolumn{8}{|c|}{ PC-interpolated XS in group 1 for isotope LFPA 0} \\
\hline & $\mathrm{x}$ & CAPTURE & FISSION & $\mathrm{N}, \mathrm{P}$ & $\mathrm{N}, \mathrm{ALPHA}$ & $\mathrm{N}, \mathrm{D}$ & $\mathrm{N}, \mathrm{T}$ \\
\hline 1 & $1.37417 \mathrm{E}-04$ & 1. $76529 \mathrm{E}-02$ & $0.00000 \mathrm{E}+00$ & $2.29344 \mathrm{E}-05$ & $1.80423 \mathrm{E}-05$ & $2.64447 \mathrm{E}-08$ & $2.57397 \mathrm{E}-09$ \\
\hline 2 & $.97267 \mathrm{E}-04$ & $1.81202 \mathrm{E}-02$ & $0.00000 \mathrm{E}+00$ & $35026 \mathrm{E}-05$ & $1.89818 \mathrm{E}-05$ & $57509 \mathrm{E}-08$ & $6892 \mathrm{~F}-$ \\
\hline 3 & $2.63523 \mathrm{E}-04$ & $1.85376 \mathrm{E}-02$ & $0.00000 \mathrm{E}+00$ & $0097 \mathrm{E}-05$ & $1.97873 \mathrm{E}-05$ & $1 E-08$ & \\
\hline 4 & $3.17032 \mathrm{E}-04$ & $1.87915 \mathrm{E}-02$ & $0.00000 \mathrm{E}+00$ & $3172 \mathrm{E}-05$ & $2.03026 \mathrm{E}-05$ & 8 & \\
\hline 5 & $3.75391 \mathrm{E}-04$ & $1.89853 \mathrm{E}-02$ & $0.00000 \mathrm{E}+00$ & $548 \mathrm{E}-05$ & 05 & 8 & \\
\hline 6 & $4.55923 \mathrm{E}-04$ & $1.92243 \mathrm{E}-02$ & $0.00000 \mathrm{E}+00$ & $2.48353 \mathrm{E}-05$ & $2.12585 \mathrm{E}$ & 2.35802 & 2 . \\
\hline 7 & $5.39746 \mathrm{E}-04$ & $1.94584 \mathrm{E}-02$ & $0.00000 \mathrm{E}+00$ & $2.51232 \mathrm{E}-05$ & $2.17368 \mathrm{E}-05$ & $2.30^{\circ}$ & 2.48 \\
\hline 8 & $5.93489 \mathrm{E}-04$ & $1.95797 \mathrm{E}-02$ & $0.00000 \mathrm{E}+00$ & $2.52768 \mathrm{E}-05$ & $3 \mathrm{E}-05$ & 2.27 & 2.46 \\
\hline 9 & $6.26913 \mathrm{E}-04$ & $1.96355 \mathrm{E}-02$ & $0.00000 \mathrm{E}+00$ & 2.53 & $9 \mathrm{E}-05$ & 2.25 & 2. \\
\hline 10 & $6.71996 \mathrm{E}-04$ & $1.97090 \mathrm{E}-02$ & $0.00000 \mathrm{E}+00$ & $2.54362 \mathrm{E}-05$ & 2.22 & $2.23292 \mathrm{E}-08$ & $25 E-09$ \\
\hline 11 & $7.17754 \mathrm{E}-04$ & 1. $97913 \mathrm{E}-02$ & $0.00000 \mathrm{E}+00$ & E-05 & 2. & 2.21 & -09 \\
\hline 12 & $7.46646 \mathrm{E}-04$ & $1.98342 \mathrm{E}-02$ & $0.00000 \mathrm{E}+00$ & 2. & 2. & 2. & -09 \\
\hline 13 & $7.64254 \mathrm{E}-04$ & $1.98518 \mathrm{E}-02$ & $0.00000 \mathrm{E}+00$ & $3-05$ & 2. & 2. & 09 \\
\hline 14 & $7.87858 \mathrm{E}-04$ & $1.98701 \mathrm{E}-02$ & $0.00000 \mathrm{E}+00$ & 2.56 & 2. & 2.17 & -09 \\
\hline 15 & $8.11630 \mathrm{E}-04$ & $1.98789 \mathrm{E}-02$ & $0.00000 \mathrm{E}+00$ & $4 \mathrm{E}-05$ & 2.26 & 2.16 & 09 \\
\hline 16 & $8.26563 \mathrm{E}-04$ & 1. $98623 \mathrm{E}-02$ & $0.00000 \mathrm{E}+00$ & $2.56303 \mathrm{E}-05$ & $2.26130 \mathrm{E}-05$ & $6 \mathrm{E}-08$ & $E-09$ \\
\hline 17 & $8.35588 \mathrm{E}-04$ & $1.98360 \mathrm{E}-02$ & $0.00000 \mathrm{E}+00$ & $2.56121 \mathrm{E}-05$ & $E-05$ & $1 \mathrm{E}-08$ & 2.37 \\
\hline 18 & $8.47654 \mathrm{E}-04$ & $1.97747 \mathrm{E}-02$ & $0.00000 \mathrm{E}+00$ & $2.55684 \mathrm{E}-05$ & $4 \mathrm{E}-05$ & 2.14 & $8-09$ \\
\hline 19 & $8.59765 \mathrm{E}-04$ & $1.96722 \mathrm{E}-02$ & $0.00000 \mathrm{E}+00$ & 2.54 & 2.23 & 2.13 & 8-09 \\
\hline 20 & $8.67352 \mathrm{E}-04$ & $1.95813 \mathrm{E}-02$ & 0.00000 & 2.537 & 2.2 & 2.1 & -09 \\
\hline 21 & $8.71921 \mathrm{E}-04$ & 1. $95179 \mathrm{E}-02$ & $0.00000 \mathrm{E}+00$ & $694 \mathrm{E}-05$ & $2.19442 \mathrm{E}-05$ & $5 E-08$ & $32 E-09$ \\
\hline 22 & $8.78022 \mathrm{E}-04$ & $1.94415 \mathrm{E}-02$ & $0.00000 \mathrm{E}+00$ & $2.50441 \mathrm{E}-05$ & $15239 \mathrm{E}-05$ & $4 \mathrm{E}-08$ & $8-09$ \\
\hline 23 & $8.82603 \mathrm{E}-04$ & $1.94121 \mathrm{E}-02$ & $0.00000 \mathrm{E}+00$ & $2.47645 \mathrm{E}-05$ & $2.09992 \mathrm{E}$ & E-08 & $E-09$ \\
\hline 24 & E-04 & E-02 & $000 \mathrm{E}+00$ & $2 \mathrm{E}-05$ & $2 \mathrm{E}-05$ & $2.12242 \mathrm{E}-08$ & $2.35379 \mathrm{E}-09$ \\
\hline 25 & 4 & E-02 & $000 \mathrm{E}+00$ & $29 \mathrm{E}-05$ & $1.97687 \mathrm{E}-05$ & $2.11010 \mathrm{E}-08$ & $2.34649 \mathrm{E}-09$ \\
\hline
\end{tabular}

\begin{tabular}{|c|c|c|c|c|c|c|c|}
\hline \multicolumn{8}{|c|}{ IATLAB-interpolated XS in group 1 for isotope LFPA_0 } \\
\hline & $\mathrm{x}$ & CAPTURE & FISSION & $N, P$ & $\mathrm{~N}, \mathrm{ALPHA}$ & $\mathrm{N}, \mathrm{D}$ & $\mathrm{N}, \mathrm{T}$ \\
\hline 1 & $1.37417 \mathrm{E}-04$ & $1.76529 \mathrm{E}-02$ & $0.00000 \mathrm{E}+00$ & $2.29344 \mathrm{E}-05$ & $1.80423 \mathrm{E}-05$ & $2.64447 \mathrm{E}-08$ & $2.57398 \mathrm{E}-\mathrm{C}$ \\
\hline 2 & $1.97267 \mathrm{E}-04$ & $1.81202 \mathrm{E}-02$ & $0.00000 \mathrm{E}+00$ & $2.35026 \mathrm{E}-05$ & $1.89818 \mathrm{E}-05$ & $2.57510 \mathrm{E}-08$ & $56892 \mathrm{E}-$ \\
\hline 3 & $2.63523 \mathrm{E}-04$ & $1.85376 \mathrm{E}-02$ & $0.00000 \mathrm{E}+00$ & $2.40098 \mathrm{E}-05$ & 1.978 & 51591E-08 & $.56211 \mathrm{E}-$ \\
\hline 4 & $3.17032 \mathrm{E}-04$ & $1.87915 \mathrm{E}-02$ & $0.00000 \mathrm{E}+00$ & $2.43171 \mathrm{E}-05$ & 2.03 & $2.46997 \mathrm{E}-08$ & $056 \mathrm{E}-\mathrm{C}$ \\
\hline 5 & $3.75391 \mathrm{E}-04$ & $1.89853 \mathrm{E}-02$ & $0.00000 \mathrm{E}+00$ & $2.45479 \mathrm{E}-05$ & & $50 \mathrm{E}-08$ & $37 \mathrm{E}-09$ \\
\hline 6 & $4.55923 \mathrm{E}-04$ & $1.92243 \mathrm{E}-02$ & $0.00000 \mathrm{E}+00$ & $2.48352 \mathrm{E}-05$ & & & $5 E-09$ \\
\hline 7 & $5.39746 \mathrm{E}-04$ & $1.94584 \mathrm{E}-02$ & $0.00000 \mathrm{E}+00$ & $2.51233 \mathrm{E}-05$ & & & \\
\hline 8 & $5.93489 \mathrm{E}-04$ & 1.9 & $0.00000 \mathrm{E}+00$ & $2.52769 \mathrm{E}-05$ & & & \\
\hline 9 & 6.26 & 1.9 & $0.00000 \mathrm{E}+00$ & -05 & & & \\
\hline 10 & 6.719 & 1.9 & $0.00000 \mathrm{E}+00$ & -05 & & & \\
\hline 1 & 7.177 & 1.9 & $0.00000 \mathrm{E}+00$ & -05 & & & \\
\hline 12 & 7.46 & 1.9 & $8+00$ & 05 & & & \\
\hline 13 & 7.6 & 1. & +00 & 05 & & & \\
\hline 14 & 7.87 & 1. & +00 & 05 & & & \\
\hline 15 & 8.11 & 1. & +00 & 05 & & & \\
\hline 16 & 8.2 & 1. & 00 & 05 & & & \\
\hline 17 & 8.3 & 1. & 00 & 05 & & & \\
\hline 18 & 8.47 & 1.9 & & & & & \\
\hline 19 & 8.59 & 1.9 & & & & & \\
\hline 20 & 8.67 & 1.9 & & & & & \\
\hline 21 & 8.71 & 1.9 & & 2.5 & & & \\
\hline 22 & 8.78 & 1.94 & 00 & & & & \\
\hline 23 & 8.82 & 1.9 & 00 & 2. & & & \\
\hline 24 & 8.8 & 1.9 & & .05 & & & \\
\hline 25 & $8.88720 \mathrm{E}-04$ & $1.94704 \mathrm{E}-02$ & $0 \mathrm{E}+00$ & $2.41130 \mathrm{E}$ & & $10 \mathrm{E}-08$ & 2.3 \\
\hline
\end{tabular}

Figure 3-40. Group One LFPA Isotope Cross Section Differences for Cubic Spline Fit in Verification Test \#19 


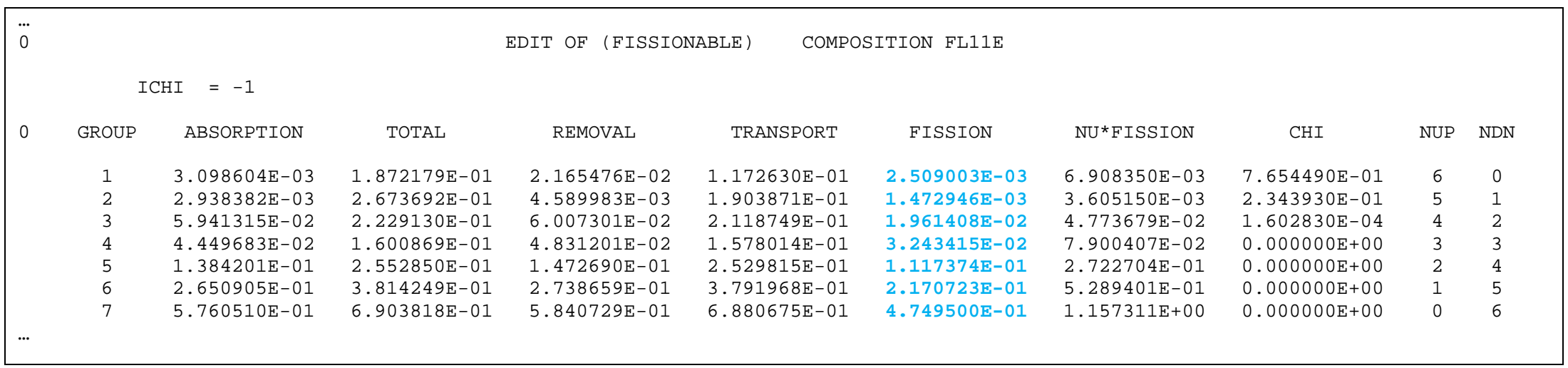

\section{Figure 3-41. REBUS-PC Macroscopic Cross Section Output Excerpt of Verification Test \#19}

\begin{tabular}{|c|c|c|c|c|c|c|c|}
\hline TimeNode / & Group 1 & 2 & 3 & 4 & 5 & 6 & 7 \\
\hline 0 & $2.50900 \mathrm{E}-03$ & $1.47295 \mathrm{E}-03$ & $1.96141 \mathrm{E}-02$ & 3.24342 & $1.11737 \mathrm{E}-01$ & 2.17072 & 4.7 \\
\hline 1 & E-03 & $5918 \mathrm{E}-03$ & $94416 \mathrm{E}-02$ & & & 1 & \\
\hline 2 & 2.4 & $1.44539 \mathrm{E}-03$ & $1.92681 \mathrm{E}-02$ & $3.18063 \mathrm{E}$ & $1.11563 \mathrm{E}-01$ & 2.12525 & 4.6 \\
\hline 3 & & & & & $0 \mathrm{E}-01$ & 2.10 & \\
\hline 4 & 03 & $1.41788 \mathrm{E}-03$ & E-02 & $3.11846 \mathrm{E}-02$ & $4 \mathrm{E}-01$ & 2.09222 & 4.5 \\
\hline 5 & -03 & $1.40417 \mathrm{E}-03$ & E-02 & 3.0873 & $1.11218 \mathrm{E}-01$ & $2.07602 \mathrm{E}-01$ & $4.53329 \mathrm{E}-01$ \\
\hline 6 & & & & & $4 \mathrm{E}-01$ & 2.0597 & \\
\hline 7 & 3 & $5 \mathrm{E}-03$ & $\mathrm{E}-02$ & 3.0251 & $1.10888 \mathrm{E}-01$ & $2.04340 \mathrm{E}-01$ & 4.4 \\
\hline 8 & $2.43781 \mathrm{E}-03$ & $1.36300 \mathrm{E}-03$ & $1.82288 \mathrm{E}-02$ & $2.99401 \mathrm{E}-02$ & $1.10690 \mathrm{E}-01$ & $2.02690 \mathrm{E}-01$ & $4.41337 \mathrm{E}-01$ \\
\hline 9 & -03 & 1.34 & & $2.96287 \mathrm{E}-02$ & $1.10473 \mathrm{E}-01$ & $2.01038 \mathrm{E}-01$ & 4. $37340 \mathrm{E}-0$ \\
\hline & & & & & & & \\
\hline
\end{tabular}

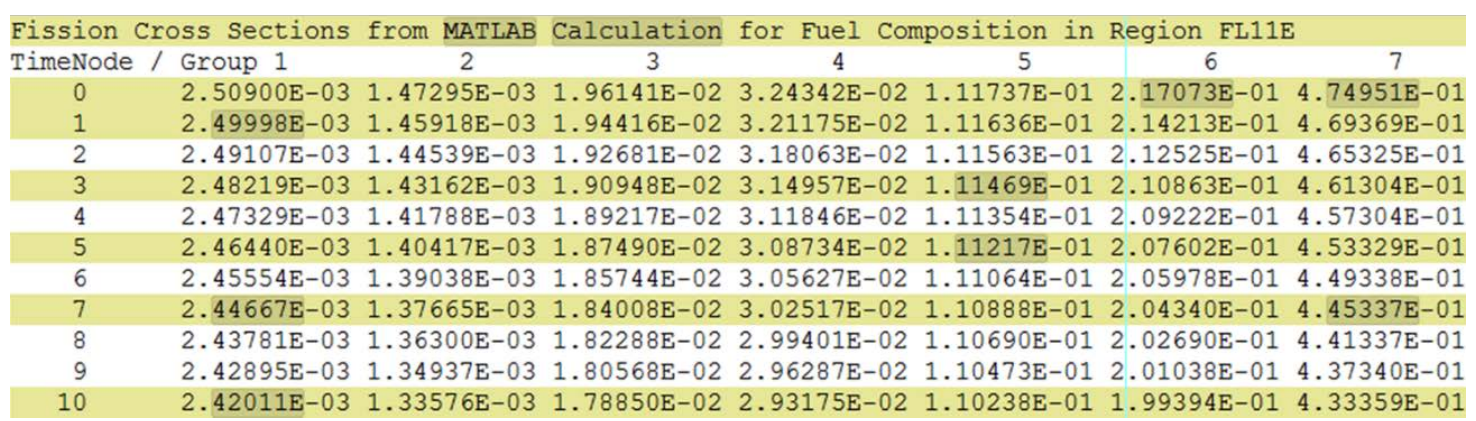

Figure 3-42. Macroscopic Fission Cross Section in Region FL11E for Cubic Spline Fit in Verification Test \#19 
Verification test \#18 uses the linear interpolation scheme for cross section data. Figure 3-43 provides an excerpt of the A.BURN input. A comparison of this input to verification test \#19 in Figure 3-36 shows only the type 40 input cards are impacted.

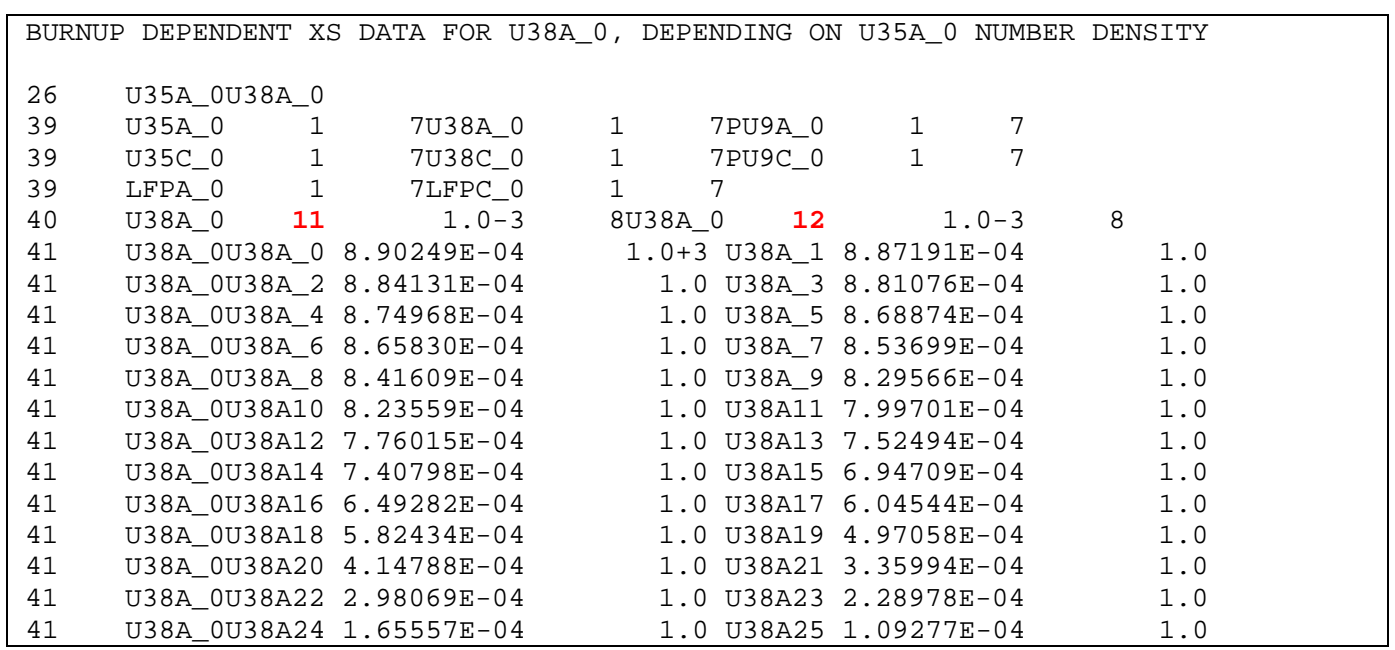

Figure 3-43. REBUS-PC A.BURN Input Excerpt for Verification Test \#18

The exact same approach to check capability \#11 was carried out for capability \#12. The piecewise linear polynomial interpolation scheme was implemented in a MATLAB program that is provided in the repository. The region isotopic densities and macroscopic cross sections were extracted from POLYFI.BCD and the REBUS-PC output. The interpolated cross sections of REBUS-PC and MATLAB were written to ASCII files with the same formats, and the resulting files were compared. Using the piecewise linear polynomial fit of microscopic cross section data, the fission cross sections of each fuel composition were tabulated at the same eleven time nodes as in verification test \#19.

Figure 3-44 compares the burnup dependent cross sections for the first energy group of the lumped fission product isotope LFPA_0. The upper section is taken from REBUS-PC while the lower section was calculated with MATLAB. As was the case with verification test \#19, the lines with differences are highlighted along with the actual numbers that are different on each line. Once again, errors only appear in the final significant digit, which is within the error of the math precision being performed in REBUS-PC. Extensive checking of all of the isotopic cross data was done and only found errors of this order, which are a result of the math precision in REBUS-PC.

Figure 3-45 provides an excerpt of the REBUS-PC output for the macroscopic cross sections. A quick comparison of these cross sections with those obtained with cubic spline shows they are very similar, with errors slightly larger than the last significant digit. These differences are attributable to the different interpolation scheme providing more evidence that the REBUS-PC input is being processed and used as expected. For completeness, a MATLAB program was used to calculate the macroscopic cross sections and display the condensed results for fission in Figure 3-46 for region FL11E. A quick survey of these results shows that the errors only appear in the final significant digit, which is attributable to the precision in REBUS-PC.

Additional comparisons for other regions and reactions were done and found with similar errors. As a consequence of this work, the piecewise linear spline routine of REBUS-PC was demonstrated to correctly perform the cross section interpolation consistent with that described in the manual, thus satisfying capability 12 . As was the case for verification test \#19, the isotopes specified in the ISOTXS file are properly linked to the region of interest, thereby verifying capability 3. 


\begin{tabular}{|c|c|c|c|c|c|c|c|}
\hline \\
\hline oup 1 for iso & $\mathrm{x}$ & CAPTURE & FISSION & $N, P$ & & $\mathrm{~N}$, & $\mathrm{N}, \mathrm{T}$ \\
\hline 1 & 1.374 & $1.76430 \mathrm{E}-$ & $0.00000 \mathrm{E}+$ & 2.292 & & $.64531 \mathrm{E}$ & $48 \mathrm{E}$ \\
\hline 2 & $1.97267 \mathrm{E}-04$ & $81078 \mathrm{~F}-02$ & $0.00000 \mathrm{E}+00$ & & & & \\
\hline 3 & $2.63523 \mathrm{E}-$ & 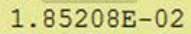 & & & & & \\
\hline 4 & & & & & & & \\
\hline 5 & & & & & & & \\
\hline 6 & & & & & & & \\
\hline 7 & 5.3 & & & & & & \\
\hline 8 & 5.93 & & & & & & \\
\hline 9 & 6.2 & & & & & & \\
\hline 0 & & & & & & & \\
\hline & & & & & & & \\
\hline & 7.4 & & & & & & \\
\hline & 7.6 & 1.9 & & & & & \\
\hline & 7.8 & & & & & & \\
\hline 15 & 8.1 & L. & & & & & \\
\hline 16 & 8. & & & & & & \\
\hline 17 & & & & & & & \\
\hline 8 & & & & & & & \\
\hline & & & & & & & \\
\hline 0 & 8.673 & & & & & & \\
\hline & 719 & & & 5 & & & \\
\hline 22 & 8.780 & 1.9 & 00 & & & & \\
\hline 23 & 8.826 & 1. $94155 \mathrm{E}-02$ & 0.00 & 2.4 & 2. & -08 & E-09 \\
\hline 24 & 8.8 & 1.9 & 0.0 & -05 & 2. & -08 & $E-09$ \\
\hline 2 & $20 \mathrm{E}-04$ & $1.94725 \mathrm{E}-02$ & $.00000 \mathrm{E}+00$ & $2.41053 \mathrm{E}-05$ & $1.97525 \mathrm{E}-05$ & $2.10798 \mathrm{E}-08$ & $2.34533 \mathrm{E}-0$ \\
\hline
\end{tabular}

\begin{tabular}{|c|c|c|c|c|c|c|c|}
\hline \multicolumn{8}{|c|}{$\mathrm{B}$-interpolated $\mathrm{XS}$ in gro } \\
\hline & $\mathrm{x}$ & CAPTURE & FISSION & $\mathrm{N}, \mathrm{P}$ & $\mathrm{N}, \mathrm{ALPHA}$ & N, D & $\mathrm{N}, \mathrm{T}$ \\
\hline 1 & $7 \mathrm{E}-04$ & $1.76429 \mathrm{E}$ & $0.00000 \mathrm{E}+$ & 2.2922 & $.80223 \mathrm{E}-05$ & $64532 \mathrm{E}-08$ & $57348 \mathrm{E}-\mathrm{C}$ \\
\hline 2 & & 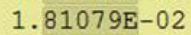 & & & & & \\
\hline 3 & & & & & & & \\
\hline 4 & & & & & & & \\
\hline 5 & & 1.8 & & & & & \\
\hline 6 & .04 & 1.9 & .00 & & & & \\
\hline 7 & .3 & 1.9 & & & & & \\
\hline 8 & 5.9 & 1.9 & & & & & \\
\hline 9 & & & & & & & \\
\hline 0 & & & & & & & \\
\hline 1 & & 1. & & & & & \\
\hline 0 & & 1. & & & & & \\
\hline 13 & & & & & & & \\
\hline 14 & 7.87 & 1.98 & 0. & 2.5 & & & -09 \\
\hline 15 & & 1. & & & & & \\
\hline 16 & & & & & & & \\
\hline 7 & & & & & & & \\
\hline 8 & & & & & & & \\
\hline 19 & & 1.9 & & & & & \\
\hline 20 & & & & & & & \\
\hline 21 & 8.7 & 1.9518 & $0.00000 \mathrm{E}$ & 2.5258 & 2. & 2.1 & -09 \\
\hline 22 & 8.7 & 1.9447 & 0.00000 & 2.50 & & 2. & $E-09$ \\
\hline 23 & 8.826 & 1. $94156 \mathrm{E}-02$ & $0.00000 \mathrm{E}+00$ & -05 & 2. & -08 & E-09 \\
\hline 24 & & & & & & & \\
\hline 25 & $.88720 \mathrm{E}-04$ & $1.94725 \mathrm{E}-02$ & & & 1.97 & 2.1 & 2.34 \\
\hline
\end{tabular}

Figure 3-44. Group One LFPA Isotope Cross Section Differences for a Piecewise Linear Fit in Verification Test \#18 


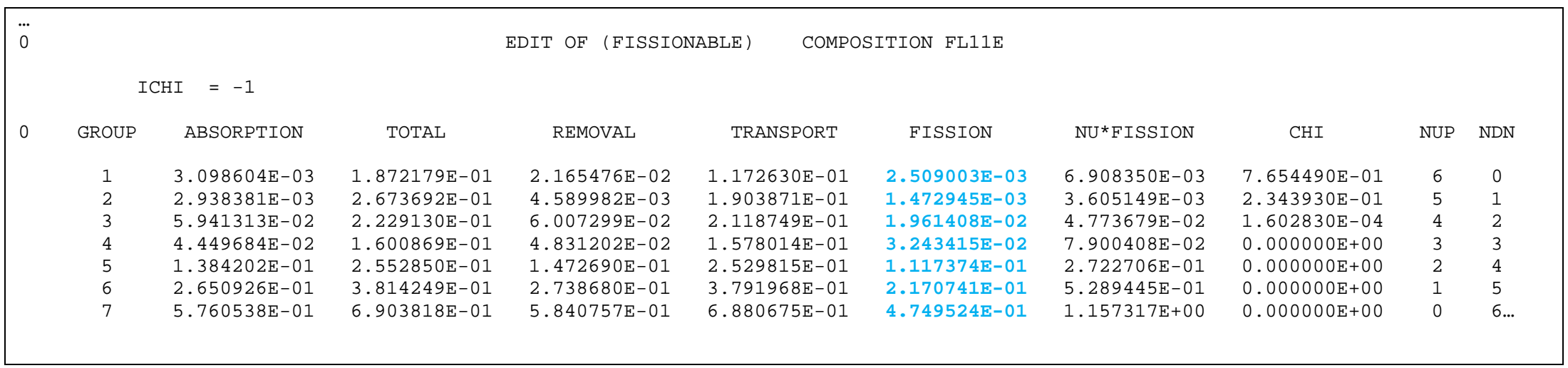

Figure 3-45. REBUS-PC Macroscopic Cross Section Output Excerpt of Verification Test \#18
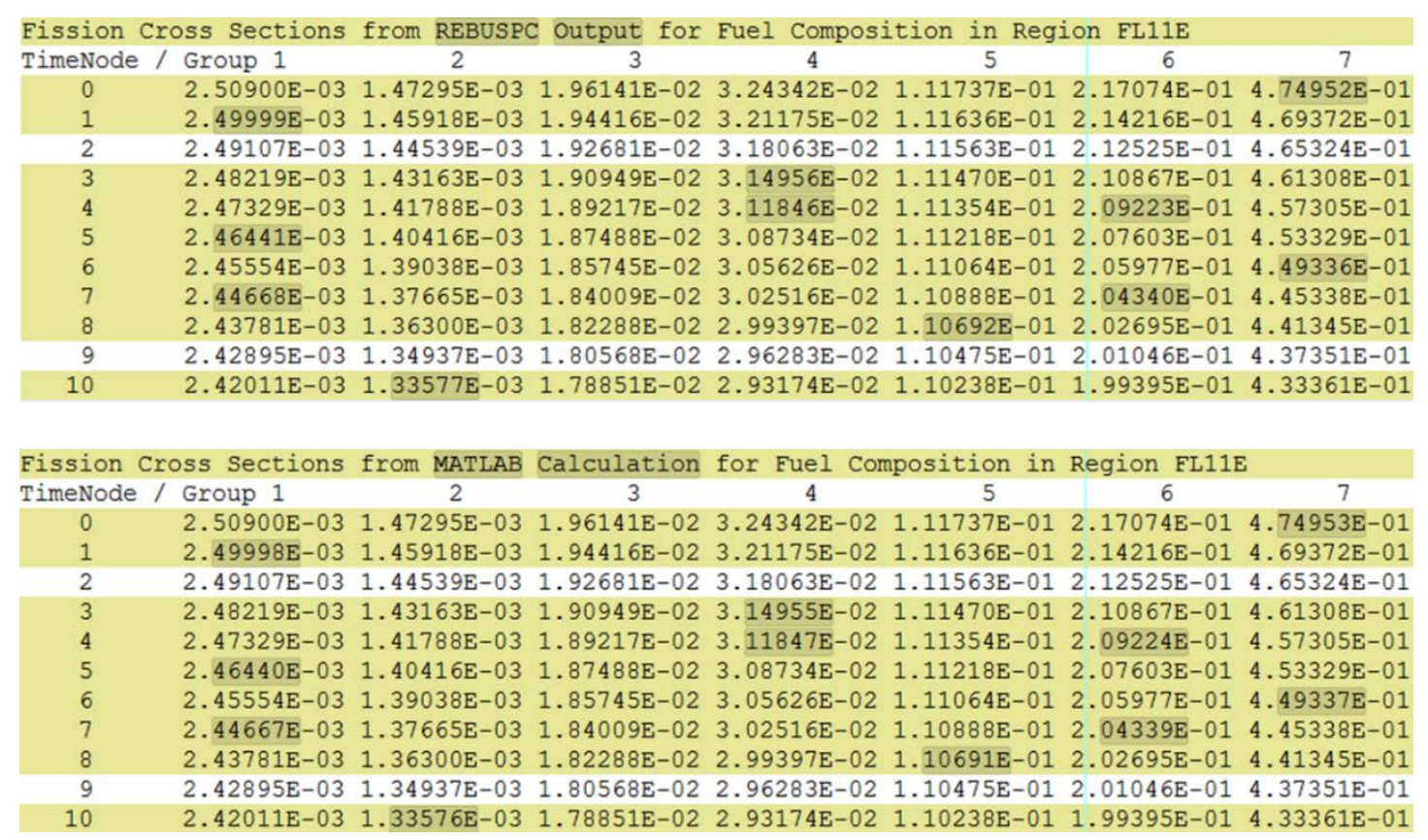

Figure 3-46. Macroscopic Fission Cross Section in Region FL11E for Piecewise Linear Fit in Verification Test \#18 
Although not stated in the list of capabilities, the polynomial approximation must also be verified, which is verification test \#20. This feature is employed by active users of REBUS-PC and thus the same comparisons of verification tests \#18 and \#19 were done for completeness. The outcome is the same, in that the MATLAB program yielded identical macroscopic cross sections at each time node. For brevity, the comparison results are not entirely displayed in this manuscript.

Although not part of the capability verification process, a comparison of the three different cross section interpolation schemes in REBUS-PC is provided for the STRZ benchmark problem. Table 3-27 provides the k-effective results obtained for each time step using a cubic spline, piecewise linear polynomial and eighth order polynomial fit of the cross section data.

Table 3-27. REBUS-PC K-effective Results for Different Cross Section Interpolation Schemes

\begin{tabular}{|c|c|c|c|c|c|}
\hline & \multicolumn{3}{|c|}{ k-effective Results } & \multicolumn{2}{c|}{ Difference } \\
\hline \multirow{2}{*}{ Time Node } & $\begin{array}{c}\text { Cubic } \\
\text { Spline }\end{array}$ & $\begin{array}{c}\text { Piecewise } \\
\text { Linear }\end{array}$ & $\begin{array}{c}8^{\text {th }} \text { Order } \\
\text { Polynomial }\end{array}$ & $\begin{array}{c}\text { Piecewise } \\
\text { Linear - Spline }\end{array}$ & $\begin{array}{c}8^{\text {th }} \text { Order } \\
\text { Polynomial - Spline }\end{array}$ \\
\hline 0 & 1.0991863 & 1.0991875 & 1.0991702 & 0.0000013 & -0.0000160 \\
\hline 1 & 1.0511679 & 1.0511693 & 1.0515422 & 0.0000014 & 0.0003742 \\
\hline 2 & 1.0463326 & 1.0463226 & 1.0464649 & -0.0000099 & 0.0001323 \\
\hline 3 & 1.0425166 & 1.0425073 & 1.0425031 & -0.0000093 & -0.0000136 \\
\hline 4 & 1.0394478 & 1.0394367 & 1.0393540 & -0.0000111 & -0.0000939 \\
\hline 5 & 1.0368255 & 1.0368110 & 1.0367079 & -0.0000145 & -0.0001176 \\
\hline 6 & 1.0344378 & 1.0344268 & 1.0343357 & -0.0000110 & -0.0001022 \\
\hline 7 & 1.0321646 & 1.0321548 & 1.0320998 & -0.0000098 & -0.0000648 \\
\hline 8 & 1.0299421 & 1.0299308 & 1.0299234 & -0.0000113 & -0.0000187 \\
\hline 9 & 1.0277363 & 1.0277292 & 1.0277643 & -0.0000071 & 0.0000280 \\
\hline 10 & 1.0255304 & 1.0255227 & 1.0255994 & -0.0000077 & 0.0000690 \\
\hline
\end{tabular}

The cubic spline and piecewise linear polynomial options yield very similar results, with errors near the convergence tolerance set for the flux and depletion solver. The $8^{\text {th }}$ order polynomial fit yields noticeably different results at several time nodes from those obtained with the other two options. The k-effective difference shown here can be considered a measure of the reactivity uncertainty introduced by the cross section fitting scheme. Because of the known approximations that the polynomial approximation introduces, it is strongly advised to use one of the other two approximations, although it is noted that all of these errors will have a minor impact on the computed results.

As was the case with the microscopic cross section comparisons, the differences between the REBUSPC and MATLAB calculations only appear in the sixth significant digit, which is within the limits of the math precision of REBUS-PC. Additional comparisons were made for other regions and reactions and found similar errors. As a consequence, the piecewise linear fit routine of REBUS-PC is shown to correctly perform the cross section interpolation, consistent with that described in the manual and thus satisfies capability \#12. In addition, the isotopes specified in the ISOTXS file are shown to be properly linked to the region of interest, thereby verifying capability 3 . This work additionally verifies the polynomial fit of burnup-dependent cross sections in REBUS-PC, although this is not listed as a capability. 
In summary, the preceding verification tests demonstrate the following capabilities:

- Capability 3 is partially satisfied, as the ISOTXS isotope cross section data and depletion results were demonstrated to be correctly linked to the region and composition input.

- Capability 11, as the cubic spline cross section interpolation scheme was verified against a MATLAB equivalent to six significant digits.

- Capability 11, as the piecewise linear cross section interpolation scheme was verified against a MATLAB equivalent to six significant digits.

\subsection{Verification Test \#21 and \#22}

To finalize verification of capability 3 , the depletion calculation itself needs to be demonstrated to be accurate and based upon the input. The depletion solver in REBUS-PC is accurate has extensive historical use and validation. To verify capability 3 , the depletion chain is simplified and an analytic flux solution is used so that the accuracy of the REBUS-PC solution can be shown mathematically. This is verification test \#21, which is based upon the 1GCYL_hom described geometry. MATLAB was used to provide the reference solution.

Table 3-28 provides the depletion chain information used in verification test \#21. The REBUS-PC input that implements it is shown in Figure 3-47. From inspection of the REBUS-PC input, one can also identify the cross section data shown in Table 3-28 for verification test \#21 as the data is provided in the A.ISO format. The isotope LUMP represents a lumped fission product and the isotope DUMP is used as a fictitious isotope to terminate burn chains. The yield fractions of the lumped fission products are omitted as it should be clear that one LUMP is produced per fission. It is noted that there is some absorption in the LUMP and DUMP isotopes, as can be seen in Table 3-28.

Table 3-28. Depletion Chain Setup for Verification Test \#21

\begin{tabular}{|c|c|c|c|c|}
\hline Isotope & Reaction & $\begin{array}{l}\text { Product } \\
\text { Isotope }\end{array}$ & $\begin{array}{l}\text { Cross } \\
\text { Sections } \\
\text { (barn) }\end{array}$ & $\begin{array}{c}\text { Decay } \\
\text { Constant }\left(\mathrm{s}^{-1}\right)\end{array}$ \\
\hline \multirow{3}{*}{ U-235 } & $\mathrm{n}, \gamma$ & DUMP & $1.15810 \mathrm{E}+01$ & \\
\hline & $n, f$ & LUMP & $5.41443 \mathrm{E}+01$ & \\
\hline & $n, 2 n$ & DUMP & $4.27508 \mathrm{E}-03$ & \\
\hline \multirow{3}{*}{ U-238 } & $\mathrm{n}, \gamma$ & $\mathrm{Pu}-239$ & $1.89742 \mathrm{E}+00$ & \\
\hline & $\mathrm{n}, \mathrm{f}$ & LUMP & 1.18442E-01 & \\
\hline & $n, 2 n$ & DUMP & 5.17885E-03 & \\
\hline \multirow{4}{*}{ Pu-239 } & $\mathrm{n}, \gamma$ & DUMP & $5.73755 \mathrm{E}+01$ & \\
\hline & $\mathrm{n}, \mathrm{f}$ & LUMP & $1.11015 \mathrm{E}+02$ & \\
\hline & $n, 2 n$ & DUMP & 2.28699E-03 & \\
\hline & $\alpha$ decay & U-235 & & 9.120E-05 \\
\hline \multirow{4}{*}{ LUMP } & $\mathrm{n}, \gamma$ & LUMP & $2.59800 \mathrm{E}+01$ & \\
\hline & $\mathrm{n}, 2 \mathrm{n}$ & LUMP & 1.28623E-03 & \\
\hline & $\beta$-decay & LUMP & & 1.526E-08 \\
\hline & $\alpha$ decay & LUMP & & $1.027 \mathrm{E}-13$ \\
\hline \multirow{2}{*}{ DUMP } & $\mathrm{n}, \gamma$ & DUMP & 1.84494E-01 & \\
\hline & $\mathrm{n}, \alpha$ & DUMP & $8.25215 \mathrm{E}+00$ & \\
\hline
\end{tabular}




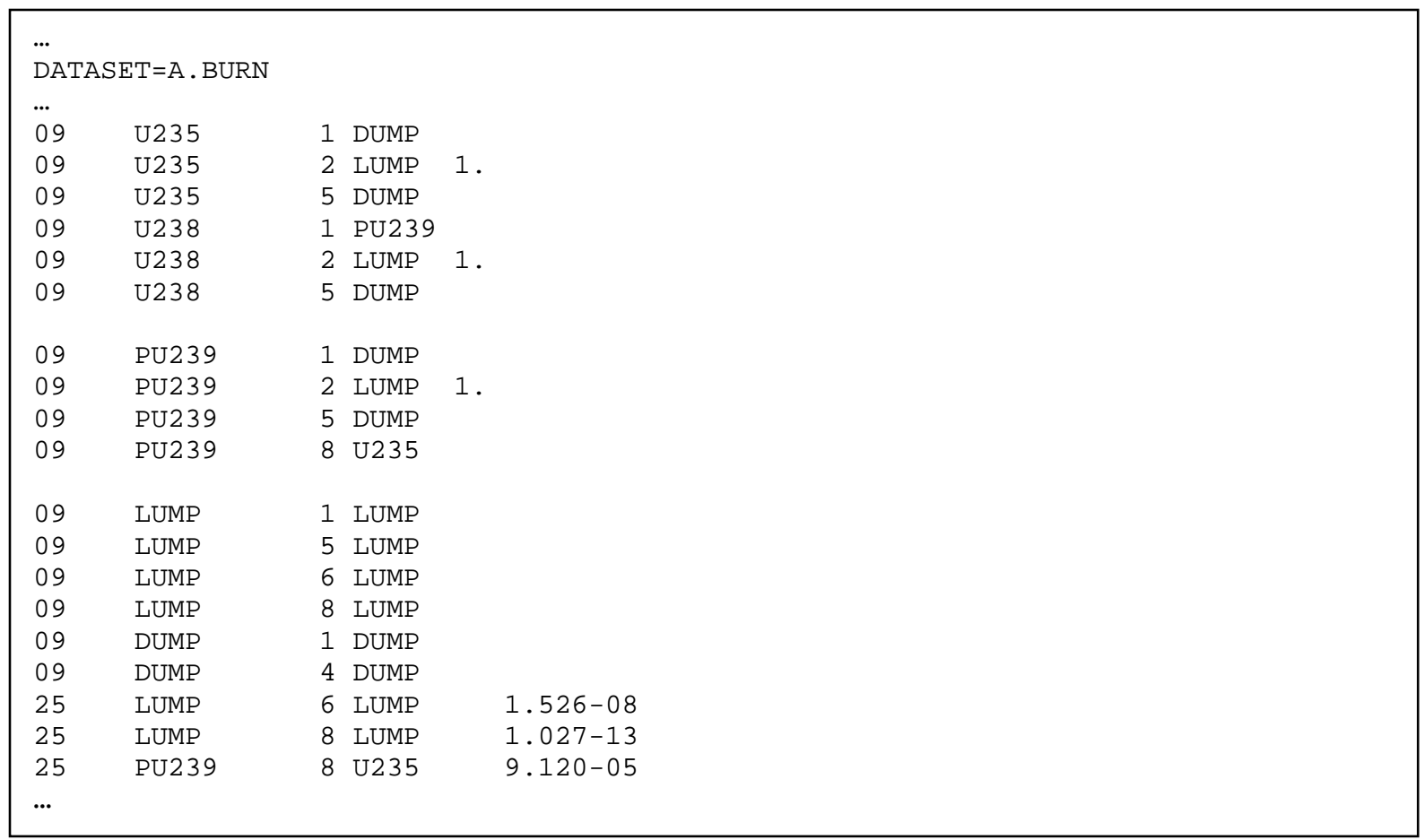

Figure 3-47. A.BURN Depletion Chain Excerpt for Verification Test \#21

In this verification test, the power level was set to $10 \mathrm{MW}$, which yields a one-group average flux level of $2.6713 \cdot 10^{16}$ neutrons $/ \mathrm{cm}^{2-s}$. When combined with a one-day burn step and one-day decay step, the nuclide depletion from both neutron reactions and radioactive decays can be tested. The system of depletion equations can be written in a matrix form as:

$$
\frac{\partial}{\partial t}\left[\begin{array}{c}
N_{U 25} \\
N_{U 28} \\
N_{P 49} \\
N_{L P} \\
N_{D P}
\end{array}\right]=\left[\begin{array}{ccccc}
-A_{U 25} & 0 & \lambda^{P 49} & 0 & 0 \\
0 & -A_{U 28} & 0 & 0 & 0 \\
0 & \sigma_{n, \gamma}^{U 28} \phi & -A_{P 49} & 0 & 0 \\
\sigma_{n, f}^{U 25} \phi & \sigma_{n, f}^{U 28} \phi & \sigma_{n, f}^{P 49} \phi & 0 & 0 \\
\left(\sigma_{n, \gamma}^{U 25}+\sigma_{n, 2 n}^{U 25}\right) \phi & \sigma_{n, 2 n}^{U 28} \phi & \left(\sigma_{n, \gamma}^{P 49}+\sigma_{n, 2 n}^{P 49}\right) \phi & 0 & 0
\end{array}\right]\left[\begin{array}{c}
N_{U 25} \\
N_{U 28} \\
N_{P 49} \\
N_{L P} \\
N_{D P}
\end{array}\right]
$$

where

$$
\begin{aligned}
& A_{U 25}=\left(\sigma_{n, \gamma}^{U 25}+\sigma_{n, f}^{U 25}+\sigma_{n, 2 n}^{U 25}\right) \phi \\
& A_{U 28}=\left(\sigma_{n, \gamma}^{U 28}+\sigma_{n, f}^{U 28}+\sigma_{n, 2 n}^{U 28}\right) \phi \\
& A_{P 49}=\left(\sigma_{n, \gamma}^{P 49}+\sigma_{n, f}^{P 49}+\sigma_{n, 2 n}^{P 49}\right) \phi+\lambda^{P 49}
\end{aligned}
$$

In equation 10, $N_{X X}$ denotes the nuclide atom density, while the subscripts $U 25, U 28, P 49, L P$, and DP denote U-235, U-238, Pu-239, lumped fission product, and the dump isotope, respectively. The system of equations during the shutdown time can be obtained by setting the flux to zero in equations 10 through 13.

The reference nuclide densities were calculated at the end of the burn step and at the end of the shutdown period using the nuclide densities defined at the beginning of the problem and the exponentials of the transmutation matrices during the burn step and the shutdown period. The exponentials of the transmutation matrices were calculated using the MATLAB program. 
Table 3-29 compares the nuclide density solutions of REBUS-PC with the MATLAB reference solutions at the end of the burn step and at the end of the decay step. At the end of both periods, one can see that the atom density solutions of REBUS-PC agree with those of the MATLAB solution.

As a further verification, one can easily solve the decay process for a simple decaying isotope using the formula $N(t)=N(0) \exp (-\lambda t)$ and obtain the expected results for the U-235 and Pu-239 atomic densities. As an example, taking the decay constant of $\mathrm{Pu}-239,9.120 \mathrm{E}-05 \mathrm{~s}^{-1}$, and the atom density at the end of the burn step of $1.4701 \mathrm{E}-06$ atoms $/ \mathrm{b}-\mathrm{cm}$, one can calculate the $\mathrm{Pu}-239$ atom density after the decay step as

$$
N(t)=1.4701 \cdot 10^{-06} \cdot \exp \left(-0.0000912 \cdot \mathrm{sec}^{-1} \cdot 1 \cdot \text { day }\right)=5.5622 \cdot 10^{-10} \text { atoms } / \mathrm{b}-\mathrm{cm} \text {, }
$$

which is similar to the result shown in Table 3-29 for Pu-239 within the precision of the REBUS-PC and MATLAB solutions within four significant figures (atom density of $1.4701 \mathrm{E}-06$ is not exactly the values computed in REBUSPC and MATLAB). It should be noted that the decay constants and cross sections used in this problem are not realistic, but are only defined to demonstrate the depletion chain accuracy. The results of this verification test show that REBUS-PC solves the transmutation equations correctly in both burn and decay modes. The test also verifies that the input isotopic cross section data is being used properly in the region of interest.

Table 3-29. Comparison of Atom Density (atoms/barn-cm) for Verification Test \#21

\begin{tabular}{|c|c|c|c|c|}
\hline \multirow{2}{*}{ Isotope } & \multicolumn{2}{|c|}{ End of Burn Step } & \multicolumn{2}{c|}{ End of Decay Step } \\
\cline { 2 - 5 } & $\begin{array}{c}\text { REBUS-PC } \\
\text { Solution }\end{array}$ & $\begin{array}{c}\text { MATLAB } \\
\text { Reference } \\
\text { Solution }\end{array}$ & $\begin{array}{c}\text { REBUS-PC } \\
\text { Solution }\end{array}$ & $\begin{array}{c}\text { MATLAB } \\
\text { Reference } \\
\text { Solution }\end{array}$ \\
\hline U-235 & $6.0658 \mathrm{E}-04$ & $6.0658 \mathrm{E}-04$ & $6.0805 \mathrm{E}-04$ & $6.0805 \mathrm{E}-04$ \\
\hline $\mathrm{U}-238$ & $2.7747 \mathrm{E}-03$ & $2.7747 \mathrm{E}-03$ & $2.7747 \mathrm{E}-03$ & $2.7747 \mathrm{E}-03$ \\
\hline Pu-239 & $1.4701 \mathrm{E}-06$ & $1.4701 \mathrm{E}-06$ & $5.5620 \mathrm{E}-10$ & $5.5620 \mathrm{E}-10$ \\
\hline LUMP & $8.2204 \mathrm{E}-05$ & $8.2204 \mathrm{E}-05$ & $8.2204 \mathrm{E}-05$ & $8.2204 \mathrm{E}-05$ \\
\hline DUMP & $1.7560 \mathrm{E}-05$ & $1.7560 \mathrm{E}-05$ & $1.7560 \mathrm{E}-05$ & $1.7560 \mathrm{E}-05$ \\
\hline
\end{tabular}

Verification test \#22 is based upon the seven-group 7GXYZ_hom problem described earlier. Its purpose is to test the region-density iteration scheme in REBUS-PC. The region-density iteration scheme updates the depletion calculation over the step based on the flux solution at the beginning and end of the burn step. Nuclide depletion over a burn step is a complex problem because the neutron flux changes throughout the step due to ongoing depletion and production of each nuclide in the problem. REBUS-PC employs the approximation of a linear change in the flux solution over the burn step and solves the depletion over each burn step by computing an average transmutation matrix over the time step. Because the flux solution and atom densities at the end of the time step are connected, the region-density calculations in REBUS-PC are solved iteratively.

Figure 3-48 shows the input geometry for verification test \#22, which defines an infinite homogeneous problem with three boxes. Because of the depletion, the spectrum changes over the time step, so that the averaging of the transmutation matrix becomes evident. As can be seen in Figure $3-48$, the region-density extrapolation option was turned off by providing a negative number of region-density iterations on the type 02 card of the dataset A.BURN. Because this test is a burnup problem of an infinite homogeneous geometry, the REBUS-PC output produces identical nuclide densities for all three regions after each iteration. 
The atom densities in each region were compared with the solution obtained using a MATLAB program that carries out the same methodology. The MATLAB nuclide densities at the end of the depletion step were also calculated using the matrix exponential method. The REBUS-PC output was examined after each region density iteration and its consistency with the MATLAB results was verified. Table 3-30 compares the atom densities in each region after each iteration.

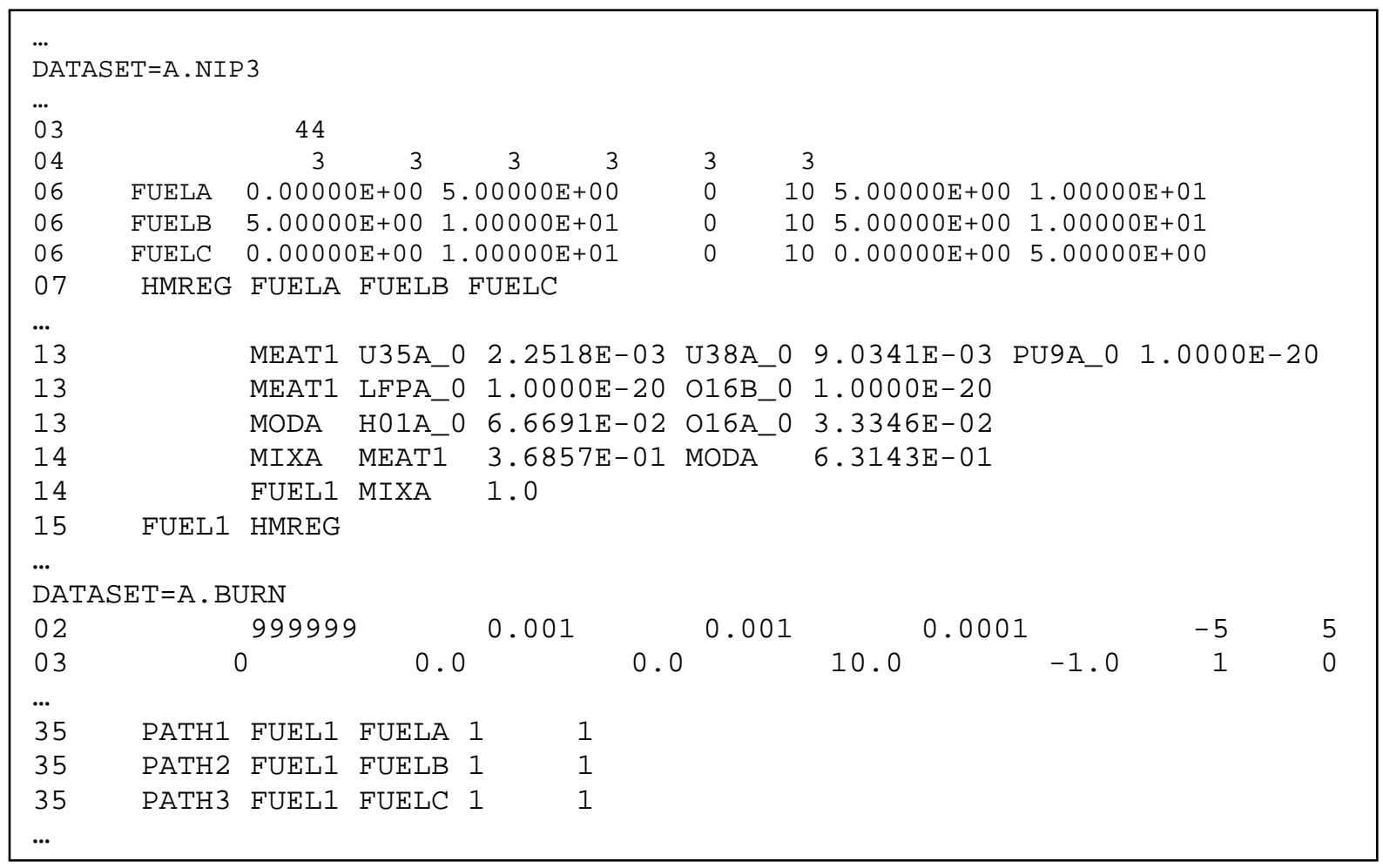

Figure 3-48. Input Geometry Definition for Verification Test \#22

Table 3-30. Comparison of Atom Densities at Each Iteration of Verification Test \#22

\begin{tabular}{|c|c|c|c|c|c|c|}
\hline Iteration & & U-235 & $\mathrm{U}-238$ & $\mathrm{Pu}-239$ & LUMP & DUMP \\
\hline \multirow{2}{*}{ BOC } & REBUS-PC & 8.29946E-04 & 3.32970E-03 & $0.0000 \mathrm{E}+00$ & $0.0000 \mathrm{E}+00$ & $0.0000 \mathrm{E}+00$ \\
\hline & $\mathrm{MA}$ & 8.29 & 3.329 & 0.0 & 0.00 & +00 \\
\hline \multirow{2}{*}{$\begin{array}{c}0 \text { th } \\
\text { Iteration }\end{array}$} & REB & 04 & 3.253 & 4.11 & 2.44 & 6.735 \\
\hline & $\mathrm{MA}$ & 5 & 3 & 4. & -04 & -05 \\
\hline \multirow{2}{*}{$\begin{array}{c}1 \mathrm{st} \\
\text { Iteration }\end{array}$} & $\mathrm{RE}$ & 5 & 3 & 5 & -04 & -05 \\
\hline & MA & 5.231 & 3.245 & 4.3 & 2.727 & 7.494 \\
\hline \multirow{2}{*}{$\begin{array}{c}2 \mathrm{nd} \\
\text { Iteration }\end{array}$} & REBUS-PC & 5.18166E-04 & $3.24402 \mathrm{E}-03$ & $6 \mathrm{E}-05$ & $2.77570 \mathrm{E}-04$ & 7.61843E-05 \\
\hline & MAT & 5.18166E-04 & 3.24402E-03 & 16E-05 & $2.77570 \mathrm{E}-04$ & 7.618 \\
\hline \multirow{2}{*}{$\begin{array}{c}\text { 3rd } \\
\text { Iteration }\end{array}$} & $\mathrm{REB}$ & 5.17192E-04 & $3.24380 \mathrm{E}-03$ & 4.373 & $2.78501 \mathrm{E}-04$ & 7.641 \\
\hline & MATLAB & 5.17192E-04 & 3.24380E-03 & 4.37374E-05 & $2.78501 \mathrm{E}-04$ & 7.64192E-05 \\
\hline Final & REBUS-PC & 5.16997E-04 & $3.24375 \mathrm{E}-03$ & 4.37440E-05 & $2.78687 \mathrm{E}-04$ & 7.64659E-05 \\
\hline
\end{tabular}

From the input shown in Figure 3-48, the convergence criteria of the region-density iteration was set to 0.001 , which was met for all nuclides in the burn matrix at the $4^{\text {th }}$ iteration. From Table 3-30, one can see that the nuclide densities of REBUS-PC calculation agree well with the MATLAB solutions at 
each iteration. A small difference occurs in the $6^{\text {th }}$ significant digit for the DUMP isotope at the third iteration, which is attributable to the single precision math used in REBUS-PC. These results indicate that the region density iteration without extrapolation works properly in the REBUS-PC depletion calculation. It is very important to note that the final density information is not reported with the same number of significant digits in the standard output file and that one must obtain this data from the TYPE13.BCD auxiliary output file.

With the preceding results, verification tests \#21 and \#22 demonstrate the following capabilities:

- Capability 3, as it verifies that the depletion is correct and based upon the isotopes assigned to each region.

- Capability 14, as the region density iteration scheme without extrapolation was verified to be accurate.

\section{Conclusions}

The preceding discussion on verification tests and the results of those tests is sufficient proof that the REBUS-PC capabilities summarized in Section 1 all work as expected. In particular, the ability of the software to carry out fuel cycle analysis on $\theta$-R-Z geometries was demonstrated producing the correct burnup, power, and isotopic depletion results. Analytic solutions were used to prove the accuracy of the finite difference spatial approximation.

\section{Acknowledgement}

This work was sponsored by the U.S. Department of Energy, Office of Material Management and Minimization in the U.S. National Nuclear Security Administration Office of Defense Nuclear Nonproliferation under Contract DE-AC02-06CH11357. 


\section{References}

1. A. P. Olson, A Users Guide for the REBUS-PC Code, Version 1.4, ANL/RERTR/TM-32, Argonne National Laboratory, December 21, 2001.

2. B. J. Toppel, "A User's Guide to the REBUS-3 Fuel Cycle Analysis Capability," ANL-83-2, Argonne National Laboratory, 1983.

3. K. L. Derstine, "DIF3D: A Code to Solve One-, Two-, and Three-Dimensional Finite-Difference Diffusion Theory Problems," ANL-82-64, Argonne National Laboratory, 1984.

4. J. Stillman, et al., Technical Basis in Support of the Conversion of the University of Missouri Research Reactor (MURR) Core from High-Enriched to Low-Enriched Uranium - Core Neutron Physics, ANL/RERTR/TM-12-30, Argonne National Laboratory, September 2012.

5. University of Missouri Research Reactor Safety Analysis Report, submitted to the U.S. Nuclear Regulatory Commission in 2006.

6. “RTR Software Evaluation: REBUS-PC v. 1.5," REBUS-PC_1.5_RTR-SWF-104a-rev, Research and Test Reactors Department, Argonne National Laboratory, January 16, 2017.

7. “Research Reactor Core Conversion Guidebook, Vol. 2: Analysis (Appendices A-F)," IAEATECDOC-643, International Atomic Energy Agency (1992).

8. John Lamarsh, Introduction to Nuclear Engineering, Second Edition. Addison-Wesley Publishing, Reading, Massachusetts 1983.

9. Website for Mathematica software retrieved on March 4, 2019 from http://www.wolfram.com/mathematica/.

10. Website for the MathCAD software distributed by the PTC software corporation retrieved on March 4, 2019 from https://www.ptc.com/en/products/mathcad.

11. Website for Richardson Extrapolation methodology retrieved on March 4, 2019 from https://en.wikipedia.org/wiki/Richardson extrapolation.

12. Website for the MatLab software distributed by the MathWorks corporation retrieved on March 4, 2019 from https://www.mathworks.com/products/matlab.html.

13. Website for Excel software distributed by the Microsoft Corporation retrieved on March 4, 2019 from https://office.microsoft.com/excel/. 



\section{Argonne}

Nuclear Science \& Engineering Division

Argonne National Laboratory

9700 South Cass Avenue, Bldg. 208

Argonne, IL 60439

www.anl.gov

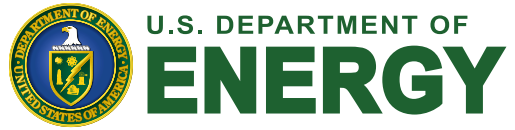

Argonne National Laboratory is a U.S. Department of Energy laboratory managed by UChicago Argonne, LLC 